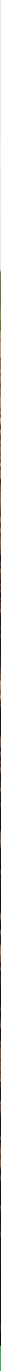

\title{
Impact of cadmium levels in fertilisers on cadmium accumulation in soil and uptake by food crops
}

Paul Römkens, René Rietra, Hans Kros, Jan Cees Voogd and Wim de Vries 



\section{Impact of cadmium levels in fertilisers on cadmium accumulation in soil and uptake by food crops}

Paul Römkens, René Rietra, Hans Kros, Jan Cees Voogd and Wim de Vries 
Römkens, P.F.A.M., Rietra R.P.J.J, J. Kros, J.C. Voogd, and W. de Vries, 2018. Impact of cadmium levels in fertilisers on cadmium accumulation in soil and uptake by food crops. Wageningen, Wageningen Environmental Research, Report 2889. 116 pp.; 23 fig.; 60 tab.; 80 ref.

Cadmium ( $\mathrm{Cd}$ ) and other heavy metals (lead ( $\mathrm{Pb}$ ), arsenic (As), chromium (Cr) and zinc ( $\mathrm{Zn}$ )) occur naturally in fertilisers but at variable levels. To determine whether or not levels of metals in fertiliser affect the absorption of $\mathrm{Cd}$ and other metals by agricultural crops, a greenhouse study was performed to measure the uptake of $\mathrm{Cd}$ and other metals from 7 different soils grounds treated with either mineral fertiliser with increasing levels of $\mathrm{Cd}$ and one type of animal manure (cattle manure). The results show that there is no significant difference in absorption of $\mathrm{Cd}$ nor on other metals when $\mathrm{P}$ fertiliser is used with levels of $\mathrm{Cd}$ varying between 0.04 and $60 \mathrm{mg} \mathrm{Cd} \mathrm{kg}^{-1} \mathrm{P}_{2} \mathrm{O}_{5}$. Differences in soil properties (e.g. acidity and organic matter content) in combination with the content of $\mathrm{Cd}$ in the soil control the short term (1 harvest cycle) variation of Cd concentrations in crops. Long-term (100 years) calculations on a field and regional scale, however, show that the content of $\mathrm{Cd}$ in $\mathrm{P}$ fertilisers does affect both levels in soil and that in crops. Dynamic model simulations at EU level indicate that accumulation of $\mathrm{Cd}$ in soil (arable and grassland) continues if the $\mathrm{Cd}$ content in $\mathrm{P}$ fertilisers exceeds $20 \mathrm{mg} \mathrm{Cd} \mathrm{kg}^{-1} \mathrm{P}_{2} \mathrm{O}_{5}$. The calculated average long-term relative changes in both soil and arable crops relative to current levels are in the order of magnitude of $+0.2 \%$ if no more Cd is applied via P fertiliser to $12.1 \%$ to $16 \%$ if, at the European level the concentration of $\mathrm{Cd}$ in mineral P-fertilisers averages 60 or $80 \mathrm{mg} \mathrm{Cd} \mathrm{kg}^{-1} \mathrm{P}_{2} \mathrm{O}_{5}$ respectively.

Cadmium (Cd) en andere zware metalen (lood (Pb), arseen (As), chroom ( $\mathrm{Cr}$ ) en zink (Zn)) komen van nature voor in kunstmeststoffen, maar in variabele gehalten. Om na te gaan of het gehalte aan metalen in kunstmest de opname van Cd en andere metalen door landbouwgewassen beïnvloedt, is in een kasopstelling de opname van $\mathrm{Cd}$ en andere metalen bepaald uit 7 gronden behandeld met kunstmest of rundermest met oplopende gehalten aan Cd. De resultaten tonen aan dat er geen significant verschil in opname van $\mathrm{Cd}$ van noch andere metalen is wanneer $\mathrm{P}$ kunstmest gebruikt wordt met gehalten aan $\mathrm{Cd}$ die variëren tussen 0,04 en $60 \mathrm{mg} \mathrm{Cd} \mathrm{kg}^{-1} \mathrm{P}_{2} \mathrm{O}_{5}$. Verschillen in bodemeigenschappen (zuurgraad en organische stof gehalte) in combinatie met het initiële gehalte aan Cd in de bodem zijn op korte termijn (1 oogstcyclus) bepalend voor de variatie in de gehalten aan Cd in gewassen. Lange termijn berekeningen op veld- en regionale schaal tonen aan dat het gehalte aan Cd in P kunstmeststoffen wel van invloed is op zowel het gehalte in de bodem als dat in gewassen. Op regionale schaal is berekend dat accumulatie van $\mathrm{Cd}$ in de bodem in de EU (akkerbouw en grasland) gemiddeld genomen doorgaat indien het Cd gehalte in $P$ kunstmeststoffen hoger is dan $20 \mathrm{mg} \mathrm{Cd} \mathrm{kg}^{-1} \mathrm{P}_{2} \mathrm{O}_{5}$. De berekende gemiddelde lange termijn veranderingen in het $\mathrm{Cd}$ gehalte van zowel bodem als akkerbouwgewassen t.o.v. de huidige gehalten liggen daarbij in de orde van grootte van $+0.2 \%$ indien geen $\mathrm{Cd}$ meer via $\mathrm{P}$ kunstmest aangewend wordt tot $12.1 \%$ en $16 \%$ indien, op Europees niveau, het gehalte aan Cd in kunstmest respectievelijk 60 of $80 \mathrm{mg} \mathrm{Cd} \mathrm{kg}{ }^{-1} \mathrm{P}_{2} \mathrm{O}_{5}$ bedraagt.

Keywords: cadmium, fertilisers, manure, DAP, food crops, model, EU-25

The pdf file is free of charge and can be downloaded at https://doi.org/10.18174/451353 or via the website www.wur.nl/environmental-research (scroll down to Publications - Wageningen Environmental Research reports). Wageningen Environmental Research does not deliver printed versions of the Wageningen Environmental Research reports.

2018 Wageningen Environmental Research (an institute under the auspices of the Stichting Wageningen Research), P.O. Box 47, 6700 AA Wageningen, The Netherlands, $\mathrm{T}+31$ (0)317 4807 00, www.wur.nl/environmental-research. Wageningen Environmental Research is part of Wageningen University \& Research.

- Acquisition, duplication and transmission of this publication is permitted with clear acknowledgement of the source.

- Acquisition, duplication and transmission is not permitted for commercial purposes and/or monetary gain.

- Acquisition, duplication and transmission is not permitted of any parts of this publication for which the copyrights clearly rest with other parties and/or are reserved.

Wageningen Environmental Research assumes no liability for any losses resulting from the use of the research results or recommendations in this report. 


\section{Contents}

$\begin{array}{ll}\text { Preface } & 5\end{array}$

$\begin{array}{ll}\text { Summary } & 7\end{array}$

1

$\begin{array}{ll}\text { Introduction } & 12\end{array}$

1.1 Cadmium in the Environment $\quad 12$

1.2 Regulation of cadmium and proposed quality limits $\quad 13$

$\begin{array}{lll}1.3 & \text { Aim of the study } & 13\end{array}$

$\begin{array}{lll}1.4 & \text { Outline of the report } & 14\end{array}$

Materials and Methods $\quad 15$

2.1 Soils, crops and fertilisers used in in the greenhouse experiment 15

2.1.1 Soils used in the greenhouse experiment and soil testing 15

2.1.2 Fertilisers and soils used in the greenhouse experiments: $2016 \quad 16$

2.1.3 Fertilisers and soils used in the greenhouse experiments: $2017 \quad 17$

$\begin{array}{lll}2.2 & \text { Set up of the greenhouse experiment } & 17\end{array}$

2.2.1 2016 experiments 17

2.2.2 2017 experiments 19

2.3 Analyses on soils, fertilisers and crops 19

$\begin{array}{lll}2.4 & \text { Model description } & 20\end{array}$

$3 \quad$ Results from greenhouse experiments

3.1 Results 2016 and 2017: soils and fertilisers used in the greenhouse experiment 23

3.2 Results greenhouse experiment 2016: lettuce and carrot 26

3.2.1 Effect of treatment on chemical availability of metals and nutrients in soil 26

3.2.2 Biomass production 31

3.2.3 Uptake of nutrients and metals by lettuce and carrot 32

3.3 Results greenhouse experiment 2017: potato, barley, carrot and spinach 41

3.3.1 Results greenhouse experiment 2017: effect of treatment on chemical availability and reactivity of metals in soil 41

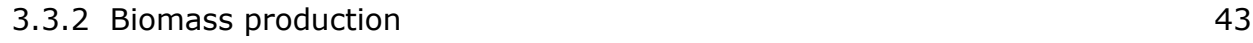

3.3.3 Uptake of metals by crops $\quad 46$

3.3.4 Statistical analysis of differences in plant uptake of metals and nutrients due to treatment and soil $\quad 50$

3.4 Conclusions from greenhouse experiments 2016 and $2017 \quad 57$

\section{Dynamic Modelling of Cadmium balances in arable soils: plot scale and} regional assessment

4.1 Soil crop transfer models and scenarios used in the model calculations

4.1.1 Soil to crop transfer models for Cadmium as derived from greenhouse experiment data 2016-2017 59

$\begin{array}{ll}4.1 .2 \text { Scenarios } & 60\end{array}$

$\begin{array}{lll}4.2 & \text { Plot level simulations } & 60\end{array}$

4.2.1 Assumptions and data used 60

4.2.2 Summary and conclusions of results from predictions at plot level 65

4.3 Impact at EU level: effect of fertiliser quality on Cd levels in potato, wheat and $\begin{array}{ll}\text { lettuce } & 67\end{array}$

4.4 Mass balance approach for other metals not included in the dynamic modelling approach $\quad 75$

$\begin{array}{ll}\text { 4.4.1 Background } & 75\end{array}$ 
5.1 Introduction

5.2 Material and Methods $\quad 83$

5.2.1 Model Outline $\quad 83$

5.2.2 Basic data used at NCU level and calculation of nutrient fluxes $\quad 84$

5.2.3 Model inputs and conversions used to calculate cadmium fluxes from inputs considered

5.2.4 Model Outputs and conversions used to calculate cadmium fluxes

5.3.1 Current Cadmium balances in Agroecosystems at country and EU level 91

5.4 Impact of policy changes on Cd balance and Cd levels in soil 96

5.5 Level of Cd in P fertilisers to achieve net zero balances in soil 102

5.6 Plausibility of results and impact of model choice on predicted changes in Cd levels in soil

$\begin{array}{ll}\text { 5.7 Conclusions from the model study } & 107\end{array}$ 


\section{Preface}

Exposure of humans and animals to potentially harmful substances like cadmium ( $\mathrm{Cd}$ ), lead $(\mathrm{Pb})$ or arsenic (As) occurs through various pathways, one being intake of food and feed products. Uptake of metals like $\mathrm{Cd}$ from soil is one of the main processes that regulates quality of food and feed products. Levels of $\mathrm{Cd}$ and other metals in soil and the variation therein not only depend on the natural background levels but increasingly also on human activities resulting in regionally variable metal loads to soil. Main sources of metals in soil include atmospheric deposition, use of inorganic and organic fertilisers and other soil amendments like compost or sludge. At present, the quality of fertilisers, considering both the nutrient and contaminant content is being discussed (COM, 2016) to reduce trade barriers that currently hamper the free trade of fertilisers across EU member states since, at present, there are no EU-wide quality standards for contaminants. This discussion also includes maximum levels of contaminants including $\mathrm{Cd}$. The use of mineral P fertilisers are a substantial source of $\mathrm{Cd}$ emissions to arable soils, the magnitude of which depends on both the amounts used and quality of the fertiliser, both of which are highly variable in member states resulting in substantially different loading rates of Cd to agro-ecosystems across the EU. As a result of the, partly historic, emission of $\mathrm{Cd}$ to soils both from agronomic and industrial sources, levels of Cd have increased, both in the EU as well as in other parts of the world. For many crops, including staple food crops like wheat, rice and potato, levels of $\mathrm{Cd}$ in soils are related to those in crops, with levels in crops increasing with increasing levels in soil even though the response of crops to increased levels of $\mathrm{Cd}$ in soil varies, both between crops as well as between soils.

Recently, EFSA (2012) stated that current levels of Cd in food are such that intake of Cd by children, and the $95^{\text {th }}$ percentile of adults, is close to or in exceedance of the tolerable daily intake (TDI) of Cd. Clearly not all Cd consumed via food is related to the soil Cd content in the EU. This includes Cd from sources like seafood or imported food products such as cacao, both of which can contribute significantly to the total intake of $\mathrm{Cd}$ depending on the diet. Nevertheless it was estimated that approximately $50 \%$ of the food consumed by consumers in the EU can be directly related to the soil (and quality thereof) in the EU (Rietra et al. 2017). This implies that there is a direct link between the quality of soil (more specifically the Cd content thereof) and the quality of food and exposure. In view of the proposed revision of the Fertiliser Legislation, which includes standards for Cd in mineral $P$ fertilisers, it is therefore relevant to assess to what extent the quality of mineral P-fertiliser affects the levels of $\mathrm{Cd}$ in soils and crops, both on a short term ( 1 year) and long term (50-100 years). To address the effect of variable levels of $\mathrm{Cd}$ in mineral $\mathrm{P}$ fertilisers on the quality of soils and crops this study focusses short- and long term effects:

- Short-term effects: to what extent does the content of Cd in mineral P fertilisers affect the quality of arable crops within one cropping cycle? The main hypothesis to be tested is that the chemical availability of $\mathrm{Cd}$ in P-fertilisers, after being introduced to the soil, is higher than that of Cd already present in soil. The use of low-Cd fertilisers might result in lower $\mathrm{Cd}$ levels in crops $\left(\mathrm{H}_{0}\right)$ compared to high-Cd fertilisers. This hypothesis will be tested experimentally using crop uptake tests in a greenhouse using various arable soils with a range in natural Cd levels, and using a range of fertilisers, including low-Cd inorganic fertilisers (DAP) with or without added Zinc (Zn), animal manure and regular $\mathrm{P}$ fertilisers (DAP) that contain more $\mathrm{Cd}$.

- Long-term effects: how does the Cd balance and the resulting levels of Cd in soil and crop change over time (100 years) when using mineral $P$ fertilisers with varying levels of $C d$ ? A reduced annual load to soil resulting from the use of low-Cd fertilisers will lead to a reduction of Cd levels in soil if the annual balance (inputs - outputs) becomes negative. Such long term effects can be observed only on a time scale of decades and cannot be simulated in an experimental setting. To predict long term (100 years) changes in soil and crop levels of $\mathrm{Cd}$ resulting from the use of mineral $\mathrm{P}$ fertilisers of varying quality in view of $\mathrm{Cd}$ content, model scenarios will be used both at field scale (plot level) as well as regional scale covering the spatial variability in soils, climate and land use at EU-25 level. 
This study was designed to evaluate the impact on crop and soil quality specifically. Results from measured or predicted levels of $\mathrm{Cd}$ in crops and soils will be presented as such. How such changes will affect exposure via intake of food, feed and processed products is beyond the scope of this project.

\section{Disclaimer}

Results presented in this report, specifically model results, have been obtained using the existing, unchanged models from Wageningen Environmental Research as available during the project period (2016-2017). At the time of writing (May 2018) a revised model to predict cadmium leaching from soil has been developed following discussion between scientists from KU Leuven and Wageningen Environmental Research. This discussion, the resulting model, and applications thereof and results obtained are beyond the commission by PhosAgro. 


\section{Summary}

This study was designed to test the short and long term effects of varying levels of cadmium (Cd), arsenic (As), chromium ( $\mathrm{Cr}$ ) and lead $(\mathrm{Pb})$ in mineral $\mathrm{P}$ fertilisers. The main hypotheses to be tested were:

1. Metals in fertilisers, notably $\mathrm{Cd}$, are more bioavailable than metals already present in soils and the use of high Cd-fertilisers in soil will result in a higher $\mathrm{Cd}$ uptake by crops within one year compared to treatments with a low-Cd fertiliser (short term effect), and

2. Increasing levels of $\mathrm{Cd}$ in mineral $\mathrm{P}$ fertilisers cause a long-term shift in the Cd balance in arable soils resulting in an increase of $\mathrm{Cd}$ in soils and crops.

To test hypothesis 1 a greenhouse experiment was performed in 2016 and 2017 including 7 soils (6 in 2016 and 3 in 2017, 2 of which were also included in 2016), 6 crops including leafy vegetables (spinach, lettuce), root crops (carrot), bulb crops (potato) and grain crops (barley and durum wheat) and 5 fertilisers representing the current range in mineral $P$ fertilisers as applied in the EU. These include 2 fertilisers supplied by PhosAgro: a low-Cd fertiliser (DAP, used in 2016 and 2017), a low-Cd fertiliser with added $\mathrm{Zn}$ (DAP-Zn, only used in 2016), a regular DAP with a medium level of Cd (40 mg $\mathrm{Cd} \mathrm{kg}{ }^{-1} \mathrm{P}_{2} \mathrm{O}_{5}$ used in 2016) and a regular DAP with a higher amount of $\mathrm{Cd}\left(60 \mathrm{mg} \mathrm{Cd} \mathrm{kg}^{-1} \mathrm{P}_{2} \mathrm{O}_{5}\right.$ used in 2017). In addition a blank (no $P$ fertiliser) and a treatment with animal manure (cow manure) were included.

The null hypothesis was tested using both soil data and crop data from the greenhouse experiment. Soil data include the measurements of $(i$.$) the available metal content in soil representing the amount$ of Cd (and other metals) that is immediately available for uptake by crops as determined by an extraction after harvest using a dilute $\mathrm{Ca}\left(\mathrm{NO}_{3}\right)_{2}$ solution, and (ii.) the reactive metal content representing the total pool of $\mathrm{Cd}$ (and other metals) from which the solution concentration is replenished. Crop data include the analysis of potentially toxic metals ( $\mathrm{Cd}, \mathrm{Cr}, \mathrm{Pb}$, and $\mathrm{As}$ ), micronutrients ( $\mathrm{Cu}$ and $\mathrm{Zn}$ ) and selected macro nutrients ( $\mathrm{P}, \mathrm{Ca}, \mathrm{K}, \mathrm{S}, \mathrm{Fe}$ ). Hypothesis 1 on the short term effects is accepted if significantly higher amounts of available metals can be detected in the soil solution and/or crop for the different fertilisers used.

Long term effects (100 years) of using fertilisers with increasing amounts of $\mathrm{Cd}$ on Cd levels in crops and soil were quantified using the model Integrator which is able to calculate annual changes in levels of $\mathrm{Cd}$ in soil and crops considering all relevant inputs and outputs from soil including fertiliser application, manure application, application of biosolids (sludge and compost) and atmospheric deposition (all inputs) as well as outputs from soil including leaching, crop uptake and biomass removal. The model scenarios were performed at three levels ranging from, (i) plot level simulations targeting changes in soil and crop Cd from one plot specifically used to grow a specific crop (the ones also included in the greenhouse experiment), to (ii) the European level where simulations are based on the real distribution of soils, crops grown, climate and agronomic practices (a.o. manure application) at country level. For this approach, calculations are performed for more than 23000 spatially explicit regions the results of which are aggregated to country and EU level. In the model scenarios the currently discussed limit values for $\mathrm{Cd}$ are used ranging from 20 to $60 \mathrm{mg} \mathrm{Cd} \mathrm{kg}{ }^{-1} \mathrm{P}_{2} \mathrm{O}_{5}$ with two additional scenarios for $\mathrm{Cd}$ levels in mineral $\mathrm{P}$ fertilisers of 0 and $80 \mathrm{mg} \mathrm{Cd} \mathrm{kg}{ }^{-1} \mathrm{P}_{2} \mathrm{O}_{5}$, respectively. Hypothesis 2 is accepted if significant changes in the soil and crop Cd content can be found in soils after 100 years. As such there is no statistical test for significance in case of long term changes of $\mathrm{Cd}$ levels in soils or crops and the results are presented and discussed using frequency distributions (of predicted levels in soil and crops), maps (showing regional patterns of changes in soil Cd) or absolute levels in soil and crops (in case of the plot level simulations). 


\section{Results from the greenhouse experiments}

\section{Availability of Cadmium and other contaminants in soil}

Both in 2016 and 2017 no significant differences in the bioavailability of $\mathrm{Cd}$ (using $\left.\mathrm{Ca}\left(\mathrm{NO}_{3}\right)_{2}\right)$ as influenced by the quality of fertilisers was observed in the soils used in this study. Total soil Cd levels range from less than $0.1 \mathrm{mg} / \mathrm{kg}$ to more than $6 \mathrm{mg} / \mathrm{kg}$ thus representing the entire range of Cd levels in soils that are used for agriculture. Apparently the differences in amounts of Cd added to the soil is too small to affect the equilibrium between soil and soil solution. Small but significant effects were observed for $\mathrm{pH}$ with slightly lower $\mathrm{pH}$ values in the mineral fertiliser treated soils compared to the blanc and manure treated soils. Also $\mathrm{Zn}$ and to a lesser extent $\mathrm{Cu}$ (both in the 2016 experiment) appear to be slightly more available in the soil treated with the PhosAgro DAP that is fortified with Zn. This apparently has no effect on uptake of Cd. Levels of As also are slightly higher in all mineral fertiliser treated soils compared to the blanc and manure treated soils. Also levels of available $P$ were higher in all soils treated with mineral fertilisers, also compared to the manure treated soils, which suggests that the availability of $\mathrm{P}$ in manure, even when applied at similar levels as by mineral fertiliser, is lower compared to $P$ applied as mineral $P$.

The results of the extraction using dilute acid (using $\mathrm{HNO}_{3}$ ) to determine the total reactive pool of metals confirms the results of the bioavailability (using $\left.\mathrm{Ca}\left(\mathrm{NO}_{3}\right)_{2}\right)$ in that differences between treatments are minor. The only significant effect was a higher amount of reactive $P$ in the mineral fertiliser treated soils compared to the blanc and cow manure treated soils. For Cd the differences between the treatments were very small, and in fact the highest reactive $\mathrm{Cd}$ content was measured in the soils treated with the low-Cd (PhosAgro) DAP and the blanc soils. This suggests that differences due to treatments are not related to additions of Cd to soil - as no Cd was added in the PhosAgro DAP and in the blanc treatment - but merely reflects the variability between soils even after homogenizing the batches of soil. This effect was only observed in 2016 but not in the experiments in 2017 where no differences in reactive $\mathrm{Cd}$ resulting from treatments was observed.

In contrast to the effect of treatment, the effect of soil on the availability and reactivity of all metals was significant. This is not surprising since the soils were chosen to reflect a wide range in both the level of contaminants and soil properties. In line with previous results, the availability of $\mathrm{Cd}$ and $\mathrm{Zn}$ largely depends on $\mathrm{pH}$, organic matter and the total amount present in soil. For As a clear relationship with $\mathrm{P}$ was found with available As levels increasing with dissolved $\mathrm{P}$. The solubility of $\mathrm{Cu}$ is controlled both by the reactive pool and the amount of dissolved organic carbon in solution. The solubility of $\mathrm{Cr}$ and $\mathrm{Pb}$ on the other hand is less controlled by soil properties and is largely related to the reactive pool in soil.

Based on these findings the hypothesis that the content of $\mathrm{Cd}$ or other contaminants in fertilisers affects the bioavailability in soils within one cropping cycle (short term effects) has to be rejected. Within the range of $\mathrm{Cd}$ levels in fertilisers tested here $\left(0-60 \mathrm{mg} \mathrm{Cd} \mathrm{kg}{ }^{-1} \mathrm{~kg} \mathrm{P}_{2} \mathrm{O}_{5}\right)$, and soils used, no effect of $\mathrm{Cd}$ from fertilisers on the availability or reactive pool was detected.

Uptake of Cadmium and other contaminants and nutrients by crops

In line with the observations on the bioavailability, effects of treatment (choice of fertilisers) were limited or inconsistent. In 2016 for example the Cd levels in lettuce appeared to be higher in the low $\mathrm{Cd}$ treated soils (PhosAgro DAP without $\mathrm{Zn}$ ) but this effect is different when comparing different soils at equal $\mathrm{Cd}$ levels in soil which suggests that it is not related to the Cd availability as affected by the fertiliser application but relates more to the interaction between crop and soil which may vary depending on the soil properties. Soil chemical properties including the bioavailability of Cd or nutrients and differences therein between soils are insufficient to explain such differences. In most soils the uptake of $\mathrm{P}$ was significantly higher in the mineral fertiliser treated soils compared to the blanc and manure treated soils, but differences between individual fertiliser treatments were absent. The higher uptake of $\mathrm{P}$ also corresponds to a slightly higher uptake of As both of which are in line with the elevated availability of both elements as measured in soil. 
In 2016 a number of additional crop quality indicators was measured, notably a number of vitamins and crop specific indicators such as beta-carotene for carrots. As for heavy metals there was no significant difference in the content of either of these compounds in lettuce or carrots (crops used in the 2016 experiments) across the soils and fertilisers included in the study that could be related to the quality of the fertilisers used here. Apparently the levels of $\mathrm{Cd}$ and other metals present in the soil did not negatively affect the crops physiological functioning and content of vitamins and other substances tested for. The only significant effect observed was a slightly reduced level of Vitamine B1 in lettuce in the soils treated with the $\mathrm{Zn}$ enriched DAP from PhosAgro. Results from the 2017 experiments using barley, spinach, carrot and potato in soils low in $\mathrm{Cd}$ again confirmed that uptake of metals ( $\mathrm{Cd}, \mathrm{As}, \mathrm{Cu}$, $\mathrm{Zn}, \mathrm{Pb}$ ) was not so much affected by the quality of fertiliser compared to the quality of the soil itself. Even in low Cd soils, the added amount of Cd via fertilisers was too low to affect the uptake by crops and no significant changes in either the bioavailable not the adsorbed pool for all metals included was detected.

Based on these findings the hypothesis that the content of $\mathrm{Cd}$ or other contaminants in fertilisers affects the quality of crops, notably the uptake of $\mathrm{Cd}, \mathrm{Cr}$, As or $\mathrm{Pb}$ from soil, within one cropping cycle (short term effects) has to be rejected. Within the range of Cd levels in fertilisers tested here $\left(0-60 \mathrm{mg} \mathrm{Cd} \mathrm{kg} \mathrm{P}_{2} \mathrm{O}_{5}\right.$ ), and soils used, no effect of $\mathrm{Cd}$ or other elements from fertilisers on the levels of $\mathrm{Cd}$ in the crops tested here was detected.

\section{Results from model studies}

\section{Plot scale simulations}

Results from plot scale simulations using the soils as included in the experiment suggest that -on average- a $34 \%$ reduction in Cd levels in food crops (compared to current levels) can be achieved after 100 years when using low-Cd P-fertilisers only. The magnitude of this change is however variable depending on soil conditions and crop type; experimental results show that the effect is more prominent in leafy vegetables compared to potato for example. The use of animal manure, on average also leads to lower $\mathrm{Cd}$ levels in crops whereas the $\mathrm{Cd}$ fertiliser that contains $60 \mathrm{mg} \mathrm{CD} \mathrm{kg}{ }^{-1} \mathrm{P}_{2} \mathrm{O}_{5}$ results in - on average - a $22 \%$ increase in Cd levels in crop. For specific crops (like leafy vegetables) and under specific soil conditions, notably in slightly acid sandy soils, $\mathrm{Cd}$ uptake can decrease even when using mineral $P$ fertilisers that contain $60 \mathrm{mg} \mathrm{Cd} \mathrm{kg}^{-1} \mathrm{P}_{2} \mathrm{O}_{5}$.

It is predicted that the use of the medium high-Cd P fertiliser ( $40 \mathrm{mg} \mathrm{Cd} \mathrm{kg}^{-1} \mathrm{P}_{2} \mathrm{O}_{5}$ ) results in a small increase of crop Cd levels. This outcome is very much in line with the more elaborate regional modelling results at EU level (chapter 5 ). The $\mathrm{Cd}$ level in the medium-Cd fertilisers used in the experiment is close to the average quality of mineral $P$ fertilisers used at present in the EU. This suggests that the models applied in both assessments are rather robust and do not lead to contrasting conclusions.

\section{Regional scale simulations}

Results from the regional assessment where the predicted levels in soil after 100 years for the 23000 spatial units were used to calculated levels of $\mathrm{Cd}$ in potato, barley and carrot show that on average a stand still for $\mathrm{Cd}$-when considering Cd levels in crops- is achieved at zero inputs of Cd via mineral P fertilisers. Predicted relative increases in the crops compared to present levels are between 4 and $17 \%$ for the Cd-20 to Cd-80 scenarios respectively. Differences between countries however are substantial which is due to both differences in the amount of fertiliser used and (in case of the Business as Usual scenario) the quality, i.e. the current Cd levels in mineral P fertilisers. Furthermore the range in predicted levels of $\mathrm{Cd}$ in all food crops considered here, when considering all spatial units, is several times larger than the predicted range due to differences for a given unit based on differences of the $\mathrm{Cd}$ content of fertilisers used in this unit. This is in agreement with the results from the experiments which reveal that differences between soils are more relevant in terms of Cd uptake by crops compared to differences in the quality of fertilisers used. Nevertheless, there is a clear positive relation between the levels of $\mathrm{Cd}$ in fertilisers applied and the resulting $\mathrm{Cd}$ content in crops when considering a time frame of 100 years. These effects are most prominent in countries that apply relatively large 
amounts of fertiliser including a.o. Poland and Portugal. In these countries the percentage of the total area used for arable crop production where Cd levels in soil increase with more than $0.05 \mathrm{mg} / \mathrm{kg}$ (which is used here as an arbitrary criterion for a detectable increase of Cd in soils) ranges from $1 \%$ in case of the Cd-0 scenario to almost $60 \%$ in case of the Cd-80-scenario. This contrasts sharply with predicted results for a.o. Belgium where even in case of the $\mathrm{Cd}-80$ scenario the total surface are with a detectable increase of $\mathrm{Cd}$ in soil after 100 years is only $3 \%$ of the total surface area used for agriculture.

These results are in line with those from the most detailed spatial analysis (as presented in chapter 5) focussing on changes of $\mathrm{Cd}$ in soil after 100 years based on the actual land use considering all crops and current forms of land use including both arable land and grassland. On average the predicted relative changes of $\mathrm{Cd}$ in soil compared to current levels ranges from $-4.4 \%$ in case of the $\mathrm{Cd}-0$ scenario, to $+12.5 \%$ in case of the $\mathrm{Cd}-80$ scenario. When considering arable soils only these relative changes vary from $+0.2 \%$ in case of the Cd-0 scenario to $16 \%$ in case of the Cd- 80 scenario. Results reveal that at EU level Cd balances are largely negative for grassland soils due to lower application rates of mineral $\mathrm{P}$ fertilisers and slightly higher leaching levels due to the lower $\mathrm{pH}$ in pasture soils. For grassland soils therefore the $\mathrm{Cd}$ content in soils decreases in all but the $\mathrm{Cd}-80$ scenario whereas in arable soils tend to accumulate $\mathrm{Cd}$ in all scenarios albeit that in case of the $\mathrm{Cd}-0$ scenario a close to stand still situation is predicted.

Results calculated with the spatially explicit model at EU level differ from those published earlier by Smolders (2017). The average levels of Cd in mineral P fertilisers at which a stand still in soil Cd levels is achieved in the current study is close to zero $\mathrm{mg} \mathrm{Cd} \mathrm{kg}^{-1} \mathrm{P}_{2} \mathrm{O}_{5}$ whereas the model presented by Smolders results in an approximate equilibrium at $73 \mathrm{mg} \mathrm{Cd} \mathrm{kg}^{-1} \mathrm{P}_{2} \mathrm{O}_{5}$.

Results from the simulations either at plot level or at EU level for more than 23000 spatially explicit units show that long term changes of $\mathrm{Cd}$ levels in soil are related to Cd levels in fertiliser with Cd levels in soil increasing between $0.2 \%$ to $16 \%$ for the $\mathrm{Cd}-0$ and $\mathrm{Cd}-80$ scenario respectively after 100 years.

These model results suggest that when reducing Cd levels in fertiliser to zero, a net stand still for arable soils at the EU level can be achieved. When considering both pasture soils and arable soils, a net zero change of $\mathrm{Cd}$ in soil (at EU level) is achieved at a corresponding level of $20 \mathrm{mg} \mathrm{Cd} \mathrm{kg}^{-1}$ $\mathrm{P}_{2} \mathrm{O}_{5}$.

The difference between this level and a previously reported level of $73 \mathrm{mg} \mathrm{Cd} \mathrm{kg}{ }^{-1} \mathrm{P}_{2} \mathrm{O}_{5}$ is largely due to different model concepts used to calculate leaching losses from soil.

\section{General conclusions}

\section{Experimental results}

- Results from the greenhouse experiments indicate that within one year after application, there is no significant difference in absorption of $\mathrm{Cd}$ or other metals included here $(\mathrm{Cu}, \mathrm{Cr}, \mathrm{As}, \mathrm{Zn}$ and $\mathrm{Pb})$ by crops when mineral $P$ fertiliser is used with levels of $C d$ varying between 0 and $60 \mathrm{mg} \mathrm{Cd} \mathrm{kg}^{-1} \mathrm{P}_{2} \mathrm{O}_{5}$.

- Soil chemical tests reveal that the added amount of contaminants via fertilisers or manure during one cropping cycle do not affect the plant available metal pool nor the total available pool adsorbed to the soil even in soils with a low to very low Cd status.

- Differences in soil properties (e.g. acidity and organic matter content) in combination with the initial content of $\mathrm{Cd}$ in the soil are the main factors that control the short term (1 harvest cycle) variation of $\mathrm{Cd}$ concentrations in crops. 


\section{Plot scale simulation studies based on soils used in the experiments}

- Long term model simulations at plot level (field) using the soils and fertilisers used in the greenhouse study reveal that a 'low' Cd fertiliser ( $0 \mathrm{mg} \mathrm{Cd} \mathrm{kg}{ }^{-1} \mathrm{P}_{2} \mathrm{O}_{5}$ ) would, on average lead to $34 \%$ lower levels of $\mathrm{Cd}$ in crops included in the experiments (potato, wheat, lettuce) whereas a 'high' Cd fertiliser (approx. $60 \mathrm{mg} \mathrm{Cd} \mathrm{kg} \mathrm{m}_{2} \mathrm{O}_{5}$ ) results in an average increase of $22 \%$ of crop Cd levels.

- The magnitude of changes in both soil and crop Cd is related to both the initial Cd content in soil as well as the acidity and organic matter content. Increases in the soil and crop Cd content are more pronounced in low $\mathrm{Cd}$ soils at near neutral $\mathrm{pH}$. In soils with higher levels of $\mathrm{Cd}$ (here: $\mathrm{Cd}>2 \mathrm{mg} \mathrm{kg}^{-1}$ soil) the Cd content of fertilisers has limited impact on the development of soil and crop Cd levels with time.

Regional scale model studies using lettuce, wheat and potato as indicator crops

- When applied to 23000 spatial units representing the range in arable soil in the EU, relative changes in crop Cd after 100 years range from $+0.9 \%$ if no $\mathrm{Cd}$ is present in mineral $\mathrm{P}$ fertilisers to $+7.9 \%$ if the quality of fertilisers remains unchanged. When applying the 'high' $\mathrm{Cd}$ fertiliser used in this study (60 $\mathrm{mg} \mathrm{Cd} \mathrm{kg}^{-1} \mathrm{P}_{2} \mathrm{O}_{5}$ ) the increase in crop $\mathrm{Cd}$ is $+13.4 \%$.

- Absolute changes in crop Cd are most pronounced for lettuce with an average (EU-25 level) increase from $0.74 \mathrm{mg} \mathrm{Cd} \mathrm{kg}{ }^{-1} \mathrm{~d} . \mathrm{m}$. (present average) to $0.81 \mathrm{mg} \mathrm{Cd} \mathrm{kg}{ }^{-1} \mathrm{~d} . \mathrm{m}$. in case of the Cd-60 scenario. For potato average $\mathrm{Cd}$ levels increase from 0.12 to $0.13 \mathrm{mg} \mathrm{Cd} \mathrm{kg}^{-1} \mathrm{~d} . \mathrm{m}$. in the same scenarios; and for wheat Cd levels increase from 0.05 to $0.06 \mathrm{mg} \mathrm{Cd} \mathrm{kg}{ }^{-1} \mathrm{~d} . \mathrm{m}$.

- Relative changes in both soil and crop Cd levels vary strongly between countries. In case of the Cd-0 scenario ( $\mathrm{Cd}$ in mineral $\mathrm{P}$ fertilisers set at 0 ), relative changes in crop Cd after 100 years at country level vary between $-10 \%$ in Ireland to $+7.9 \%$ for Bulgaria. In case of the Cd-60 scenario, Cd crop levels still decrease by $4.8 \%$ in Sweden but increase by almost $30 \%$ in Spain.

- In general the magnitude of the change is highly correlated to $i$. leaching rates (water flow), with lower leaching rates in Mediterranean areas compared to northern areas in the EU, ii. soil acidity which low $\mathrm{pH}$ values in north-western parts of the EU enhancing leaching of Cd versus near neutral or alkaline soils in southern Europe which favours accumulation of $\mathrm{Cd}$.

\section{Regional scale models at EU-25 based on actual land use}

- Long-term (100 years) calculations on a regional scale for EU-25 show that the content of Cd in P fertilisers does affect both levels in soil and that in crops. Dynamic model simulations at EU level indicate that accumulation of $\mathrm{Cd}$ in soil (arable and grassland) continues if the Cd content in $\mathrm{P}$ fertilisers exceeds $20 \mathrm{mg} \mathrm{Cd} \mathrm{kg}{ }^{-1} \mathrm{P}_{2} \mathrm{O}_{5}$.

- For arable land, zero inputs of Cd via fertiliser would result in an approximate -EU average- stand still (no change in the soil Cd content) at $t=100$ years.

- The calculated average long-term changes in both soil and arable crops relative to current levels are in the order of magnitude of $+0.2 \%$ if no more $\mathrm{Cd}$ is applied via $\mathrm{P}$ fertiliser to $+12.1 \%$ or $+16 \%$ if, at the European level the concentration of $\mathrm{Cd}$ in mineral P-fertilisers averages 60 or $80 \mathrm{mg} \mathrm{Cd} \mathrm{kg}^{-1}$ $\mathrm{P}_{2} \mathrm{O}_{5}$ respectively.

- Cd balances at EU-25 level agree well with those presented earlier (Smolders, 2017) except for leaching losses which are, in the model used here, significantly lower resulting in higher accumulation of $\mathrm{Cd}$ at lower loading rates.

- Differences between predicted leaching rates appear to be due to differences in model structure where the use of a $\mathrm{Kd}$ model implicitly leads to higher predicted $\mathrm{Cd}$ solution concentrations compared to those predicted by a non-linear model.

- A second reason for differences between the two leaching models is the differences in concentrations ranges present in the source data. A shift towards higher concentrations in the source data leads to an increase of the predicted levels of Cd in solution when applied to the spatial units at NCU level. 


\section{Introduction}

\subsection{Cadmium in the Environment}

\section{Background}

Phosphate $(P)$ fertilisers are one of the most widely used sources for $P$ fertilization of crops. Most inorganic $P$ fertilisers, however, especially those derived from sedimentary rocks, also contain varying amounts of cadmium (Cd) and in addition also arsenic (As), and lead (Pb). Several documented cases exist showing that the use of $P$ fertiliser indeed is one of the dominant sources of $C d$ in arable cropping systems. Long-term use of P-fertiliser can thus lead to significant $\mathrm{Cd}$ accumulation in soils which in turn can lead to elevated $\mathrm{Cd}$ uptake by crops. The degree to which $\mathrm{Cd}$ accumulates in soil and becomes or remains available to plants strongly depends on a combination of soil type, as expressed in differences in $\mathrm{pH}$, organic matter, clay or redox (in case of paddy rice for example), and crop type. Especially vegetable crops like lettuce and leek are known to accumulate Cd quite easily compared to for example fruit or peas.

Since $\mathrm{Cd}$ is a potentially toxic substance, with known effects on kidney functioning and bone stability, it is crucial to minimize inputs of $\mathrm{Cd}$ to agricultural soils or to reduce the availability of Cd once present in the soil. Cadmium behaviour in soils is characterized by a relatively high mobility compared to other heavy metals like lead $(\mathrm{Pb})$ or chromium $(\mathrm{Cr})$, and uptake by crops is mainly related to the content pool of $\mathrm{Cd}$ in soil in combination with some specific soil properties. In low organic matter/low $\mathrm{pH}$ soils for example, Cd uptake by crops is high compared to high organic matter/neutral pH soils. The current status of many agricultural soils is such that $\mathrm{Cd}$ levels in crops largely meet food quality standards currently used in the EU. There are regions and crops that approach the food safety limit due to either high uptake (e.g. scorzonera or leek) characteristics or because of historic (mainly industrial) inputs or ongoing accumulation due to, among others, application of $\mathrm{P}$ fertilisers that may contain elevated levels of Cd. More importantly, the current mean dietary exposure to cadmium in European countries are close to or slightly exceeding the tolerable weekly intake of $2.5 \mathrm{ug} / \mathrm{kg}$ body weight.

Since crop Cd levels are partially related to levels of Cd in soils, changes in the soil Cd level will result in changes in the crop $\mathrm{Cd}$ level. In those cases where annual inputs of $\mathrm{Cd}$ to the soil exceed removal from soil (by crops and leaching), crop Cd levels are bound to increase. The rate at which crop Cd levels increase depends on both soil properties, input levels, leaching rates and crop removal rates. In case of a substantial reduction of inputs, $\mathrm{Cd}$ levels in soil in time may even be reduced since outputs via leaching and crop uptake will continue. In current agro-ecosystems, the contribution of mineral $P$ fertilisers to the total input of $\mathrm{Cd}$ to soils is substantial if variable between countries. Nevertheless, the use of a low-Cd P fertiliser, such as the ones made from igneous rocks, will therefore results in reduced inputs to soil and hence can help to achieve a stand-still (no accumulation) or even a reduction of $\mathrm{Cd}$ levels in soil with time.

Currently, however, it is still unclear to what extent the use of low-Cd P fertilisers will result in a significant reduction of uptake of $\mathrm{Cd}$ during the first few years. This is related to the fact that $\mathrm{Cd}$ introduced to the soil in the past remains available to a large extent (80-90\%) meaning that the previous $\mathrm{Cd}$ inputs to soil strongly affects $\mathrm{Cd}$ uptake by crops. In most cases, the amount of Cd added to soil in one year via fertilisers or otherwise is only a fraction (usually less than $1 \%$ ) of the total amount of $\mathrm{Cd}$ in the rooting zone. This would imply that the short term effect of using low Cd-P fertilisers is minimal since the contribution to the total pool of $\mathrm{Cd}$ in soil is small. This assumption however is based on the concept that $\mathrm{Cd}$ in soil and $\mathrm{Cd}$ in fertilisers is equally available for crops to be taken up from soil. This assumption has not been validated for most crops, and a hypothesis therefore is that given the high solubility of mineral P fertilisers, Cd in fertiliser is relatively more available for crop uptake in the season of application compared to the native $\mathrm{Cd}$ in soil. If true, this would imply that levels of $\mathrm{Cd}$ in crops also depend on $\mathrm{Cd}$ present in fertiliser applied during the growing season. 
As stated, the difference between the chemical availability of soil-Cd versus fertiliser-Cd and its short term consequences for crop quality (i.e. Cd content in the crop) are poorly documented and if proven to be correct (i.e. fertiliser $\mathrm{Cd}$ is an important source of immediately available Cd that is taken up by the plant during the growing season) the shift from the use of high-Cd P fertilisers to low-Cd P fertiliser could be an effective way to protect $\mathrm{Cd}$ from being accumulated by crops, not only on the long term, but also on the short term.

If used for longer periods of time, the reduced Cd load to soil will change the Cd balance in soil and, depending on the total load, soil type, crop type and climate can lead to a reduction of Cd levels in soil once the balance (inputs minus outputs) becomes negative. The rate at which this occurs and the absolute change in Cd levels in soils that can be achieved depending on the Cd levels in fertilisers has not been addressed in a systematic way using the regional variation (in the EU) of soils, land use, climate and fertiliser quality.

\subsection{Regulation of cadmium and proposed quality limits}

The European Commission has proposed a new regulation for fertilisers on 18 March 2016 (COM, 2016). The first objective of the proposal is improve recycling of biowaste and other secondary raw materials via innovative fertilising products. The second objective of the proposal is to introduce harmonised Cd limits for phosphate fertilisers. In the current proposal $\mathrm{Cd}$ is to be subsequently reduced from $60 \mathrm{mg} \mathrm{Cd} \mathrm{kg}^{-1}$ $\mathrm{P}_{2} \mathrm{O}_{5}$ to $40 \mathrm{mg} \mathrm{Cd} \mathrm{kg}{ }^{-1} \mathrm{P}_{2} \mathrm{O}_{5}$ after three years, and further to $20 \mathrm{Cd} \mathrm{mg} \mathrm{kg}{ }^{-1} \mathrm{P}_{2} \mathrm{O}_{5}$ after twelve years.

\subsection{Aim of the study}

The main hypothesis to be tested is to what extent Cd from fertilisers is available for crops compared to the $\mathrm{Cd}$ pool already present in the soil and the consequences thereof on the quality of crops and development of soil quality with time ( 0 - 100 years). If, based on soil chemical tests, Cd from P fertiliser proves to be more available compared to $\mathrm{Cd}$ already present in soil, this would imply that the use of low-Cd fertiliser immediately will result in lower Cd levels in crops. Hence the related main research questions are:

1. Does the use of low-Cd fertiliser result in a reduction of Cd uptake by crops within a short time period ( 1 - 2 years)? This part of the study focuses on experimental work regarding the chemical availability of $\mathrm{Cd}$ in soil and corresponding uptake by crops. Results from this part will provide evidence to what extent the use of low-Cd P fertilisers affect crop quality and performance compared to regular $\mathrm{P}$ fertilisers. Also, the results from the experiments to be performed can be used to improve existing soil to cop transfer models to be used in regional model studies (part 2). To establish the short term effect of using low-Cd P fertilisers on the Cd level in arable crops as compared to treatments with fertiliser with a higher $\mathrm{Cd}$ content and animal manure a greenhouse experiment has been conducted in 2016 and 2017. In total 7 different soils with a range in Cd levels and soil properties reflecting both low and medium high Cd contaminated soils including the main soil types used for arable crop production, ie sand, loam and clay soils were used. In total 5 different crops are used including grain crops (barley), bulb crops (potato), root crops (carrot) and leafy vegetables (lettuce and spinach). Fertilisers used are mainly DAP-type fertilisers with Cd levels ranging from 0 to $60 \mathrm{mg} \mathrm{Cd} \mathrm{kg}{ }^{-1} \mathrm{P}_{2} \mathrm{O}_{5}$ and one type of animal manure (cow manure) as well as blanc treatments receiving no $P$ fertilization.

2. To what extent does the use of low-Cd P fertiliser affect the quality of soil and crops on a long term ( 0 - 100 year)? Since annual changes of the total Cd pool in soil are small, long term model scenario calculations are used to predict the long term changes of $\mathrm{Cd}$ in soil and crop. This will be done both at plot level for specific crops as well as on a European level based on the current (real) combinations of land use, soil type, climate and Cd levels (at time zero) in soil. A dynamic model is then used to predict annual changes in inputs and outputs which then will yield the long term effects after 100 years. 
Aside from Cd, the above mentioned questions regarding the short term effects (uptake experiments) are also considered for the other two metals included in this study (As and $\mathrm{Pb}$ ). In addition we will also evaluate the influence of $\mathrm{Zn}$ as a micronutrient on both the chemical availability of $\mathrm{Cd}, \mathrm{As}$ and $\mathrm{Pb}$ in soil and uptake by crops.

\subsection{Outline of the report}

In chapter 2 a description of the soils and greenhouse study design is given as well as a description of the model used to predict long term changes in soil, crops and leachate when using low-Cd fertilisers compared to regular fertilisers. Chapter 3 contains the results of the greenhouse experiments including the characterization of soils and fertilisers. Here also a statistical analysis of the data is included to test whether or not the treatments (fertilisers) lead to differences in both (micro) nutrient levels in crops as well as levels of metals (As, $\mathrm{Pb}$ and $\mathrm{Cd}$ ) in crops. Chapter 4 describes the outcome of the modelling study for $\mathrm{Cd}$ where data from the experimental study will be used to predict changes in soil and corresponding crops. It also includes results from a simplified metal balance approach for As, $\mathrm{Cu}, \mathrm{Cr}, \mathrm{Ni}, \mathrm{Pb}$ and $\mathrm{Zn}$ to demonstrate the possible impact of different levels of these metals present in fertiliser on levels in soil. Chapter 5 contains the results of a modelling study based on the Integrator model developed at Wageningen Environmental Research at EU level on long term changes in soil Cd levels as affected by the Cd concentration in mineral P fertilisers according to current proposed limit values. Chapter 6 contains the main conclusions and recommendations that were derived from this study. The modelling results presented in chapters 4 and 5 focusses on $\mathrm{Cd}$ considering its relevance in view of the proposed changes in the fertiliser regulation and relevance in view of food quality. In a separate annex (Annex 1) results from a simplified balance approach reveal that the expected impact of differences in fertiliser quality on the long term changes in soil of arsenic ( $\mathrm{As}$ ) and lead ( $\mathrm{Pb}$ ) being the most relevant is negligible. 


\section{$2 \quad$ Materials and Methods}

\subsection{Soils, crops and fertilisers used in in the greenhouse experiment}

\subsubsection{Soils used in the greenhouse experiment and soil testing}

In the 2016 and 2017 experiments 7 typical soils used for arable cropping were used. These soils have been or still are used for regular crop growing. Four of these soils (listed in Table 2.1) have not been affected by any (known) diffuse or point source pollution; the other three soils received various metals from either atmospheric deposition (Cranendonck) or deposition of polluted sediments (Epen, Lottum).

Table 2.1 Overview of soils selected for the greenhouse experiment

\begin{tabular}{|c|c|c|c|c|}
\hline Name & Soil Type & Land use & Pollution status & Pollution Source \\
\hline $\begin{array}{l}\text { A Droevendaal } \\
(2016+2017)\end{array}$ & $\begin{array}{l}\text { Non-calcareous } \\
\text { sand }\end{array}$ & $\begin{array}{l}\text { Arable soil, range of crops } \\
\text { including food and fodder crops }\end{array}$ & $\begin{array}{l}\text { Normal } \\
\text { (non polluted) }\end{array}$ & - \\
\hline $\begin{array}{l}\text { C Wijnandsrade } \\
(2016+2017)\end{array}$ & $\begin{array}{l}\text { Non-calcareous } \\
\text { Silt Loam }\end{array}$ & Arable soil, range of food crops & $\begin{array}{l}\text { Normal } \\
\text { (non-polluted) }\end{array}$ & - \\
\hline $\begin{array}{l}\text { D Epen } \\
(2016)\end{array}$ & $\begin{array}{l}\text { Non-calcareous } \\
\text { Silt Loam }\end{array}$ & Natural pasture used for grazing & $\begin{array}{l}\text { Moderate - high } \\
(\mathrm{Cd}, \mathrm{Zn}, \mathrm{Pb}\end{array}$ & $\begin{array}{l}\text { Deposition of polluted river } \\
\text { sediment (Geul river) }\end{array}$ \\
\hline $\begin{array}{l}\text { E Grebbedijk } \\
(2016)\end{array}$ & $\begin{array}{l}\text { Calcareous river } \\
\text { Clay }\end{array}$ & Arable soil, range of food crops & $\begin{array}{l}\text { Normal } \\
\text { (non-polluted) }\end{array}$ & - \\
\hline $\begin{array}{l}\text { F Lottum } \\
(2016)\end{array}$ & $\begin{array}{l}\text { Non-calcareous } \\
\text { loamy clay }\end{array}$ & $\begin{array}{l}\text { Extensively used pasture formerly } \\
\text { used for arable crop production }\end{array}$ & $\begin{array}{l}\text { Medium - high } \\
(\mathrm{Cd}, \mathrm{Cu}, \mathrm{Zn}, \mathrm{Pb})\end{array}$ & $\begin{array}{l}\text { Deposition of polluted river } \\
\text { sediment (Meuse River) }\end{array}$ \\
\hline
\end{tabular}

In the early summer of 2016, approx. $3 \mathrm{~m}^{3}$ soils $A$ to $F$ were collected in the field and transferred to the experimental facilities at Unifarm (Wageningen UR). After collection of the soils in June 2016, the soils were air-dried for 3 to 4 days, sieved $(2 \mathrm{~mm}$ ) and homogenized to obtain a soil that can be easily used to fill pots. Sufficiently large amounts of soil were collected to perform both the 2016 and 2017 experiments. Soils not used in the 2016 experiments were stored indoors in closed large $\left(1 \mathrm{~m}^{3}\right)$ plastic containers (with sufficient aeration) at room temperature (10-15 degrees). Two of these soils (Droevendaal and Wijnandsrade) are also used in the 2017 experiments. The Lioessens soil was collected early 2017 to represent low Cd soils (see Chapter 3) and was prepared in a similar way as the 6 soils collected in 2016 .

The following soils were used in the 2016 experiments (between brackets the abbreviations used in the report):

1. Droevendaal (DROE) soil: a sandy soil, collected at the Droevendaal experimental farm in the immediate vicinity of the Wageningen Campus, Wageningen ( $\mathrm{N} 51^{\circ} 59^{\prime} 26^{\prime \prime}, \mathrm{E} 5^{\circ} 39^{\prime} 40^{\prime \prime}$ ).

2. Cranendonck (CRA) soil: a sandy soil, collected at a former experimental farm in Cranendonck $\left(51^{\circ} 18^{\prime} 06^{\prime \prime} \mathrm{N}, 5^{\circ} 35^{\prime} 02^{\prime \prime} \mathrm{E}\right)$ which is located at $2 \mathrm{~km}$ from a zinc smelter with a history of pollution.

3. Wijnandsrade (WIJN): a loamy soil, collected at the experimental farm Wijnandsrade $\left(50^{\circ} 53^{\prime} 40^{\prime \prime}\right.$ $\left.\mathrm{N}, 5^{\circ} 53^{\prime} 33^{\prime \prime} \mathrm{E}\right)$.

4. Epen (EPEN): a loamy soil, collected at $5 \mathrm{~m}$ distance from the river Geul in Epen a river that formerly has polluted the soil $\left(50^{\circ} 46^{\prime} 12^{\prime \prime} N, 5^{\circ} 55^{\prime} 12^{\prime \prime} \mathrm{E}\right)$. 
5. Grebbedijk (GREB): a clay soil, collected at the Unifarm experimental farm Wageningen $\left(51^{\circ} 57^{\prime} 26^{\prime \prime} \mathrm{N}, 5^{\circ} 38^{\prime} 22^{\prime \prime} \mathrm{E}\right)$.

6. Lottum (LOTTUM): a light clay soil, collected at $20 \mathrm{~m}$ distance from the river Meuse in Lottum, a river that formerly has polluted the soil $\left(51^{\circ} 26^{\prime} 08^{\prime \prime} \mathrm{N}, 6^{\circ} 09^{\prime} 09^{\prime \prime} \mathrm{E}\right)$.

In the 2017 experiment an additional soil was used that represents the soils with low Cd levels:

1. Lioessens (LIOESSENS): a sandy soil collected at the experimental farm in the village of Lioessens, representing very young polder soils ( $<100$ years) with very low additions of Cd via either atmosphere or otherwise $\left(53^{\circ} 23^{\prime} 45^{\prime \prime} \mathrm{N}, 6^{\circ} 06^{\prime} 31^{\prime \prime} \mathrm{E}\right)$.

Peat soils are used far less for the food crops considered here and will, therefore, not be included at this stage.

\subsubsection{Fertilisers and soils used in the greenhouse experiments: 2016}

Fertilisers will be applied that represent the common range of Cd in P-fertiliser in inorganic and organic fertilisers. For the 2016 experiments this includes two inorganic low-Cd fertilisers (one regular DAP and one DAP with added Zn levels); one regular DAP with Cd levels approximately equal to average Cd content in P fertilisers used across the EU, and one type of animal (cow) manure (dried).

Aside from $\mathrm{P}$ fertilisers $\mathrm{N}$, and $\mathrm{K}$ fertilisers are used to provide sufficient nutrients based on standard crop requirements.

For the 2016 experiments this results in 6 (soil types) $\times 2$ (crops, ie carrot and lettuce) $\times 5$ (Fertiliser treatments) $\times 3$ replicates, being 180 pots to be used in soil testing and crop uptake experiments. Results on analyses of both nutrients and metals in the fertilisers used are given in the results section in Chapter 3 (par. 3.1) for both years (2016 and 2017)

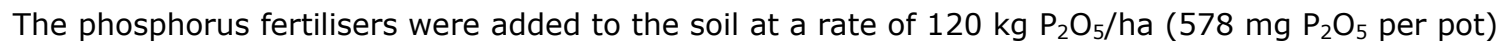
which is the upper limit according to the Dutch fertiliser legislation. The fertilisers were used as originally delivered and not broken or ground. To ensure a good plant growth the soils were fertilised according to the Dutch fertilisation standards for carrot and lettuce. The soils were analysed using standard methods to obtain fertilisation rates for of $\mathrm{N}, \mathrm{K}, \mathrm{Ca}, \mathrm{S}, \mathrm{Mg}$ carrot and lettuce for each soil. Fertiliser solutions were prepared from pro analysis (p.a.) salts (Merck) to prevent contribution of cadmium or zinc from other fertilisers. In a separate Appendix nog included in this report more details are given of the amounts of $\mathrm{N}, \mathrm{P}$ and fertilisers applied to each combination of soil and crop. This appendix can be requested via PhosAgro AS.

Nitrogen fertiliser as applied in two steps according to the fertilisation advice, at the start, and three (lettuce) or four (carrot) weeks after the start of growth of the plants. The nitrogen advice in the Netherlands is based on the crop (140 and $100 \mathrm{~kg} / \mathrm{ha}$ for lettuce and carrot respectively) and is corrected for the measured amount of nitrogen which is still available in a soil layer of $25 \mathrm{~cm}\left(\mathrm{~N}_{\min }\right)$, and a $\mathrm{N}$ correction $(0-20 \mathrm{~kg} / \mathrm{ha})$. Potassium fertiliser was added to carrot using $\mathrm{KCl}$ as this is the standard potassium fertiliser in the Netherlands. In case of lettuce $\mathrm{K}_{2} \mathrm{SO}_{4}$ was used because lettuce is sensitive to chloride. Magnesium fertiliser was added to lettuce using $\mathrm{MgSO}_{4} 7 \mathrm{H}_{2} \mathrm{O}$, which is a standard fertiliser for magnesium. No sulphate needs to be added to lettuce because by using magnesium and potassium sulphate more than enough sulphate is added.

All fertilisers (except $P$ fertilisers and manure) were added in a liquid form (Table 2.2) for to ensure a homogenous mixing with the soil. For $\mathrm{N}, \mathrm{P}$ and $\mathrm{K}$ the standard stock solutions were used which were prepared using high grade chemicals to avoid additional inputs of metals to the soil. 
Table 2.2 Overview salts used to prepare $N, K$, and $M g$ stock solutions used in the greenhouse experiments

\begin{tabular}{lll} 
Compound & Solution used & Concentration \\
$\mathrm{N}$ & $\mathrm{NH}_{4} \mathrm{NO}_{3}$ & 9.14 \\
\hline $\mathrm{K}$ & $\mathrm{K}_{2} \mathrm{SO}_{4}$ & 25.90 \\
\hline $\mathrm{K}$ & $\mathrm{KCl}$ & 22.16 \\
\hline $\mathrm{Mg}$ & $\mathrm{MgSO}_{4} \cdot 7 \mathrm{H}_{2} \mathrm{O}$ & 61.15
\end{tabular}

\subsubsection{Fertilisers and soils used in the greenhouse experiments: 2017}

Based on results from 2016, in 2017 an additional P-fertiliser was used to represent the higher range of $\mathrm{Cd}$ levels in P fertiliser (see chapter 3). In addition the low-Cd DAP with added Zn was omitted from the study resulting in a total of 4 treatments including a blanc treatment (normal fertilisation but no $\mathrm{P})$, animal manure, DAP with low Cd, DAP with elevated Cd content. Fertiliser application ranges were comparable to those in 2016. The number of crops was extended to 5, including carrot, potato, barley, durum wheat and spinach, resulting in 5 (crops) $\times 3$ (soils) $\times 3$ (replicates) $\times 4$ (fertilisers including blanks) in a total of 180 pots (similar to 2016).

\subsection{Set up of the greenhouse experiment}

\subsubsection{6 experiments}

A greenhouse experiment using four different phosphorous fertilisers and a blanc was set up as a randomized block design with three factors:

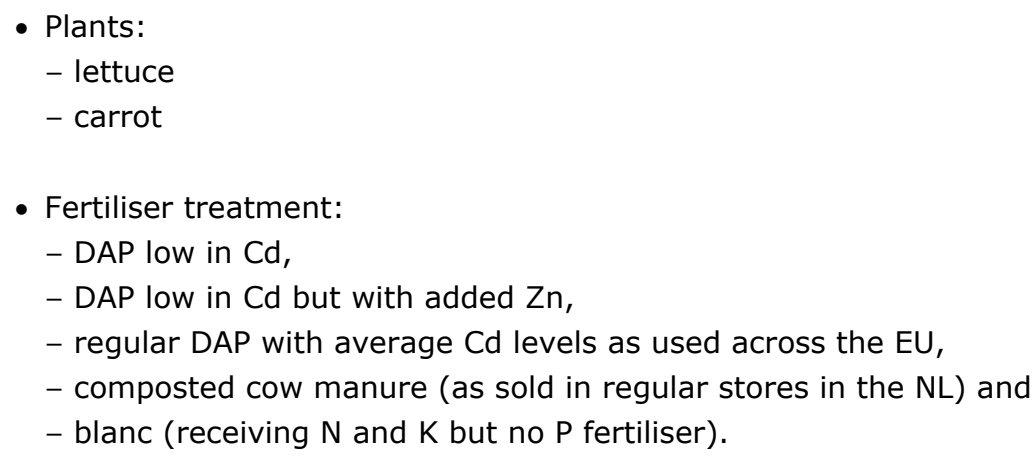

- Soil type (sandy, loamy and clay soils with varying degree of contamination)(Table 2.1).

The PhosAgro fertilisers were supplied by PhosAgro AS (DAP low in Cd, DAP low in Cd with added Zn); the regular DAP was provided by Prof. E. Smolders from KU Leuven (university in Belgium). A commercially available composted cow manure (pellets) was ordered from Komeco (Dronten, the Netherlands).

This resulted in 60 treatments, with three replicates per treatment.

The crop uptake studies were performed at the greenhouse facilities of Unifarm, part of Wageningen UR. During crop growth (ranging from 3 weeks for lettuce to 4-5 months for wheat) pots are kept at constant weight (correcting for crop growth). Temperature (18-20 degrees), moisture and light intensity are controlled to maintain constant growing conditions throughout the experiment.

For the greenhouse experiment standard 10 litre nursery pots (Bamaplast, article number 26/B, Italy) were used. The pots have six ventilation holes on the bottom. At the bottom of the pot a cloth was installed to prevent loss of soil and rooting outside the pot through the holes. To avoid potential 
leaching from the pot, a plate was used to intercept excess water; watering of the pots however was such that leaching did not occur. Prior to seeding disinfected lettuce seed (Lactuca sativa, L., Lucrecia Rijkszwaan, the Netherlands) was germinated in a tray filled with quartz sand and a nutrient solution, two weeks before the start of the experiment. After germination, three plants were transferred to each pot at the start of the experiment. Quartz sand was used for germination instead of a potting soil to avoid any influence of $\mathrm{Cd}$ present in regular potting soil. This method of transplantation guaranteed uniform lettuce plants at the start of the experiment. Carrot seeds were seeded directly in the quartz layer on top of the soil to avoid any salt stress during germination (see below).

The pots used in the experiment as well as the watering pipe and cloth installed at the bottom are made of PVC which potentially can release $\mathrm{Zn}$. To avoid this, all materials used in the greenhouse experiment in 2016 were washed with $0.2 \mathrm{M} \mathrm{HCl}$ and subsequently rinsed 5 times with demi-water. Each pot was filled with 10 (sandy soils) or $9 \mathrm{~kg}$ (other soils) air dried soil.

To reduce risk of soil washout due to watering the pots and to avoid salt stress during germination, a germination layer of approximately $3 \mathrm{~cm}(1 \mathrm{~kg} / \mathrm{pot})$ of washed quartz sand was used for carrot (Daucus carota L., Mokum), and a layer of approximately $1 \mathrm{~cm}(0,3 \mathrm{~kg})$ quartz sand was used for lettuce. All pots were filled up to $1 \mathrm{~cm}$ below the rim of the pot resulting in a surface area of $0.048 \mathrm{~m}^{2}$.

A watering tube with a diameter of $5 \mathrm{~cm}$ and a length of $20 \mathrm{~cm}$ was inserted in the middle of each pot.

Soil moisture content was established one week before the start of the experiment by adding demineralized water resulting in 117,108, 150, 153, 246 and $150 \mathrm{~g}$ water/kg dry soil respectively in soil 1 to 6 . These amounts were established previously to achieve the $60 \%$ level of the water holding capacity of each soil. At this level no leaching from the pots occurs. The total weight (soil + water) was recorded at the outside of each pot and this weight was maintained throughout the experiment by adding demineralised water daily.

The carrot pots were initially covered with transparent plastic to prevent drying of soil during the germination of carrot. After germination the plastic was removed. The loss of weight by water evaporation was compensated daily using demineralized water keeping the pots at the original weight. Water was given daily via the watering tubes.

Crops were harvested when ready for consumption. Before drying the fresh weight (biomass) was determined by weighing the total biomass per pot. After sampling, the edible parts were washed using regular tap water to remove any visible soil particles. Before drying the lettuce and carrots, the biomass was cut in small pieces followed by drying at $70^{\circ} \mathrm{C}$ for 72 hours. After drying the total weight was determined to calculate the dry matter content of the crops. The remaining plant parts were ground using contaminant free titanium mills. For carrots both the edible roots and the above ground leaves were analysed. For lettuce only the leaves were included, roots were discarded.

The dried and ground plant material was used to determine the total metal content after microwave destruction in concentrated acid using ICP-AES or ICP-MS depending on the metal and expected concentration range. Components thus measured include $\mathrm{Cd}, \mathrm{As}, \mathrm{Pb}$ and $\mathrm{Zn}$ as well as nutrients $(\mathrm{N}, \mathrm{P}$, $\mathrm{K}, \mathrm{S}, \mathrm{Zn}, \mathrm{Cu}$ ). All parameters have been determined according to Temminghoff et al. (2000). In Appendix 1 an overview of the combinations of pots/crops/fertiliser is given. 


\section{$2.2 .2 \quad 2017$ experiments}

Based on the experimental results from 2016 (see Chapter 3) it was decided to use the low to medium Cd soils from 2016 (Wijnandsrade and Droevendaal) and an additionally sampled low Cd soil in 2017 (Lioessens) in the 2017 experiments. This in combination with a modified crop and fertiliser scheme. Instead of 2 crops, in 20175 crops were grown:

$$
\begin{aligned}
& \text { - Crops } \\
& \text { - Carrot } \\
& \text { - Spinach } \\
& \text { - Potato } \\
& \text { - Barley } \\
& \text { - Durum wheat }
\end{aligned}
$$

- Fertiliser treatments:

- Blanc (no P fertiliser)

- Low-Cd DAP supplied by PhosAgro (without $\mathrm{Zn}$ ) representing low Cd mineral P fertilisers (similar to the one used in 2016)

- High Cd DAP from Tunesia representing medium-high Cd fertiliser

- Animal manure, similar to 2016 we used a dried cow manure

Both the low and high Cd DAP were supplied by PhosAgro. The low Cd DAP was from the same batch as used in 2016.

This setup ( 3 soils, 4 fertilisers, 5 crops, 3 replicates) resulted in 180 pots (similar to 2016). These were installed in the greenhouse (Unifarm) under similar conditions as in 2016. Pots were prepared and filled in early May and seeds were added to the pots on $25^{\text {th }}$ May 2017. Aside from different crops and soils being used in the greenhouse experiment, all other aspects of the greenhouse experiment remained unchanged compared to the 2016 set-up (see par. 2.2.1)

\section{NOTE}

During crop growth of Durum Wheat it was observed that flowering did not start. After consulting with the manager at Unifarm it became clear that for the 2017 experiments a winter variety of Durum Wheat was used. To start flowering this variety needs a cold spell which was not done in the greenhouse experiments. Results from Durum therefore are not included in this report.

\subsection{Analyses on soils, fertilisers and crops}

To be able to quantify the availability and uptake of metals in soil and to construct the metal balance the following properties of soils, crops and fertilisers were measured:

1. Chemical composition of fertilisers added to the soil prior to the experiment (including both nutrient content and metal content).

2. Chemical composition and relevant soil characteristics of the soils at the beginning of the experiment. This includes determination of the organic matter, clay content, $\mathrm{CEC}, \mathrm{pH}$ and $\mathrm{Fe}-$ and Al-oxide content, nutrient content (total $\mathrm{N}, \mathrm{P}, \mathrm{K}, \mathrm{S}, \mathrm{Zn}$ ), total $\mathrm{Cd}$, As and $\mathrm{Pb}$ content as well as reactive $\left(0.43 \mathrm{~N} \mathrm{HNO}_{3}\right)$ and available $\left(0.002 \mathrm{M} \mathrm{Ca}\left(\mathrm{NO}_{3}\right)_{2}\right)$ was determined.

3. Chemical composition of all soils in all pots at the end of the crop growth experiment focussing on the reactive $\left(0.43 \mathrm{~N} \mathrm{HNO}_{3}\right)$ and available $\left(0.002 \mathrm{M} \mathrm{Ca}\left(\mathrm{NO}_{3}\right)_{2}\right)$ extractable metal content $(\mathrm{Cd}, \mathrm{Pb}$, As) as well as micro $(\mathrm{Cu}, \mathrm{Zn})$ and macro nutrients $(\mathrm{K}, \mathrm{Mg}, \mathrm{S}, \mathrm{P}, \mathrm{K}, \mathrm{N})$ in the $\mathrm{Ca}\left(\mathrm{NO}_{3}\right)_{2}$ extract.

4. Chemical composition of edible parts of lettuce (above ground biomass), and carrot as well as the above ground biomass (carrot leaves, measured separately). The metal content in roots is not included. Analyses were similar to those in soil.

To determine the chemical and biological availability of $\mathrm{Cd}$ in soils before and after application of fertiliser the following extractions were performed. 
Assessment of chemical availability of $\mathrm{Cd}$ in soil prior to the experiment. After collecting the soils, an initial characterization of the soil (including main soil properties) was done using the dried (72 hours at 40 degrees), homogenized and sieved $(<2 \mathrm{~mm}$ ) soils. Individual soils have been characterised by soil organic matter, clay content, $\mathrm{CEC}, \mathrm{pH}$ and $\mathrm{Fe}$ - and $\mathrm{Al}$-oxide content, nutrient content (total $\mathrm{N}, \mathrm{P}$, $\mathrm{K}, \mathrm{Mg}, \mathrm{S}, \mathrm{Cu}, \mathrm{Zn}$ ), total $\mathrm{Cd}, \mathrm{As}, \mathrm{Cr}$ and $\mathrm{Pb}$. All these parameters have been determined according to Houba et al. (1997). Aside from the initial characterization, availability was determined in 18 soil samples ( 3 soil types, 2 initial soil Cd levels, 3 replicates) by:

a. Total destruction (Aqua Regia)

b. Reactive pool (adsorbed Cd) by $0.43 \mathrm{~N} \mathrm{HNO}_{3}$

c. Available pool (for plant uptake) by extraction using $0.002 \mathrm{Ca}\left(\mathrm{NO}_{3}\right)_{2}$

The background of the use of these extractions is described in a.o. Römkens et al. (2004; 2009); Rodrigues et al. (2010a,b;2012;2013); Groenenberg et al. (2010); Franz et al (2008) and De Vries et al. (2008). Aside from the metal content standard soil properties including soil organic matter content, clay content, $\mathrm{pH} \mathrm{CaCl}$, reactive $\mathrm{Fe}$ - and $\mathrm{Al}$ content and cation exchange capacity (CEC) were determined. Also the nutrient and metal content of the 4 fertilisers used in the experiments were measured (total levels, see Table 2). Analyses included are N, P, K, S, Cd, As, Pb and Zn.

To assess to what extent metals added through fertilisers increases the level of available metals, the reactivity $\left(0.43 \mathrm{HNO}_{3}\right)$ and availability $\left(0.002 \mathrm{Ca}\left(\mathrm{NO}_{3}\right)_{2}\right)$ on the fertiliser amended soils (metals and nutrients include the same ones as mentioned under 1 ) were analysed after the greenhouse experiment was completed. For this purpose approx. 150 gram of soil was collected from each pot after harvest.

Aqua Regia extraction in soils after the crop growth experiment was not performed since it is unlikely that part of the added metals will be reverted to a chemically non-reactive form within such a short time frame.

In addition of the chemical properties also the nutritional value of both carrots and lettuce was determined in the crop samples from 2016. For this purpose crop samples from all 5 treatments from 3 soils (Cranendonck, Droevendaal and Wijnandsrade) were sent to Nutrilab for analyses. For lettuce the following properties were measured: vitamin B1, B2, B6, folic acid, luteine and zaxanthine. For carrot vitamin B1, B2, B6, folic acid, and beta carotene were included. To this purpose a composite crop sample was prepared from each of the three replicate pots for each treatment for the three selected soils, which results in 15 samples from each crop. To conserve the quality prior to analyses, the fresh biomass was freeze-dried rather than stove-dried. After freeze-drying the samples were transferred to Nutrilab for further processing.

In 2017 no additional analyses (vitamins etc) on crops were made apart from the micro- and macronutrients analysed at CBLB in the harvested crops samples.

\subsection{Model description}

One of aims of the study is to assess how the Cd content in fertilisers affects the uptake by crops and accumulation in soil. The greenhouse experiments are used to address the short term ( 1 year) effects of using low vs normal to high Cd fertilisers. To assess long term changes in soil and crops, models are needed to simulate the effect of ranges in amounts of $\mathrm{Cd}$ added to the soil via fertiliser. In this study 3 different types of assessments will be made:

1. Prediction of long term consequences of $C d$ added to soil at plot level. To this purpose we use a relatively simple model that is able to predict changes in the Cd content in soil and crops at plot level considering different soil types as used in the study. Changes in the Cd content are calculated assuming different inputs from fertilisers as used in the study. Outputs from leaching are calculated using similar models as in the regional assessments whereas crop uptake are described using the data from the greenhouse experiments. Here we use both soil $\mathrm{Cd}$ and $\mathrm{pH}$ as explaining variables to predict changes in the crop Cd content. Changes in the Cd content in soil and crop are calculated for a time period of 0 (current), 50 and 100 years from now. The model is applied to all soils included in the study. 
2. Prediction of long term changes (100 years from now) in soil and crop levels at EU level. To this purpose the INTEGRATOR model is be used that is able to calculate inputs and outputs of Cd to arable cropping systems at a $1 \times 1 \mathrm{~km}$ grid for both arable land and grassland. Rather than working with assumed combinations of soil and crop as is done at plot scale (see 1), the INTEGRATOR model is based on the actual land use across the EU. Underlying maps include a.o. soil maps (used to derive values for $\mathrm{pH}$, organic matter, clay content at $1 \times 1 \mathrm{~km}$ gridlevel), data on animal density, manure production and distribution rates, data on (inorganic) fertiliser consumption rates (at country level and downscaled to regional level), application of biosolids (compost and sludge) and atmospheric deposition. Outputs considered include leaching (correcting for differences in water fluxes across the EU depending on crop type and climate) and crop removal rates calculated as the product of $\mathrm{Cd}$ content in the crops times the harvested biomass. Results are presented at regional levels (maps) and country/EU levels (tables) to assess the impact of difference Cd levels in (inorganic) $\mathrm{P}$ fertilisers. Here 5 different levels of $\mathrm{Cd}$ in $\mathrm{P}$ fertilisers are used in the scenarios ranging from $0 \mathrm{mg} \mathrm{Cd} \mathrm{kg}{ }^{-1} \mathrm{P}_{2} \mathrm{O}_{5}$ reflecting the Cd content in DAP from PhosAgro to $80 \mathrm{mg} \mathrm{Cd} \mathrm{kg}^{-1}$ $\mathrm{P}_{2} \mathrm{O}_{5}$ reflecting the upper end of the proposed levels of $\mathrm{Cd}$. A more elaborate description on the model assumptions and data used to calibrate the model is included in Chapter 5.

3. Prediction of long term changes ( 100 years from now) in soil and crops for 3 specific crops. In addition to the second analyse levels of $\mathrm{Cd}$ are predicted for all spatial units (at NCU level) for three crops that contribute most to intake of $\mathrm{Cd}$ by humans: lettuce, potato and wheat. To this purpose the $\mathrm{Cd}$ levels in soil as calculated for the $2^{\text {nd }}$ option are used as input to calculate the Cd levels in the 3 crops mentioned. Changes in soil Cd levels thus lead to a change in the Cd level in the three crops.

In Table 2.3 the main differences between the analyses at plot level (1) versus the spatially explicit ( 2 and 3 ) are summarized.

Table 2.3 Main aspects of the 3 assessments of long term changes of Cd in crops related to different allowed Cd levels in crops

\begin{tabular}{|c|c|c|}
\hline Aspect & Prediction at plot level & $\begin{array}{l}\text { prediction at regional levels } \\
\text { (Integrator) }\end{array}$ \\
\hline Scale & Plot level & EU levels based on $1 \times 1 \mathrm{~km}$ levels \\
\hline Soil type and properties & $\begin{array}{l}\text { Soil types as used in greenhouse experiments, } \\
\text { bulk density fix at } 1.1 \mathrm{~kg} / \mathrm{L} \text {, soil depth at } 20 \mathrm{~cm}\end{array}$ & Soil map for EU scaled to $1 \times 1 \mathrm{~km}$ \\
\hline Water fluxes & $\begin{array}{l}\text { Fixed level ( } 350 \mathrm{~mm} / \text { year) representing the } \\
\text { conditions that prevail in Dutch agriculture }\end{array}$ & $\begin{array}{l}\text { Variable depending on climate, crop } \\
\text { and rainfall patterns. }\end{array}$ \\
\hline Fertiliser application & $\begin{array}{l}\text { Fixed for all crops based on general } \\
\text { recommendations using data from specific } \\
\text { fertilisers (PhosAgro, regular DAP with variable } \\
\text { Cd content) }\end{array}$ & $\begin{array}{l}\text { Real applications based on fertiliser } \\
\text { consumption rates and animal } \\
\text { density }\end{array}$ \\
\hline
\end{tabular}

\section{Soil to crop transfer models}

To predict the $\mathrm{Cd}$ content in crops grown on arable soils, various models have been used. Most commonly used is the BioConcentration Factor (BCF), sometimes also referred to as Transfer Factor (TF) which basically represents the average ratio between the metal content in crops divided by that in soil:

$\mathrm{BCF}\left(\right.$ or TF) $=\left[\mathrm{Me}_{\text {crop }}\right] /\left[\mathrm{Me}_{\text {soil }}\right]$

This approach is currently used in the spatially explicit model Integrator applied in analyses 2 and 3. 
Although this BCF approach is robust and easy to apply, especially if data are limited, the approach also has a disadvantage in that it does not account for differences in soil properties that affect the bioavailability of metals in soils, notably soil $\mathrm{pH}$. It is known that $\mathrm{pH}$ controls the solubility of metals (see also results from greenhouse experiments) with solubility increasing with a decrease in $\mathrm{pH}$. In addition to this, the relation between the metal content in soil and that in crops is not linear as assumed when using a BCF or TF model. To account for both the non-linearity effect and soil pH, we will use a modified soil to crop uptake model in approach 1 (plot level calculations) using both the soil metal content and the $\mathrm{pH}$ to predict the $\mathrm{Cd}$ content in crops according to:

${ }^{10} \log \left[\mathrm{Cd}_{\text {crop }}\right]=$ Constant $+\mathrm{a} \cdot \mathrm{pH} \mathrm{H}_{\text {soil }}+\mathrm{b} \cdot \log \left[\mathrm{Cd}_{\text {soil }}\right]$

Clearly other factors like soil organic matter and clay content also have an effect on the uptake but since the ranges in SOM and clay in the soils used in this study are limited, or the effect of both parameters is not always consistent, we only use $\mathrm{pH}$ and $\mathrm{Cd}$ content of the soil in the present study.

Models derived from the data for all crops are listed in Table 4.1. Table 4.1 also contains some general data used in the model scenarios like average biomass (based on FAO statistics for 2014 and 2014 for European countries), dry matter content (based on experimental data), average P fertiliser application rates (based on European averages per crop as given by Amery and Schoumans, 2014) and some model parameters $\left(R^{2}\right.$, se(Y-est) and F-value of the model).

In all assessments (from $\mathrm{t}=0$ to $\mathrm{t}=100$ years) soil $\mathrm{pH}$ is assumed to be constant which is not unreasonable since soil $\mathrm{pH}$ is managed by the farmer through lime application or otherwise. Changes in the soil Cd content are taken into account however since these will change due to a combination of leaching, uptake and inputs which may either lead to a decrease or an increase in the soil cd content depending on the scenario of choice.

Inputs from fertilisers in the plot level study are taken from the experimental data in 2016 and 2017 and listed in Table 2.4. Data in Table 2.4 are based on replicate measurements on the samples as used in the greenhouse experiment.

Table 2.4 Overview of fertiliser used in the simulations at plot level

\begin{tabular}{llcccc} 
Material Used & Abbreviation & Cd content & P content & \multicolumn{2}{c}{ Cadmium Content } \\
\hline PhosAgro DAP & Low-Cd & mg kg-1 product & $\%$ & $\mathrm{mg} \mathrm{Cd} \mathrm{kg}^{-1} \mathrm{P}$ & $\mathrm{mg} \mathrm{Cd} \mathrm{kg}^{-1} \mathrm{P}_{2} \mathrm{O}_{5}$ \\
\hline Regular DAP (2016) & Medium-Cd & 0.02 & 19.8 & 0.10 & 0.04 \\
\hline DAP-Tunesia (2017) & High-Cd & 17.7 & 19.1 & 92.7 & 40.5 \\
\hline Animal Manure & An.man. & 26.7 & 19.6 & 136.0 & 59.4 \\
\hline
\end{tabular}




\subsection{Results 2016 and 2017: soils and fertilisers used in the greenhouse experiment}

In Table 3.1 to 3.3 the results from the characterization of the soils is shown. The soils used in 2016 contain Cd ranging from $0.2 \mathrm{mg} / \mathrm{kg}$ to $6 \mathrm{mg} / \mathrm{kg}$ thus representing a large range of soils. Four out of six soils used here are representative for normal Dutch arable soils with Cd levels ranging from 0.2 to $0.6 \mathrm{mg} / \mathrm{kg}$. These levels are common in the majority of all European soils used for agriculture. The two remaining soils (Epen and Lottum) both are floodplain soils and have been subjected to long term inputs of polluted sediments. Both soils however have been (Lottum, used for crop production) or are still (Epen) being used for agriculture (Epen soil: grassland soil used for extensive cattle grazing). As such the levels of $\mathrm{Cd}$ in these two soils are not considered normal but these were included to assess to what extent the availability of $\mathrm{Cd}$ in fertilisers differs in low and medium polluted soils.

In addition to these soils, a low Cd soil (Lioessens) was collected in the spring of 2017 to represent soils with no or very limited inputs of metals including $\mathrm{Cd}$. The Lioessens soil is a calcareous sandy soil collected from the polder areas in the Northern sea coast area of the Netherlands. Due to the relatively young age of these soils, there is almost no enrichment of contaminants.

Soil fertility levels show a large range and include well fertilised soils (Wijnandsrade and Cranendonck) with a $\mathrm{P}$ status indicating a normal to high $\mathrm{P}$ availability. On the other hand the Lottum soil is representative for a $\mathrm{P}$ depleted soil $(\mathrm{Pw}=5)$ with a very low $\mathrm{P}$ availability level. This soil has not received fertiliser for several years since it was converted from a normal arable soil to a natural reserve used for extensive cattle grazing.

Soil properties as listed in Table 3.1 indicate that the soils cover a wide range in clay content ranging from 3 to $32 \%$. Organic matter content is fairly constant between 3 and $7 \%$ and also pH levels are normal for agricultural soils ranging from 5.4 in the sandy soil to 7.3 in the clay soil. Total P levels are relatively constant reflecting a history of arable land use. This is confirmed by the $P$ saturation degree, calculated as the amount of oxalate extractable P divided by 0.5 times the sum of oxalate extractable Fe and Al. The P saturation ranges from $17 \%$ in the Lottum soil to almost $60 \%$ in the Cranendonck soil, the latter soil having a long history of treatment with animal manure.

The fertilisers used in the study (Table 3.2) have a normal nutrient content for both the mineral fertilisers and the organic fertiliser. Clearly the nutrient content in animal manure is lower compared to the inorganic fertilisers (for $\mathrm{N}$ and $\mathrm{P}$ ) which results in ten times higher application rates for the manure treatment (Appendix 1). The metal content of the fertilisers clearly differs with low to very low levels of $\mathrm{Cd}$ and $\mathrm{Zn}$ in the PhosAgro-DAP. In order to compare the data in terms of metal load per $\mathrm{kg}$ of $\mathrm{P}$ or $\mathrm{N}$ we converted the amounts of metals to an equivalent per $\mathrm{kg}$ of nutrient as well (Table 3.2b). For all metals the PhosAgro DAP has low to very low $\mathrm{Cd}, \mathrm{Pb}$ and As levels. The regular DAP has a Cd content roughly equal to the average Cd content of DAP used across the EU. Due to the low nutrient content, the metal load in animal manure per $\mathrm{kg} \mathrm{N}$ or $\mathrm{P}$ is much higher for $\mathrm{Cd}, \mathrm{Zn}$ and $\mathrm{Pb}$ when compared to the PhosAgro DAP. When compared to regular DAP, the Cd load from manure is considerably lower reflecting the relatively low amounts of $\mathrm{Cd}$ in the source materials of manure (fodder). For $\mathrm{Zn}$ this is clearly not the case since $\mathrm{Zn}$ is being used as additive to feed and fodder in animal husbandry which is reflected in the high $\mathrm{Zn}$ to $\mathrm{N}$ or $\mathrm{P}$ ratio.

In 2017 additional fertilisers were tested to obtain a larger range in Cd levels. In Tables 3.2a and b the results from all fertilisers used are included. Not all fertilisers tested in 2017 were used. After determination of the Cd content, only the DAP-Tunesia was used here representing the moderate to high Cd fertilisers. In 2017 only the regular DAP-PhosAGRO (no Zn added) and the DAP-Tunesia were used in combination with a larger number of crops. 
Table 3.1 Soil analysis ( $n=2$ for each analysis) (AR: Aqua Regia)

\begin{tabular}{|c|c|c|c|c|c|c|}
\hline & CEC total & CEC-AI & CEC-Ca & $\mathrm{CEC}-\mathrm{Fe}$ & CEC-K & CEC-Mg \\
\hline & \multicolumn{6}{|c|}{$\operatorname{cmol}(+) / \mathrm{kg}$} \\
\hline Droevendaal & 8.0 & 0.0 & 9.1 & 0.0 & 0.1 & 0.6 \\
\hline Wijnandsrade & 12.0 & 0.0 & 11.2 & 0.0 & 0.6 & 1.1 \\
\hline Epen & 12.5 & 0.0 & 10.0 & 0.0 & 0.1 & 1.8 \\
\hline Lottum & 16.0 & 0.0 & 15.2 & 0.0 & 0.1 & 1.5 \\
\hline Lioessens & 5.2 & $<0.1$ & 4.6 & $<0.1$ & 0.3 & 0.3 \\
\hline
\end{tabular}

\begin{tabular}{|c|c|c|c|c|c|c|c|c|}
\hline & $\mathbf{N}_{\mathrm{t}}$ & $\mathrm{C}_{\mathrm{t}}$ & $P_{t}$ & K & s & SOM & Clay & pH \\
\hline Method: & \multicolumn{3}{|c|}{$\mathrm{H}_{2} \mathrm{SO}_{4}-\mathrm{H}_{2} \mathrm{O}_{2}-\mathrm{Se}$} & AR & AR & $550^{\circ} \mathrm{C}$ & $<2 \mu \mathrm{m}$ & $0.01 \mathrm{M} \mathrm{CaCl} 2$ \\
\hline & \multicolumn{2}{|c|}{$\mathrm{g} / \mathrm{kg}$} & \multicolumn{3}{|c|}{$\mathrm{mg} / \mathrm{kg}$} & \multicolumn{2}{|c|}{$\%$} & \\
\hline Cranendonck & 1.4 & 19.9 & 580 & 312.5 & 196 & 3.8 & 3.1 & 5.4 \\
\hline Wijnandsrade & 1.5 & 20.9 & 741 & 1876 & 230 & 4.3 & 13.4 & 6.6 \\
\hline Grebbedijk & 1.8 & 20.5 & 890 & 3949 & 306 & 5.6 & 31.7 & 7.3 \\
\hline Lottum & 2.2 & 34.9 & 636 & 1238 & 341 & 6.8 & 16.0 & 6.5 \\
\hline Lioessens & 0.7 & 5.0 & 547 & 920 & $<150$ & 1.1 & 5.0 & 7.1 \\
\hline
\end{tabular}

\begin{tabular}{lcccccccccc} 
& As & As & Cd & Cd & Pb & Pb & Zn \\
& Method: & AR & HNO3 & AR & HNO3 & AR & HNO3 & AR & HNO3 \\
\hline Droevendaal & 2.6 & 1.6 & 0.20 & 0.19 & 15.4 & 15.4 & 38.0 & 27.4 \\
\hline Cranendonck & 2.6 & 1.5 & 0.49 & 0.46 & 63.2 & 36.1 & 61.0 & 32.1 \\
\hline Wijnandsrade & 8.1 & 1.3 & 0.56 & 0.39 & 33.7 & 26.2 & 92.0 & 32.8 \\
\hline Epen & 15.9 & 4.2 & 6.33 & 5.52 & 742.0 & 660.5 & 2821.0 & 2353.0 \\
\hline Grebbedijk & 12.7 & 0.9 & 0.46 & 0.32 & 34.6 & 16.0 & 98.5 & 23.2 \\
\hline Lottum & 16.4 & 1.2 & 4.22 & 3.22 & 222.0 & 149.0 & 624.5 & 286.5 \\
\hline Lioessens & 2.9 & 1.3 & 0.08 & 0.09 & 16.5 & 14.5 & 42.0 & 25.5 \\
\hline
\end{tabular}

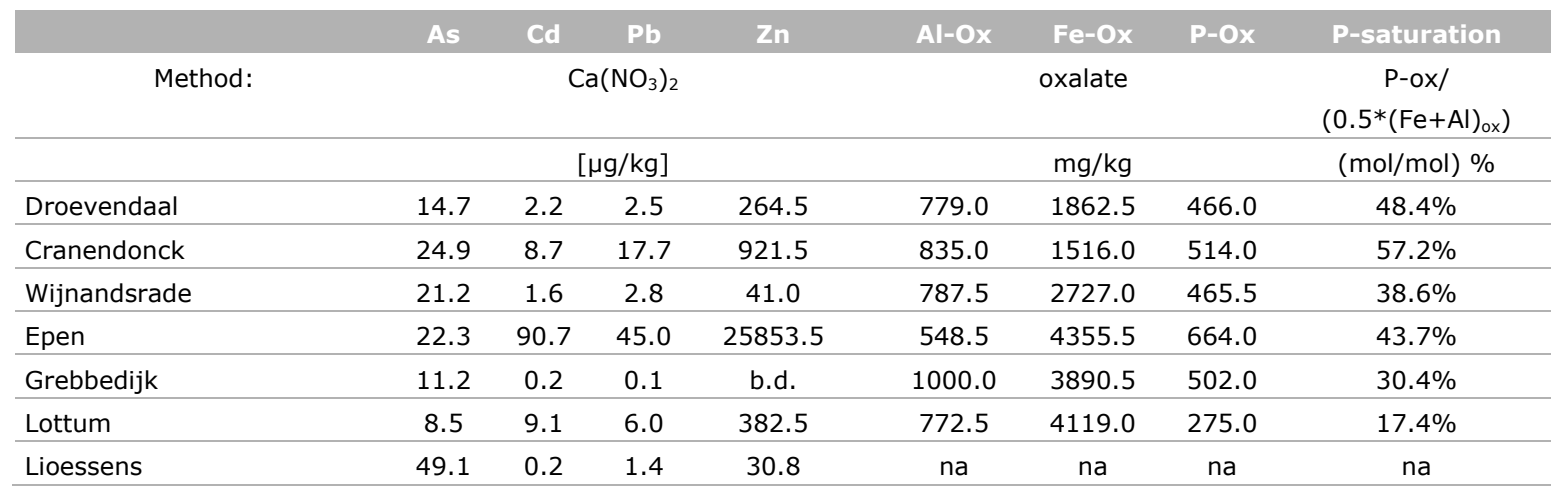


Table 3.2a Nutrient and metal content of the fertilisers used in the greenhouse experiment ( $n=2$, for each fertiliser; between brackets the years in which the fertilisers were used in the experiments is mentioned)

\begin{tabular}{|c|c|c|c|c|c|c|c|c|c|c|c|c|}
\hline Fertil & $\mathbf{N}_{\mathrm{t}}$ & $P_{t}$ & $\mathrm{Ca}$ & K & Mg & $\mathrm{Na}$ & $\mathbf{P}$ & s & $\mathrm{Zn}$ & As & $\mathrm{Cd}$ & $\mathrm{Pb}$ \\
\hline & {$[\mathrm{g} / \mathrm{kg}]$} & {$[\mathrm{g} / \mathrm{kg}]$} & {$[\mathrm{g} / \mathrm{kg}]$} & {$[\mathrm{g} / \mathrm{kg}]$} & {$[\mathrm{g} / \mathrm{kg}]$} & {$[\mathrm{mg} / \mathrm{kg}]$} & {$[\mathrm{g} / \mathrm{kg}]$} & {$[\mathrm{g} / \mathrm{kg}]$} & {$[\mathrm{mg} / \mathrm{kg}]$} & {$[\mu \mathrm{g} / \mathrm{kg}]$} & {$[\mu \mathrm{g} / \mathrm{kg}]$} & {$[\mu \mathrm{g} / \mathrm{kg}]$} \\
\hline $\begin{array}{l}\text { PhosAgro-DAP (2016 + } \\
\text { 2017) }\end{array}$ & 179 & 197 & 4.6 & 1.1 & 0.65 & 1635 & 197 & 29.8 & 12 & 931 & 19.1 & 42.7 \\
\hline $\begin{array}{l}\text { PhosAgro-DAP + Zn } \\
(2016)\end{array}$ & 168 & 147 & 31.0 & 1.7 & 7.70 & 1376 & 142 & 57.9 & 5431 & 799 & 75.7 & 64.8 \\
\hline Regular DAP (2016) & 180 & 192 & 9.04 & 0.5 & 8.01 & 1728 & 188 & 29.6 & 105 & 6519 & 17512 & 97.9 \\
\hline $\begin{array}{l}\text { Animal manure (cow) } \\
(2016+2017)\end{array}$ & 23.3 & 15.3 & 61.5 & 25.6 & 7.96 & 3921 & 15.9 & 6.37 & 371 & 520 & 279 & 1723 \\
\hline $\begin{array}{l}\text { DAP-Tunesia } \\
(2017)\end{array}$ & na & 196 & na & a & a & na & 11а & na & 200 & 2624 & 26647 & 458 \\
\hline $\begin{array}{l}\text { DAP-Poland } \\
\text { (not used) }\end{array}$ & na & 193 & na & na & na & na & na & na & 562 & 7942 & 23467 & 386 \\
\hline $\begin{array}{l}\text { DAP-Senegal } \\
\text { (not used) }\end{array}$ & na & 126 & na & na & na & na & na & na & 77 & 4356 & 9193 & 5091 \\
\hline
\end{tabular}

Table 3.2b Nutrient and metal content of the fertilisers used in the greenhouse experiment expressed in $\mathrm{mg}$ metal per $\mathrm{kg} N$ or $P$

\begin{tabular}{lcccccccc} 
Fertiliser & \multicolumn{3}{c}{ mg metal $/ \mathrm{kg} \mathrm{N}$} & \multicolumn{4}{c}{$\mathrm{mg}$ metal/kg P } \\
\hline PhosAgro-DAP & $\mathrm{Zn}$ & $\mathrm{As}$ & $\mathrm{Cd}$ & $\mathrm{Pb}$ & $\mathrm{Zn}$ & $\mathrm{As}$ & $\mathrm{Cd}$ & $\mathrm{Pb}$ \\
\hline PhosAgro-DAP + Zn & 67 & 5.2 & 0.11 & 0.24 & 61 & 4.7 & 0.10 & 0.22 \\
\hline Regular DAP & 32327 & 4.8 & 0.45 & 0.39 & 36946 & 5.4 & 0.51 & 0.44 \\
\hline Animal manure (cow) & 583 & 36.2 & 97.3 & 0.54 & 547 & 34.0 & 91.2 & 0.51 \\
\hline DAP-Tunesia (2017) & 15923 & 22.3 & 12.0 & 73.9 & 24248 & 34.0 & 18.2 & 112.6 \\
\hline DAP-Poland (not used) & na & na & na & na & 1018 & 13.4 & 136.0 & 2.3 \\
\hline DAP-Senegal (not used) & na & na & na & na & 2917 & 41.3 & 121.9 & 2.0 \\
\hline
\end{tabular}

Table 3.3 Additional nutrient analysis to determine fertiliser requirements

\begin{tabular}{|c|c|c|c|c|c|c|}
\hline Soil & $\mathrm{pH}$ & $\mathrm{N}-\mathrm{NH}_{4}$ & $\mathbf{N}-\mathbf{N O} \mathbf{O}_{x}$ & P-Al & $P_{w}$ & $\begin{array}{c}\text { Moisture } \\
\text { content }\end{array}$ \\
\hline & & $\mathrm{mg} / \mathrm{kg}$ & $\mathrm{mg} / \mathrm{kg}$ & $\mathrm{mg} / \mathrm{kg}$ & $\mathrm{mg} \mathrm{P}_{2} \mathrm{O}_{5} / \mathrm{I}$ soil & $\%\left(\right.$ fresh $-40^{\circ} \mathrm{C}$ ) \\
\hline Cranendonck & 5.3 & 0.1 & 8.8 & 232 & 29 & 15.8 \\
\hline Wijnandsrade & 6.6 & 0.1 & 16.1 & 183 & 35 & 21.4 \\
\hline Grebbedijk & 7.4 & 3.7 & 9.2 & 124 & 19 & 2.1 \\
\hline Lottum & 6.4 & 0.2 & 5.0 & 47 & 5 & 17.6 \\
\hline Lioessens & 7.1 & $<0.1$ & 2.2 & 52 & 44 & 13.1 \\
\hline
\end{tabular}




\subsection{Results greenhouse experiment 2016: lettuce and carrot}

\subsubsection{Effect of treatment on chemical availability of metals and nutrients in soil}

In Table 3.4 and 3.5 the ANOVA results from the soil chemical extractions are shown. Tables 3.4.a. and 3.5.a include the average data of the $\mathrm{Ca}\left(\mathrm{NO}_{3}\right)_{2}$ and $\mathrm{HNO}_{3}$ extracts respectively, whereas Tables 3.4.b and 3.5.b include the results from the ANOVA analysis on the significance of difference between soils and treatments.

Results in Table 3.4.a and 3.5.a clearly show large differences in the availability of most metals and nutrients between soils. Here data from lettuce and carrot are combined since there was no significant difference between data from either crop (analysis not include here). This suggests that as such carrot or lettuce has a similar effect on the availability of metals and nutrients in the pots.

Based on these data it can be concluded that the use of different fertilisers had no systematic effect on the availability of metals in the soil solution. Clearly the availability in the Epen, Cranendonck and Lottum soil for metals like $\mathrm{Cd}, \mathrm{Pb}$ and even more so $\mathrm{Zn}$ are higher than in the non-polluted soils from Wijnandsrade, Grebbedijk or Droevendaal. Differences between treatments were only visible for $P$ and As which appear to be slightly higher in the fertiliser treated soils compared to the blanc and manure treated soil. This is not surprising since $P$ was not added to the blanc treatments and the availability of $P$ in manure treated soils also was lower compared to that of fertiliser treated soils.

Apparently such small differences in P availability induce an equivalent higher availability of As as well which is likely due to competition between $\mathrm{P}$ and $\mathrm{As}$, with higher $\mathrm{P}$ levels in soil and solution leading to higher dissolved As levels. For $\mathrm{Cd}, \mathrm{Zn}, \mathrm{Pb}$ and $\mathrm{Cr}$ however no impact of the quality of fertilisers on the availability was detected.

The same is true for the reactive fractions, extracted using $0.43 \mathrm{~N} \mathrm{HNO}_{3}$ (Table 3.5). The amounts added by fertilisers, even the ones with high added levels of $\mathrm{Zn}$, do not have a measurable impact on the reactive fraction measured after the greenhouse experiment. 


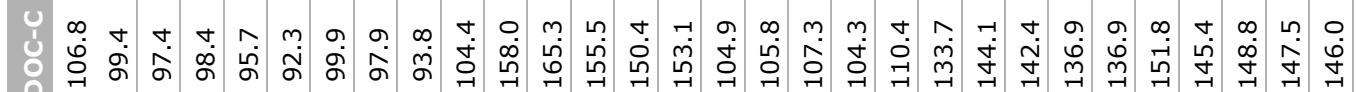

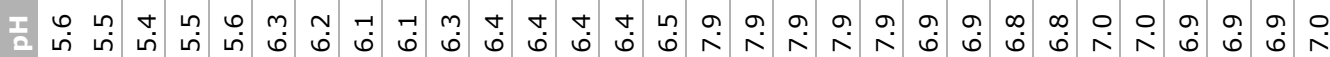
शे
है
है
वे
บ
0

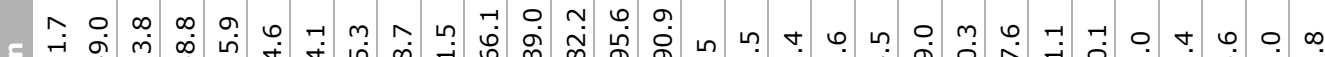

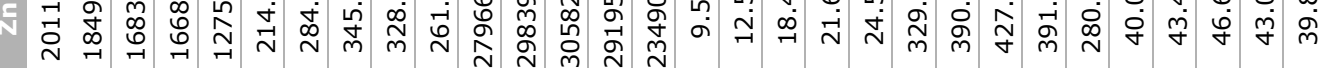

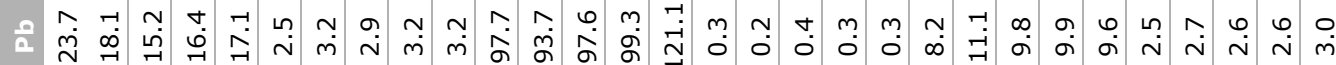

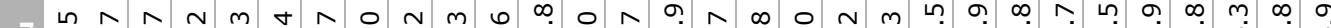

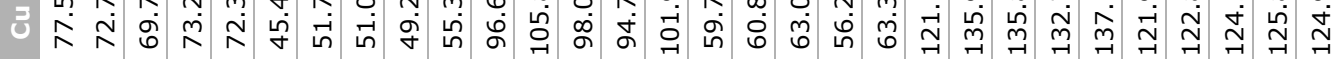

$\stackrel{2}{2}$

要

$\subseteq$

$\stackrel{n}{\mathbb{2}}$

ह

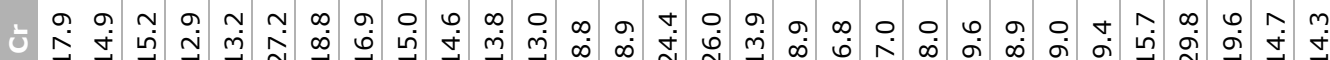

$$
\text { (1) }
$$$$
\text { ○ี }
$$

$$
\stackrel{0}{\stackrel{2}{\infty}}
$$

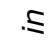

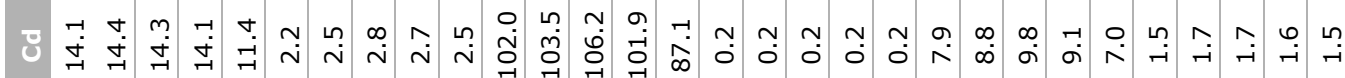

$\sum_{\substack{0 \\ \text { ind }}}^{n}$

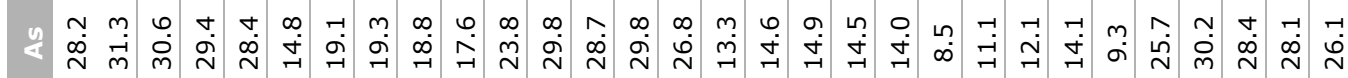

Dे

音

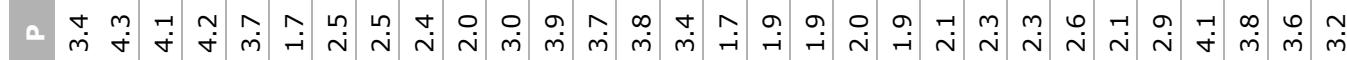

ह

$\stackrel{2}{5}$

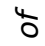

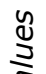

齐

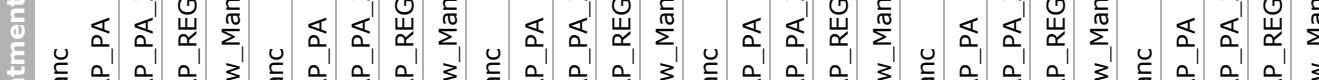

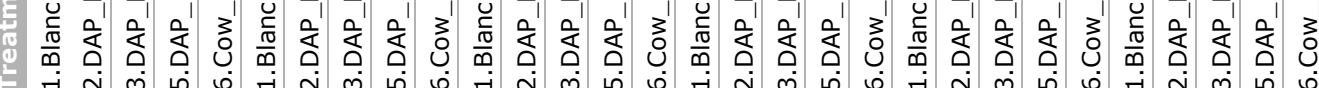




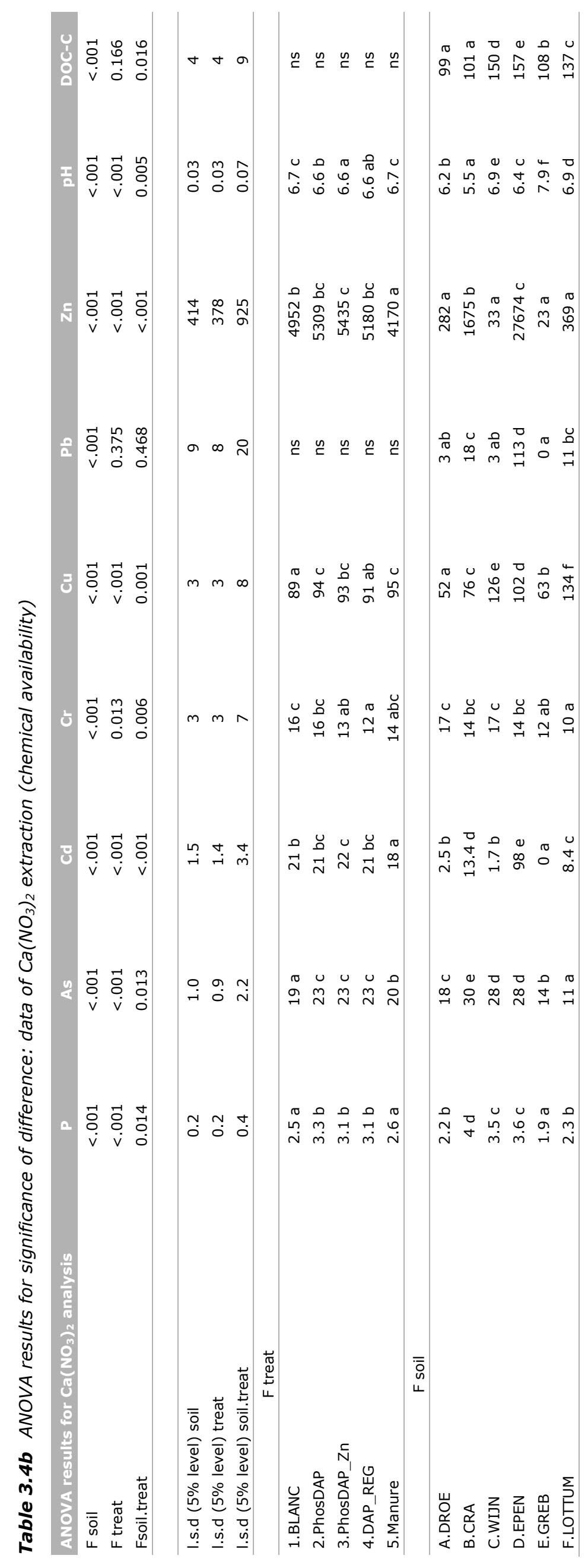

28 | Wageningen Environmental Research report 2889 


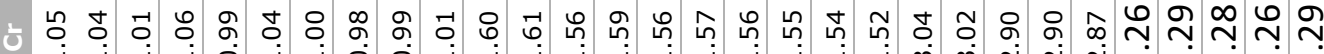

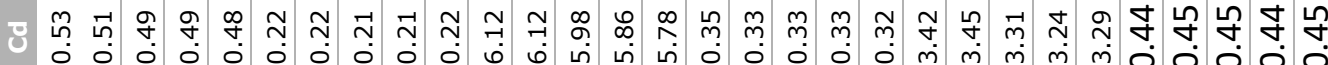

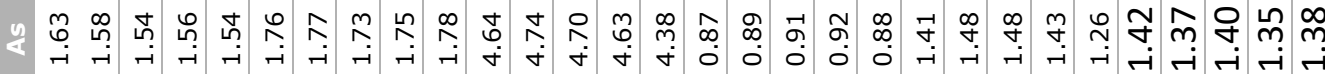

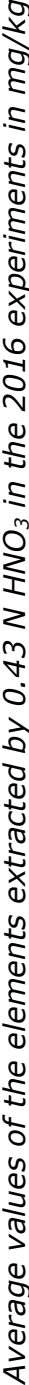

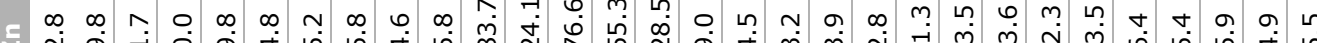

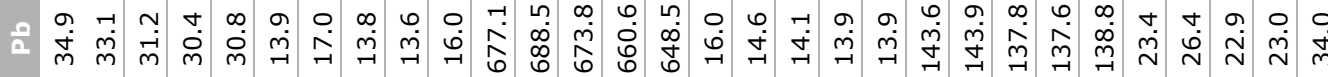

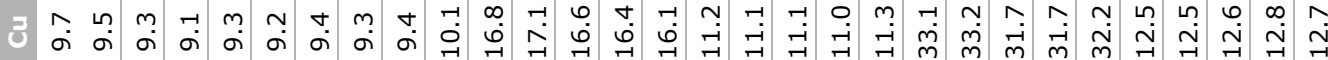

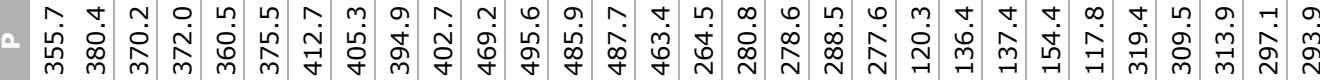<smiles>C1CCC1</smiles>
西 


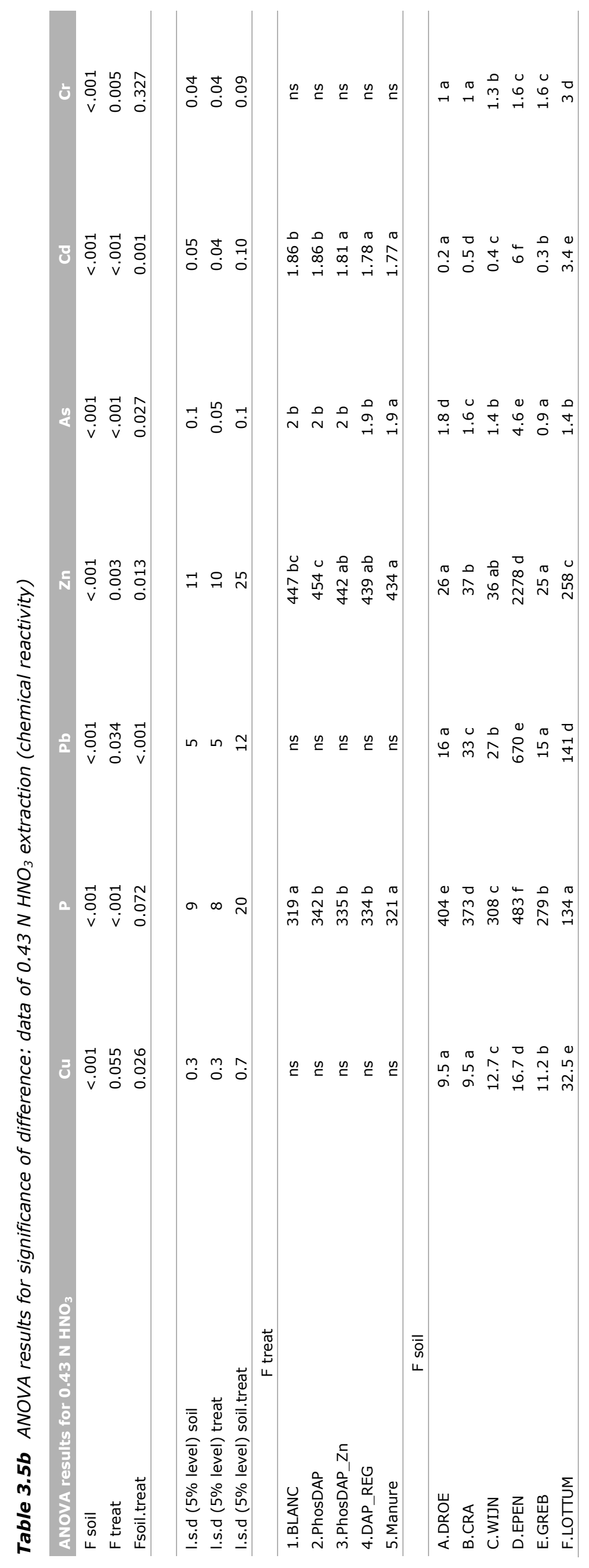

30 | Wageningen Environmental Research report 2889 


\subsubsection{Biomass production}

Differences in crop performance (biomass production) were pronounced, both between soils and treatments. In general fertilisation resulted in a clear increase in biomass production. This increase was more pronounced in the $\mathrm{P}$ depleted soils (notably for lettuce in the Lottum soil which has a very low $\mathrm{P}$ availability) and decreased towards the soils recently receiving fertiliser (e.g. the Grebbedijk clay soil).

For carrot a very poor crop performance was observed in the Epen soil despite the reasonably normal $P$ status of the soil. For lettuce this reduced growth in the (polluted) Epen soil was not observed and a poor crop performance was only observed in the blanc treatment. Whether or not the reduced crop growth by carrot was due to the degree of pollution could not be established.

In the Lottum, Droevendaal, and to a lesser extent also in the Wijnandsrade soil, the crop performance in the soils receiving inorganic $\mathrm{P}$ fertiliser was better compared to the manure treated soil which could indicate a somewhat lower availability of $P$ supplied by animal manure. This effect was not observed in the Grebbedijk soil even though this soil has a lower P availability (Pw of 19 compared to 29-35 as measured in the Cranendonck and Wijnandsrade soil).

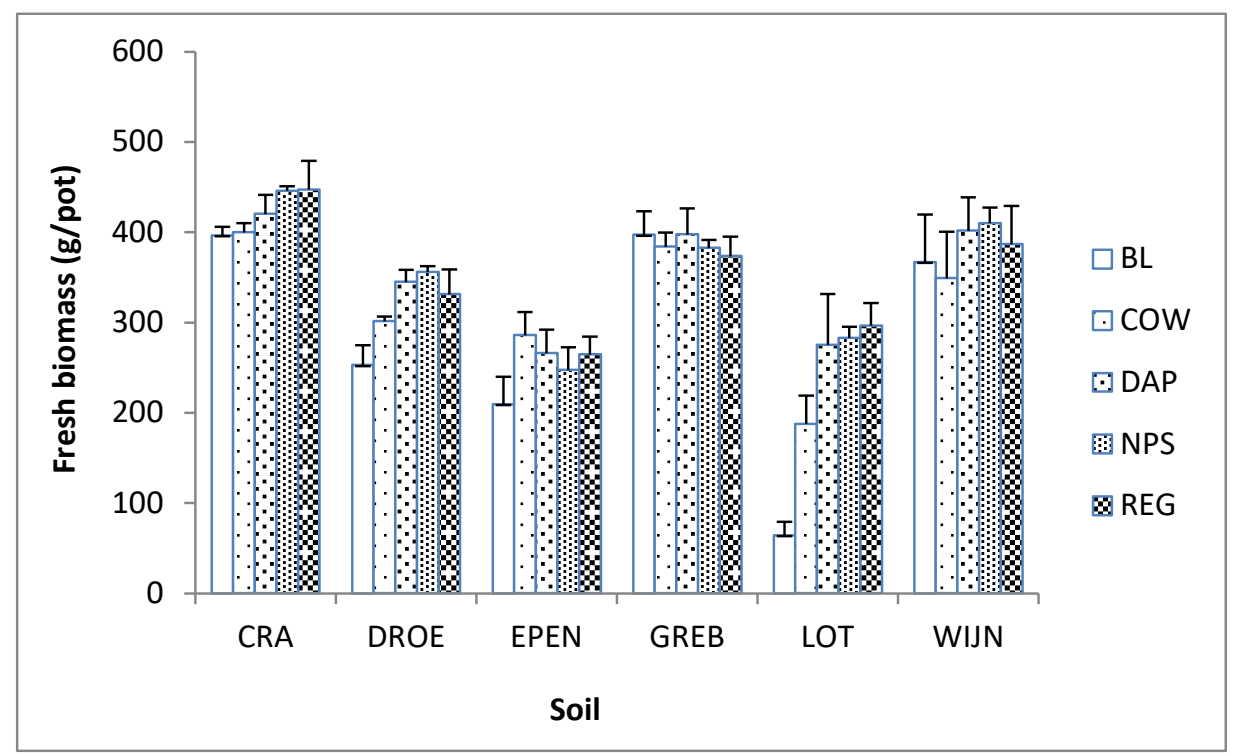

Figure 3.1 Biomass production of lettuce per soil and treatment

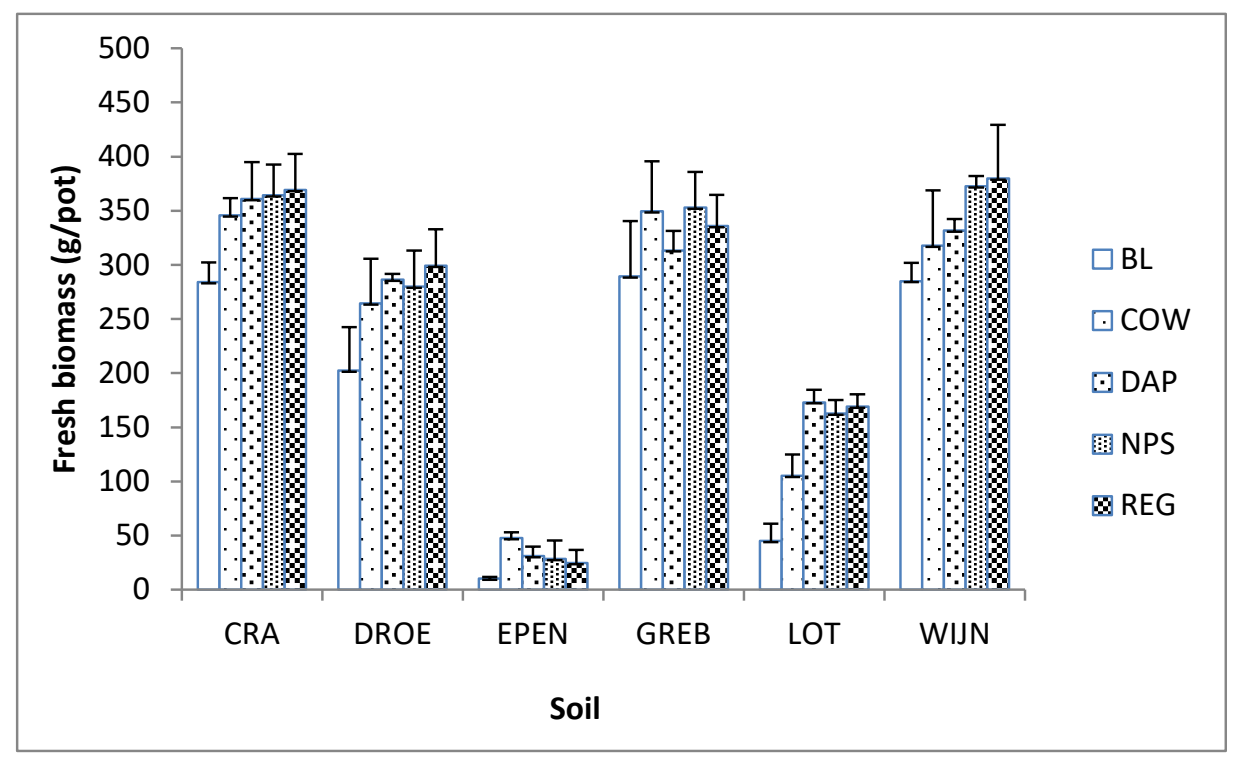

Figure 3.2 Biomass production of carrot per soil and treatment (carrots only) 
Table 3.6 ANOVA results for biomass production (dry matter, gram/pot)

\begin{tabular}{|c|c|c|c|c|}
\hline & lettuce & Carrot & Leaves of carrot & Carrot whole plant \\
\hline F soil & $<.001$ & $<.001$ & $<.001$ & $<.001$ \\
\hline $\mathrm{F}$ treat & $<.001$ & $<.001$ & $<.001$ & $<.001$ \\
\hline l.s.d ( $5 \%$ level) soil & 1.3 & 2 & 1 & 3 \\
\hline I.s.d (5\% level) soil.treat & 3 & 5 & 2 & 6 \\
\hline \multicolumn{5}{|l|}{$\mathrm{F}$ treat } \\
\hline 1.BLANC & $17 a$ & $18 \mathrm{a}$ & $9 \mathrm{a}$ & $27 a$ \\
\hline 2.PhosDAP & $22 \mathrm{c}$ & $24 b$ & $12 b$ & $36 \mathrm{bc}$ \\
\hline 3.PhosDAP_Zn & $22 \mathrm{c}$ & $26 c$ & $12 b$ & $38 \mathrm{~d}$ \\
\hline A.DROE & $20 \mathrm{c}$ & $26 c$ & $13 \mathrm{c}$ & $39 \mathrm{c}$ \\
\hline B.CRA & $23 d$ & $34 \mathrm{~d}$ & $16 \mathrm{~d}$ & $49 \mathrm{~d}$ \\
\hline C.WIJN & 24 e & $33 \mathrm{~d}$ & $15 \mathrm{~d}$ & $48 d$ \\
\hline D.EPEN & $17 b$ & $3 a$ & $2 a$ & 5 a \\
\hline E.GREB & $22 \mathrm{~d}$ & $32 \mathrm{~d}$ & $15 \mathrm{~d}$ & $48 \mathrm{~d}$ \\
\hline F.LOTTUM & $15 \mathrm{a}$ & $13 b$ & $7 \mathrm{~b}$ & $20 \mathrm{~b}$ \\
\hline
\end{tabular}

Fisher's protected least significant difference test

\subsubsection{Uptake of nutrients and metals by lettuce and carrot}

In Table 3.7 the average values for metals ( $\mathrm{As}, \mathrm{Cd}, \mathrm{Pb})$, micronutrients ( $\mathrm{Cu}$ and $\mathrm{Zn}$ ) and nutrients $(\mathrm{N})$ are listed per soil and treatment (fertiliser). Here average values are given for the three replicates per combination of soil and treatment. 
Table 3.7 Overview of average ( $n=3$ for each treatment) levels of metals ( $\mathrm{As}, \mathrm{Cd}, \mathrm{Cr}$ and $\mathrm{Pb}$ in $\mu g \mathrm{~kg}^{-1} \mathrm{FW}$ ) micronutrients ( $\mathrm{Cu}, \mathrm{Zn}$ in $\mathrm{mg} \mathrm{kg}^{-1} \mathrm{FW}$ ) and nutrients $\left(\mathrm{N} \mathrm{in} \mathrm{g} \mathrm{kg}^{-1}\right.$ ) in crops (data on fresh weight)

\begin{tabular}{|c|c|c|c|c|c|c|c|}
\hline Soil/Crop/treatment & As & Cd & Cu & $\mathrm{Cr}$ & $\mathrm{Pb}$ & $\mathrm{Zn}$ & $\mathbf{N}$ \\
\hline Droevendaal & $\mu g \mathrm{~kg}^{-1}$ & $\mu \mathrm{gg}^{-1}$ & $\mathrm{mg} \mathrm{kg}^{-1}$ & $\mu g \mathrm{~kg}^{-1}$ & $\mu g \mathrm{~kg}^{-1}$ & $\mathrm{mg} \mathrm{kg}^{-1}$ & $\mathrm{~g} \mathrm{~kg}^{-1}$ \\
\hline \multicolumn{8}{|l|}{ Carrot (leaves) } \\
\hline 1.BLANC & 5.8 & 102.7 & 1.09 & 113.2 & 29.9 & 9.1 & 4.2 \\
\hline 2.PhosDAP & 9.4 & 123.1 & 1.00 & 114.4 & 41.3 & 9.3 & 4.2 \\
\hline 3.PhosDAP_Zn & 11.5 & 149.2 & 0.97 & 133.9 & 47.2 & 9.4 & 4.2 \\
\hline 4.DAP_REG & 9.3 & 156.0 & 1.09 & 115.8 & 37.4 & 9.7 & 4.2 \\
\hline 5.Manure & 7.5 & 114.5 & 0.99 & 105.5 & 31.0 & 9.2 & 3.9 \\
\hline \multicolumn{8}{|l|}{ Carrot (root) } \\
\hline 1.BLANC & 4.4 & 54.7 & 0.72 & 73.4 & 28.7 & 3.7 & 1.3 \\
\hline 2.PhosDAP & 4.1 & 64.7 & 0.61 & 25.3 & 20.8 & 3.6 & 1.3 \\
\hline 3.PhosDAP_Zn & 5.1 & 62.6 & 0.60 & 32.1 & 23.9 & 3.6 & 1.3 \\
\hline 4.DAP_REG & 4.2 & 62.5 & 0.61 & 87.6 & 22.2 & 3.6 & 1.3 \\
\hline 5.Manure & 4.8 & 52.3 & 0.65 & 50.0 & 28.9 & 3.6 & 1.2 \\
\hline \multicolumn{8}{|l|}{ Lettuce (head) } \\
\hline 1.BLANC & 4.2 & 47.2 & 0.42 & 142.6 & 14.9 & 4.4 & 2.1 \\
\hline 2.PhosDAP & 4.7 & 48.4 & 0.34 & 107.6 & 16.8 & 4.1 & 1.8 \\
\hline 3.PhosDAP_Zn & 4.9 & 50.8 & 0.33 & 56.5 & 11.6 & 4.3 & 1.8 \\
\hline 4.DAP_REG & 5.0 & 49.7 & 0.33 & 41.2 & 11.1 & 4.2 & 1.9 \\
\hline 5.Manure & 3.8 & 57.7 & 0.43 & 61.5 & 10.7 & 4.7 & 1.7 \\
\hline \multicolumn{8}{|l|}{ Cranendonck } \\
\hline \multicolumn{8}{|l|}{ Carrot (leaves) } \\
\hline 1.BLANC & 9.7 & 322.6 & 0.99 & 85.5 & 48.1 & 31.6 & 4.2 \\
\hline 2.PhosDAP & 15.2 & 337.4 & 1.00 & 155.7 & 53.5 & 27.3 & 4.8 \\
\hline 3.PhosDAP_Zn & 16.1 & 343.6 & 0.93 & 132.7 & 44.4 & 24.8 & 4.4 \\
\hline 4.DAP_REG & 16.1 & 340.5 & 0.91 & 100.4 & 46.5 & 24.4 & 4.3 \\
\hline 5.Manure & 12.4 & 288.3 & 1.02 & 74.8 & 40.0 & 20.5 & 4.5 \\
\hline \multicolumn{8}{|l|}{ Carrot (root) } \\
\hline 1.BLANC & 4.5 & 131.3 & 0.68 & 16.5 & 56.5 & 6.9 & 1.3 \\
\hline 2.PhosDAP & 4.4 & 121.5 & 0.52 & 13.4 & 39.8 & 5.8 & 1.2 \\
\hline 3.PhosDAP_Zn & 5.7 & 131.2 & 0.56 & 24.0 & 42.8 & 6.0 & 1.3 \\
\hline 4.DAP_REG & 6.4 & 140.2 & 0.56 & 17.8 & 44.3 & 6.0 & 1.3 \\
\hline 5.Manure & 4.9 & 112.0 & 0.58 & 20.9 & 49.7 & 5.3 & 1.2 \\
\hline \multicolumn{8}{|l|}{ Lettuce (head) } \\
\hline 1.BLANC & 4.0 & 142.3 & 0.38 & 39.0 & 15.0 & 8.3 & 2.1 \\
\hline 2.PhosDAP & 5.8 & 128.7 & 0.34 & 93.6 & 19.6 & 7.4 & 2.0 \\
\hline 3.PhosDAP_Zn & 5.7 & 117.9 & 0.29 & 100.4 & 15.8 & 6.8 & 2.0 \\
\hline 4.DAP_REG & 5.9 & 117.3 & 0.30 & 52.6 & 15.5 & 6.4 & 2.0 \\
\hline 5.Manure & 5.1 & 118.0 & 0.32 & 41.8 & 16.0 & 5.8 & 1.9 \\
\hline
\end{tabular}




\begin{tabular}{|c|c|c|c|c|c|c|c|}
\hline Soil/Crop/treatment & As & Cd & $\mathrm{Cu}$ & $\mathrm{Cr}$ & $\mathrm{Pb}$ & $\mathrm{Zn}$ & $\mathbf{N}$ \\
\hline Wijnandsrade & $\mu \mathrm{g} \mathrm{kg} g^{-1}$ & $\mu \mathrm{gg}^{-1}$ & $\mathrm{mg} \mathrm{kg}^{-1}$ & $\mu \mathrm{g} \mathrm{kg}^{-1}$ & $\mu \mathrm{kg}^{-1}$ & $\mathrm{mg} \mathrm{kg}^{-1}$ & $\mathrm{~g} \mathrm{~kg}^{-1}$ \\
\hline \multicolumn{8}{|l|}{ Carrot (leaves) } \\
\hline 1.BLANC & 13.1 & 105.8 & 1.03 & 126.4 & 45.6 & 5.2 & 4.6 \\
\hline 2.PhosDAP & 19.7 & 97.0 & 0.96 & 155.5 & 55.6 & 4.4 & 4.3 \\
\hline 3.PhosDAP_Zn & 23.6 & 129.4 & 1.03 & 194.7 & 75.6 & 5.1 & 4.4 \\
\hline 4.DAP_REG & 21.4 & 113.0 & 0.97 & 240.1 & 67.4 & 4.4 & 4.2 \\
\hline 5.Manure & 42.4 & 119.6 & 1.13 & 299.7 & 130.0 & 5.5 & 4.7 \\
\hline \multicolumn{8}{|l|}{ Carrot (root) } \\
\hline 1.BLANC & 6.6 & 50.0 & 0.58 & 38.1 & 27.8 & 2.7 & 1.4 \\
\hline 2.PhosDAP & 7.2 & 44.2 & 0.53 & 46.9 & 27.0 & 2.5 & 1.4 \\
\hline 3.PhosDAP_Zn & 7.6 & 51.4 & 0.49 & 53.3 & 26.9 & 2.5 & 1.2 \\
\hline 4.DAP_REG & 8.1 & 47.4 & 0.48 & 75.1 & 27.5 & 2.5 & 1.3 \\
\hline 5.Manure & 11.1 & 47.7 & 0.56 & 88.8 & 41.1 & 2.8 & 1.4 \\
\hline \multicolumn{8}{|l|}{ Lettuce (head) } \\
\hline 1.BLANC & 5.1 & 67.3 & 0.44 & 139.8 & 16.0 & 3.3 & 2.1 \\
\hline 2.PhosDAP & 4.8 & 61.1 & 0.41 & 57.3 & 13.9 & 2.9 & 1.8 \\
\hline 3.PhosDAP_Zn & 4.8 & 60.7 & 0.39 & 139.8 & 15.2 & 3.0 & 1.7 \\
\hline 4.DAP_REG & 4.5 & 62.8 & 0.41 & 51.3 & 11.7 & 2.9 & 1.8 \\
\hline 5.Manure & 4.4 & 57.0 & 0.44 & 213.0 & 12.2 & 2.9 & 1.9 \\
\hline \multicolumn{8}{|l|}{ Epen-Geuldal } \\
\hline \multicolumn{8}{|l|}{ Carrot (leaves) } \\
\hline 1.BLANC & 11.4 & 455.6 & 0.59 & 147.2 & 268.2 & 229.7 & 4.3 \\
\hline 2.PhosDAP & 14.7 & 541.2 & 0.61 & 192.2 & 244.0 & 259.2 & 4.2 \\
\hline 3.PhosDAP_Zn & 14.8 & 567.7 & 0.57 & 196.7 & 187.8 & 241.4 & 5.4 \\
\hline 4.DAP_REG & 17.2 & 563.8 & 0.59 & 157.0 & 235.7 & 234.7 & 4.6 \\
\hline 5.Manure & 13.0 & 280.1 & 0.68 & 136.5 & 212.1 & 144.3 & 5.2 \\
\hline \multicolumn{8}{|l|}{ Carrot (root) } \\
\hline 1.BLANC & 16.1 & 252.0 & 0.36 & 125.8 & 534.1 & 41.0 & 1.9 \\
\hline 2.PhosDAP & 13.6 & 162.5 & 0.25 & 133.4 & 414.1 & 37.2 & 1.6 \\
\hline 3.PhosDAP_Zn & 15.0 & 188.1 & 0.26 & 103.5 & 525.3 & 40.2 & 1.6 \\
\hline 4.DAP_REG & 12.6 & 178.7 & 0.24 & 109.0 & 404.9 & 35.7 & 1.7 \\
\hline 5. Manure & 16.9 & 122.0 & 0.29 & 135.4 & 548.5 & 24.7 & 1.4 \\
\hline \multicolumn{8}{|l|}{ Lettuce (head) } \\
\hline 1.BLANC & 3.9 & 500.2 & 0.27 & 77.8 & 29.0 & 33.3 & 2.5 \\
\hline 2.PhosDAP & 5.6 & 401.5 & 0.22 & 96.7 & 34.1 & 35.7 & 2.2 \\
\hline 3.PhosDAP_Zn & 7.1 & 408.1 & 0.24 & 353.3 & 89.4 & 37.2 & 2.3 \\
\hline 4.DAP_REG & 6.3 & 408.0 & 0.21 & 180.6 & 36.1 & 34.9 & 2.3 \\
\hline 5.Manure & 3.8 & 366.1 & 0.28 & 138.2 & 43.0 & 28.4 & 2.0 \\
\hline
\end{tabular}




\begin{tabular}{|c|c|c|c|c|c|c|c|}
\hline Soil/Crop/treatment & As & Cd & $\mathrm{Cu}$ & $\mathrm{Cr}$ & $\mathrm{Pb}$ & $\mathrm{Zn}$ & $\mathbf{N}$ \\
\hline Grebbedijk & $\mu \mathrm{g} \mathrm{kg}-1$ & $\mu \mathrm{g} \mathrm{kg}{ }^{-1}$ & $\mathrm{mg} \mathrm{kg}-1$ & $\mu \mathrm{g} \mathrm{kg}{ }^{-1}$ & $\mu \mathrm{g} \mathrm{kg}{ }^{-1}$ & $\mathrm{mg} \mathrm{kg}^{-1}$ & $\mathrm{~g} \mathrm{~kg}^{-1}$ \\
\hline \multicolumn{8}{|l|}{ Carrot (leaves) } \\
\hline 1.BLANC & 98.2 & 72.7 & 1.18 & 798.8 & 208.6 & 4.2 & 4.4 \\
\hline 2.PhosDAP & 15.4 & 67.4 & 1.16 & 188.3 & 48.9 & 3.7 & 4.6 \\
\hline 3.PhosDAP_Zn & 27.3 & 72.8 & 1.08 & 268.6 & 110.0 & 3.7 & 4.3 \\
\hline 4.DAP_REG & 40.6 & 70.0 & 1.14 & 454.5 & 104.9 & 3.9 & 4.5 \\
\hline 5.Manure & 86.9 & 62.8 & 1.16 & 553.4 & 182.6 & 3.9 & 4.1 \\
\hline \multicolumn{8}{|l|}{ Carrot (root) } \\
\hline 1.BLANC & 5.1 & 31.0 & 0.65 & 30.5 & 17.2 & 2.2 & 1.3 \\
\hline 2.PhosDAP & 6.5 & 27.2 & 0.67 & 79.4 & 18.1 & 2.1 & 1.4 \\
\hline 3.PhosDAP_Zn & 7.7 & 30.1 & 0.68 & 102.9 & 24.7 & 2.2 & 1.4 \\
\hline 4.DAP_REG & 4.4 & 29.3 & 0.66 & 61.7 & 20.0 & 2.3 & 1.3 \\
\hline 5.Manure & 5.1 & 24.1 & 0.64 & 50.7 & 15.5 & 2.1 & 1.3 \\
\hline \multicolumn{8}{|l|}{ Lettuce (head) } \\
\hline 1.BLANC & 2.2 & 96.3 & 0.54 & 41.7 & 7.6 & 3.2 & 2.1 \\
\hline 2.PhosDAP & 2.7 & 98.7 & 0.53 & 89.6 & 9.2 & 3.0 & 2.2 \\
\hline 3.PhosDAP_Zn & 2.3 & 99.6 & 0.52 & 37.5 & 7.0 & 2.8 & 2.2 \\
\hline 4.DAP_REG & 2.3 & 101.8 & 0.52 & 45.6 & 6.7 & 2.8 & 2.3 \\
\hline 5.Manure & 2.4 & 112.0 & 0.57 & 67.2 & 7.1 & 2.9 & 2.1 \\
\hline \multicolumn{8}{|l|}{ Lottum } \\
\hline \multicolumn{8}{|l|}{ Carrot (leaves) } \\
\hline 1.BLANC & 27.2 & 513.7 & 1.28 & 189.7 & 253.3 & 11.3 & 5.0 \\
\hline 2.PhosDAP & 31.6 & 466.2 & 1.18 & 144.8 & 251.5 & 10.5 & 4.7 \\
\hline 3.PhosDAP_Zn & 20.6 & 472.0 & 1.11 & 100.8 & 174.5 & 12.0 & 4.7 \\
\hline 4.DAP_REG & 14.0 & 506.0 & 1.16 & 104.0 & 102.3 & 10.9 & 5.1 \\
\hline 5.Manure & 9.1 & 432.1 & 1.21 & 64.2 & 77.4 & 9.3 & 5.0 \\
\hline \multicolumn{8}{|l|}{ Carrot (root) } \\
\hline 1.BLANC & 9.4 & 212.9 & 0.80 & 158.5 & 113.0 & 5.0 & 1.5 \\
\hline 2.PhosDAP & 8.0 & 161.9 & 0.57 & 34.7 & 83.5 & 3.8 & 1.2 \\
\hline 3.PhosDAP_Zn & 7.0 & 170.7 & 0.60 & 83.5 & 77.5 & 4.0 & 1.3 \\
\hline 4.DAP_REG & 5.1 & 160.9 & 0.54 & 31.6 & 53.9 & 3.7 & 1.2 \\
\hline 5.Manure & 9.0 & 161.8 & 0.67 & 98.9 & 104.1 & 3.9 & 1.3 \\
\hline \multicolumn{8}{|l|}{ Lettuce (head) } \\
\hline 1.BLANC & 3.7 & 213.7 & 0.66 & 66.7 & 15.3 & 6.8 & 3.0 \\
\hline 2.PhosDAP & 3.9 & 193.2 & 0.44 & 37.2 & 13.4 & 5.5 & 2.4 \\
\hline 3.PhosDAP_Zn & 3.5 & 197.7 & 0.43 & 51.2 & 12.5 & 5.7 & 2.3 \\
\hline 4.DAP_REG & 4.3 & 191.2 & 0.45 & 53.7 & 16.8 & 5.8 & 2.3 \\
\hline 5. Manure & 3.3 & 143.5 & 0.58 & 48.8 & 11.2 & 5.2 & 2.5 \\
\hline
\end{tabular}

In Tables 3.8 to 3.10 the ANOVA results from the analyses of the metals ( $\mathrm{As}, \mathrm{Cd}, \mathrm{Cr}, \mathrm{Pb}$ ), nutrients $(\mathrm{Ca}, \mathrm{Fe}, \mathrm{K}, \mathrm{Mg}, \mathrm{P}$ and $\mathrm{S})$, micronutrients $(\mathrm{Cu}, \mathrm{Zn})$ and nutritional value are listed. Here we present the results of the two main factors that were used, i.e. effect of soil ( $F$ Soil) and treatment ( $F$ Treat).

Results from the interaction between soil and treatment ( $F$ Soil.Treat) are not shown apart from the significance of the effect. Please note that the meaning of the numbers listed under $F$ Treat are not to be interpreted as real data of the metal or nutrient content in crops since these are averaged across all soils to look into difference of treatment regardless of the soil. The letters following the statistical indicator indicate whether or not the result from one soil or treatment is different from the other. 


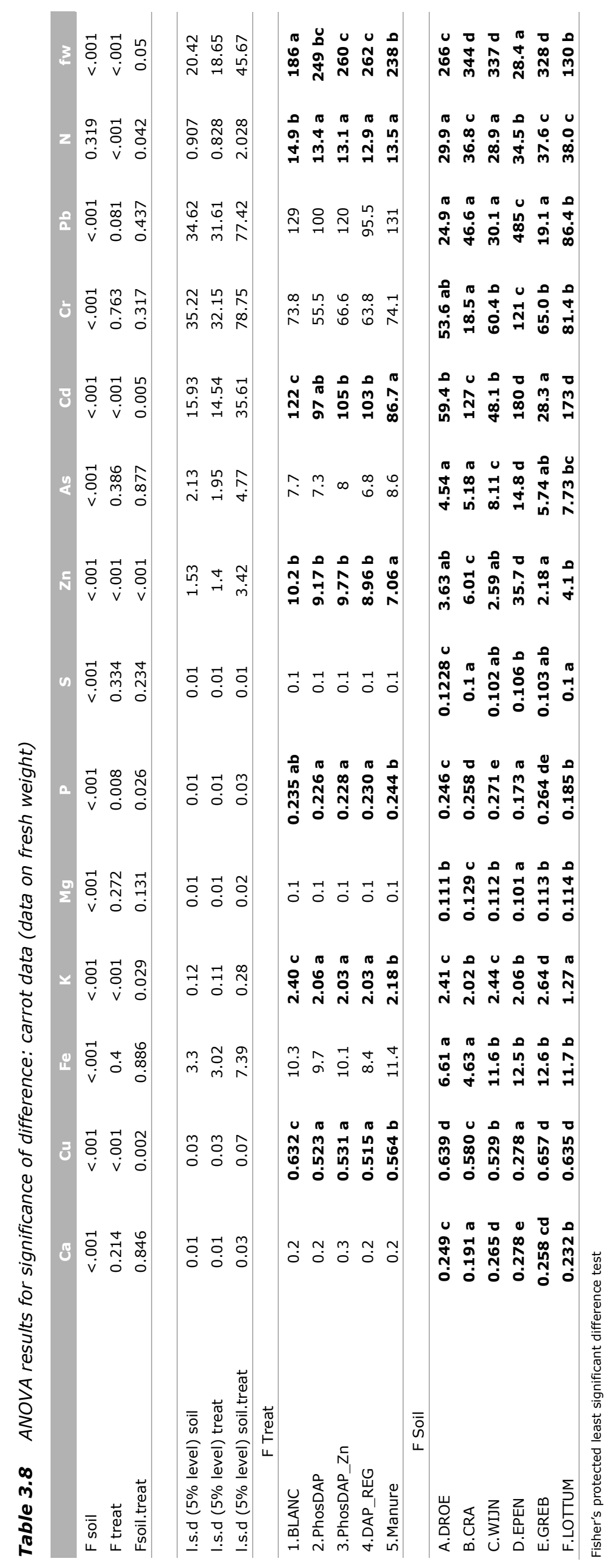




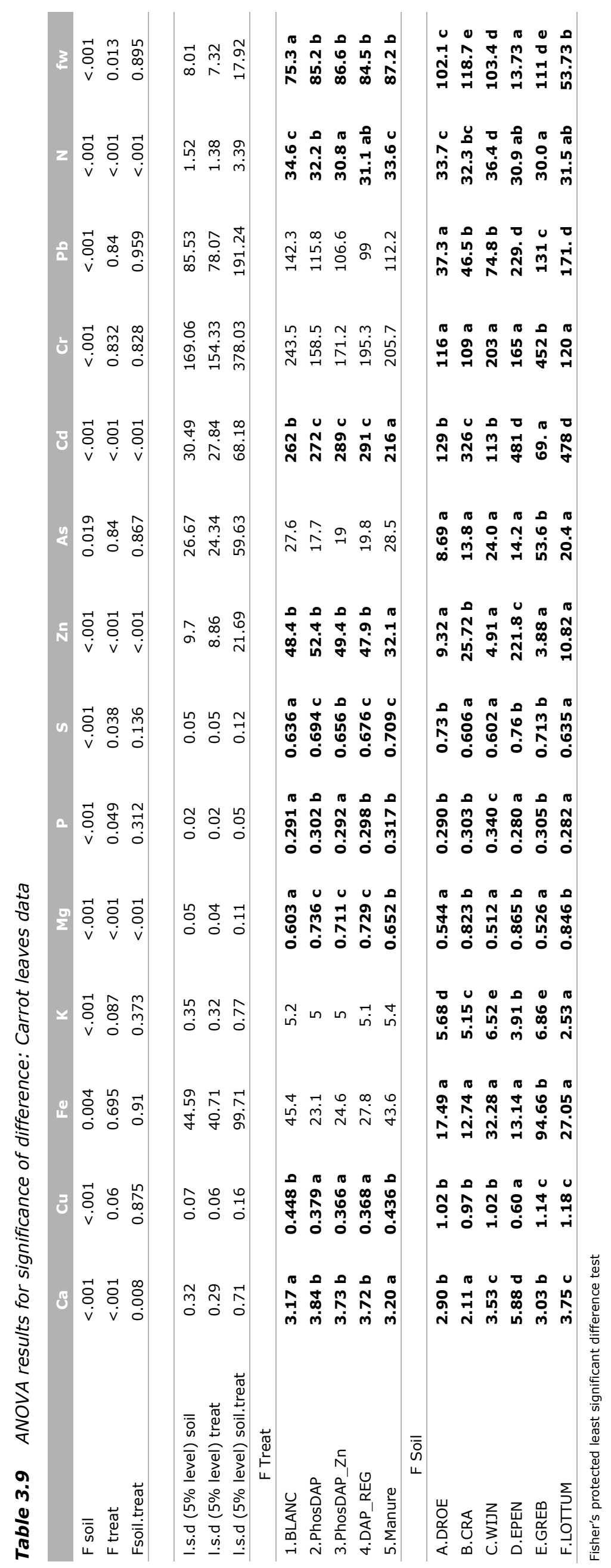




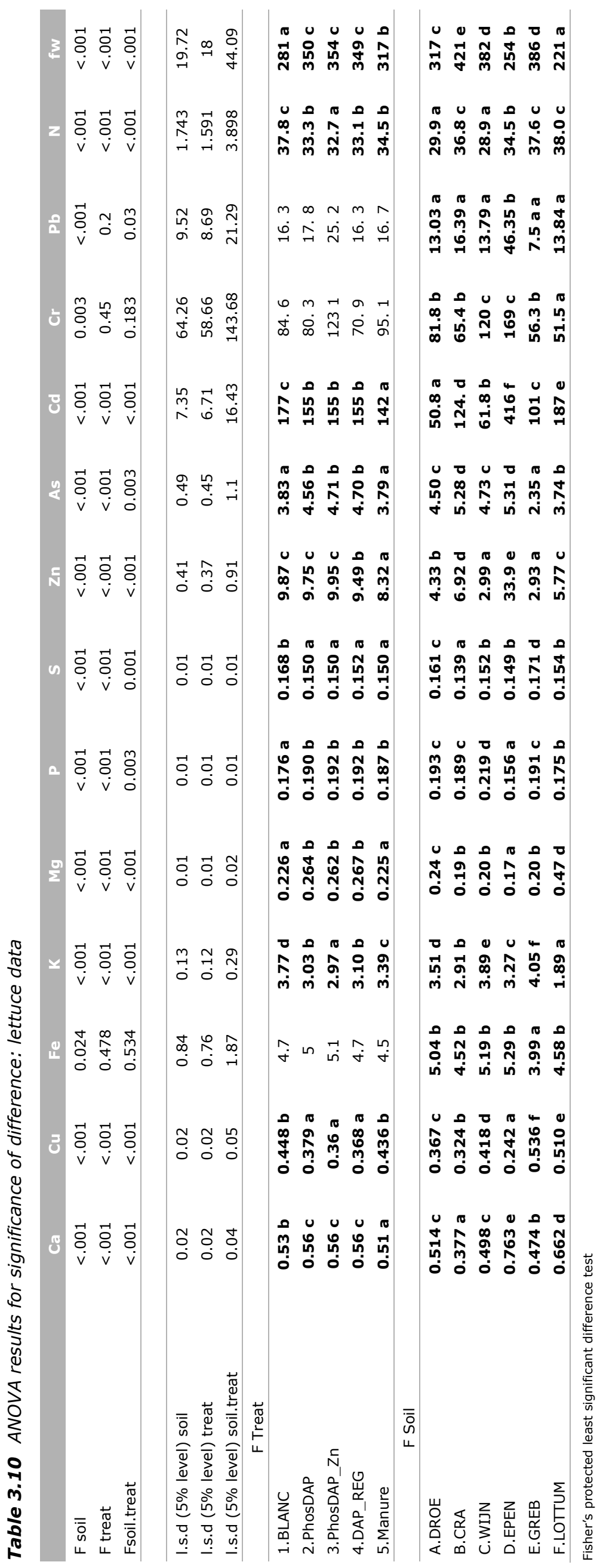




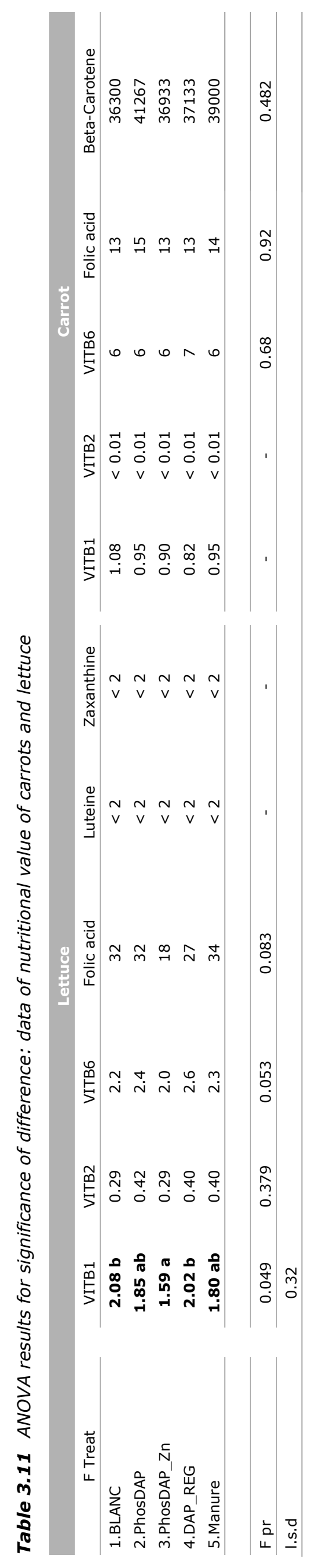


Conclusions from the crop data analysis:

- For both nutrients and metals differences between soils are prominent and significant which is related to the large inherent difference in soil quality (both nutrient status and contaminant levels), differences between soils are far more pronounced than differences between treatments in terms of metal content in crops: the Cd levels in lettuce increase with a factor of 8 when comparing results from the Droevendaal soil (clean sand) with the Epen soil (polluted loamy soil).

- For nutrients the mineral fertiliser treatments result in a significant increase in biomass production (Table 3.6) even in soils with a good fertility status (Wijnandsrade/Wageningen)

- The use of mineral fertilisers, when compared to blanc treatments has a beneficial effect for the crop quality in view of Cd uptake. Cadmium levels in lettuce and carrot are significantly lower in mineral fertiliser treated crops compared to blanc treatments (Table 3.8 and 3.10).

- For As however crop levels in mineral fertiliser treated soils are higher compared to blanc treatments.

- Animal manure results in the lowest Cd levels in lettuce and carrot compared to both blanc and mineral fertiliser treated soils.

- For Cd there appears to be no significant effect of the amount of Cd added via fertilisers and the final levels of $\mathrm{Cd}$ in either lettuce or carrot. For Cd levels in lettuce, uptake in the PhosAgro treated soil appear to be higher compared to the other treatments. For carrot the opposite is observed. Differences in $\mathrm{Cd}$ by either crop are most likely more related to differences in crop growth than to differences in Cd applied to the soil as such.

- For some combinations of soil and crops there are differences between the blanc soil and fertilised soils; Cd and As uptake by lettuce for examples is lower in the blanc soil compared to the fertilised soils. The lower As uptake in the blanc soil can be related to the high P status of the fertilised soils which can result in an equivalent uptake of As. Differences between treatments however are small.

- Addition of $\mathrm{Zn}$ in case of the PhosAgro DAP fertiliser does not result in a reduction of Cd by either crops nor an increase in the $Z n$ content.

- For metals with a low solubility like $\mathrm{Pb}$ or $\mathrm{Cr}$ the differences between treatments are largely nonsignificant.

In conclusion the data suggest that short term effects of fertilisers on crop quality, either in terms of metal uptake or nutrient uptake are absent or inconsistent in case of $\mathrm{Cd}, \mathrm{As}, \mathrm{Pb}$ or $\mathrm{Cr}$. It appears that the amount nor the availability of $\mathrm{Cd}$, As, and $\mathrm{Pb}$ as added by fertilisers to the soil has no immediate effect on crop quality. Also the addition of $\mathrm{Zn}$ to DAP seems to have no significant effect on the uptake of either $\mathrm{Zn}$ itself nor on the uptake of nutrients or metals. It should be noted that the soils included in this study are not $\mathrm{Zn}$ deficient and in $\mathrm{Zn}$ deficient soils, the response to fertilisers that include $\mathrm{Zn}$ can be very different.

From this it was concluded that uptake of metals like $\mathrm{Cd}$ or $\mathrm{Zn}$ in the soils included here (without any deficiency regarding micronutrients) during one growing season is controlled by the total available pool of metals already in the soil in combination with the soil properties (notably $\mathrm{pH}$ and organic matter). Apparently the addition of a small amount of $\mathrm{Cd}$ or $\mathrm{Zn}$ via fertilisers does not affect this equilibrium between soil and crop. 


\subsection{Results greenhouse experiment 2017: potato, barley, carrot and spinach}

\subsubsection{Results greenhouse experiment 2017: effect of treatment on chemical availability and reactivity of metals in soil}

After termination of the greenhouse experiments, levels of reactive $\left(0.43 \mathrm{~N} \mathrm{HNO}_{3}\right)$ and available $\left(0.002 \mathrm{M} \mathrm{Ca}\left(\mathrm{NO}_{3}\right)_{2}\right)$ were measured in mixed samples taken from all pots. Results from this analyses including the ANOVA test data are listed in Tables 3.12 and 3.13 below. Significant effects $(F<0.005)$ are marked in bold.

Table 3.12 Soil extract using $0.43 \mathrm{M} \mathrm{HNO}_{3}$ in $\mathrm{mg} \mathrm{kg}^{-1}$

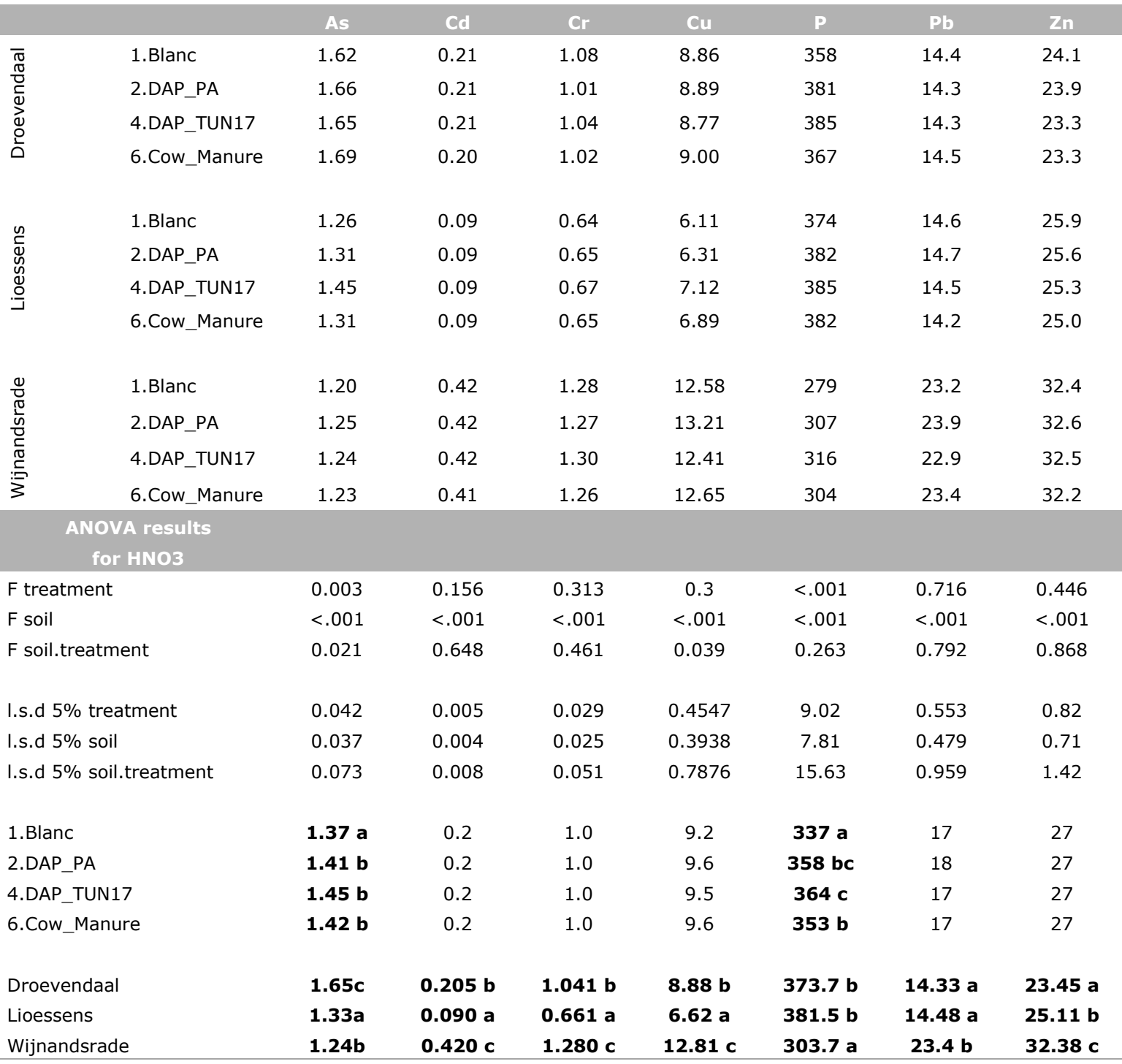

Data in Table 3.12 reveal that the amount of metals added to the soil via fertilisers did not result in a significant increase in soil when considering treatments across all soils. When considering individual soils however, the effect of fertilisers is significant for $\mathrm{Cd}, \mathrm{Cu}$ and $\mathrm{As}$ in case of the Lioessens soil where $\mathrm{Cd}, \mathrm{Cu}$ and As levels in the soil treated with PhosAgro Dap are significantly lower compared to those treated with the Tunesian DAP. Differences are however (very) small ( $<0.01 \mathrm{ppm}$ difference for $\mathrm{Cd}$ ) and, within one year do not lead to differences in the availability of the same metals (As, Cu) as is shown in Table 3.13. In fact levels of $\mathrm{Cu}$ in the Tunesian DAP are lower compared to those in the lowCd DAP from PhosAgro which implies that such small changes as observed here are not related to the 
quality of fertiliser since additions of $\mathrm{Cu}$ to the soils treated with the Tunesian DAP are lower than those added to the soils treated with PhosAgro DAP.

As was observed in 2016, the chemical availability is clearly different between soils due to differences in soil properties and the reactive metal content but are not affected by the levels of metals in the fertilisers applied in the study. The small increase in the reactive pool for $\mathrm{Cu}$, As and Cd due to the higher levels in the Tunesian DAP apparently does not affect the chemical availability nor the crop uptake within one cropping cycle.

Table 3.13 Soil extract using $0.002 \mathrm{M} \mathrm{Ca}\left(\mathrm{NO}_{3}\right)_{2}$

\begin{tabular}{|c|c|c|c|c|c|c|c|c|c|}
\hline & $\mathbf{P}$ & As & Cd & $\mathrm{Cr}$ & $\mathrm{Cu}$ & $\mathrm{Pb}$ & $\mathrm{Zn}$ & pH & DOC-C \\
\hline Droevendaal & $\mathrm{mg} / \mathrm{kg}$ & $\mu \mathrm{g} / \mathrm{kg}$ & $\mu \mathrm{g} / \mathrm{kg}$ & $\mu \mathrm{g} / \mathrm{kg}$ & $\mu \mathrm{g} / \mathrm{kg}$ & $\mu \mathrm{g} / \mathrm{kg}$ & $\mu \mathrm{g} / \mathrm{kg}$ & & $\mathrm{mgC} / \mathrm{kg}$ \\
\hline 1.Blanc & 1.77 & 15.9 & 2.45 & 4.78 & 66 & 4.44 & 356 & 6.00 & 101 \\
\hline 4.DAP_TUN17 & 2.34 & 18.3 & 2.63 & 4.94 & 70 & 4.67 & 377 & 6.01 & 103 \\
\hline 6.Cow_Manure & 1.91 & 16.8 & 2.41 & 5.67 & 75 & 5.56 & 326 & 6.08 & 108 \\
\hline 1.Blanc & 4.52 & 42.8 & 0.18 & 2.22 & 54 & 1.17 & 31 & 7.63 & 52 \\
\hline 2.DAP_PA & 6.51 & 51.6 & 0.22 & 1.89 & 54 & 1.00 & 30 & 7.59 & 50 \\
\hline 4.DAP_TUN17 & 5.63 & 51.6 & 0.21 & 2.61 & 59 & 1.33 & 30 & 7.63 & 50 \\
\hline 6.Cow_Manure & 5.46 & 50.3 & 0.22 & 3.72 & 66 & 2.00 & 33 & 7.62 & 53 \\
\hline \multicolumn{10}{|l|}{ Wijnandsrade } \\
\hline 6.Cow_Manure & 3.39 & 25.8 & 1.76 & 9.39 & 175 & 4.44 & 69 & 6.85 & 184 \\
\hline \multicolumn{10}{|l|}{$\begin{array}{l}\text { ANOVA results } \\
\text { for } \mathrm{Ca}(\mathrm{NO} 3)_{2}\end{array}$} \\
\hline $\mathrm{F}$ treatment & $<.001$ & $<.001$ & 0.165 & 0.196 & 0.251 & 0.029 & $<.001$ & $<.001$ & 0.044 \\
\hline F soil & $<.001$ & $<.001$ & $<.001$ & $<.001$ & $<.001$ & $<.001$ & $<.001$ & $<.001$ & $<.001$ \\
\hline F soil.treatment & $<.001$ & $<.001$ & 0.543 & 0.765 & 0.996 & 0.955 & $<.001$ & 0.043 & 0.409 \\
\hline I.s.d $5 \%$ treatment & 0.2501 & 1.307 & 0.0999 & 0.781 & 14.46 & 0.4943 & 8.63 & 0.03252 & 6.88 \\
\hline 6.Cow_Manure & $3.55 \mathrm{~b}$ & $30.69 \mathrm{~b}$ & 1.5 & 6.1 & 112 & $3.92 \mathrm{~b}$ & 142.1 a & $6.85 \mathrm{c}$ & $113 b$ \\
\hline Droevendaal & $2.1 \mathrm{a}$ & 17.5 a & $2.59 c$ & $5.13 \mathrm{~b}$ & $72.7 \mathrm{~b}$ & $4.85 \mathrm{c}$ & $353.9 \mathrm{c}$ & 6.02 a & $102.8 \mathrm{~b}$ \\
\hline Lioessens & $5.5 \mathrm{c}$ & $48.9 \mathrm{c}$ & $0.19 a$ & $2.44 \mathrm{a}$ & 59.7 a & $1.29 \mathrm{a}$ & 30.7 a & $7.62 \mathrm{c}$ & 49.9 a \\
\hline Wijnandsrade & $3.6 \mathrm{~b}$ & 25.7 b & $1.82 b$ & $9.15 \mathrm{c}$ & $178.2 \mathrm{c}$ & $4.23 \mathrm{~b}$ & $75.1 \mathrm{~b}$ & 6.77 b & $172.9 \mathrm{c}$ \\
\hline
\end{tabular}

\section{Conclusions from the soil tests performed in 2017}

Based on all data (soils and crop) there is no effect of fertiliser quality on the levels of metals in either the bioavailable form $\left(\mathrm{Ca}\left(\mathrm{NO}_{3}\right)_{2}\right.$ extract) or reactive form $\left(\mathrm{HNO}_{3}\right.$ extract).

Differences between soils clearly are markedly and even at relatively low levels of Cd in soil, the combination of soil properties and reactive amount of $\mathrm{Cd}$ in soils results in a 10 -fold higher availability of $\mathrm{Cd}$ in the sandy soil of Droevendaal compared to the sandy soil of Lioessens.

In the Lioessens soil a small but significant increase in the reactive pool for $\mathrm{Cu}$, As and $\mathrm{Cd}$ was found in the soils treated with Tunesian DAP compared to those treated with other fertilisers but this cannot be related to the quality of fertiliser only since, for $\mathrm{Cu}$, levels in the Tunesian DAP are lower than those in the DAP from PhosAgro. 


\subsubsection{Biomass production}

In contrast to 2016, there were no extreme outliers in terms of crop production for the blancs as was observed in the Lottum and Epen soils. In Figure 3.3 to 3.8 the average biomass production data per soil, crop and fertiliser treatments are shown. Vertical bars are the values for the standard deviation $(n=3)$. All data are based on the fresh weight production as measured at harvest.

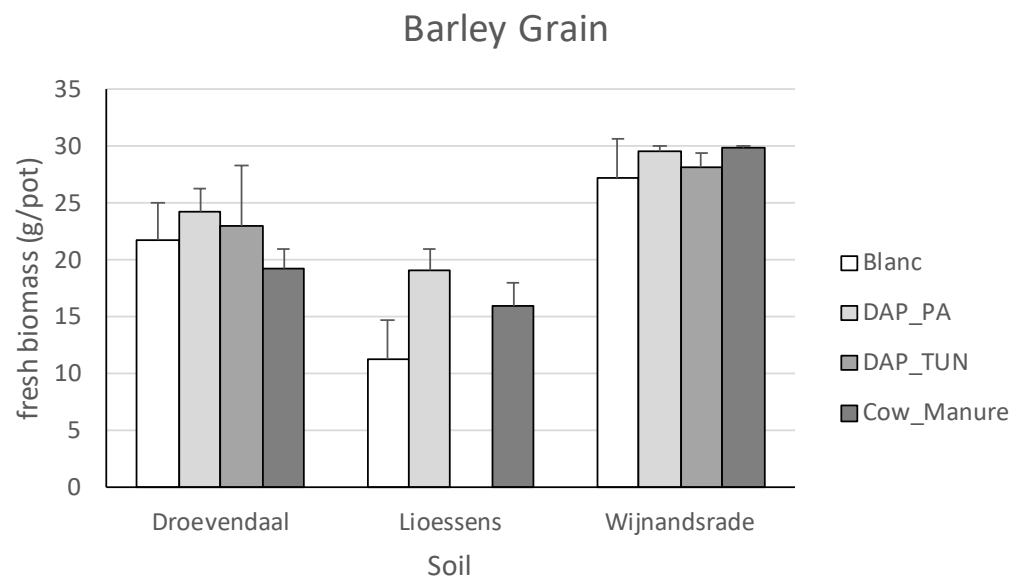

Figure 3.3 Barley grain biomass production (note: for Lioessens no crop data are available for DAPTUN treatment)

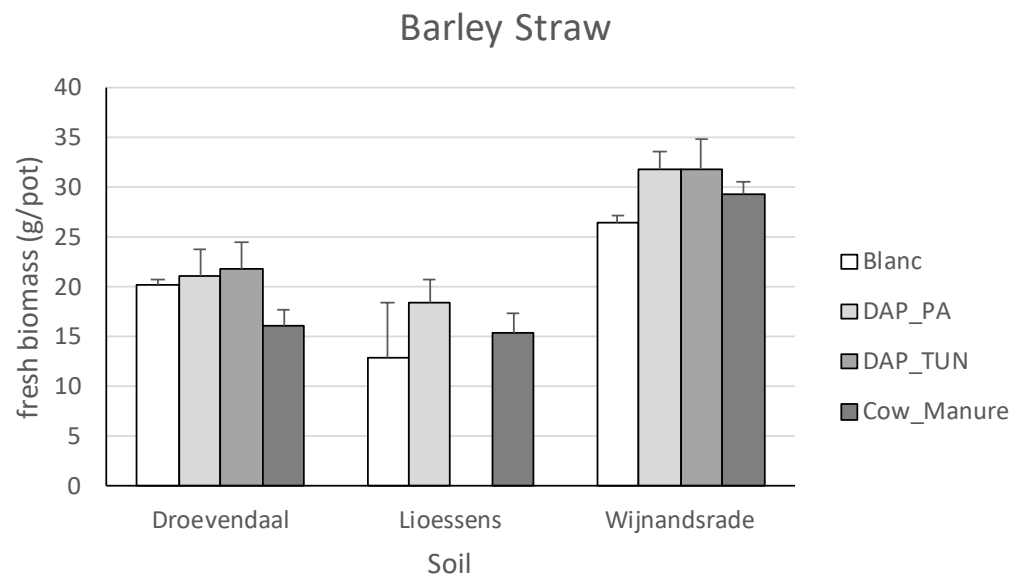

Figure 3.4 Barley straw biomass production (note: for Lioessens no crop data are available for DAPTUN treatment) 


\section{Carrot}

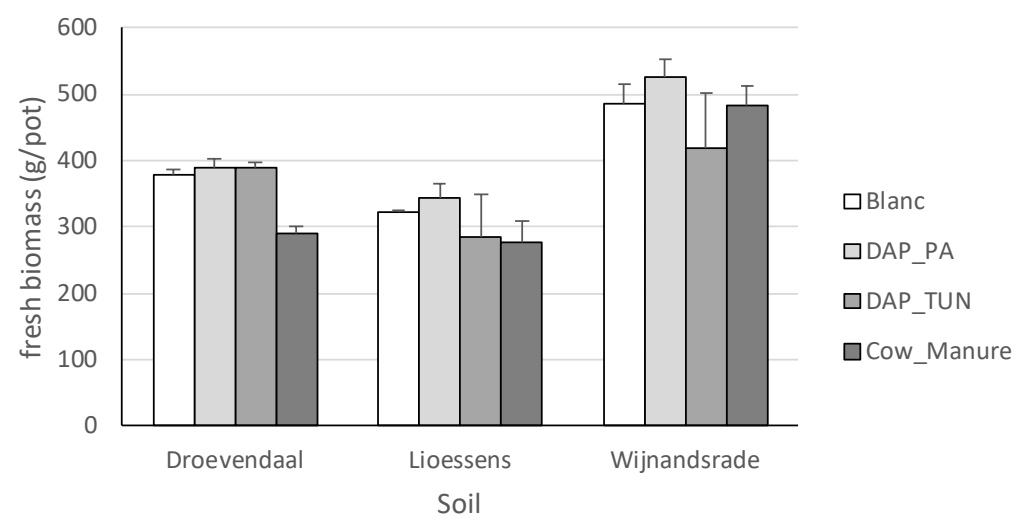

Figure 3.5 Carrot biomass production

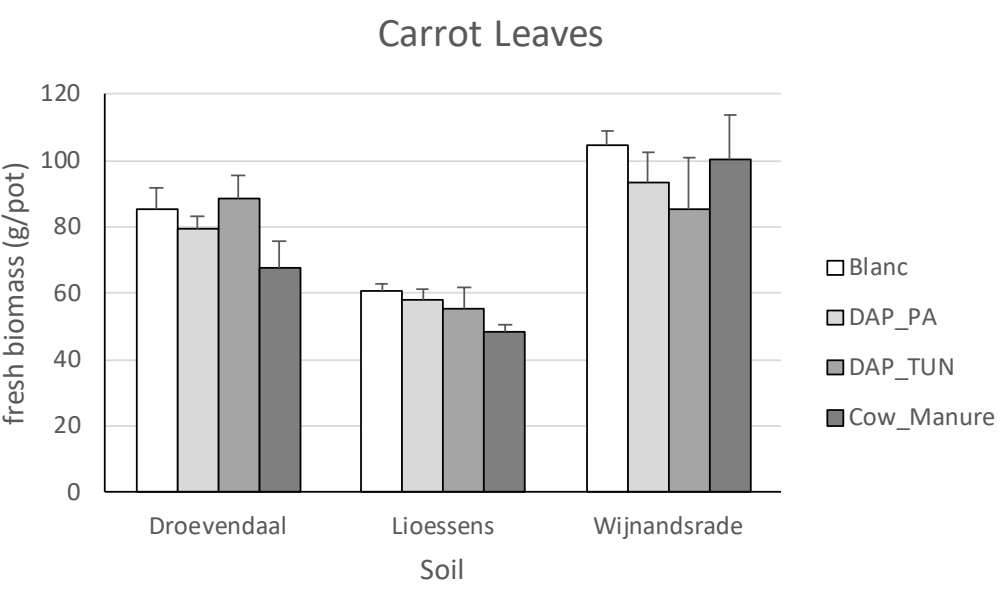

Figure 3.6 Carrot leaves biomass production

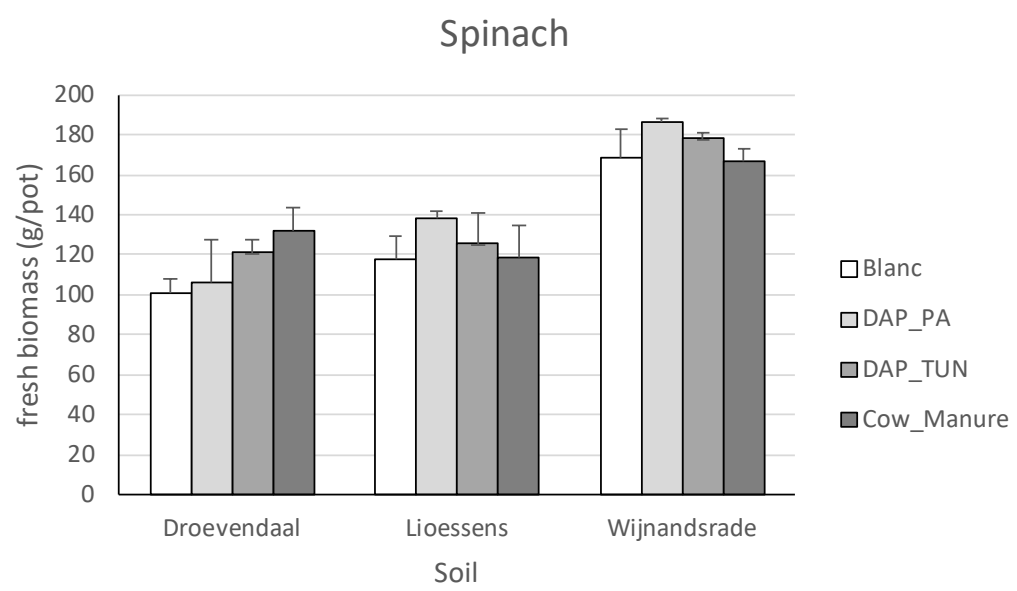

Figure 3.7 Spinach biomass production 


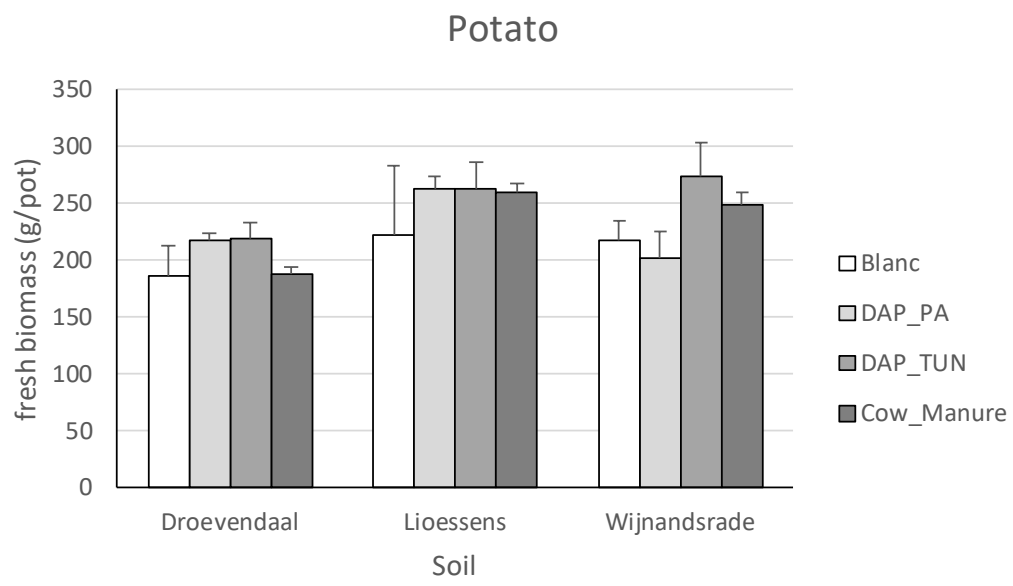

Figure 3.8 Potato biomass production

Differences between soils and treatments were visible with slightly higher yields in the Wijnandsrade soil for most crops compare to the Lioessens soil and, to a lesser extent also the Droevendaal soil. Apparently the loamy texture of the Wijnandsrade soil provides better growing conditions compared to the more sandy soils from Droevendaal and Lioessens. Differences between treatments were visible but appear not consistent. Also differences between treatments appear to be minimal in the Wijnandsrade soil which again shows the natural fertility of the soil; differences between the blanc treatment vs the treatments with P fertilisers for this soil appear not significant. For the Droevendaal and to a lesser extent the Lioessens soil the blanc and cow manure treated soils show a slight reduction of yield but also for these soils, differences are small (except for carrot) and for most crops not significant. To assess if crop production differences can be related to differences in the nutrient status of the soil, average values for the available (Figure 3.9) and reactive (Figure 3.10) P content were prepared. In most soils the available $P$ levels as measured in the soil using the $0.002 \mathrm{M}$ $\mathrm{Ca}(\mathrm{NO} 3) 2$ extraction after harvest are slightly reduced in the blanc and cow manure treated soils, the effect being more visible in the sandy and loess soils (Cranendonck, Droevendaal, Epen and Wijnandsrade soil) compared to the clay (Grebbedijk and Lottum) soils. Differences in the reactive $P$ content between treatments at harvest are less pronounced although the reactive $\mathrm{P}$ content in the Lottum appears to be very low compared to the other soils even though differences in the available $\mathrm{P}$ content between soils are less pronounced.

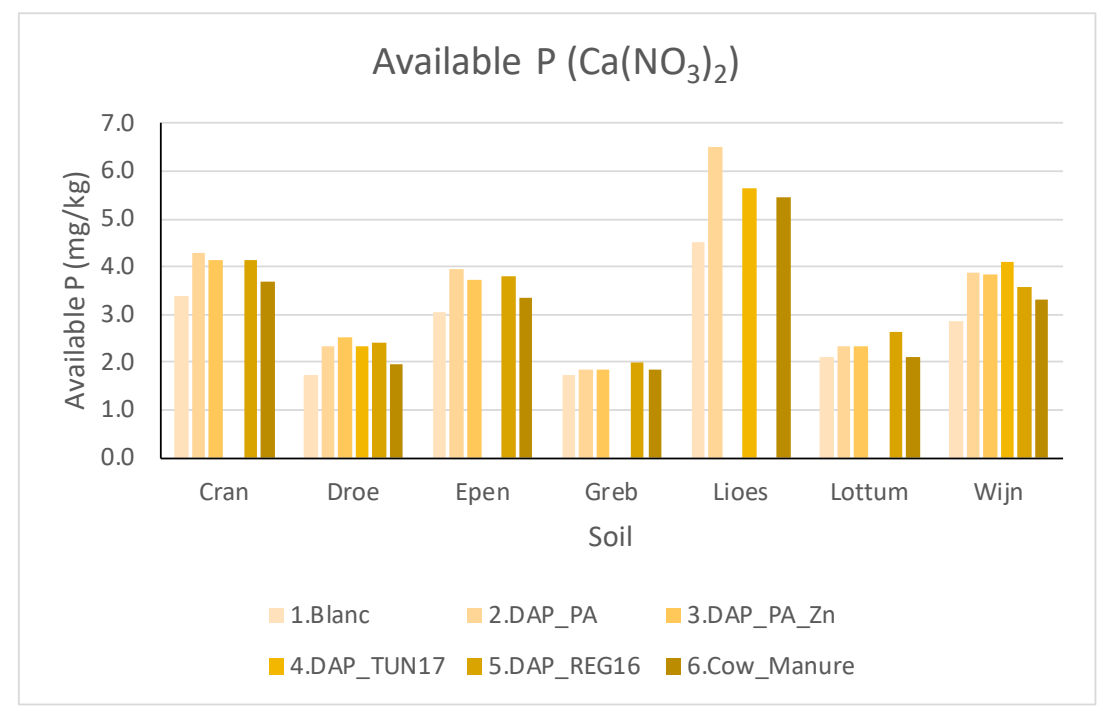

Figure 3.9 Available $P$ in soil as measured in the $0.002 \mathrm{M} \mathrm{Ca}\left(\mathrm{NO}_{3}\right)_{2}$ extraction after harvest 


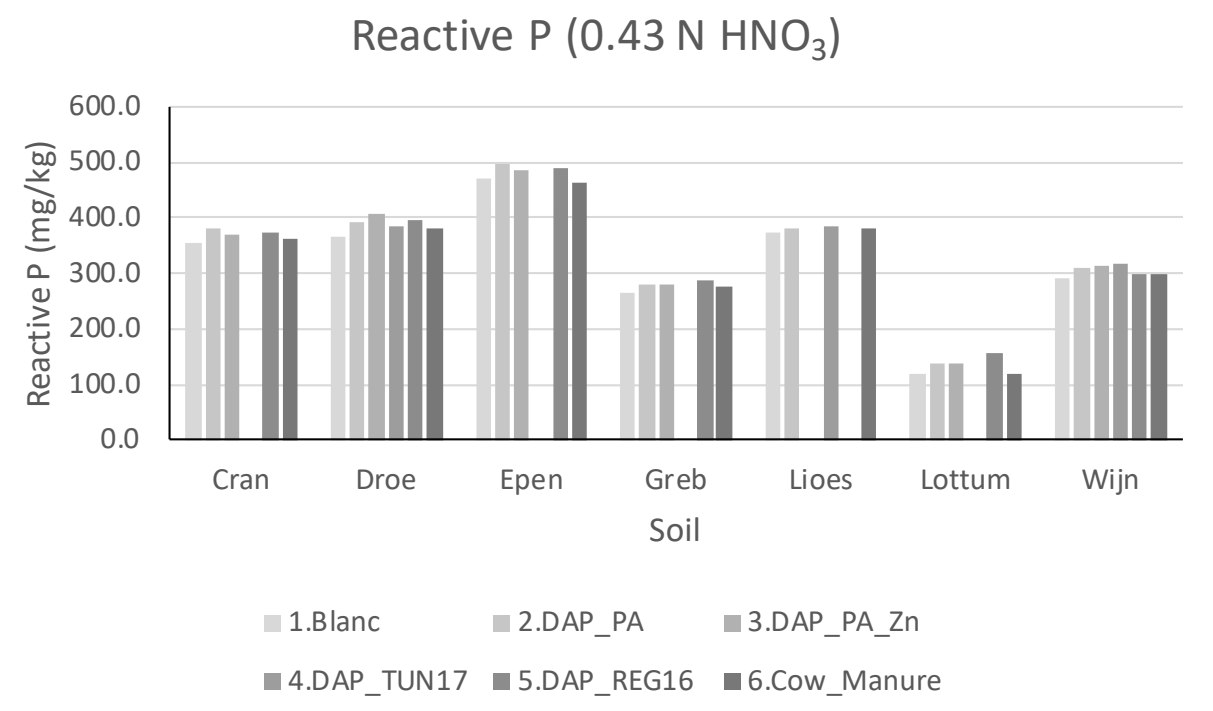

Figure 3.10 Reactive $P$ in soil as measured in the $0.43 \mathrm{M} \mathrm{HNO}_{3}$ extraction after harvest

\section{Conclusions from the yield and soil nutrient data 2017}

- From the yield data obtained in 2017 no significant differences in crop performance (biomass) or P supply to the crop (available and reactive $\mathrm{P}$ ) could be detected between the 2 mineral P fertilisers used.

- Both crop production and P supply in the blanc treatment and to a lesser extent in the cow manure treated soils are slightly reduced compared to the mineral fertiliser treated soils but differences are less pronounced compared to some results from 2016 notably in the Lottum and also Droevendaal soil.

\subsubsection{Uptake of metals by crops}

In Table 3.14 data of nutrients and metals in crops (fresh weight) are summarized by soil and treatment. 


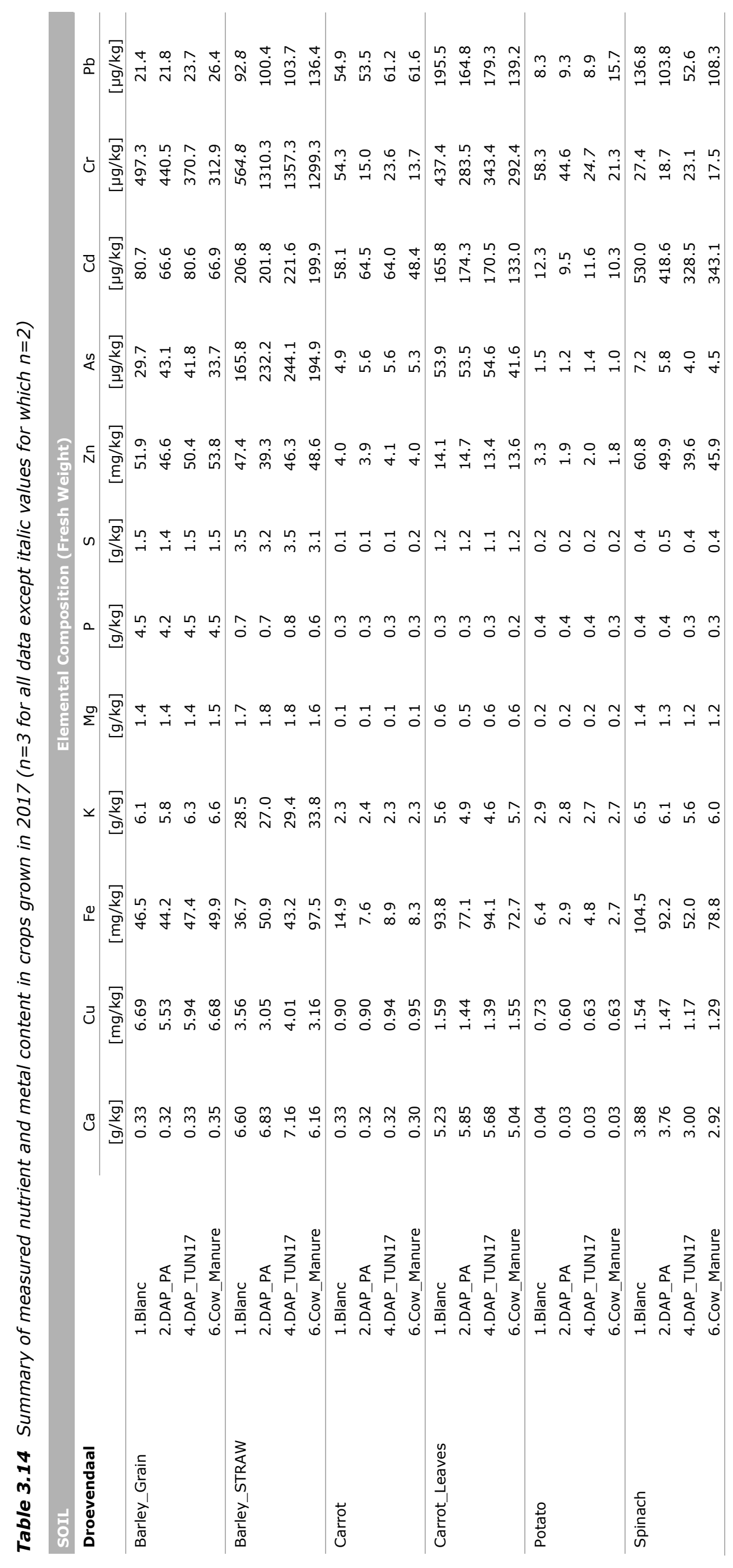




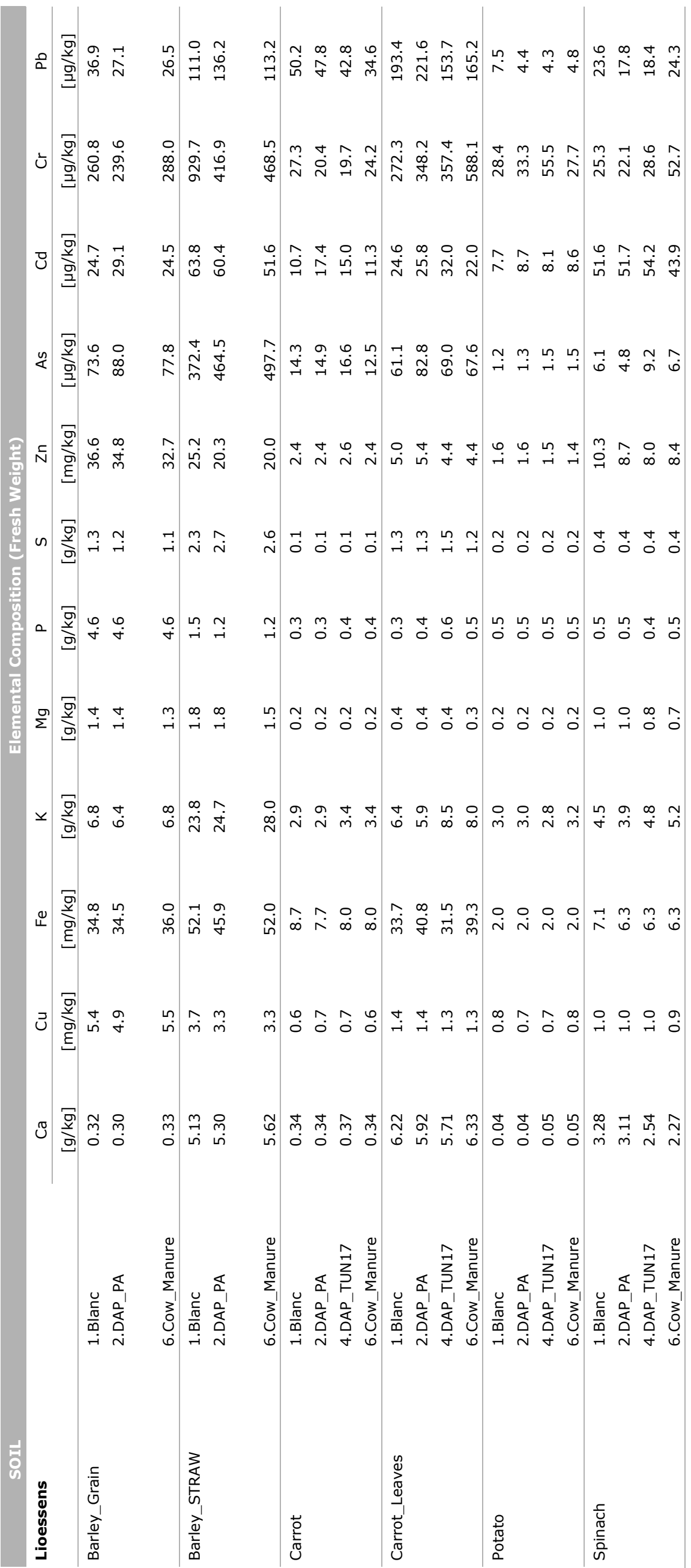




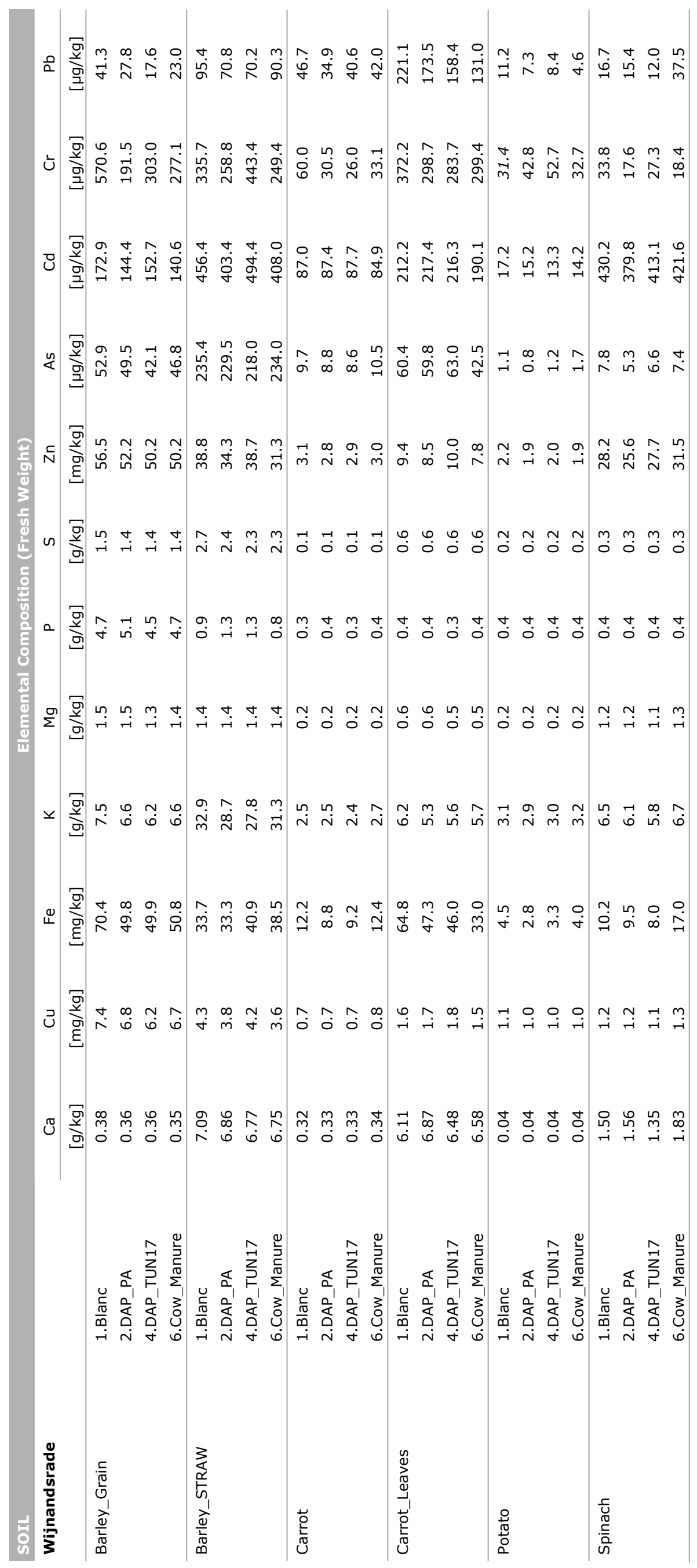




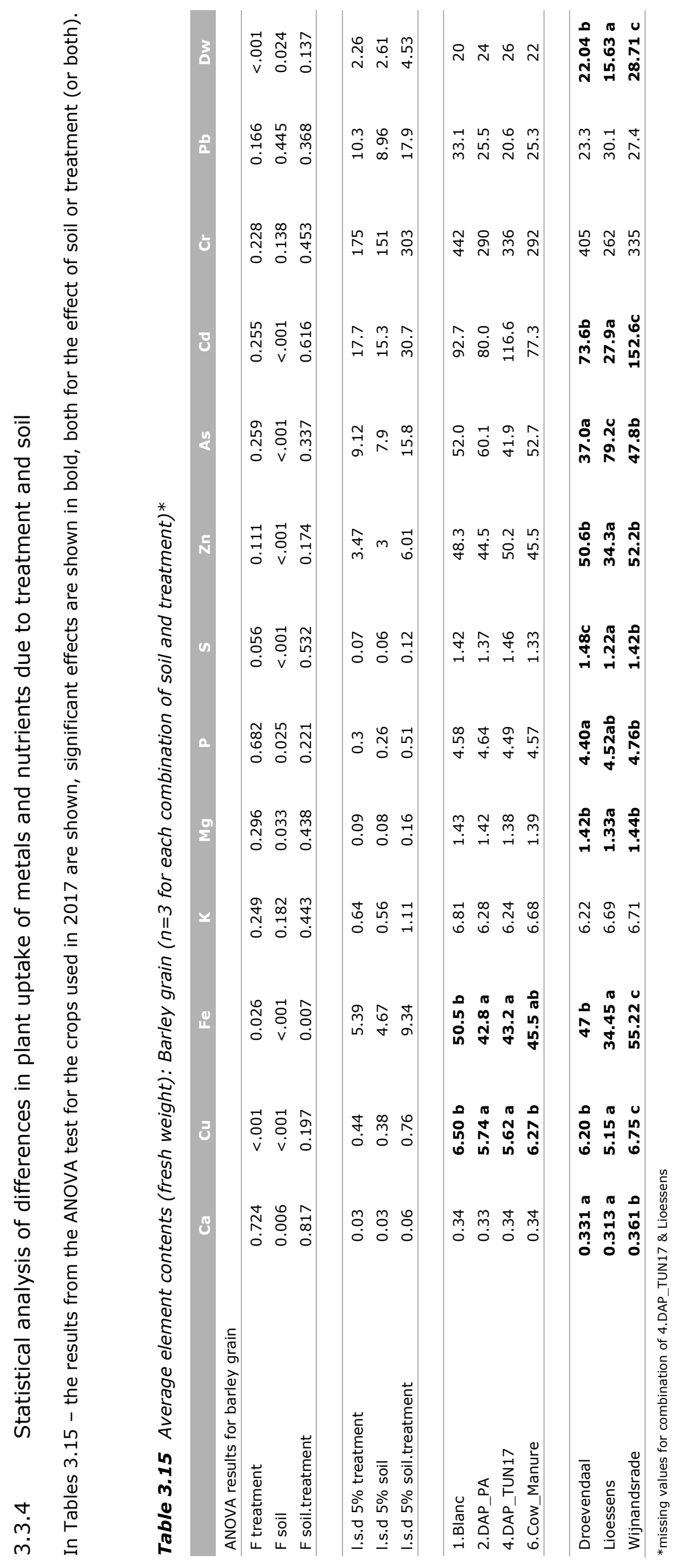




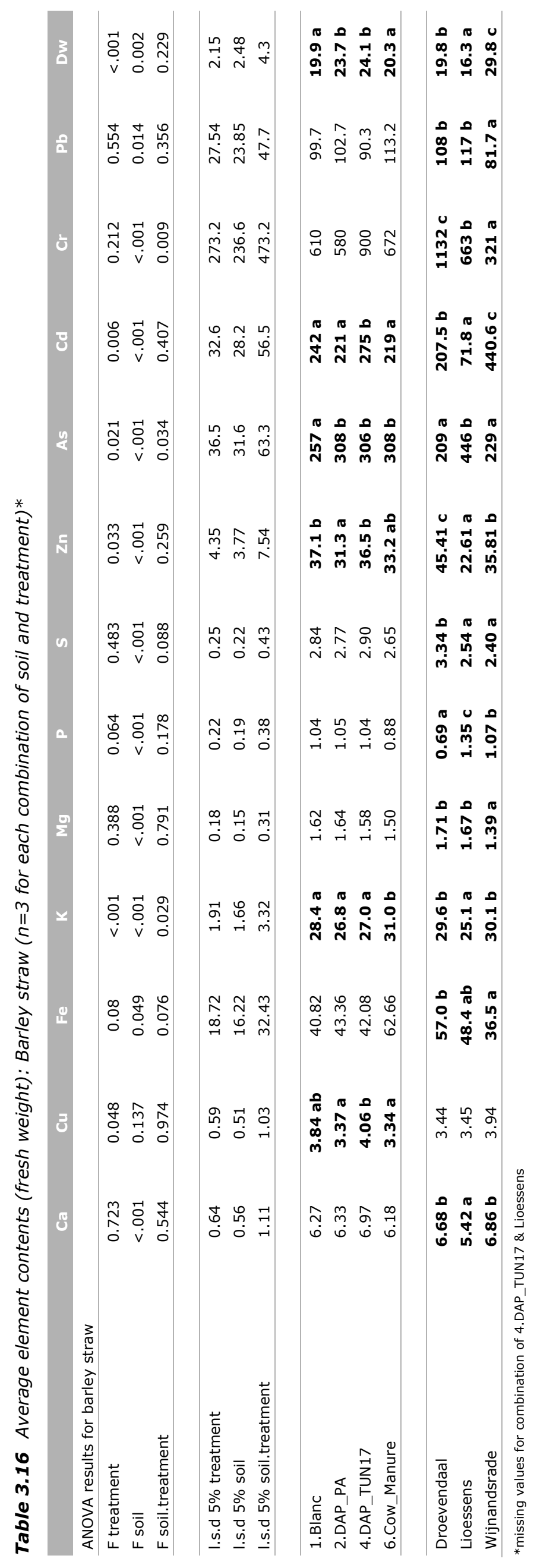




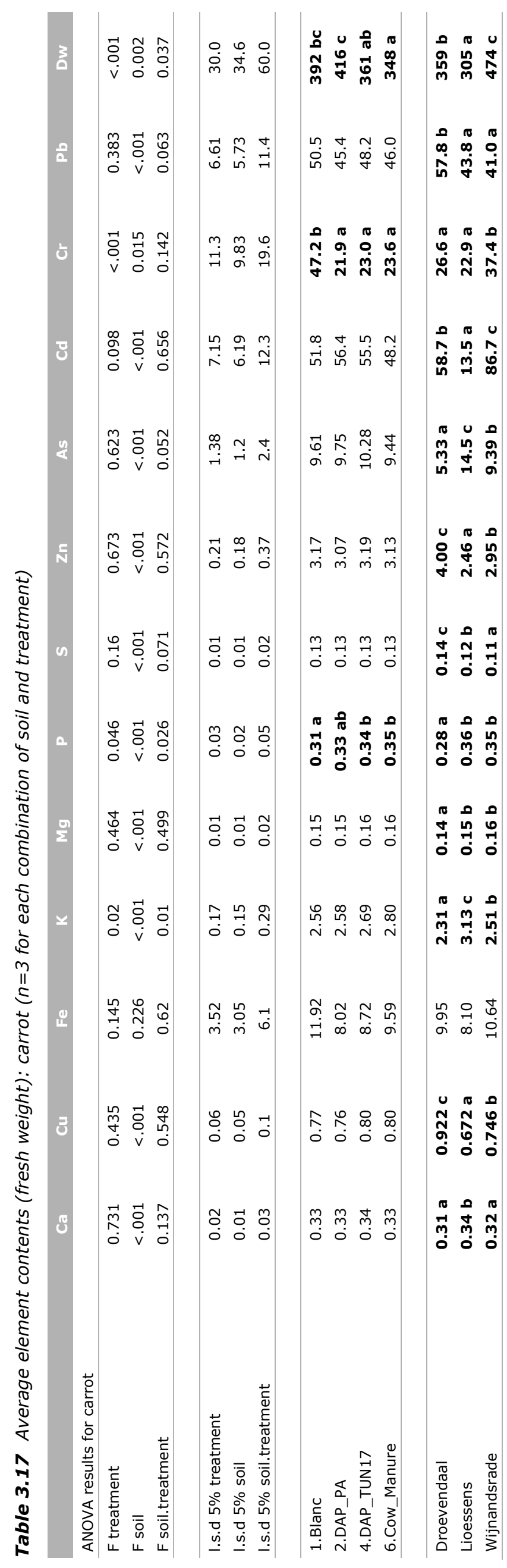




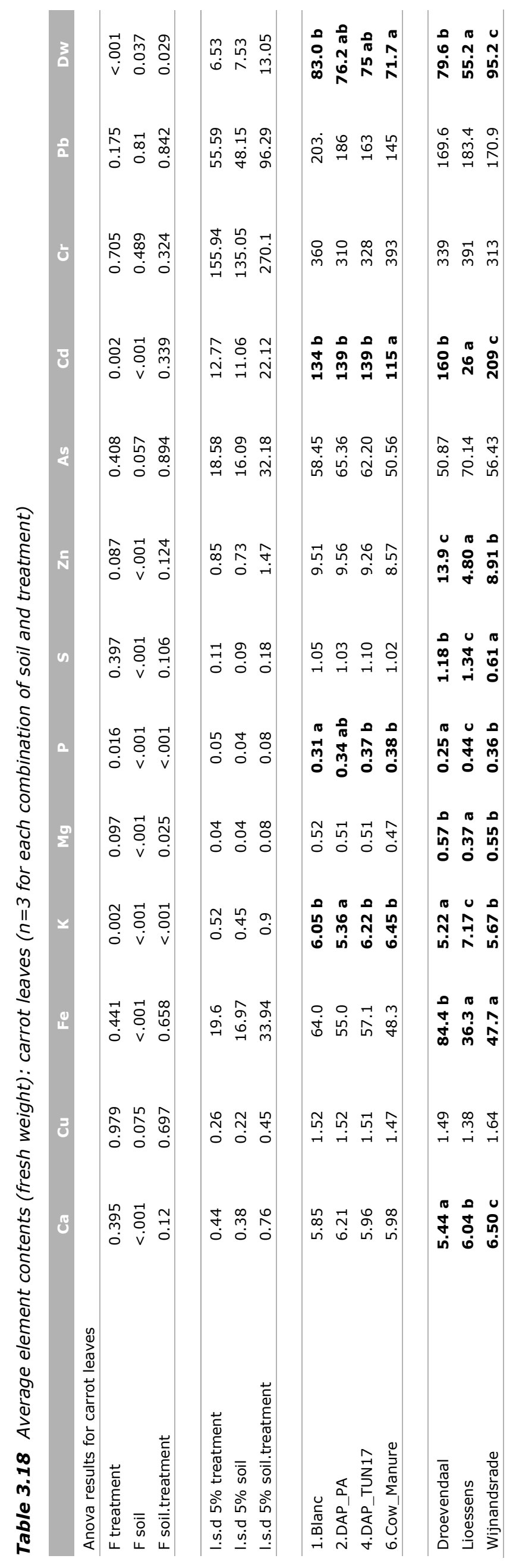




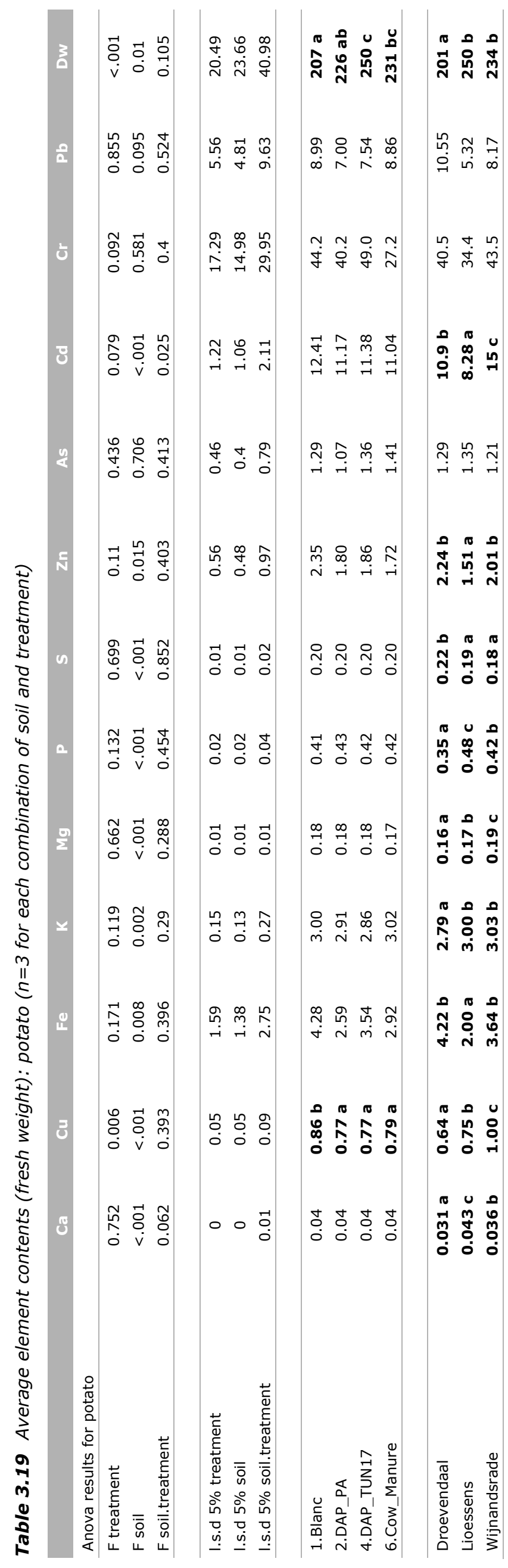




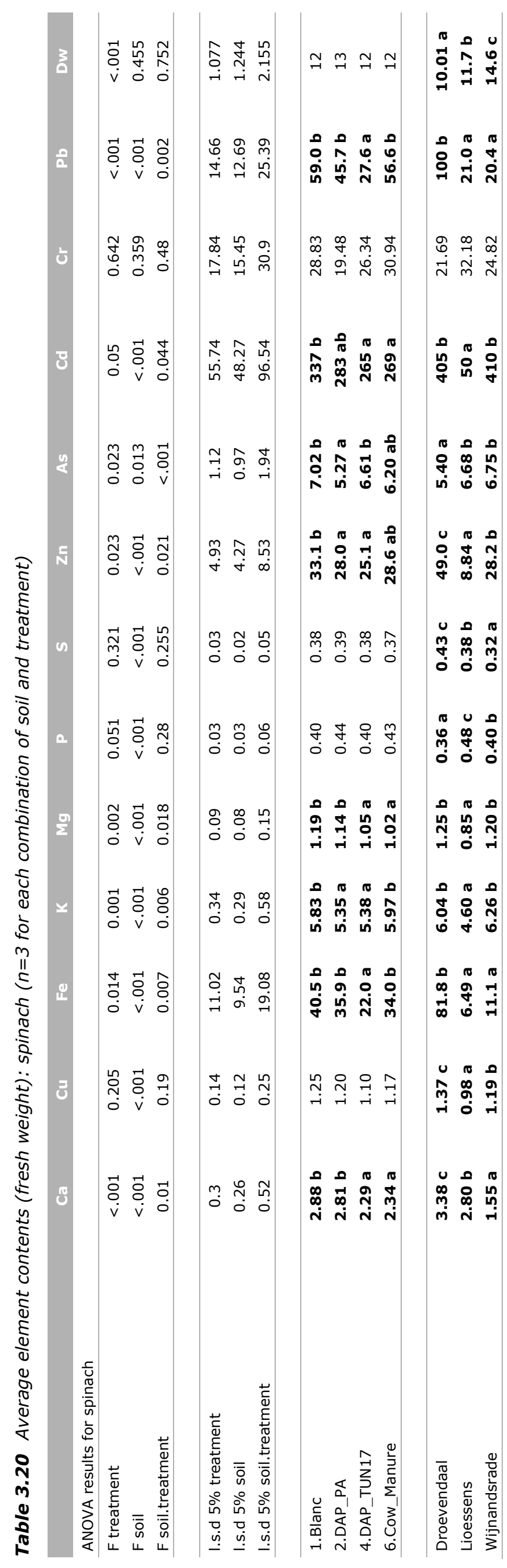


In Table 3.21 below, all significant differences from either treatment or soil are given per crop.

Table 3.21 Summary of significant changes due to either soil or treatment

\begin{tabular}{|c|c|c|c|c|c|c|c|c|c|c|c|c|c|}
\hline & $\mathrm{Ca}$ & $\mathrm{Cu}$ & $\mathrm{Fe}$ & $\mathbf{K}$ & $\mathrm{Mg}$ & $\mathbf{P}$ & $s$ & $\mathrm{Zn}$ & As & Cd & $\mathrm{Cr}$ & $\mathrm{Pb}$ & Dw \\
\hline \multicolumn{14}{|c|}{ TREATMENT } \\
\hline Barley grain & & $x$ & $x$ & & & & & & & & & & \\
\hline Carrot & & & & & & $x$ & & & & & $x$ & & $x$ \\
\hline Carrot - Leaves & & & & $x$ & & $x$ & & & & $x$ & & & $x$ \\
\hline Spinach & $x$ & $x$ & $x$ & & & & & $x$ & $x$ & $x$ & $x$ & $x$ & $x$ \\
\hline \multicolumn{14}{|l|}{ SOIL } \\
\hline Barley grain & $x$ & $x$ & $x$ & & $x$ & $\mathrm{X}$ & $x$ & $x$ & $x$ & $x$ & & & $x$ \\
\hline Potato & $x$ & $x$ & $x$ & $x$ & $x$ & $x$ & $x$ & $x$ & & $x$ & & & $x$ \\
\hline Spinach & $x$ & $x$ & $x$ & $x$ & $x$ & $x$ & $x$ & $x$ & & $x$ & & & $x$ \\
\hline
\end{tabular}

The data in Table 3.14 show that the effect of soil on the uptake of metals and nutrients is more prominently visible in the data obtained in 2017. Even at relatively low metal levels in the soils used here (polluted soils were excluded in 2017), differences in $\mathrm{pH}$, clay content and organic matter content are such that uptake from the Wijnandsrade soil often is higher compare to that of Droevendaal followed by Lioessens. It should be noted however that although these reported differences are significant, they are also small and the order of uptake is also not always consistent.

For most crops, differences due to the treatment are not significant for most metals. Spinach, however, appears to be the crop most sensitive for the treatments with reported differences for most metals. There is however no single trend, with $\mathrm{Cd}$ uptake being the highest in the blanc treatment, As and $\mathrm{Pb}$ in the manure treated pots and $\mathrm{Cr}$ uptake in the PhosAgro DAP treated pots.

When considering specific differences between the low and high Cd fertilisers used in 2017, differences for all crops used here are minor and inconsistent. For Cd and Zn measured crop levels in barley straw are marginally higher in the pots treated with the Tunesian DAP compared to those treated with the PhosAgro DAP. On the other hand, levels of $\mathrm{Cd}$ and $\mathrm{Pb}$ in spinach are higher in the pots treated with the PhosAgro DAP compared to those treated with the Tunesian DAP. The main conclusion from this ANOVA analyses therefore is that there is no consistent difference for specific metals when using the low or high Cd fertiliser on a short term.

Compared to 2016, the soils used in the 2017 experiments can be considered non-polluted and representative for the range in Cd levels in normal arable soils across the EU. The Lioessens soil was added to represent low Cd soils ( $C d$-Lioessens $=0.08 \mathrm{mg} \mathrm{kg}^{-1}$ ) but even in this soil there is no effect of the added $\mathrm{Cd}$ via fertiliser on $\mathrm{Cd}$ uptake by the crops included here. This then leads us to conclude that the nul-hypothesis that Cd from fertilisers is more available on the short term is to be rejected. 


\subsection{Conclusions from greenhouse experiments 2016 and 2017}

The aim of the greenhouse experiments was to establish whether or not the content of contaminants present in mineral fertilisers and animal manure affect the chemical availability in soils and uptake by crops. The soils used here include a wide range in soils typically used for crop production in the Netherlands and as such also represent common arable soils across the EU as far as the range in soil properties is concerned (acidity, organic matter, clay content) including sandy, loamy and clay soils. Also the range in heavy metals present in the 7 selected soils is representative for both the NL and the EU when comparing the ranges with for example data from the European Geochemical Atlas (Reimann et al., 2014). Fertilisers used here also match those used in European agriculture. Aside from the lowCd fertilisers supplied by PhosAgro two additional types of DAP were used. In 2016 the DAP applied is representative for the average European DAP with a Cd content of approx. $42 \mathrm{mg} \mathrm{Cd} \mathrm{kg}{ }^{-1} \mathrm{P}_{2} \mathrm{O}_{5}$ whereas in 2017 the DAP applied contains $60 \mathrm{mg} \mathrm{Cd} \mathrm{kg}^{-1} \mathrm{P}_{2} \mathrm{O}_{5}$. In addition animal manure was used which also contained relatively low amounts of $\mathrm{Cd}$ at $8 \mathrm{mg} \mathrm{Cd} \mathrm{kg}{ }^{-1} \mathrm{P}_{2} \mathrm{O}_{5}$. Crops tested included barley, durum, lettuce, spinach, carrot and potato. Data for durum are however not available due to variety issues where a winter variety was used which did not ripen during the growing season.

\section{Results from soil tests}

Results from the soil tests in 2016 indicate that at normal to high (for arable soils) levels of Cd in soil, the total $\mathrm{Cd}$ pool in soil is sufficiently large so that differences in loading rates from fertilisers have no significant impact on the reactive (adsorbed) or available (soil solution) pool of metals in soils. For this reason a very low Cd soil was included in the 2017 experiments, a sandy soil which has been formed only during the last century after the polders were created in the northern parts of the Netherlands (Lioessens soil). As such Cd levels in this soil represent the lower limit of levels found in the Netherlands at $0.09 \mathrm{mg} \mathrm{kg}^{-1} \mathrm{Cd}$. Also for other elements including $\mathrm{Cu}, \mathrm{Zn}, \mathrm{Cr}$ and As total levels are low. For this specific soil, it was observed that the difference in load of Cd using a low- and high-Cd fertiliser, was detectable albeit that detected changes are minimal with a reported increase of Cd of $0.0048 \mathrm{mg} \mathrm{kg}^{-1}$. This small difference however is more than the amount of $\mathrm{Cd}$ added via fertiliser which, at the rates added to the pots corresponds to an equivalent amount of $0.0034 \mathrm{mg} \mathrm{kg}^{-1}$. This shows that annual changes, if detectable become significant only in soils with extremely low Cd levels as was the case for the Lioessens soil and even in that case, part of the increase cannot be explained from the fertilisers used but is merely a matter of variability between samples.

The conclusion from the soil tests for both 2016 and 2017 therefore when considering the availability of metals in soil, is that short term effects on bioavailability or reactivity due to differences in quality of either mineral or organic fertilisers is minimal to absent or cannot be related to the fertiliser quality.

The hypothesis that Cd (or other metals) present in fertilisers is more available than Cd already present in soil has to be rejected based on the outcome of the tests applied here.

\section{Results from crop tests}

Crops included in 2016 and 2017 represent major food crops including leafy vegetables (lettuce and spinach), bulb crops (potato) and root crops (carrot). Aside from these products that are consumed both processes and unprocessed also grain crops (barley) was grown. Clearly crop growth was enhanced when applying mineral $P$ fertiliser compared to the blanc soil receiving all but $P$ in a liquid form. Even though most of the soil have a good $P$ status, the absence of $P$ in the fertilization scheme leads to reduced crop growth, an effect that becomes even more pronounced in those soils with a lower $\mathrm{P}$ status like the Lottum soil. In some cases the use of mineral $\mathrm{P}$ fertiliser also resulted in an enhanced biomass production compared to soils treated with animal manure at the same $\mathrm{P}$ application rate, an effect that was more pronounced also in the soils with a lower $\mathrm{P}$ status like the Lottum and Droevendaal soil. This indicates that $\mathrm{P}$ from mineral fertiliser is more available at a short term 
compared to $\mathrm{P}$ added as organic manure. Differences in biomass production when comparing the different mineral $P$ fertilisers applied in 2016 and 2017 however reveals that there is no significant difference in crop performance. The presence of increasing amounts of metals like $\mathrm{Cd}, \mathrm{Cr}$ or $\mathrm{Pb}$ in any of the fertilisers tested has no effect on biomass production or dry matter content. This was also observed for the additional nutritional parameters including vitamins and beta-carotene which were analysed in 2016 in carrot and lettuce. Apparently the quality of the fertilisers used or the differences therein had no effect on the plant physiological processes that control the production of nutritional parameters.

The hypothesis that metals in fertilisers, in the range tested here, has an effect on crop performance (biomass production) or nutritional value, therefore has to be rejected.

Both nutrients and metals are taken up by plants from the soil solution. In some cases plants stimulate the uptake as is the case for micronutrients $\mathrm{Cu}$ and $\mathrm{Zn}$ whereas for others, plants tend not to accumulate metals in the above ground biomass an if so the majority is stored in leaves and straw and not in the reproductive parts. The latter is the case for metals like $\mathrm{Cr}$ and $\mathrm{Pb}$ which show higher values in (carrot) leaves compared to roots and to a lesser extent also in (barley) straw compared to grains.

Differences in metal uptake is pronounced both between crops as well as between soils with uptake increasing with increasing levels of metals in the soil. In addition, soil properties like $\mathrm{pH}$ have a clear effect on uptake via the impact on the availability. This largely explains the up to 10 times higher uptake of Cd by spinach from the Droevendaal soil compared to that of the Lioessens soil although the $\mathrm{Cd}$ content differs only by a factor of 2 . As such the levels of $\mathrm{Cd}$ taken up by crops from the soils included here could be explained well using the reactive $\mathrm{Cd}$ content and soil $\mathrm{pH}$ both of which explained between 72 and $98 \%$ of the observed variation of $\mathrm{Cd}$ in all crops.

However, there appears to be no significant effect of the quality of fertiliser, i.e. the metal content in the fertilisers used, on the uptake of metals or nutrients by crops. Apparently the difference in the availability of metals as controlled by the soil and its properties outweighs the additional amount of metals added via fertilisers. This also means that there is no experimental evidence that metals present in mineral fertilisers, within the range applied here, are more available than metals already present in the soil, even at very low levels as represented by the Lioessens soil.

The hypothesis that higher levels of metals in fertilisers lead to higher uptake by crops within one cropping cycle has to be rejected. 


\section{Dynamic Modelling of cadmium balances in arable soils: plot scale and regional assessment}

\subsection{Soil crop transfer models and scenarios used in the model calculations}

\subsubsection{Soil to crop transfer models for cadmium as derived from greenhouse experiment data 2016-2017}

Based on the results of the soil and crop analyses performed on the samples from the greenhouse experiments, soil to crop transfer models were derived. For carrot, data from 2016 and 2017 were combined since we used the same seeds (no cultivar effect). As is shown in Table 4.1, relationships between soil and crops were significant with a good to excellent explanatory capacity with $\mathrm{R}^{2}$ values ranging from 0.72 for potato to 0.98 for barley straw. For all crops the effect of soil Cd was the dominant factor explaining the difference in $\mathrm{Cd}$ uptake by crops with soil $\mathrm{pH}$ (for carrot, carrot leaves, and spinach) being the second most important factor. The effect of organic matter and clay (regression data not shown here) appeared not significant which is most likely due to the limited range in these soil properties (for organic matter) and the limited effect (for clay) in general. This was also true for $\mathrm{pH}$ in case of potato, barley, and, rather surprising lettuce. Usually Cd uptake by leafy crops also depends on $\mathrm{pH}$ but apparently the range in $\mathrm{pH}$ applied was such that this did not affect uptake by lettuce in a significant way. This clearly also shows the limitations of the models derived here which cannot be applied freely to all soils with properties far outside the range as present in the soils used in the experiments. However the models can (and will) be used in the plot level calculations to assess long term impact of inputs of Cd to soils via fertilisers (see paragraph 4.2).

Table 4.1 Model coefficients for the soil-crop models based on experimental data in 2016 and 2017

\begin{tabular}{|c|c|c|c|c|c|c|c|}
\hline Model coefficients ${ }^{1}$ & Carrot & Carrot leaves & Potato & Barley Grain & Barley Straw & Lettuce & Spinach \\
\hline INT & 4.60 & 5.05 & 2.11 & 2.78 & 3.56 & 3.41 & 6.45 \\
\hline Cd-soil & 0.50 & 0.57 & 0.37 & 1.10 & 1.26 & 0.49 & 0.97 \\
\hline $\mathrm{R}^{2}$ & 0.85 & 0.89 & 0.72 & 0.95 & 0.98 & 0.76 & 0.97 \\
\hline $\operatorname{se}(Y)$ & 0.15 & 0.14 & 0.06 & 0.07 & 0.05 & 0.15 & 0.07 \\
\hline \multicolumn{8}{|l|}{ General Data Used } \\
\hline Biomass (ton DM/ha/yr) & 5.66 & 1.51 & 5.73 & 3.87 & 3.61 & 1.28 & 1.25 \\
\hline Biomass (ton FM/ha/yr) & 37.72 & 7.54 & 24.92 & 4.30 & 4.30 & 20.58 & 14.20 \\
\hline $\mathrm{P}$ application rate $(\mathrm{kg} \mathrm{P} / \mathrm{ha} / \mathrm{yr})$ & 35 & 0 & 100 & 30 & 0 & 35 & 35 \\
\hline
\end{tabular}

${ }^{1}$ INT = intercept of regression model; $\mathrm{Cd}$-soil is defined by the total available amount, as determined using $\mathrm{Cd}\left(\mathrm{HNO}_{3}\right)$

using microsoft excel regression analysis, $R^{2}, s e(Y), F$ are respectively: coefficient of determination, standard error for $y$, the $F$ observed value 


\subsubsection{Scenarios}

In all three assessments a range in scenarios are included, that is, crop Cd levels are predicted for the following scenarios. For each of the scenarios listed below Cd levels in crops are calculated either at time zero (current situation) and after 100 years.

1. Plot level simulations (par 4.2): in these calculation it is assumed that specific crops are grown on a specific field with soil properties equal to those of the soils used in the greenhouse experiments. This enables us to use the soil-crop transfer relationships as derived in this study since these are explicitly valid for the soils from the study. Application of the relationships for the same soils and crops as used in the greenhouse experiments prevents extrapolation of such equation to soils for which they have not been validated. Levels of $\mathrm{Cd}$ in fertiliser as well as application rates as assumed to valid for the simulation period are the same as those used in the greenhouse experiment in 2016 and 2017.

2. Regional assessment (par. 4.3 and Chapter 5): in the regional assessments assumptions regarding the $\mathrm{Cd}$ content in fertilisers are based on the current situation (current levels of $\mathrm{Cd}$ in mineral $\mathrm{P}$ fertilisers as used in the EU), called here the Business as Usual scenario ( $\mathrm{BaU})$. In addition, 5 scenarios are included that calculate regional changes in soil and crop Cd at different (fixed) levels of $\mathrm{Cd}$ in mineral $\mathrm{P}$ fertilisers which are partly based on the proposed revision of EU2003/2003 and 2 additional scenarios:

a. Cd-20: maximum allowed $\mathrm{Cd}$ level in mineral $\mathrm{P}$ fertiliser of $20 \mathrm{mg} \mathrm{Cd} \mathrm{kg}{ }^{-1} \mathrm{P}_{2} \mathrm{O}_{5}$

b. Cd-40: maximum allowed $\mathrm{Cd}$ level in mineral $\mathrm{P}$ fertiliser of $40 \mathrm{mg} \mathrm{Cd} \mathrm{kg} \mathrm{m}^{-1} \mathrm{P}_{2} \mathrm{O}_{5}$

c. Cd-60: maximum allowed $\mathrm{Cd}$ level in mineral $\mathrm{P}$ fertiliser of $60 \mathrm{mg} \mathrm{Cd} \mathrm{kg}{ }^{-1} \mathrm{P}_{2} \mathrm{O}_{5}$

d. In addition a scenario is added where $\mathrm{Cd}$ in $\mathrm{P}$ fertiliser is set at zero $(\mathrm{Cd}-0)$ and at $80 \mathrm{mg} \mathrm{Cd}$ $\mathrm{kg}^{-1} \mathrm{P}_{2} \mathrm{O}_{5}(\mathrm{Cd}-80)$ a value also included in the discussions.

In par 4.3 and Chapter 5 the Integrator model is used to calculate changes in soil and crop Cd levels. The Integrator model is capable of calculating changes at a regional level (NCU levels) which then can be upscaled to country or even EU level. The advantage of this approach is that, as far as data allow, regional differences in soil type, $\mathrm{Cd}$ level in soil, land use, climate and manure distribution are accounted for. At present it is the only regionally explicit model at EU level available.

\subsection{Plot level simulations}

\subsubsection{Assumptions and data used}

For the soils used in the experiment, long term changes in the soil and crop Cd content were calculated using a simplified model as is used in the regional assessment. During a period of 100 years inputs from fertiliser, atmosphere and manure is considered. It was assumed here that biosolids were not applied. Outputs including leaching and crop uptake were calculated using the soil-solution model (leaching) that takes into account the $\mathrm{Cd}$ content of the soil, $\mathrm{pH}$, organic matter content and clay. Soil properties were kept constant throughout the simulation period. Removal (or addition) from and to soil were calculated at an annual basis and added (or subtracted) from the initial pool of $\mathrm{Cd}$ in soil considering a soil depth of $20 \mathrm{~cm}$.

In Table 4.2 an overview of the soil properties and initial $\mathrm{Cd}$ content (at $\mathrm{t}=0$ ) are listed. Table 4.1 shows the soil - crop relationships as well as the default values for crop production (based on EU average values according to FAO stat, http://www.fao.org/faostat/en/\#data/QC), conversion factor for dry weight to fresh weight (based on the experimental data from the greenhouse study) and the annual $\mathrm{P}$ application rate based on legal criteria as listed by Amery and Schoumans (2014). In the calculations the measured $\mathrm{pH}$ (average from all pots per soil) was used in combination with the (measured) data on organic matter, clay and $\mathrm{Cd}$ content in soil. For both barley and carrot it was assumed that the total biomass produced (including straw and leaves) were removed from the soil. The biomass production for leaves and straw were derived from the measured ratio in the greenhouse experiment (ratio carrot:leaves $=5: 1$ on fresh weight, ratio grain:straw $=1: 1$ fresh weight). In total 4 simulations per soil/crop experiment were done 
including the low Cd fertiliser (used in 2016 and 2017), medium Cd fertiliser (used in 2016), high Cd fertiliser (used in 2017) and animal manure (used both in 2016 and 2017).

Here results for spinach, potato and barley are included, results for lettuce and carrot are very similar to those of spinach (data not shown here).

Table 4.2 Overview of soil and crop properties used in the plot level simulations

\begin{tabular}{lccccccc} 
& type & $\mathrm{pH}$ & $\mathrm{pH} \mathrm{CaNO}_{3}{ }^{1}$ & $\begin{array}{c}\mathrm{SOM} \\
(\%)\end{array}$ & $\begin{array}{c}\text { Clay } \\
(\%)\end{array}$ & $\begin{array}{c}\mathrm{Cd} \mathrm{HNO}_{3}{ }^{1} \\
\left(\mathrm{mg} \mathrm{kg}^{-1}\right)\end{array}$ & $\begin{array}{c}\mathrm{Cd}-\text { total } \\
\left(\mathrm{mg} \mathrm{kg}^{-1}\right)\end{array}$ \\
\hline Droevendaal & sand & 6 & 6.1 & 4.4 & 3.3 & 0.19 & 0.2 \\
\hline Cranendonck & sand & 5.4 & 5.5 & 3.8 & 3.1 & 0.46 & 0.49 \\
\hline Wijnandsrade & loam & 6.6 & 6.8 & 4.3 & 13.4 & 0.39 & 0.56 \\
\hline Epen & loam & 6 & 6.4 & 5.9 & 9.3 & 5.52 & 6.33 \\
\hline Grebbedijk & clay & 7.3 & 7.9 & 5.6 & 31.7 & 0.32 & 0.46 \\
\hline Lottum & loamy clay & 6.5 & 6.9 & 6.8 & 16 & 3.22 & 4.22 \\
\hline Lioessens & sand & 7.1 & 7.6 & 1.1 & 5 & 0.09 & 0.1 \\
\hline
\end{tabular}

${ }^{1}$ value based on the average of all measurements per soil in the greenhouse experiment. This value was used in the calculations

Results of plot level simulations for potato, spinach and barley

In Table 4.3 the predicted changes in soil $\mathrm{Cd}$ are given at $\mathrm{t}=100$ years for the 7 soils used in the study and 3 crops (Potato, Spinach and Barley). In Figure 4.1 the relative changes are plotted to compared changes between soils. Here the abbreviations 'Low', 'Medium' and 'High' are used for the 3 types of fertiliser applied in the greenhouse experiments respectively corresponding to the PhosAgro (no $\mathrm{Zn}$ ) fertiliser, the regular DAP used in 2016 and the DAP from Tunesia used in 2017 (data presented in Table 3.2). For 'Animal Manure' the data from the cow manure used in both 2016 and 2017 were used.

Table 4.3 Predicted changes in soil Cd at $t=100$ years assuming a 100 year crop production

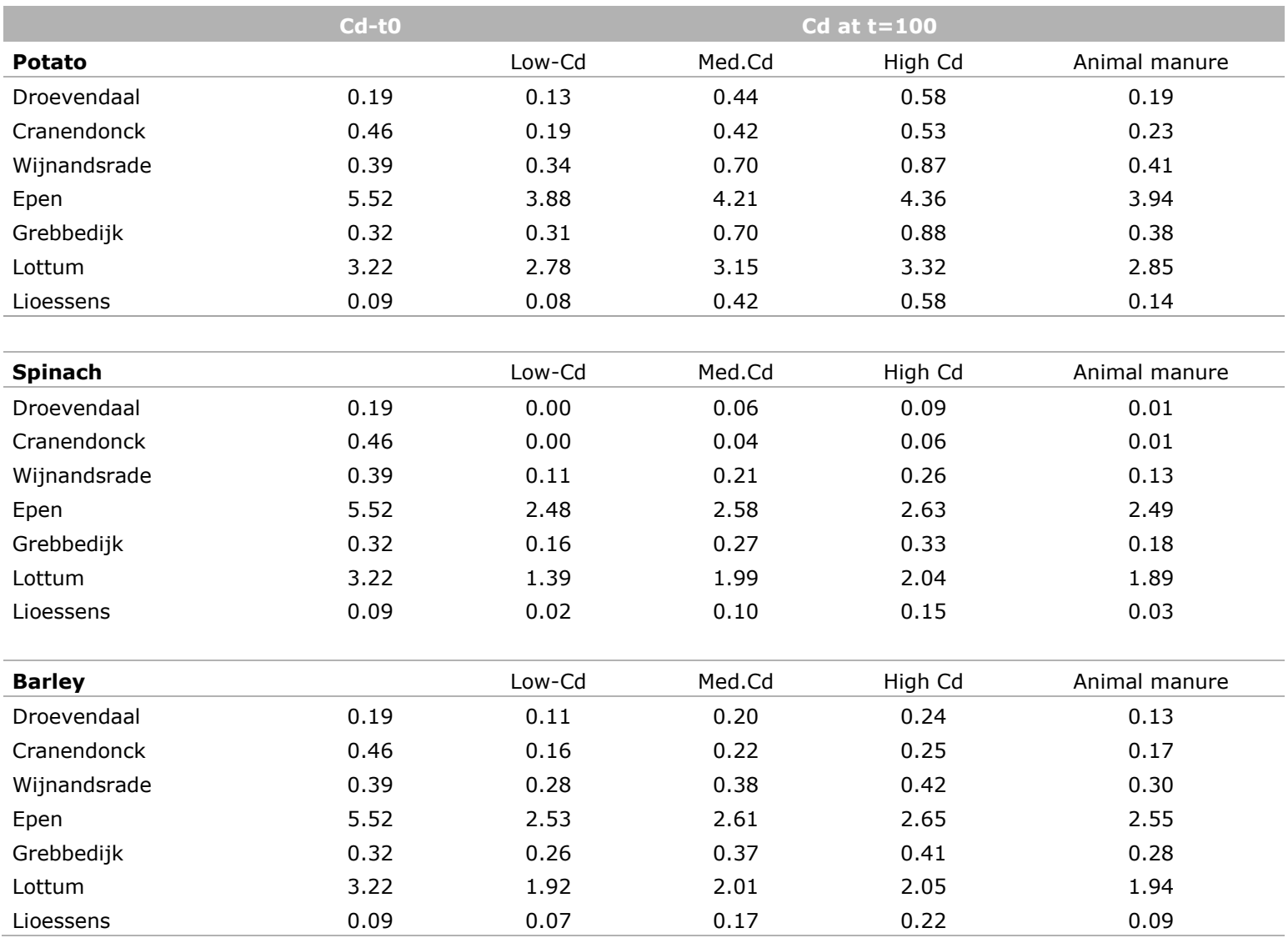



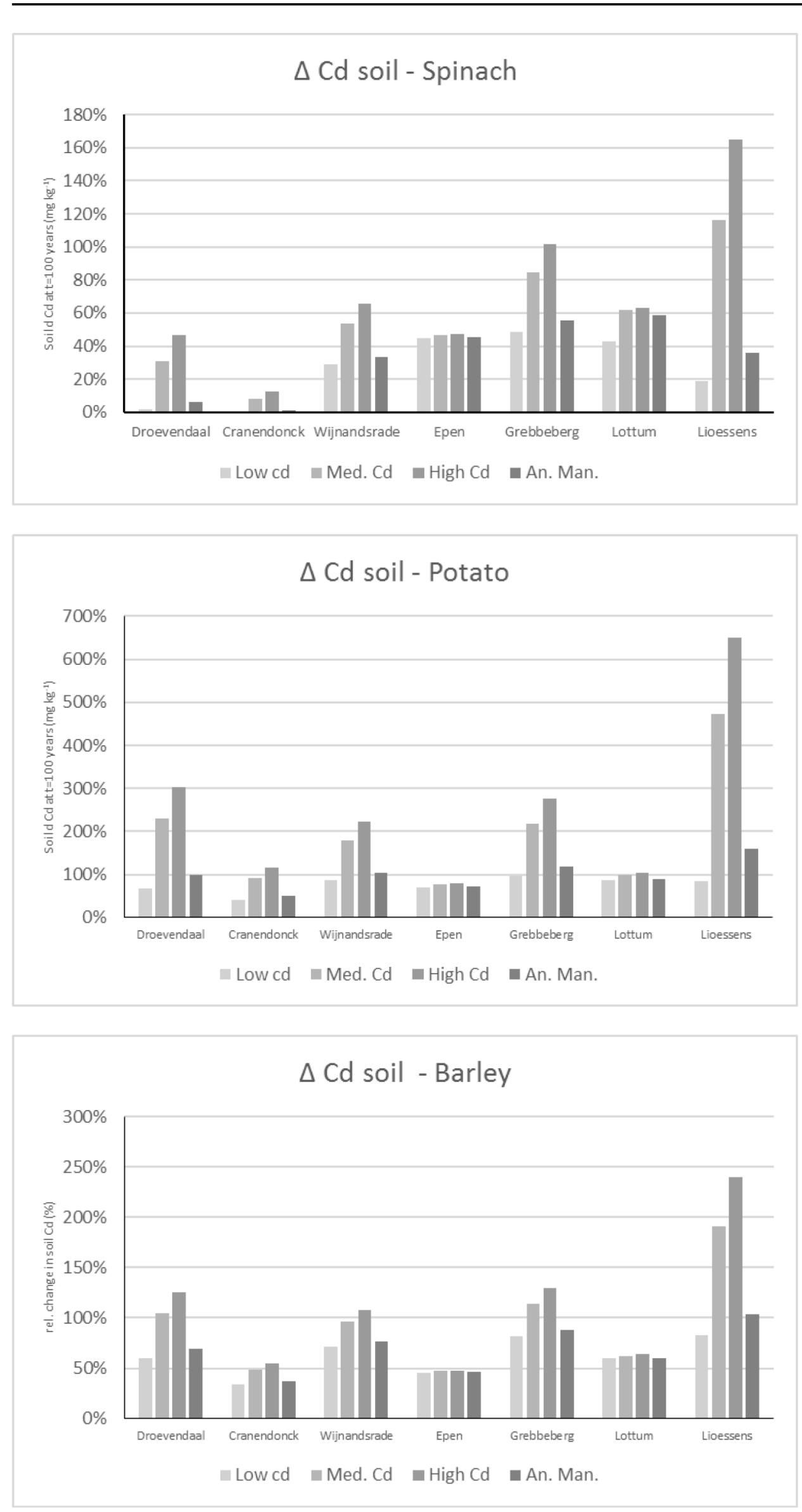

Figure 4.1 Predicted absolute changes in soil Cd for the soils used in the greenhouse study at $t=100$ for the 4 types of fertiliser for spinach (top), potato (middle) and barley (bottom) 
Table 4.4 Predicted changes in crop Cd at $t=100$ years assuming a 100 year crop production (values in italic are to be considered not reliable since these are beyond the application range of the model). Data in $\mathrm{mg} \mathrm{kg}^{-1} \mathrm{FM}$

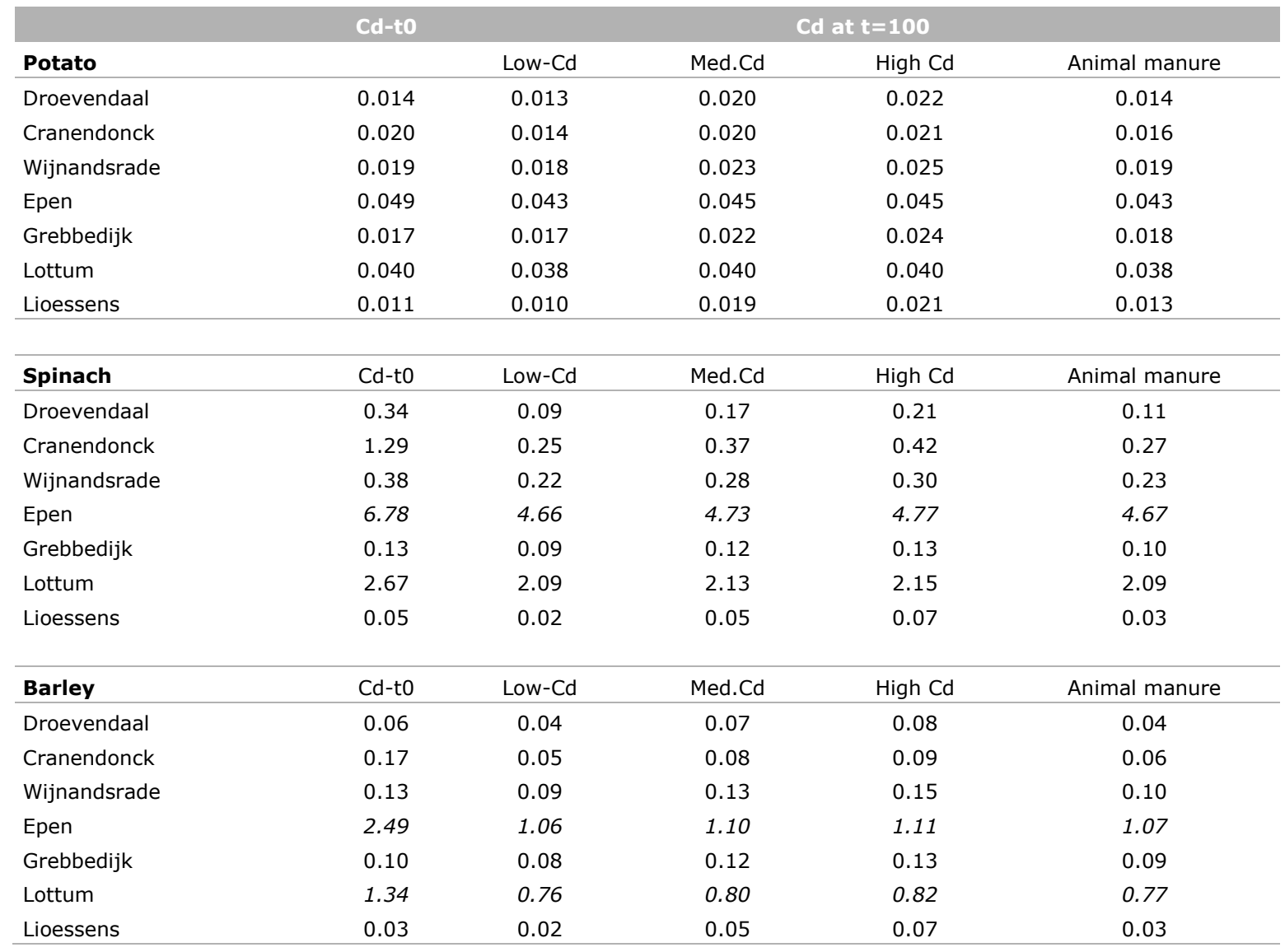

In Figure 4.2 the predicted relative changes in the crop Cd content are shown for all soils. For the more polluted soils (Lottum and Epen), the absolute predicted levels are less relevant since these are outside the range of data upon which the model is based. 

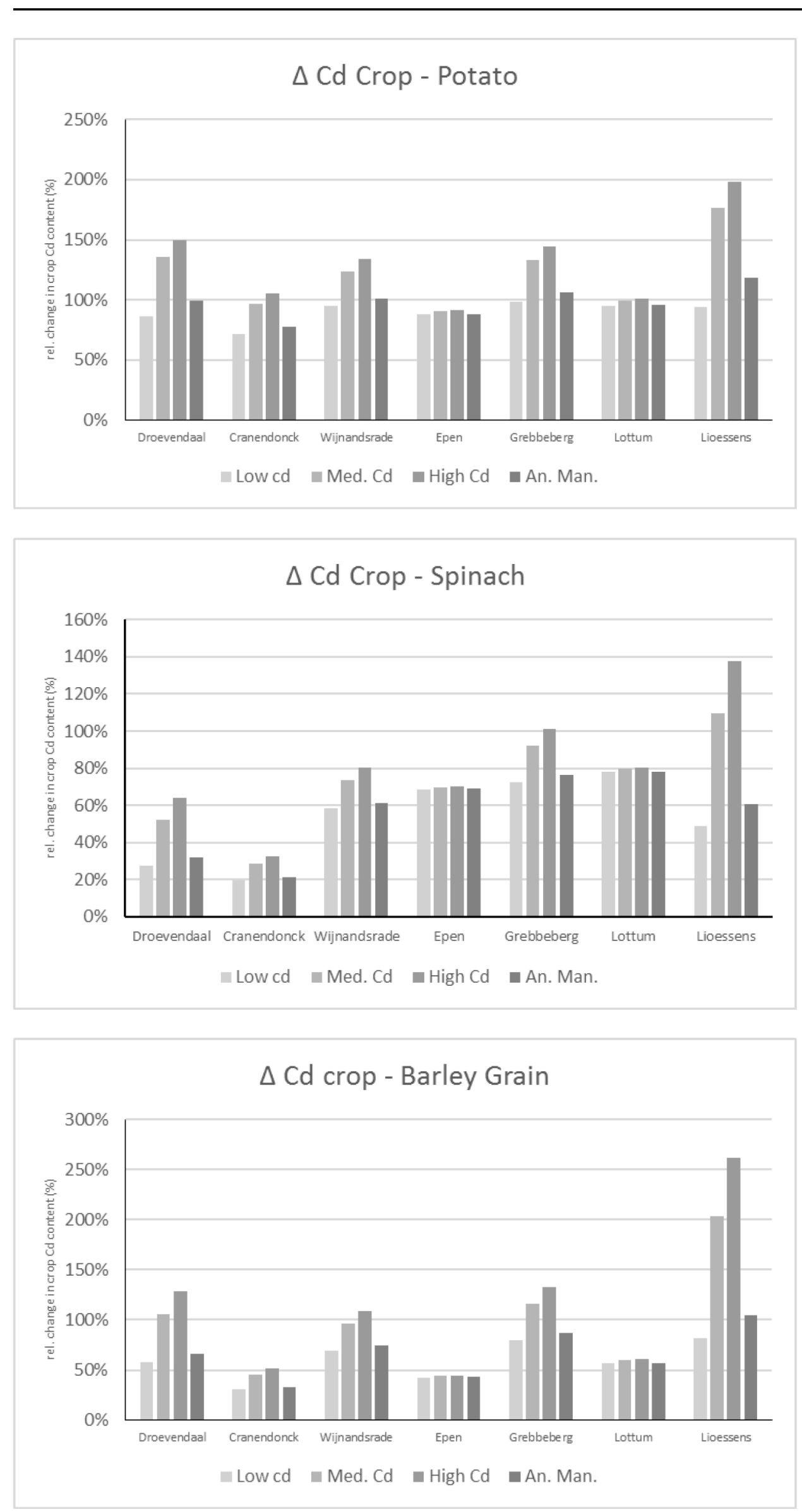

Figure 4.2 Predicted relative changes in crop Cd for potato (top), spinach (middle) and barley grain (bottom) for all soils included in the greenhouse study 


\subsubsection{Summary and conclusions of results from predictions at plot level}

The simulation results indicate that in medium (Lottum) to high polluted soils (Epen) the quality of fertiliser is almost irrelevant when considering the high amount of Cd already in the soil. Even after 100 years differences between treatments in the Cd levels in either the Lottum or Epen soil are small and dynamics of $\mathrm{Cd}$ in soil are largely controlled by leaching losses.

On the other hand, the effect of the level of $\mathrm{Cd}$ in fertiliser as applied here is very strong in the low Cd soils, notably in the Lioessens and Droevendaal soil where changes in soil Cd are significant, the magnitude of the effect depending on both the crop type and soil properties.

- In case of crops that accumulate relatively high amounts of $\mathrm{Cd}$, in this case spinach, soil Cd levels largely decrease due to leaching losses and uptake by crop. In 6 out of 7 soils the soil Cd content decreases even when using high Cd fertilisers, the rate of the decrease being more pronounced when applying low-Cd fertilisers or manure compared to those treatments using medium or high-Cd fertilisers. Only in the Lioessens the use of the high $\mathrm{Cd}$ fertiliser would lead to an $60 \%$ increase with time where the use of low-Cd fertiliser would result in a $80 \%$ decrease of the soil Cd content.

- For crops that are less specific in accumulating $\mathrm{Cd}$ from soil, such as potato, changes in the soil Cd are moderate. Again, changes in the low Cd soils are more pronounced. In the Lioessens soil, characterized by a low $\mathrm{Cd}$ content and high $\mathrm{pH}$, inputs to soil (without considering fertilisers) and outputs are close to equilibrium resulting in a near equilibrium when using the low-Cd fertiliser. In this soil, most of the $\mathrm{Cd}$ is retained in the topsoil and in case of low to medium crop removal rates, Cd levels in soil can increase markedly as is shown for potato.

- Grain crops like barley show an in-between pattern with close to zero net changes in the soil Cd level when applying medium to high Cd fertilisers and a clear decrease in the soil Cd level when using the zero-Cd fertiliser.

These simulation show that the resulting change in soil $\mathrm{Cd}$ strongly depends on both the initial conditions in soil. Based on the plot simulations it can be concluded that for most low Cd soils (Cd < 0.1 to $0.15 \mathrm{mg} / \mathrm{kg}$ ) the use of low-C fertilisers (or manure) as used here will lead to decrease (for vegetables) or close to stand still situation (potato/grain) of Cd in soil, whereas the use of mediumand high Cd fertilisers will lead to a marked increase in the soil Cd level.

In soils that represent the 'normal' $\mathrm{Cd}$ status ( $\mathrm{Cd}$ ranging from 0.2 to $0.5 \mathrm{mg} / \mathrm{kg}$ ) changes in soil $\mathrm{Cd}$ appear more modest or at equilibrium, although the use of medium to high-Cd fertilisers tends to result in an increase of $\mathrm{Cd}$ in soil in the order of 10 to $30 \%$ for potato and up to $100 \%$ for barley. For leafy vegetables on the on the hand removal rates (via leaching and crop uptake) are more substantial and $\mathrm{Cd}$ level in soils generally decrease regardless of the quality of fertilisers used.

In Table 4.5 the average relative changes per crop across all soils is given to more or less simulate the average effect considering all soils (assuming they are representative). Here the results from the medium to high polluted soils were not included since these are not likely to be used for crop production.

Table 4.5 Average relative change at $t=100$ (expressed as fraction of the amount at time 0 ) in soil Cd per crop across all soils

\begin{tabular}{|c|c|c|c|c|}
\hline \multirow[t]{2}{*}{ crop } & \multicolumn{4}{|c|}{ Fertiliser used } \\
\hline & low $\mathrm{Cd}$ & medium $\mathrm{Cd}$ & high Cd & animal manure \\
\hline Potato & 0.75 & 2.39 & 3.13 & 1.07 \\
\hline Barley & 0.68 & 1.11 & 1.32 & 0.75 \\
\hline
\end{tabular}


Changes in the Cd content in crops are less pronounced as those in soil. This is partly due to that fact that, for lettuce, carrot and potato the Cd content in the crop does not linearly depend on the $\mathrm{Cd}$ content in the soil when using the non-linear models derived from the data in this study. For barley and lettuce, the coefficient in the soil to crop transfer model is close to one which would suggest that the uptake by crop increases almost linear with that in soil.

As for soil, the average changes per crop are listed in Table 4.6.

Table 4.6 Average relative change at $t=100$ (expressed as fraction of the amount at time 0 ) in crop cd levels across all soils (high Cd soils were removed)

\begin{tabular}{|c|c|c|c|c|}
\hline crop change & Low Cd & Medium Cd & High Cd & Animal manure \\
\hline Potato & 0.89 & 1.33 & 1.46 & 1.01 \\
\hline Spinach & 0.45 & 0.71 & 0.83 & 0.50 \\
\hline All & 0.66 & 1.06 & 1.22 & 0.75 \\
\hline
\end{tabular}

Results in Table 4.6 show that on average a 34\% reduction in Cd levels in food crops can be achieved after 100 years when using low-Cd P-fertilisers. As shown in Figure 4.2 the magnitude of this change is variable depending on soil conditions and crop type; experimental results show that the effect is more prominent in leafy vegetables compare to potato for example. The use of animal manure, on average also leads to lower net Cd levels in crops whereas the high Cd fertiliser results in, on average $22 \%$ higher Cd levels in crop even though for specific crops (like leafy vegetables) Cd uptake can decrease as well despite the higher inputs of $\mathrm{Cd}$ to soil.

The use of the medium high-Cd P fertiliser would result in a small increase in crop Cd levels. This outcome is very much in line with the regional modelling results at EU level as presented in chapter 5. As it is, the Cd level in the medium-Cd fertilisers used in the experiment is close to the average quality of mineral $P$ fertilisers used at present in the EU and results from the BaU scenario at the EU level (see also Chapter 5) are in line with the predicted changes in Cd levels in crops in this section (Table 4.6). 


\subsection{Impact at EU level: effect of fertiliser quality on Cd levels in potato, wheat and lettuce}

For all NCU plots (approx. 23000 combinations of soil, climate, land use) the predicted final Cd content in soil were used to calculate the Cd levels in the three selected crops (summarized in Table 4.7). Here, results are shown for the $\mathrm{Cd}-0$ to $\mathrm{Cd}-80$ scenario as calculated with Integrator during a time period of 100 years. This results in a series of predicted Cd levels in soil. From these, levels of Cd in the selected crops (here potato, wheat and lettuce) are calculated using the soil Cd levels and soil properties of the NCU unit. In Table 4.7 and Figure 4.3 the predicted absolute levels of Cd in soil and crop are listed. As can be seen from the tables the predicted range ( $\min$ - max) is quite large, but when looking at the 5 to 95 percentile results suggest that changes in soil $\mathrm{Cd}$ are moderate even though the conclusion is clear in that $\mathrm{Cd}$ will accumulate in most soils, and a substantial reduction of the Cd supply to soil is needed to reach stand still. Based on these data, equilibrium of Cd in soil only is achieved if supply of Cd via fertilisers is reduced to zero. This is illustrated as well in Figure 4.3 where the average relative changes of $\mathrm{Cd}$ in crops is shown for the 6 scenarios (BaU, $\mathrm{Cd}-0$ to $\mathrm{Cd}-80$ ) compared to current levels of $\mathrm{Cd}$ in crops. Since the crop levels in this case are calculated using a BCF, the relative changes are similar for all crops included here. As was shown in the previous paragraph, crop response to changes in soil $\mathrm{Cd}$ is variable even though the predicted median (50\%) changes in crop Cd levels do correspond quite well with average values based on plot level calculations (Table 4.6).

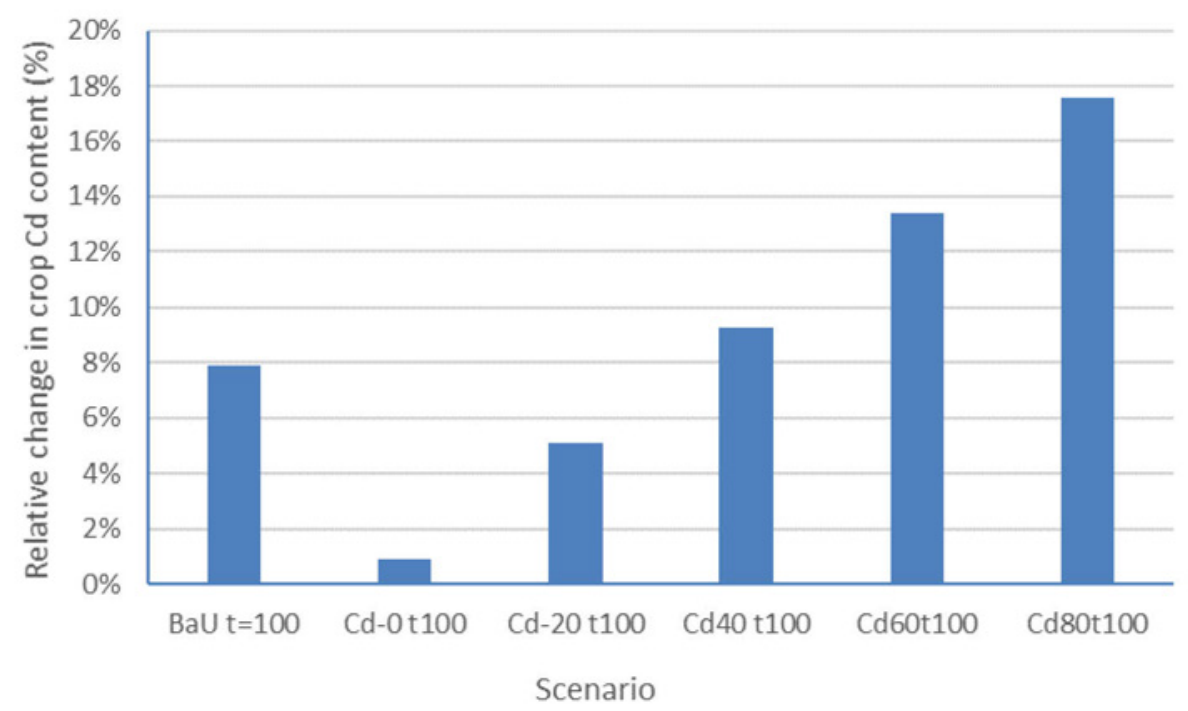

Figure 4.3 Relative increase in Cd crop levels for all scenario's included 
Table 4.7 Overview of predicted changes on Cd in soil, potato, lettuce and wheat (scenario's see $\S 4.1 .2)$

\begin{tabular}{|c|c|c|c|c|c|c|c|}
\hline \multicolumn{8}{|c|}{ Cd in soil } \\
\hline Percentile & $\mathrm{BaU} t=0$ & $\mathrm{BaU} t=100$ & Cd-0 t100 & Cd-20 t100 & $\mathrm{Cd} 40 \mathrm{t} 100$ & Cd60t100 & Cd80t100 \\
\hline minimum & 0.03 & 0.03 & 0.04 & 0.04 & 0.03 & 0.02 & 0.02 \\
\hline $1 \%$ & 0.07 & 0.10 & 0.08 & 0.09 & 0.10 & 0.11 & 0.12 \\
\hline $5 \%$ & 0.12 & 0.15 & 0.13 & 0.14 & 0.15 & 0.15 & 0.16 \\
\hline $25 \%$ & 0.22 & 0.24 & 0.23 & 0.24 & 0.25 & 0.25 & 0.26 \\
\hline $50 \%$ & 0.27 & 0.29 & 0.28 & 0.29 & 0.30 & 0.31 & 0.32 \\
\hline $75 \%$ & 0.36 & 0.37 & 0.35 & 0.36 & 0.37 & 0.38 & 0.39 \\
\hline $95 \%$ & 0.51 & 0.50 & 0.48 & 0.49 & 0.50 & 0.51 & 0.53 \\
\hline $99 \%$ & 0.65 & 0.62 & 0.60 & 0.62 & 0.63 & 0.64 & 0.65 \\
\hline maximum & 1.36 & 3.05 & 1.80 & 2.33 & 3.40 & 4.45 & 5.44 \\
\hline
\end{tabular}

\begin{tabular}{|c|c|c|c|c|c|c|c|}
\hline \multicolumn{8}{|c|}{ Cd in Potato } \\
\hline $1 \%$ & 0.03 & 0.04 & 0.03 & 0.04 & 0.04 & 0.04 & 0.05 \\
\hline $25 \%$ & 0.09 & 0.10 & 0.09 & 0.09 & 0.10 & 0.10 & 0.11 \\
\hline $50 \%$ & 0.11 & 0.12 & 0.11 & 0.11 & 0.12 & 0.12 & 0.13 \\
\hline $95 \%$ & 0.20 & 0.20 & 0.19 & 0.20 & 0.20 & 0.21 & 0.21 \\
\hline $99 \%$ & 0.26 & 0.25 & 0.24 & 0.25 & 0.25 & 0.26 & 0.26 \\
\hline maximum & 0.54 & 1.22 & 0.72 & 0.93 & 1.36 & 1.78 & 2.18 \\
\hline
\end{tabular}

\begin{tabular}{|c|c|c|c|c|c|c|c|}
\hline \multicolumn{8}{|c|}{ Cd in Lettuce } \\
\hline minimum & 0.08 & 0.07 & 0.09 & 0.10 & 0.07 & 0.06 & 0.06 \\
\hline $1 \%$ & 0.18 & 0.25 & 0.20 & 0.23 & 0.25 & 0.27 & 0.29 \\
\hline $25 \%$ & 0.55 & 0.60 & 0.57 & 0.59 & 0.61 & 0.63 & 0.66 \\
\hline $50 \%$ & 0.68 & 0.73 & 0.69 & 0.71 & 0.74 & 0.76 & 0.79 \\
\hline $95 \%$ & 1.28 & 1.25 & 1.20 & 1.23 & 1.26 & 1.29 & 1.32 \\
\hline $99 \%$ & 1.63 & 1.55 & 1.51 & 1.54 & 1.57 & 1.60 & 1.64 \\
\hline maximum & 3.40 & 7.62 & 4.49 & 5.82 & 8.50 & 11.12 & 13.60 \\
\hline
\end{tabular}

\begin{tabular}{|c|c|c|c|c|c|c|c|}
\hline \multicolumn{8}{|c|}{ Cd in Wheat } \\
\hline $1 \%$ & 0.01 & 0.02 & 0.01 & 0.02 & 0.02 & 0.02 & 0.02 \\
\hline $25 \%$ & 0.04 & 0.04 & 0.04 & 0.04 & 0.04 & 0.05 & 0.05 \\
\hline $50 \%$ & 0.05 & 0.05 & 0.05 & 0.05 & 0.05 & 0.05 & 0.06 \\
\hline $95 \%$ & 0.09 & 0.09 & 0.09 & 0.09 & 0.09 & 0.09 & 0.09 \\
\hline $99 \%$ & 0.12 & 0.11 & 0.11 & 0.11 & 0.11 & 0.12 & 0.12 \\
\hline maximum & 0.24 & 0.55 & 0.32 & 0.42 & 0.61 & 0.80 & 0.98 \\
\hline
\end{tabular}

To assess to what extent these calculated changes in crop Cd levels would lead to an exceedance of food quality criteria, all predicted Cd concentrations for the scenarios were compared to the current Cd food quality criteria. For Cd these range between $0.1 \mathrm{mg} \mathrm{kg}^{-1}$ (fresh weight) for potato to $0.2 \mathrm{mg} \mathrm{kg}^{-1}$ for lettuce and wheat ((EG) nr. 1881/2006). As such the absolute area where crop quality standards are exceeded are very small (the total number of NCU equals 23361 units). In Table 4.8 the total number of NCU areas (out of 23000) where Cd levels in crops are predicted to exceed current food quality criteria at $\mathrm{t}=100$ years are listed for the most extreme scenarios and the business as usual scenario. 
These data show that as such food quality standards are exceeded in a minor number of plots only, ranging from 2 for wheat and lettuce to 8 for potato in case of the $\mathrm{Cd}-0$ scenario. This number increases to 12 (Lettuce) to 14 (for wheat) and 20 for potato in case of the Cd-80 scenario. This shows that although the average content of Cd in crops increases (Figure 4.3), the area where food quality criteria are exceeded remains very small.

Table 4.8 Number of spatial units where Cd in crops is predicted to exceed the food quality criteria at $t=100$ years

\begin{tabular}{lccc} 
& Scenario & BaU -0 & Cd-80 \\
Crop & & & 17 \\
\hline Potato & 8 & 7 & 20 \\
\hline Lettuce & 2 & 9 & 12 \\
\hline Wheat & 2 & 14 \\
\hline
\end{tabular}

Aside from an absolute evaluation of Cd levels in crops relative to the food quality criteria the absolute number of NCU plots where Cd levels in crops are predicted to increase was calculated (Table 4.9).

In Table 4.9 both the total number of plots as well as the surface are covered by those plots where Cd is accumulating depending on the scenario is calculated. As was demonstrated in Table 4.7, changes in soil $\mathrm{Cd}$ in a substantial number of plots are small (less than $5 \%$ of the total content compared to current levels in soil) which in fact would be very difficult to verify using field measurements considering the spatial variability which is likely to be larger than 1 to $5 \%$ increase in the metal content of the soil. To account for this, a second calculation was made including only those plots where $\mathrm{Cd}$ in soil increases with more than $0.05 \mathrm{mg} \mathrm{kg}^{-1}$. Data in Table 4.9 show that the total number of plots with an increase of more than $0.05 \mathrm{mg} \mathrm{kg}^{-1}$ are far less abundant, with the percentage of areas exceeding this value increasing from $0.3 \%$ for the $\mathrm{Cd}-0$ scenario to $12.7 \%$ for the $\mathrm{Cd}-60$ scenario.

Table 4.9 Overview of area in EU where Cd levels in soil increase (based on analysis at NCU level)

\begin{tabular}{lcccccc} 
scenario & BaU & $\mathrm{Cd}-0$ & $\mathrm{Cd}-20$ & $\mathrm{Cd}-40$ & $\mathrm{Cd}-60$ & $\mathrm{Cd}-80$ \\
NCU units $\Delta \mathrm{Cd}>0$ & 18540 & 13194 & 17677 & 19609 & 20578 & 21146 \\
\hline \% of total & 79 & 56 & 76 & 84 & 88 & 91 \\
\hline$\%$ of surface area EU & $85 \%$ & $64 \%$ & $82 \%$ & $90 \%$ & $94 \%$ & $95 \%$ \\
\hline Surface area with $\Delta \mathrm{Cd}>0.05$ ppm change (ha) & 3597137 & 300115.9 & 650271.1 & 3023432 & 14423236 & 40211112 \\
\hline \% of total surface area & $3.2 \%$ & $0.3 \%$ & $0.6 \%$ & $2.7 \%$ & $12.7 \%$ & $35.5 \%$ \\
\hline
\end{tabular}

Data in Table 4.9 show that in all scenarios Cd in soil will accumulate across the EU in the majority of soils even though predicted average changes are small in a substantial number of NCU plots. Based on the criterion of $\Delta \mathrm{Cd}>0.05 \mathrm{mg} / \mathrm{kg}$ which can be representative of a level that can be detected at field level as being a significant change, the area where $\mathrm{Cd}$ in soil increases is clearly reduced and now ranges from $3 \%$ in case of the BaU scenario to $36 \%$ in case of the $\mathrm{Cd}-80$ scenario. If no Cd were to be added to soils via fertilisers (Cd-0 scenario), there is a close to standstill situation (based on the criterion used here which was arbitrarily chosen to reflect detectable changes in soil).

Considering the large regional differences in both soil properties and Cd levels in soil across Europe, the area where $\mathrm{Cd}$ in soil increases are also given at country level (Table 4.10 for all data, Table 4.11 based on the $\Delta \mathrm{Cd}>0.05$ criterion).

These table indicates that differences between countries are substantial and percentages where Cd increases in soil range from less than $20 \%$ (BaU) in Belgium and Sweden to $100 \%$ in a.o. Bulgaria and Hungary regardless of the scenario (based on all data). The latter observation (accumulation $>0$ even at $(\mathrm{d}-0$ ) suggests that inputs from other sources apart from mineral fertilisers are larger than the sum 
of leaching and uptake which makes that equilibrium (stand still) cannot be achieved even at zero inputs from fertilisers. Note that such high percentages not necessarily mean that the increase in soil Cd is substantial as is shown in Table 4.11 where at country level only the area where Cd increases with more than $0.05 \mathrm{mg} \mathrm{kg}^{-1}$ is summarized.

This analysis (Table 4.11) shows that in case of the Cd-20 and even more so $\mathrm{Cd}-0$ scenarios, the surface area where $\mathrm{Cd}$ levels increase more than this threshold is almost zero whereas $\mathrm{Cd}$ levels in soil are increased in $3 \%(\mathrm{Cd}-40)$ to $36 \%(\mathrm{Cd}-80)$ of the total area in case of the $\mathrm{Cd}-40$ to $\mathrm{Cd}-80$ scenarios as was also listed in Table 4.9).

Data in Table 4.11 also reveal the substantial differences between countries with Poland and Portugal being the countries with the most substantial expected changes in $\mathrm{Cd}$ in soil. This is largely due to the relatively high levels of $\mathrm{Cd}$ in current mineral $\mathrm{P}$ fertilisers used in both countries (Smolders, 2017) compared to the EU average levels.

Based on this analysis, the data in Table 4.11 suggest that substantial $\left(>0.05 \mathrm{mg} \mathrm{kg}^{-1}\right)$ accumulation is reduced to less than $1 \%$ of the surface area if a threshold of $20 \mathrm{mg} \mathrm{Cd} \mathrm{kg}^{-1} \mathrm{P}_{2} \mathrm{O}_{5}$ is used. In order to reach an absolute standstill in arable soils a more stringent reduction is needed. On average an EUwide level at which standstill is achieved equals $0 \mathrm{mg} \mathrm{Cd} \mathrm{kg} \mathrm{P}_{2} \mathrm{O}_{5}$ as derived from these data. Even though the approach used in this paragraph differs from that discussed in Chapter 5 , the conclusion from both the plot and regional analysis correspond well with the more regionally explicit approach in Chapter 5.

Table 4.10 Surface area at country level (percentage of total) where Cd levels in soil increase

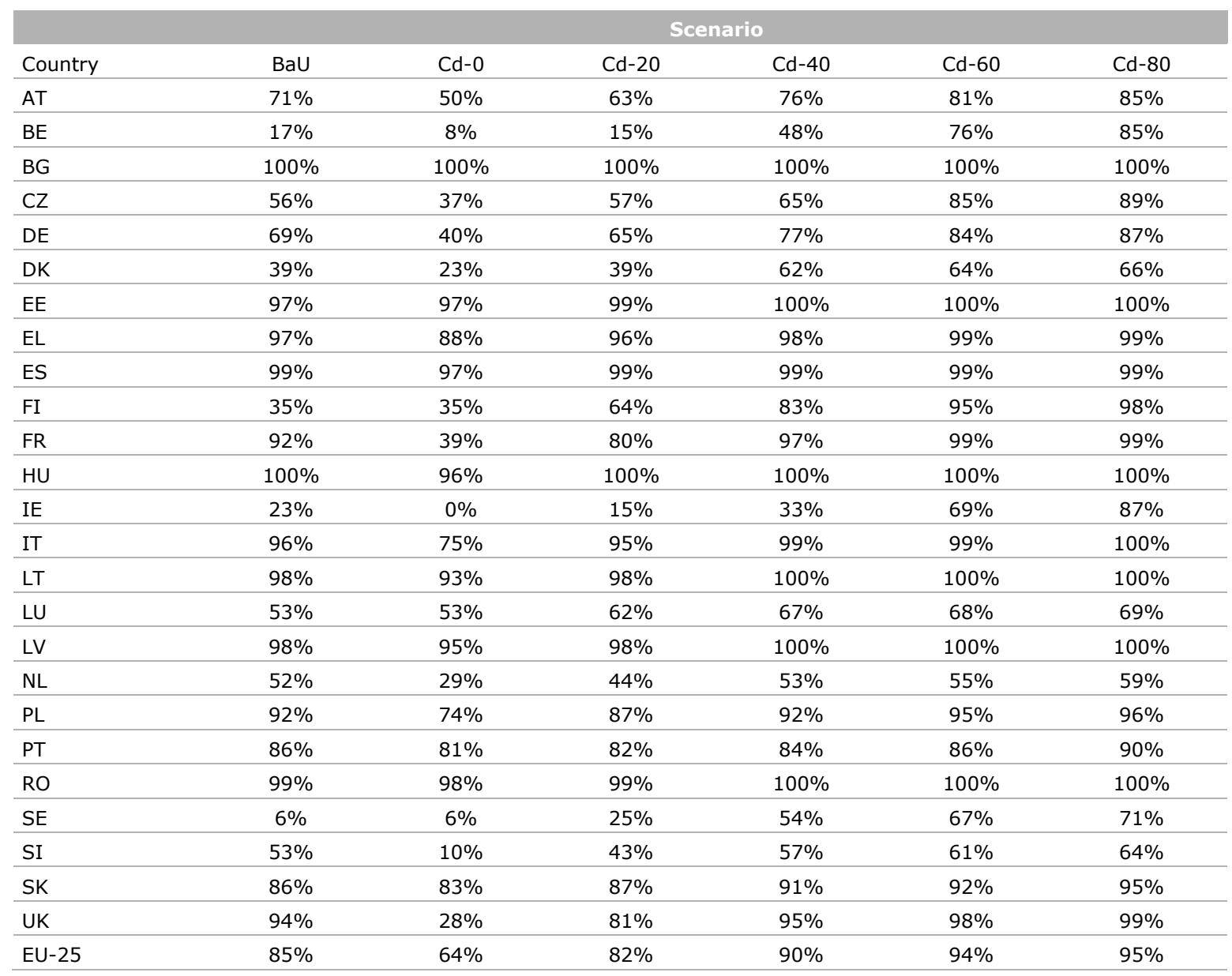


Table 4.11 Surface area (percentage of total) where Cd levels in soil increase with more than $0.05 \mathrm{mg} \mathrm{kg}^{-1}$

\begin{tabular}{|c|c|c|c|c|c|c|}
\hline \multirow[b]{2}{*}{ Country } & \multicolumn{6}{|c|}{ Scenario } \\
\hline & BaU & $\mathrm{Cd}-0$ & $\mathrm{Cd}-20$ & $\mathrm{Cd}-40$ & Cd-60 & Cd-80 \\
\hline AT & $0 \%$ & $0 \%$ & $0 \%$ & $0 \%$ & $7 \%$ & $40 \%$ \\
\hline BG & $3 \%$ & $1 \%$ & $3 \%$ & $3 \%$ & $5 \%$ & $7 \%$ \\
\hline$C Z$ & $0 \%$ & $0 \%$ & $0 \%$ & $0 \%$ & $1 \%$ & $1 \%$ \\
\hline DK & $0 \%$ & $0 \%$ & $0 \%$ & $0 \%$ & $0 \%$ & $0 \%$ \\
\hline EE & $0 \%$ & $0 \%$ & $0 \%$ & $3 \%$ & $4 \%$ & $5 \%$ \\
\hline $\mathrm{EL}$ & $1 \%$ & $0 \%$ & $0 \%$ & $4 \%$ & $29 \%$ & $65 \%$ \\
\hline ES & $8 \%$ & $0 \%$ & $0 \%$ & $4 \%$ & $29 \%$ & $66 \%$ \\
\hline IE & $6 \%$ & $0 \%$ & $0 \%$ & $8 \%$ & $8 \%$ & $17 \%$ \\
\hline IT & $0 \%$ & $0 \%$ & $0 \%$ & $0 \%$ & $10 \%$ & $42 \%$ \\
\hline LT & $0 \%$ & $0 \%$ & $0 \%$ & $0 \%$ & $0 \%$ & $1 \%$ \\
\hline LU & $0 \%$ & $0 \%$ & $0 \%$ & $0 \%$ & $0 \%$ & $0 \%$ \\
\hline LV & $0 \%$ & $0 \%$ & $0 \%$ & $0 \%$ & $0 \%$ & $1 \%$ \\
\hline $\mathrm{NL}$ & $5 \%$ & $3 \%$ & $5 \%$ & $5 \%$ & $7 \%$ & $16 \%$ \\
\hline PL & $14 \%$ & $1 \%$ & $2 \%$ & $13 \%$ & $40 \%$ & $59 \%$ \\
\hline PT & $17 \%$ & $0 \%$ & $0 \%$ & $2 \%$ & $19 \%$ & $31 \%$ \\
\hline RO & $0 \%$ & $0 \%$ & $1 \%$ & $1 \%$ & $1 \%$ & $1 \%$ \\
\hline
\end{tabular}

Due to the spatial differences in soil $\mathrm{Cd}$ at both $\mathrm{t}=0$ and $\mathrm{t}=100$ as shown in the previous sections, differences in the crop Cd content is highly variable between countries as well as is shown in Tables 4.12 and 4.13. Relative changes in crop Cd content as shown in Table 4.13 are similar for the three crops since a BCF was used which only considers the soil cd content. The increase or decrease in the soil content is for all crops grown in a specific unit the same which therefor results in a similar relative change in crop $\mathrm{Cd}$ content. Absolute levels of $\mathrm{Cd}$ in crops and changes therein are listed in Table 4.14 a to $\mathrm{c}$. 
Table 4.12 Average predicted crop Cd levels at country and EU level at $t=0$ (in $\mathrm{mg} \mathrm{kg}^{-1}$ dry weight)

\begin{tabular}{llll}
\hline Country & Average of potato & Average of lettuce & Average of wheat \\
AT & 0.12 & 0.77 & 0.06 \\
\hline BE & 0.17 & 1.07 & 0.08 \\
\hline BG & 0.09 & 0.58 & 0.04 \\
\hline CZ & 0.13 & 0.81 & 0.06 \\
\hline DE & 0.13 & 0.81 & 0.06 \\
\hline DK & 0.10 & 0.61 & 0.04 \\
\hline EE & 0.06 & 0.40 & 0.03 \\
\hline EL & 0.13 & 0.80 & 0.06 \\
\hline ES & 0.08 & 0.49 & 0.04 \\
\hline FI & 0.06 & 0.39 & 0.03 \\
\hline FR & 0.13 & 0.79 & 0.06 \\
\hline HU & 0.09 & 0.56 & 0.04 \\
\hline IE & 0.21 & 1.31 & 0.09 \\
\hline LT & 0.13 & 0.83 & 0.06 \\
\hline LU & 0.05 & 0.32 & 0.02 \\
\hline LV & 0.14 & 0.89 & 0.06 \\
\hline NL & 0.05 & 0.32 & 0.02 \\
\hline PL & 0.16 & 0.99 & 0.07 \\
\hline PT & 0.11 & 0.67 & 0.05 \\
\hline SE & 0.05 & 0.32 & 0.02 \\
\hline SI & 0.10 & 0.65 & 0.05 \\
\hline SK & 0.09 & 0.56 & 0.04 \\
\hline EK & 0.20 & 1.27 & 0.09 \\
\hline
\end{tabular}

Table 4.13 Predicted relative changes in crop Cd levels at $t=100$ for the BaU, CdO, Cd20, Cd4O and Cd60 and Cd80 scenario

\begin{tabular}{|c|c|c|c|c|c|c|}
\hline \multirow[b]{2}{*}{ Country } & \multicolumn{6}{|c|}{ Scenario } \\
\hline & BaU & Cd-O & Cd-20 & Cd-40 & Cd-60 & Cd-80 \\
\hline AT & $2.2 \%$ & $-3.4 \%$ & $-0.3 \%$ & $2.8 \%$ & $6.0 \%$ & $9.1 \%$ \\
\hline BG & $9.6 \%$ & $7.9 \%$ & $10.0 \%$ & $12.2 \%$ & $14.3 \%$ & $16.5 \%$ \\
\hline $\mathrm{CZ}$ & $-0.4 \%$ & $-2.4 \%$ & $-0.4 \%$ & $1.7 \%$ & $3.8 \%$ & $5.9 \%$ \\
\hline EE & $5.4 \%$ & $5.2 \%$ & $9.2 \%$ & $13.3 \%$ & $17.3 \%$ & $21.3 \%$ \\
\hline EL & $12.0 \%$ & $2.6 \%$ & $8.2 \%$ & $13.7 \%$ & $19.2 \%$ & $24.5 \%$ \\
\hline ES & $24.5 \%$ & $4.5 \%$ & $12.9 \%$ & $21.4 \%$ & $29.9 \%$ & $38.3 \%$ \\
\hline FI & $1.1 \%$ & $1.0 \%$ & $5.9 \%$ & $10.8 \%$ & $15.7 \%$ & $20.5 \%$ \\
\hline IT & $4.9 \%$ & $0.9 \%$ & $4.4 \%$ & $7.8 \%$ & $11.3 \%$ & $14.8 \%$ \\
\hline LT & $9.4 \%$ & $5.3 \%$ & $10.9 \%$ & $16.4 \%$ & $22.0 \%$ & $27.6 \%$ \\
\hline LU & $-1.5 \%$ & $-1.5 \%$ & $0.1 \%$ & $1.7 \%$ & $3.2 \%$ & $4.8 \%$ \\
\hline LV & $8.5 \%$ & $6.1 \%$ & $10.7 \%$ & $15.4 \%$ & $20.0 \%$ & $24.7 \%$ \\
\hline NL & $2.0 \%$ & $-2.1 \%$ & $0.3 \%$ & $2.7 \%$ & $5.0 \%$ & $7.4 \%$ \\
\hline PL & $12.5 \%$ & $1.1 \%$ & $6.7 \%$ & $12.3 \%$ & $17.9 \%$ & $23.4 \%$ \\
\hline PT & $24.6 \%$ & $7.3 \%$ & $13.3 \%$ & $19.2 \%$ & $25.2 \%$ & $31.1 \%$ \\
\hline RO & $4.7 \%$ & $4.2 \%$ & $6.0 \%$ & $7.9 \%$ & $9.7 \%$ & $11.5 \%$ \\
\hline SE & $-9.3 \%$ & $-9.4 \%$ & $-7.9 \%$ & $-6.3 \%$ & $-4.8 \%$ & $-3.2 \%$ \\
\hline
\end{tabular}


In Table 4.14 predicted changes in absolute levels are shown for the three food crops considered.

Table 4.14a Predicted absolute levels of Cadmium in Potato (in $\mathrm{mg} \mathrm{kg}^{-1}$ dry matter) at country level at $t=100$ (plus $t=0$ for $\mathrm{BaU}$ )

\begin{tabular}{|c|c|c|c|c|c|c|c|}
\hline \multirow[b]{2}{*}{ Country } & \multirow{2}{*}{$\begin{array}{l}\mathrm{BaU} \\
\mathbf{t}=\mathbf{0}\end{array}$} & \multicolumn{6}{|c|}{ Scenario results at $\mathrm{t}=\mathbf{1 0 0}$} \\
\hline & & BaU & Cd-O & Cd-20 & Cd-40 & Cd-60 & Cd-80 \\
\hline AT & 0.12 & 0.12 & 0.12 & 0.12 & 0.12 & 0.13 & 0.13 \\
\hline BG & 0.09 & 0.10 & 0.10 & 0.10 & 0.10 & 0.11 & 0.11 \\
\hline $\mathrm{CZ}$ & 0.13 & 0.13 & 0.13 & 0.13 & 0.13 & 0.13 & 0.14 \\
\hline DK & 0.10 & 0.10 & 0.10 & 0.10 & 0.10 & 0.10 & 0.10 \\
\hline $\mathrm{EE}$ & 0.06 & 0.07 & 0.07 & 0.07 & 0.07 & 0.08 & 0.08 \\
\hline $\mathrm{EL}$ & 0.13 & 0.14 & 0.13 & 0.14 & 0.14 & 0.15 & 0.15 \\
\hline ES & 0.08 & 0.09 & 0.08 & 0.09 & 0.09 & 0.10 & 0.10 \\
\hline IE & 0.21 & 0.20 & 0.19 & 0.20 & 0.20 & 0.21 & 0.22 \\
\hline IT & 0.13 & 0.14 & 0.13 & 0.14 & 0.14 & 0.15 & 0.15 \\
\hline $\mathrm{LT}$ & 0.05 & 0.06 & 0.05 & 0.06 & 0.06 & 0.06 & 0.07 \\
\hline LU & 0.14 & 0.14 & 0.14 & 0.14 & 0.14 & 0.15 & 0.15 \\
\hline LV & 0.05 & 0.05 & 0.05 & 0.06 & 0.06 & 0.06 & 0.06 \\
\hline $\mathrm{NL}$ & 0.16 & 0.16 & 0.15 & 0.16 & 0.16 & 0.16 & 0.17 \\
\hline $\mathrm{PL}$ & 0.11 & 0.12 & 0.10 & 0.11 & 0.12 & 0.12 & 0.13 \\
\hline PT & 0.05 & 0.06 & 0.05 & 0.05 & 0.06 & 0.06 & 0.06 \\
\hline RO & 0.10 & 0.11 & 0.11 & 0.11 & 0.11 & 0.11 & 0.11 \\
\hline
\end{tabular}


Table 4.14b Predicted absolute levels of lettuce (in $\mathrm{mg} \mathrm{kg}^{-1}$ dry matter) at country level at $t=100$ (plus $t=0$ for $\mathrm{BaU}$ )

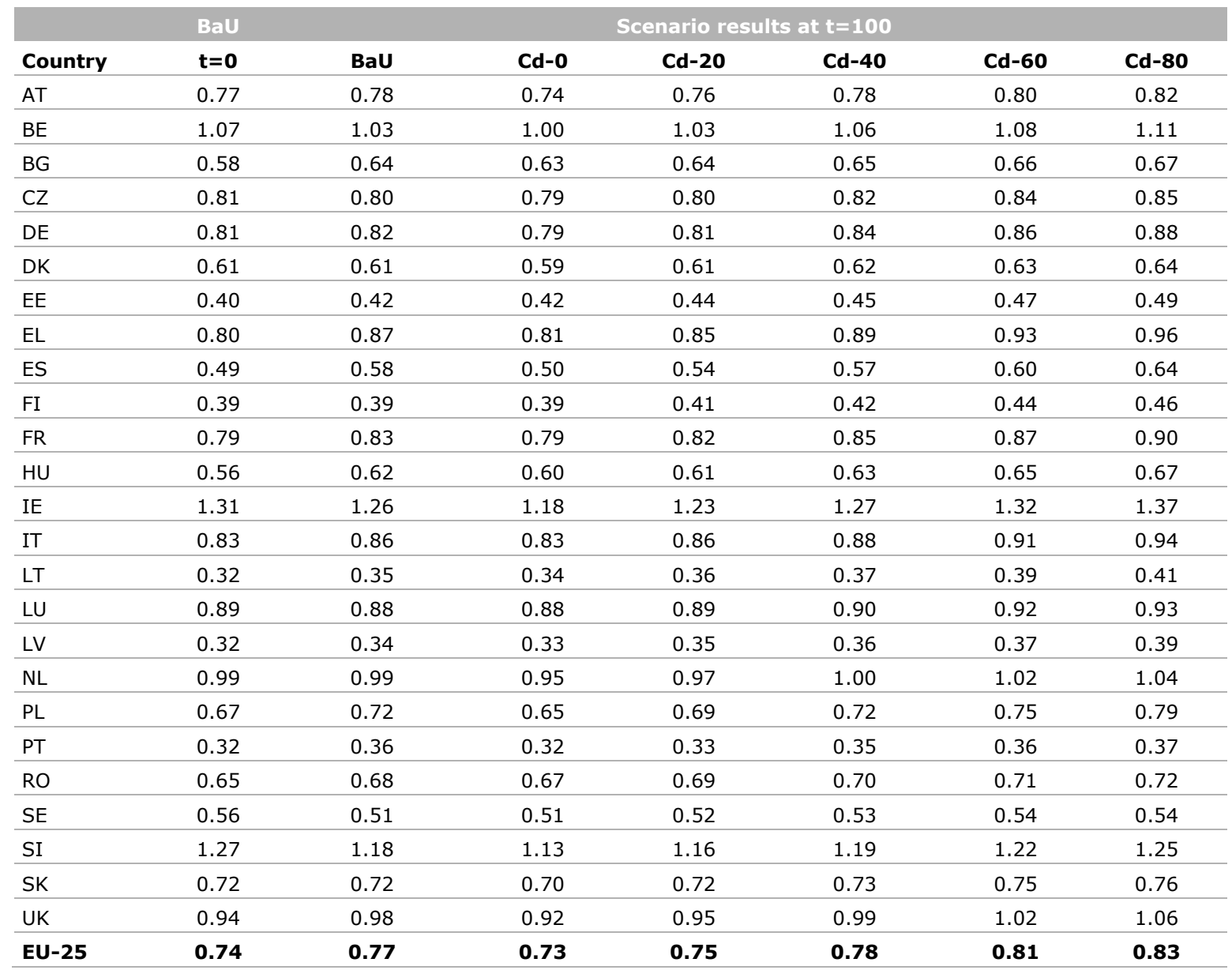


Table 4.14c Predicted absolute levels of wheat (in $\mathrm{mg} \mathrm{kg}^{-1} \mathrm{dry}$ matter) at country level at $t=100$ (plus $t=0$ for $B a U$ )

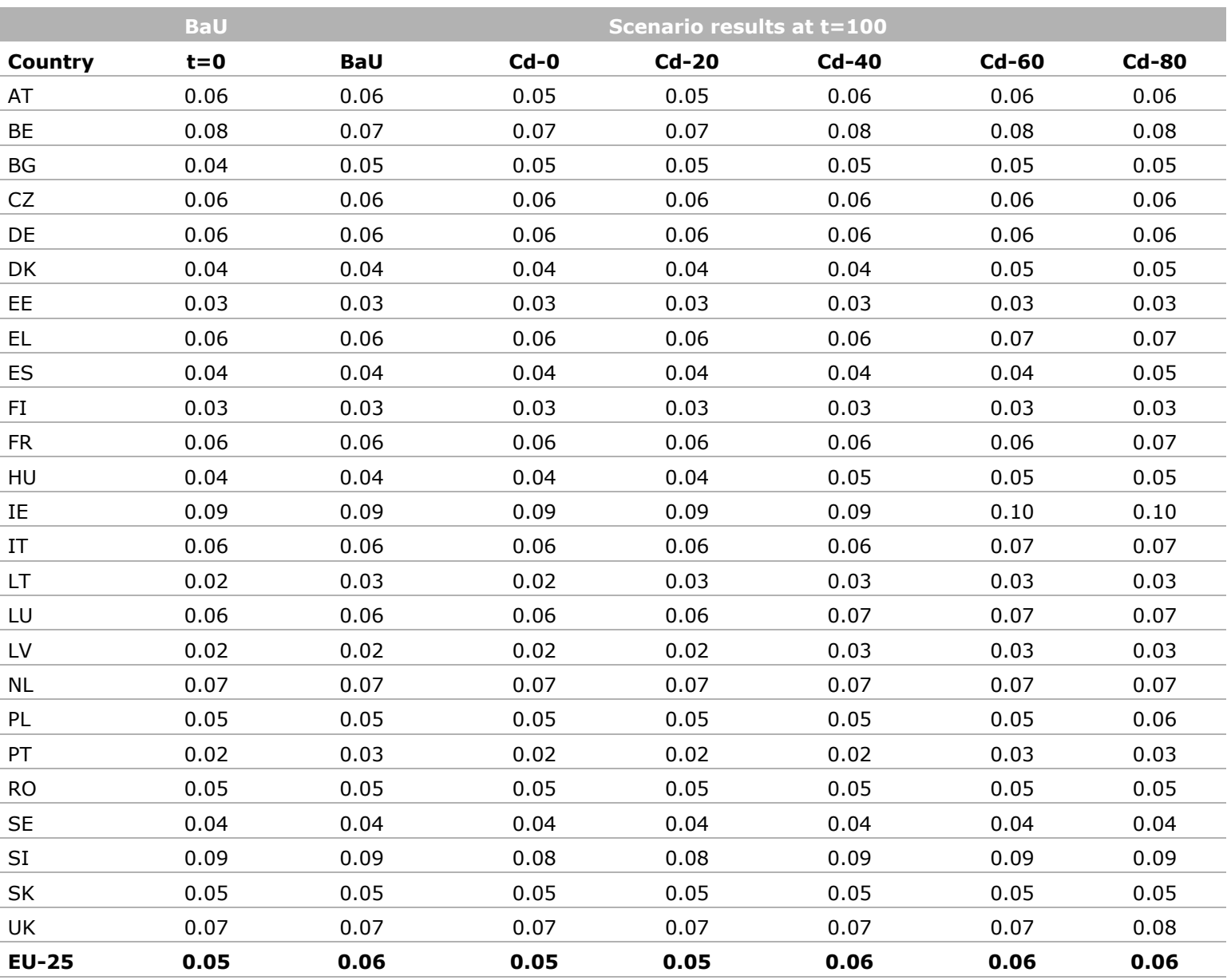

\subsection{Mass balance approach for other metals not included in the dynamic modelling approach}

\subsubsection{Background}

In addition to cadmium, other toxic metals, notably arsenic and lead as well as micro nutrients like $\mathrm{Zn}$ are present in fertiliser in variable quantities. For some metals like $\mathrm{Cr}, \mathrm{Ni}$ and to a lesser extent $\mathrm{Pb}$ models to predict leaching of metals and/or crop uptake are not available which hampers a similar approach as is done for $\mathrm{Cd}$. To assess to what extent differences in the levels of such metals (here we consider $\mathrm{Zn}, \mathrm{Cu}, \mathrm{As}, \mathrm{Cr}, \mathrm{Ni}$ and $\mathrm{Pb}$ ) between different fertilisers could lead to differences in levels in soil, a simplified mass balance approach is carried out assuming that all metals added to soil were to remain in the (top)soil. This represents a worst case analysis since for all metals there will be losses due to crop uptake and leaching.

In Table 4.15 the average measured metal content in the fertilisers and cow manure used in the experimental studies are listed. 
Table 4.15 Average metal and P content in fertilisers used in the experimental work

\begin{tabular}{lccccccccc} 
& $P$ & $\mathrm{Zn}$ & $\mathrm{As}$ & $\mathrm{Cd}$ & $\mathrm{Cr}$ & $\mathrm{Cu}$ & $\mathrm{Ni}$ \\
Average data 2016+2017 & {$[\mathrm{g} / \mathrm{kg}]$} & {$[\mathrm{mg} / \mathrm{kg}]$} & {$[\mathrm{mg} / \mathrm{kg}]$} & {$[\mathrm{mg} / \mathrm{kg}]$} & {$[\mathrm{mg} / \mathrm{kg}]$} & {$[\mathrm{mg} / \mathrm{kg}]$} & {$[\mathrm{mg} / \mathrm{kg}]$} & {$[\mathrm{mg} / \mathrm{kg}]$} \\
\hline PhosAgro DAP & 198 & 12 & 0.9 & 0.0 & 3.1 & 7.4 & 2.9 & 0.0 \\
\hline PhosAgro DAP-Zn & 148 & 4897 & 0.8 & 0.1 & 7.2 & 7.4 & 5.1 & 0.1 \\
\hline Dried cow manure & 16 & 383 & 0.5 & 0.3 & 6.1 & 84.4 & 5.4 & 1.7 \\
\hline Moroccan DAP & 196 & 34 & 4.4 & 4.4 & 31.9 & 16.5 & 7.8 & 0.1 \\
\hline Senegal DAP & 126 & 77 & 4.4 & 9.2 & 80.1 & $\mathrm{na}$ & 15.0 & 5.1 \\
\hline Regular DAP & 191 & 106 & 6.6 & 17.7 & 71.4 & 26.7 & 14.7 & 0.1 \\
\hline Polish DAP & 193 & 562 & 7.9 & 23.5 & 158.9 & $\mathrm{na}$ & 92.6 & 0.4 \\
\hline Tunesian DAP & 196 & 200 & 2.6 & 26.6 & 254.1 & 0.9 & 10.7 & 0.5 \\
\hline
\end{tabular}

\subsubsection{Simplified mass balance approach for $\mathrm{As}, \mathrm{Cr}, \mathrm{Cu}, \mathrm{Ni}, \mathrm{Pb}$ and $\mathrm{Zn}$}

For $\mathrm{Cd}$ the long term impact on soils is presented in chapters 4 and 5 of this report. For some of the elements listed here (a.o. As, $\mathrm{Cr}$, and $\mathrm{Ni}$ ) models are not yet available (i.e. soil-solution models or plant uptake models) whereas for $\mathrm{Pb}$ the models in general perform quite poorly.

Nevertheless it is relevant to assess to what extend the difference in the quality of fertilisers as used here, assuming this is a representative range of fertilisers available at the moment, would contribute to differences in the load of metals to soil and to what extent the quality affects long term changes of the metal content in soil.

This is estimated as follows:

1. Based on the quality as listed in Table 4.15, an average annual load in gram ha-1 of these metals is calculated assuming a yearly application of $100 \mathrm{~kg} \mathrm{P}_{2} \mathrm{O}_{5} \mathrm{ha}^{-1}$ :

Annual Load Me-fert. $=0.001 * 100 *$ Metal content fertiliser

2. This total load is converted to a cummulative load for 100 years

$\operatorname{Load}_{100 \text { years }}=100 *$ Annual Load

3. The total load thus calculated is converted to a corresponding change in the metal content in soil. Here we assume that $100 \%$ of the metals added to soil are retained in the soil. This clearly is an overestimation since part of the metals are lost via leaching and or plant uptake. The corresponding change in the soil metal content therefore presents the worst case scenario in view of impact on soil quality. Here we assume a mixing layer of $25 \mathrm{~cm}$ (plough layer) and an average- bulk density of 1.3 (Hollis et al., 2012)

4. The change in the soil metal content for 100 years is then compared to the current metal content in the soil based on the data in the GEMAS Atlas (Reimann et al., 2014) which at present is the most reliable database for metals in arable soils.

This approach allows for a quick assessment to what extent differences in the metal content of fertiliser affects the soil quality without correcting for those processes which would reduce this impact. The actual change in the soil metal content therefore is always lower than the changes this predicted. 
Table 4.16 Total cumulative metal load at $t=100$ in gram per hectare

\begin{tabular}{lccccccc} 
Fertiliser used & $\mathrm{Cd}$ & $\mathrm{Pb}$ & $\mathrm{As}$ & $\mathrm{Zn}$ & $\mathrm{Cr}$ & $\mathrm{Cu}$ & $\mathrm{Ni}$ \\
\hline PhosAgro DAP & 0.4 & 0.9 & 20 & 265 & 69 & 164 & 65 \\
\hline PhosAgro DAP-Zn & 2.2 & 1.9 & 23 & 144453 & 212 & 217 & 151 \\
\hline Dried cow manure & 78 & 471 & 142 & 107746 & 1706 & 23775 & 1523 \\
\hline Moroccan DAP & 98 & 2.5 & 98 & 757 & 711 & 368 & 173 \\
\hline Senegal DAP & 319 & 176 & 151 & 2668 & 2777 & - & 520 \\
\hline Regular DAP & 405 & 2.1 & 151 & 2429 & 1637 & 612 & 336 \\
\hline Polish DAP & 532 & 8.7 & 180 & 12736 & 3604 & - & 2099 \\
\hline Tunesian DAP & 594 & 10 & 59 & 4444 & 5661 & 20 & 239 \\
\hline
\end{tabular}

Table 4.17 Calculated potential change in the soil metal content (in $\mathrm{mg} \mathrm{kg}^{-1}$ ) of the $0-25 \mathrm{~cm}$ layer in arable soils due to fertiliser application in 100 years

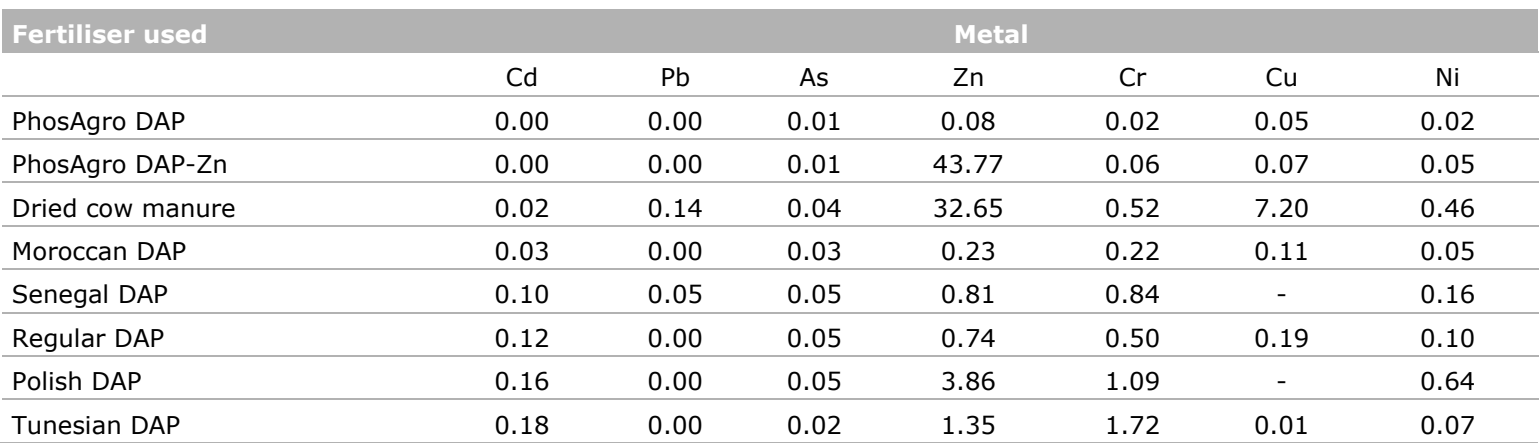

The data in Table 4.17 demonstrate that for metals like $\mathrm{Cd}, \mathrm{Zn}$ and to a lesser extent $\mathrm{Cu}$, the difference in fertiliser quality could have an impact on the soil quality within 100 years. For $\mathrm{Cd}$ this is further elaborated on in chapters 4 and 5 of this report. For $\mathrm{Pb}, \mathrm{As}, \mathrm{Cr}$ and $\mathrm{Ni}$, the total change in the soil metal content is very low and usually below the $1 \mathrm{mg} \mathrm{kg}^{-1}$ level. However, to put the data in Table 4.17 in the context of actual levels in soil, the median levels of all metals considered here was used to determine the relative impact of these absolute changes. An absolute increase of 0.1 for $\mathrm{Cd}$ is more relevant than an increase of $0.1 \mathrm{mg} \mathrm{kg}^{-1}$ for $\mathrm{Zn}$ for example when looking at the absolute levels as listed in Table 4.18. Here absolute levels are based on the median value as determined by Aqua Regia or XRF as listed in the GEMAS Atlas for agricultural soils (Reimann et al., 2014).

Table 4.18 Current median metal content in arable soil (GEMAS, 2014) and relative potential changes in the metal content in soil due to fertiliser application without considering crop uptake and leaching

\begin{tabular}{|c|c|c|c|c|c|c|c|}
\hline \multirow[t]{2}{*}{ Fertiliser used } & \multicolumn{7}{|c|}{ Metal } \\
\hline & $\mathrm{Cd}$ & $\mathrm{Pb}$ & As & $\mathrm{Zn}$ & $\mathrm{Cr}$ & $\mathrm{Cu}$ & $\mathrm{Ni}$ \\
\hline $\begin{array}{c}\text { Current Median Soil metal } \\
\text { content in arable soils: }\end{array}$ & 0.18 & 20 & 6 & 55 & 45 & 14 & 17 \\
\hline PhosAgro DAP & $0.1 \%$ & $0.0 \%$ & $0.1 \%$ & $0.1 \%$ & $0.0 \%$ & $0.4 \%$ & $0.1 \%$ \\
\hline PhosAgro DAP-Zn & $0.4 \%$ & $0.0 \%$ & $0.1 \%$ & $79.6 \%$ & $0.1 \%$ & $0.5 \%$ & $0.3 \%$ \\
\hline Moroccan DAP & $16.6 \%$ & $0.0 \%$ & $0.5 \%$ & $0.4 \%$ & $0.5 \%$ & $0.8 \%$ & $0.3 \%$ \\
\hline Senegal DAP & $53.6 \%$ & $0.3 \%$ & $0.8 \%$ & $1.5 \%$ & $1.9 \%$ & - & $0.9 \%$ \\
\hline Regular DAP & $68.2 \%$ & $0.0 \%$ & $0.8 \%$ & $1.3 \%$ & $1.1 \%$ & $1.3 \%$ & $0.6 \%$ \\
\hline Polish DAP & $89.6 \%$ & $0.0 \%$ & $0.9 \%$ & $7.0 \%$ & $2.4 \%$ & - & $3.7 \%$ \\
\hline Tunesian DAP & $99.9 \%$ & $0.0 \%$ & $0.3 \%$ & $2.4 \%$ & $3.8 \%$ & $0.0 \%$ & $0.4 \%$ \\
\hline
\end{tabular}


The data in Table 4.18 reveal that

- For Cd the potential impact of fertiliser quality on soil metal levels is large and the potential increase in the soil metal content due to fertiliser application varies between 0 and $100 \%$ of the current median Cd content in soil. This is addressed in detail in the remainder of this report.

- For $\mathrm{As}$ and $\mathrm{Pb}$ being relevant in view of soil health and food quality, the predicted change in the soil metal content is negligible when compared to current levels (ranging from 0 to $0.9 \%$ increase relative to current levels. These changes are, in reality. not even detectable in monitoring studies when considering the spatial variability at field level.

- For $\mathrm{Cu}$ and $\mathrm{Zn}$, both relevant as micronutrient on one hand but also potentially toxic for soil and/or aquatic organisms, the increase in the soil metal content can be significant in case of animal manure or when using the $\mathrm{Zn}$ fortified fertiliser. Considering the current absolute levels in soil, it is however unlikely that soil health will be affected at the levels predicted here which is in line with previous spatially explicit model studies that reveal that even at elevated inputs of $\mathrm{Cu}$ and $\mathrm{Zn}$ in intensive animal husbandry systems soil ecology is largely not affected (De Vries et al., 2004, 2007, Groenenberg et al., 2006). On the other hand however, current emissions of $\mathrm{Zn}$ to surface waters from soil are such that already at present the ecological quality standards for aquatic organisms are exceeded. For $\mathrm{Zn}$ and to a lesser extend for $\mathrm{Cu}$, the assumption that $100 \%$ of the metals are retained in soil is however not valid which implies that the calculated absolute increase (Table 4.17) or relative change (Table 4.18) will be lower than the data in the table which further reduces the potential impact of fertiliser quality.

- For $\mathrm{Cr}$ and Ni predicted changes are also small when compared to actual levels in soil and it is highly unlikely that such differences, which also will be smaller due to losses from soil, will lead to effects on either soil life of crop quality. For both $\mathrm{Ni}$ and $\mathrm{Cr}$ there is also very little information on the relation between the soil metal content and that in crops. Within the range of theoretically predicted changes in the soil $\mathrm{Cr}$ or $\mathrm{Ni}$ content it is not to be expected that there is a response in crop $\mathrm{Cr}$ or $\mathrm{Ni}$ levels.

\section{To conclude}

- For Cd differences in the quality of fertiliser is relevant in view of soil quality. The extent to which fertiliser quality affects soil Cd levels will be further elaborated on in chapter 4 and 5 of this report.

- For $\mathrm{As}, \mathrm{Pb}, \mathrm{Cr}$, and $\mathrm{Ni}$, differences in fertiliser quality will not results in detectable changes in the soil quality within 100 years. It is also highly unlikely that differences in fertiliser quality will affect crop quality in 100 years.

- For $\mathrm{Cu}$ and $\mathrm{Zn}$ the use of animal manure or $\mathrm{Zn}$ fortified fertilisers can lead to a substantial increase in the soil metal content. Within the range of soil metals currently present, it is unlikely that this will affect soil health but leaching losses to surface waters can be significant.

- For all metals discussed here, the absolute (and relative) increase in the soil metal content is less than shown in the tables here since part of the metals added via fertiliser will be lost from soil due to uptake by crops or leaching. This is especially relevant for $\mathrm{Cd}, \mathrm{Zn}, \mathrm{Ni}$ and $\mathrm{As}$ being the most mobile elements. For $\mathrm{Cr}$ and $\mathrm{Pb}$ losses via uptake and leaching are minor and predicted changes as shown here can be in same order after correcting for leaching and uptake. 


\subsection{Conclusions from the plot and regional modelling studies}

\section{Results from model studies}

Plot scale simulations

Results from plot scale simulations suggest that -on average- a 34\% reduction in Cd levels in food crops (compared to current levels) can be achieved after 100 years when using low-Cd P-fertilisers. The magnitude of this change is however variable depending on soil conditions and crop type; experimental results show that the effect is more prominent in leafy vegetables compare to potato for example. The use of animal manure, on average also leads to lower net Cd levels in crops whereas the $\mathrm{Cd}$ fertiliser that contains $60 \mathrm{mg} \mathrm{Cdkg}{ }^{-1} \mathrm{P}_{2} \mathrm{O}_{5}$ results in, on average a $22 \%$ increase in Cd levels in crop. Again, for specific crops (like leafy vegetables) and under specific soil conditions, notably in slightly acid sandy soils, $\mathrm{Cd}$ uptake can decrease even when using mineral $\mathrm{P}$ fertilisers that contain $60 \mathrm{mg} \mathrm{Cd} \mathrm{kg}^{-1} \mathrm{P}_{2} \mathrm{O}_{5}$.

The use of the medium high-Cd $\mathrm{P}$ fertiliser as applied in the plot level simulations yields a predicted small increase in crop Cd levels. This outcome is very much in line with the more elaborate regional modelling results at EU level as presented in chapter 5 . As it is, the Cd level in the medium-Cd fertilisers used in the experiment is close to the average quality of mineral $P$ fertilisers used at present in the EU. This suggests that the models applied in both assessments are rather robust and do not lead to contrasting conclusions.

\section{Regional scale simulations}

Results from the regional assessment where the predicted levels in soil at $t=100$ for the 23000 spatial units were used to calculated levels of $\mathrm{Cd}$ in potato, barley and carrot show that on average a stand still for $\mathrm{Cd}$-when considering $\mathrm{Cd}$ levels in crops- is achieved at zero inputs of Cd via mineral $\mathrm{P}$ fertilisers. Predicted relative increases in the crops compared to present levels increase between 4 and $17 \%$ for the Cd-20 to Cd-80 scenarios respectively. Differences between countries however are substantial which is due to both differences in the amount of fertiliser used and (in case of the Business as Usual scenario) the quality, i.e. the current Cd levels in mineral P fertilisers. Furthermore the range in predicted levels of $\mathrm{Cd}$ in all food crops considered here when considering all spatial units is several times larger than the predicted range due to differences for a given unit based on differences of the $\mathrm{Cd}$ content of fertilisers used in this unit. This is in agreement with the results from the experiments which reveal that differences between soils are more relevant in terms of Cd uptake by crops compared to differences in the quality of fertilisers used. Nevertheless, there is a clear positive relation between the levels of $\mathrm{Cd}$ in fertilisers applied and the resulting $\mathrm{Cd}$ content in crops when considering a time frame of 100 years. These effects are most prominent in countries that apply relatively large amounts of fertiliser including a.o. Poland and Portugal. In these countries the percentage of the total area used for arable crop production where Cd levels in soil increase with more than $0.05 \mathrm{mg} / \mathrm{kg}$ (which is used here as an arbitrary criterion for a detectable increase of Cd in soils) ranges from $1 \%$ in case of the Cd-0 scenario to almost $60 \%$ in case of the Cd-80-scenario. This contrasts sharply with predicted results for a.o. Belgium where even in case of the Cd-80 scenario the total surface are with a detectable increase of $\mathrm{Cd}$ in soil after 100 years is only $3 \%$ of the total surface area used for agriculture.

These results are in line with those from the most detailed spatial analysis as presented in chapter 5 focussing on changes of $\mathrm{Cd}$ in soil after 100 years based on the actual land use considering all crops and current forms of land use including both arable land and pasture. On average the predicted relative changes of $\mathrm{Cd}$ in soil compared to current levels ranges from $-4.4 \%$ in case of the $\mathrm{Cd}-0$ scenario to $+12.5 \%$ in case of the $\mathrm{Cd}-80$ scenario. When considering arable soils only these relative changes vary from $+0.2 \%$ in case of the $\mathrm{Cd}-0$ scenario to $16 \%$ in case of the $\mathrm{Cd}-80$ scenario. Results reveal that at EU level Cd balances are largely negative for pasture soils due to lower application rates of mineral $\mathrm{P}$ fertilisers and slightly higher leaching levels due to the lower $\mathrm{pH}$ in pasture soils. For pasture soils therefore the $\mathrm{Cd}$ content in soils decreases in all but the $\mathrm{Cd}-80$ scenario whereas in arable soils tend to accumulate $\mathrm{Cd}$ in all scenarios albeit that in case of the $\mathrm{Cd}-0$ scenario a close to stand still situation is predicted. 
Long term (100 years) plot simulations using the range in fertiliser insofar related to the Cd content, reveal that substantial changes in both soil and crop can be observed. Model results indicate that low-Cd fertiliser lead to $34 \%$ decrease of $\mathrm{Cd}$ in crops whereas high-Cd (60 mg Cd kg-1 $\mathrm{P}_{2} \mathrm{O}_{5}$ ) fertiliser result in an -average- increase of $22 \%$ in food crops. The magnitude of the changes however strongly depends on both local soil conditions $(\mathrm{pH}$, organic matter content) and crop considered.

Long term effects are most pronounced in low Cd soils prone to accumulation, i.e. soils with near neutral $\mathrm{pH}$ such as the Lioessens soil included in this study.

Results from the simulations either at plot level or at EU level for more than 23000 spatially explicit units show that long term changes of $\mathrm{Cd}$ levels in soil are related to Cd levels in fertiliser with Cd levels in soil increasing between $0.2 \%$ to $16 \%$ for the Cd-0 and Cd-80 scenario respectively after 100 years.

These model results suggest that when reducing Cd levels in fertiliser to zero, a net stand still for arable soils at the EU level can be achieved. When considering both pasture soils and arable soils, a net zero change of $\mathrm{Cd}$ in soil (at EU level) is achieved at a corresponding level of $20 \mathrm{mg} \mathrm{Cd} \mathrm{kg}^{-1}$ $\mathrm{P}_{2} \mathrm{O}_{5}$.

The difference between this level and a previously reported level of $73 \mathrm{mg} \mathrm{Cd} \mathrm{kg}{ }^{-1} \mathrm{P}_{2} \mathrm{O}_{5}$ is largely due to different model concepts used to calculate leaching losses from soil (see also discussion in Chapter 5). 


\section{Spatially explicit prediction of changes in $\mathrm{Cd}$ balances and $\mathrm{Cd}$ in soil}

\section{$5.1 \quad$ Introduction}

The presence of heavy metals in arable soil and pasture soils and accumulation thereof due to continuous inputs via atmosphere and soil amendments is of concern in view of food safety (EFSA, 2012), water quality (e.g. Peng et al., 2016, Mirzabeygi et al., 2017) and soil health, notably the impact on micro-organisms (e.g. Giller et al., 1998). Accumulation of $\mathrm{Cd}$ in food crops and subsequent transfer into the food chain is one of major exposure pathways for animals and human beings (Franz et al., 2009; Peng et al., 2016). Recent estimates by the European Food Safety Authority (EFSA, 2012 ) indicate that the average exposure for infants and the $95^{\text {th }}$ percentile exposure for adults is in excess of the reduced Tolerable Weekly Intake (TWI) of $2.5 \mu \mathrm{g} / \mathrm{kg}$ b.w. per week, which led EFSA to conclude that there was a need to reduce intake of cadmium via dietary exposure. Since $\mathrm{Cd}$ in important food groups like vegetables or grain products are positively correlated to the Cd content in the soil (McLaughlin et al., 2011), reducing levels of Cd in soils via reduction of inputs seems a viable option to reduce exposure. However, the total intake of $\mathrm{Cd}$ via food cannot be related entirely to the Cd content in soil since part of the food consumed by people is either not produced in the EU (a.o. intake via chocolate) or has no relation with soil at all. This relates a.o. to Cd intake via seafood or products grown in soil-less cultures including vegetables grown in greenhouses. Nevertheless, recent estimates show that up to $54 \%$ of the total Cd intake by average consumers in the EU can be related to the Cd content in soils (Rietra et al., 2017). Hence, reduction of Cd inputs to soil is one of the tools to lower $\mathrm{Cd}$ accumulation rates or even achieve a negative balance which ultimately would result in lower levels of $\mathrm{Cd}$ in soil. At present however, it is unclear how fast and to what degree a reduction of $\mathrm{Cd}$ levels in soil can be obtained so as to reduce exposure of Cd below the TWI. Recent inventories in Switzerland (Bigalke et al., 2017) and New Zealand (Schipper et al., 2017) for example showed that inputs of $\mathrm{Cd}$ inputs to arable cropping systems have been reduced, but the response of the soil Cd level to such reduced inputs is slow or absent.

Accumulation of $\mathrm{Cd}$ in soil occurs when inputs to soil exceed outputs. Major sources of Cd include the use of mineral P-fertiliser and animal manure, inputs via atmospheric deposition and the use of organic soil amendments like compost and sludge (Amlinger, 2004; Nicholson et al., 1999, Eckel et al., 2005). During the last two decades, however, industrial emissions, including traffic and waste combustion have decreased substantially (EEA, 2017). Also consumption rates of mineral $P$ fertiliser have decreased from almost 8000 kton in 1980 to 2000 kton in 2010 (Six and Smolders, 2014) which has resulted in a marked decrease in inputs of $\mathrm{Cd}$ via fertiliser to soil. Based on the average $\mathrm{Cd}$ content in mineral $P$ fertilisers of approx. $40 \mathrm{mg} \mathrm{Cd} \mathrm{kg}^{-1} \mathrm{P}_{2} \mathrm{O}_{5}$ (Nziguheba and Smolders, 2008) the reduced consumption rate corresponds with a decrease of the Cd load to arable soil of 320 tons at EU level. Currently, however, there is a trend towards a more efficient re-use of existing resources for nutrients (End of Waste; COM 2005) which includes the use of organic resources like compost, digestate, biochar or sludge in agriculture to replace part of the mineral fertilisers used at present. Such resources can contain elevated levels of contaminants and the partial replacement of mineral fertiliser by such organic resources may induce a higher load of contaminants to agro-ecosystems across the EU. In addition, proposals to reduce the minimum nutrient requirements for fertilisers (COM, 2016) also can lead to an increase in the load of contaminants present in such products. The degree to which such policy changes affect the regional or national load of contaminants including Cd to soil is, as of now, unclear although estimates at country level for the Netherlands suggest that loads of Cd can increase from the current load of 2.6 tons Cd/year to 7.2 or even 15.9 tons/year if all mineral fertiliser applied were to meet the minimum nutritional requirements (Römkens et al., 2016). Accumulation of $\mathrm{Cd}$ has been extensively documented both at farm level (Eckel, 2005), regional and national level like including but not limited to studies for the Netherlands (de Vries et al., 2004); Switzerland (Keller and Schulin, 2003) and the UK (Nicholson et al., 2006). On a local scale numerous case studies have been performed showing that in arable cropping systems inputs exceed outputs (e.g. Moolenaar and Lexmond, 1998; Keller and Schulin, 2003; resulting in a substantial accumulation 
of $\mathrm{Cd}$ in soil with time. Recent studies however also document a potential decline in accumulation rates either due to reduced inputs or increased removal via leaching (Salmanzadeh et al., 2017). However, the majority of studies including an EU-wide compilation of farm and field metal balances by Eckel et al (2005) show that metal accumulation is common but accumulation rates vary substantially between countries and farm type. Typical (median) accumulation rates for $\mathrm{Cd}$ are $+1.7 \mathrm{~g} \mathrm{ha}^{-1} \mathrm{yr}^{-1} \mathrm{but}$ the ranges are substantial and vary from $-0.3 \mathrm{~g} \mathrm{ha}^{-1} \mathrm{yr}^{-1}$ to $+20 \mathrm{~g} \mathrm{ha}^{-1} \mathrm{yr}^{-1}$. More recent estimates of $\mathrm{Cd}$ balances at EU level using representative average data from soils and $\mathrm{Cd}$ inputs and outputs also suggest that $\mathrm{Cd}$ balances at the EU level are close to equilibrium and predicted changes in the $\mathrm{Cd}$ content of soils range from $-64 \%$ to $+12 \%$ relative to the current level within 100 years from now (Six and Smolders, 2014). The latter results however are not based on real combinations of soil, land use and location but based on simulated distributions of soil properties and variable inputs. The distribution rates used, however are rather representative for the range in Cd levels in soils and soil properties.

Despite the range in observations of the degree of accumulation of $\mathrm{Cd}$ in specific arable cropping systems and the recent concern about current exposure levels due to intake of food (EFSA, 2012) most European agricultural soils still can be considered as relatively uncontaminated (Reimann et al., 2014) and the quality of food, ecosystem and water quality at large is not yet under threat (de Vries et al., 2007). This obviously does not apply to areas with high actual or historic inputs from industry. Such areas include for example areas near (former) mining sites (e.g. Van der Fels-Klerkx, 2011; Rodrigues et al., 2012) where levels in animal feed exceed current feed quality standards. This shows that there is a clear need for a regionally explicit tool to assess where Cd levels in soil can lead to excess exposure or $\mathrm{Cd}$ balances will remain positive thus leading to a further increase of the levels in soils.

At present, a model approach to calculate and compare metal balances and the impact of land use or proposed policy changes like the proposed revision of the EU Fertiliser Regulation (EU2003-2003) on soil and crop quality at a regional level across the EU, is still lacking. This is partly due to the fact that it proved to be quite difficult to obtain reliable data on the major components of the metal balance including both inputs and outputs (Eckel et al., 2005). Key issues to be addressed are a.o. the derivation a consistent set of input data related to levels of metals in various sources like manure, sludge and inorganic fertiliser across many different types of land use, climate soil type etc. Due to the variability in both application rates and quality of soil amendments like manure and compost direct estimates of inputs to soil and outputs from soil regarding metals are lacking in many countries across the EU. One of the first approaches to obtain estimates of accumulation rates and long term changes in soil quality on a national level has been developed for Canada (Sheppard et al., 2009). As such this is a first approach applied at this scale level but also here, the approach was based on a rather limited number of soil data and inputs of manure were related to contaminant levels in feed which is not necessarily representative for manure considering the wide range in metals in different feed compounds (Nicholson et al., 1999). To overcome this limitation, fluxes of metals to and from soils have to be derived partially from meta-information such as nutrient loading rates that can be converted to equivalent loading rates of metals. In this study we will use such data which are available at the regional level to convert fluxes of $\mathrm{N}$ and $\mathrm{P}$ to soil to fluxes of metals. This can be done based on available data regarding the metal to $\mathrm{N}$ or $\mathrm{P}$ ratio in the major inputs to soil including manure, fertiliser and sludge.

Aside from more precise estimates of inputs, also outputs from soil including leaching and crop uptake are often poorly quantified or based on average data. Even though leaching may not be equally relevant in all agro-ecosystems, in areas with high groundwater tables leaching of metals from soil to ground- and surface waters is one of the major pathways by which metals are released into the environment. Model studies by Moolenaar and Lexmond (1998) and Bonten et al. (2012) for the Netherlands indicate that leaching makes up for $70 \%$ of the total Cd outputs from soil (aside from crop off-take). Estimates at EU level (Six and Smolders, 2014) even suggest that leaching losses are equal to more than $90 \%$ of the total Cd output from soil. Despite the obvious relevance of leaching to construct a reliable $\mathrm{Cd}$ mass balance, $\mathrm{Cd}$ balances do not always account for leaching partially because reliable estimates of leaching fluxes are difficult to obtain. Hence, in most studies presenting $\mathrm{Cd}$ balances, models are used to estimate leaching losses. Clearly reliable estimates of leaching losses 
based on model predictions are prone to model uncertainty but during recent years various robust Cd partition models have been developed and calibrated that allow the user to calculate soil solution concentration based on a combination of soil properties including $\mathrm{pH}$, organic matter and clay content (a.o. Groenenberg et al., 2012; Six and Smolders, 2014). Such models appeared to give reliable results over a wide range of soils when applied to independent data. The same is true for crop uptake models and even though the contribution of crop uptake appears to be quantitatively smaller compared to leaching losses, relatively simple transfer models are now available and despite the variability between regions and crop varieties, such models allow for a reasonable estimate of crop off take rates of Cd from soil (McLaughlin et al., 2011).

The aim of this paper is to describe the framework of a spatially explicit model at EU-27 level that is able to calculate $\mathrm{Cd}$ metal balances at a regional level considering all relevant in- and outputs based on local, regional or national data in combination with models to calculate leaching and crop uptake rates. The model will be used to calculate current $\mathrm{Cd}$ balances at a regional level which will be upscaled to the national and EU level. Aside from the current balance ("Business as Usual", BaU) current $\mathrm{Cd}$ balances will be presented for grassland and arable land as well as Cd balances that reveal the impact of a range in $\mathrm{Cd}$ levels in mineral $\mathrm{P}$ fertilisers in line with the proposed Cd limits for mineral fertilisers (EU2003-2003). Results included in this chapter are based on the 2017 version of the Integrator model.

\subsection{Material and Methods}

\subsubsection{Model Outline}

To calculate $\mathrm{Cd}$ balances for the topsoil in agro-ecosystems the INTEGRATOR model is (De Vries et al., 2011a, b; Kros et al., 2012) is used. INTEGRATOR is an environmental agricultural model which calculates nitrogen and greenhouse gas emissions from housing and manure storage systems, agricultural soils, non-agricultural soils and surface waters for the EU-27 (note that for metals no data for Malta and Cyprus were included, results are presented for 25 Member States only). The model was developed to calculate detailed nutrient (N, P, K) balances at NCU and NUTS3 level considering a.o. inputs via (animal) manure, mineral fertiliser, lime, biosolids and atmospheric deposition as well as outputs including leaching losses, and crop removal rates. In addition some specific processes like volatilization and nitrogen fixation are accounted for in INTEGRATOR (de Vries et al., 2011a, $b$; Kros et al., 2012) but these are not considered relevant to calculate Cd mass balances. In addition, data for Malta and Cyprus have been omitted since these were largely not available.

Equation 1 shows the fluxes that are considered in the Cd balance, including both inputs and outputs:

$\mathrm{F}-\mathrm{Me} .=\mathrm{F}-\mathrm{Me}_{\text {man. }}+\mathrm{F}-\mathrm{Me}_{\text {inorgfert.. }}+\mathrm{F}-\mathrm{Me}_{\text {lime }}+\mathrm{F}-\mathrm{Me}_{\text {biosolids }} .+\mathrm{F}-\mathrm{Me}_{\text {atm dep. }}-\mathrm{F}-\mathrm{Me}_{\text {plup }}-\mathrm{F}-\mathrm{Me}_{\text {leach }}$

With

F-Me: $\quad$ Cadmium flux in $\mathrm{g} \mathrm{ha}^{-1} \mathrm{yr}^{-1}$

Man. Sum of cattle, pig and poultry manure

Inorgfert Sum of mineral N, P and $\mathrm{K}$ fertilisers

Lime Sum of lime and dolomite application rate

biosolids Total of compost and sewage treatment plant derived sludge

Atm.Dep Atmospheric deposition

Pl.up. Plant uptake

Leach Leaching loss from topsoils $(0-10 \mathrm{~cm}$ for grassland, $0-25 \mathrm{~cm}$ for arable land)

A schematic representation is given in Figure 5.1, this includes also an overview of the scale at which various data are available which either requires down- or upscaling.

Here, we only consider inputs and outputs to and from the topsoil, both for grassland and arable land. In case of grassland a depth of $10 \mathrm{~cm}$ was used, in arable soils a layer of $25 \mathrm{~cm}$ was used. These layers are assumed to be the most relevant in view of crop quality in that the majority of the uptake 
from soil will occur from the $0-10 \mathrm{~cm}$ layer (grassland) and the $0-25 \mathrm{~cm}$ (arable land). To calculate metal fluxes for all inputs from fertiliser, manure, and biosolids, the calculated nutrient fluxes for $\mathrm{N}, \mathrm{P}$ and $\mathrm{K}$ (INTEGRATOR) are converted to corresponding metal fluxes. This includes inputs from mineral fertiliser (for N, P, and K), animal manure (cow, pig and poultry), bio-solids (compost and sludge).

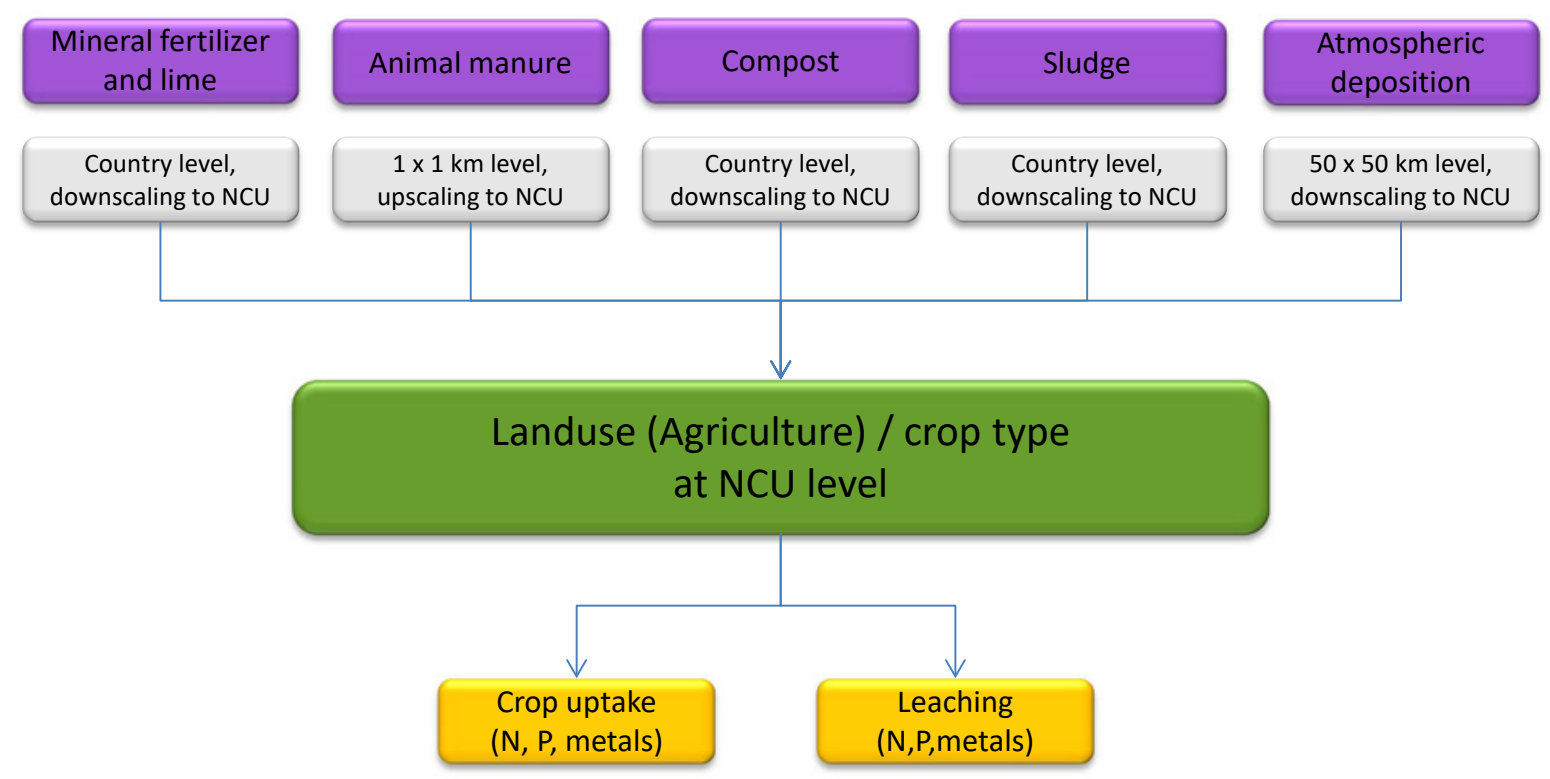

Figure 5.1 Main components considered in the mass balance model and scale level of original data

Inputs of metals by manure, sludge, fertiliser were calculated as the product of the load of the product in $\mathrm{kg} \mathrm{N}, \mathrm{P}$ or $\mathrm{K}$ per hectare per year and the metal to $\mathrm{N}, \mathrm{P}$ or $\mathrm{K}$ ratio of the specific product. This approach was chosen since application rates for $\mathrm{N}, \mathrm{P}$ and $\mathrm{K}$ are available at the desired scale level by the INTEGRATOR model and we thus only needed to convert $\mathrm{N}$ and $\mathrm{P}$ fluxes to metal fluxes. The Cdload from application of lime was calculated based on the total consumption rate of lime (data at country level) times the average cd content in lime. Data on atmospheric deposition were obtained from Ilyin et al. (2009) which provides regionally explicit inputs at a 50x50 km grid. Metal removal rates via crop off-take where was calculated via the crop yields based on the crops specified in the CAPRI (Britz and Witzke, 2008) database (removal rates in ton dry matter ha ${ }^{-1}$ ) which were converted to equivalent removal Cd rates using appropriate Uptake Factors for specific crops or crop groups. Leaching losses are calculated using the net water flux at the bottom of the layer considered (i.e. -10 or $-25 \mathrm{~cm}$ ) calculated as the difference between rainfall and crop specific evapotranspiration rates which are then multiplied by the calculated concentration of $\mathrm{Cd}$ in the corresponding layer considering differences in the $\mathrm{Cd}$ content of the soil, $\mathrm{pH}$, organic matter content and clay content.

\subsubsection{Basic data used at NCU level and calculation of nutrient fluxes}

\subsubsection{Source data used to derive representative data at NCU level}

Representative values for soil $\mathrm{pH}\left(\mathrm{pH} \mathrm{H}_{2} \mathrm{O}\right.$ and $\left.\mathrm{CaCl}_{2}\right)$ at $\mathrm{NCU}$ level to be used in Integrator, are derived from the Land Use/Cover statistical Area frame Survey (LUCAS) soil database (Tóth et al., 2013). A recently developed machine learning approach (Hengl et al., 2014) was used to derive $1 \times 1$ $\mathrm{km}$ data using the LUCAS source data, after which the median value of all grid cells within a specific NCU was used as representative value for the NCU as a whole. The Corine land use map (EEA, 2009) was used to distinguish between arable land and grassland to derive separate values for $\mathrm{pH}$ for both types of land use. Total Cd levels in soils at a $1 \times 1 \mathrm{~km}$ level applying the same technique were obtained using the data from the GEMAS (Geochemical Mapping of Agricultural and Grazing Land in Europe, Reiman et al., 2014) database. Considering the relatively low sample density in this database, the data from grassland and arable land were used together to derive the best fit model. At NCU level, a single representative value for $\mathrm{Cd}$ was derived using the best fit model using the median values from all individual $1 \times 1 \mathrm{~km}$ grid cells belonging to that NCU. The machine learning technique was also used 
to calculate NCU average levels of soil organic matter (SOM) and clay, but the resulting maps appeared to be implausible in various regions. Hence, for soil organic matter and clay, the data from the joint WISE, SPADE 1 and EFSDB databases were used, which jointly contain approximately 3,600 soil profiles, irregularly distributed over Europe (Heuvelink et al., 2014). Data for organic matter and clay content at NCU level were derived with a multivariate regression kriging model accounting for the spatial structure of the soil properties and their dependency on explanatory variables such as soil type and land cover (Heuvelink et al., 2016).

Atmospheric metal deposition (in $\mathrm{g} \mathrm{ha}^{-1} \mathrm{yr}^{-1}$ ) was derived by downscaling results from the EMEP heavy metal (HM) model (Ilyin et al., 2009) available in a $50 \mathrm{~km} \times 50 \mathrm{~km}$ grid to NCU level.

\subsubsection{Calculation of manure, mineral fertiliser, biosolid and lime application rates}

The total $\mathrm{N}$ and $\mathrm{P}$ loads via manure, mineral fertiliser, biosolids and lime were calculated based on $i$. crop nutrient demands, ii. total allowed manure application rates according to EU legislation (COM, 1991), iii. animal density and manure production per animal, iv. total country wide consumption rates of mineral fertiliser and biosolids and, $v$. soil pH for lime application (de Vries et al., 2011 a,b). Here we describe how inputs for the various fluxes were derived using country specific of EU-wide data depending on the availability and assumed variability between countries.

\section{Calculation of application rates of manure, fertiliser, and biosolids}

Initially the $\mathrm{N}$ and $\mathrm{P}$ load via manure is calculated based on the data on animal density and allowed manure application. If the amount of available manure exceeds the required amount, the excess manure is distributed in surrounding spatial units. Data on animal density, crop demand, crop type and soil type are available at the NCU level (Neumann et al., 2009; Kros et al., 2012) and hence used to calculate the manure application at NCU level. The remaining mineral fertiliser application rate, for which no data are available at NCU level, then are calculated as the difference between recommended application rates which are crop and soil specific and the application supplied via manure. This is done separately for $\mathrm{N}$ and $\mathrm{P}$. Subsequently the total calculated mineral fertiliser application rate, defined as the sum of all application rates at NCU per country, are scaled to the known national data to ensure that the total fertiliser consumption is in line with known data (de Vries et al., 2018). For both compost and sludge no spatially explicit application data are available and country wide consumption data, separate for compost and sludge, by agriculture are used (Barth et al., 2008; Evans, 2012) which are equally applied to the arable land fraction within the NCUs that is used for fodder production (maize) and arable crops with a medium to high $\mathrm{N}$ demand; no biosolids are applied to grassland. The equal distribution of biosolids across all arable land clearly is an oversimplification but the error thus introduced on the metal balance is small due to the small amount of biosolids used compared to manure and mineral fertiliser. For lime only country level consumption data are available (UNFCCC, 2012) and this amount is equally divided, at country level, among all arable land with a $\mathrm{pH}<6.5$. No distinction between Dolomite and lime was made and a single composition was used (Dittrich and klose, 2008) to calculate the resulting Cd inputs. With the exception of the UK and Ireland, lime was applied to arable land only.

In Table 5.1 an overview of the source data used in this study is given including the data that were used to calculate the corresponding metal load that results from the application of the fertilisers, biosolids and lime applied here. 
Table 5.1 Overview of source data and conversion used to derive country or EU specific levels of Cd in inputs

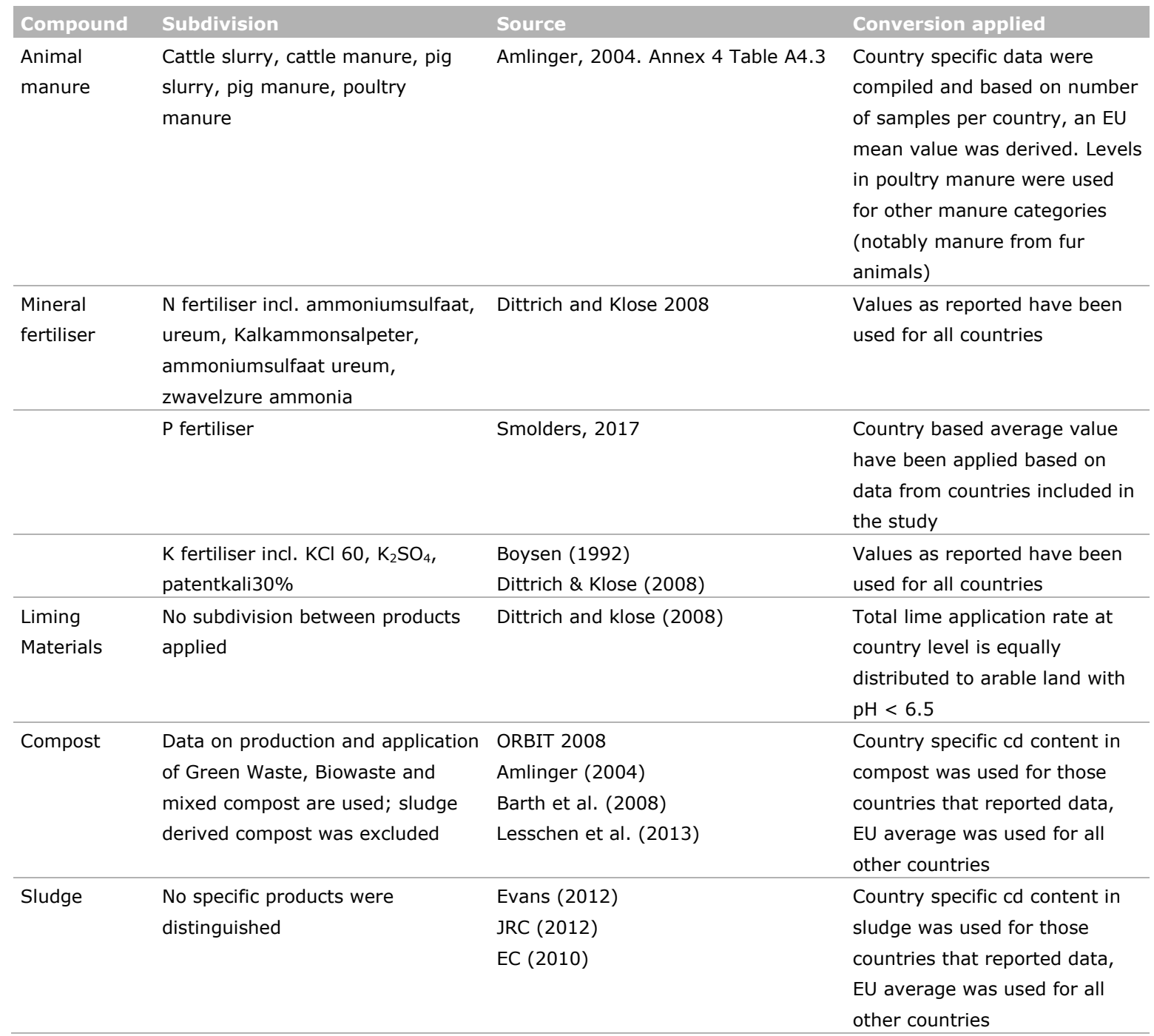

Source data used to calculate the metal load from fertilisers, lime, compost, sludge and animal manure

Country average values for the $\mathrm{Cd}$ content in $\mathrm{P}$ fertilisers have used derived from the study by Smolders (2017). In total 389 samples of $P$ fertilisers with a $\mathrm{P}_{2} \mathrm{O}_{5}$ content of $5 \%$ or more are included in the database. Country wide average levels of $\mathrm{Cd}$ expressed as $\mathrm{mg} \mathrm{Cd} \mathrm{kg}^{-1} \mathrm{P}_{2} \mathrm{O}_{5}$ range from 0.7 to $58.1 \mathrm{mg} \mathrm{Cd} \mathrm{kg}{ }^{-1} \mathrm{P}_{2} \mathrm{O}_{5}$. For countries without data a value of $32 \mathrm{mg} \mathrm{Cd} \mathrm{kg}^{-1} \mathrm{P}_{2} \mathrm{O}_{5}$ was used which is equivalent to the weighted mean value correcting for the actual use of $\mathrm{P}$ fertilisers in the countries included in the study (Smolders, 2017). For nitrogen and potassium fertilisers EU wide average data have been used as reported by Dittrich and Klose (2008) and Boysen (1992) without further specification. For lime, data from Dittrich and Klose (2008) were used for all countries to account for inputs of Cd via lime. To calculate country specific application rates for compost, data from ORBIT (2008) were used on country specific production rates and application rates in agriculture. Here we used data on Green compost (GC), Biowaste compost (BC) and Mixed compost (MC). Sludge based compost was not included since inputs from sludge are accounted for directly and double counting was thus avoided. Data from Amlinger (2004) and Barth et al. (2008) were used to calculate an EU-wide median cadmium level in each of these three types of compost after correction for the number of samples collected in each country. Recent data published by JRC (2014) indicate that average levels of metals in various types of compost largely remained the same as those published by Amlinger (2004). Data of the metal content for mixed waste compost are not available and the average of green waste and biowaste compost was used instead. For all countries the median value of all reported data has been used. Multiplication of the total compost application rate at country level of compost by the averaged $\mathrm{Cd}$ content in the three types of compost yields the total $\mathrm{Cd}$ load at country level. To calculate the country average Cd to P or N ratio, data from Lesschen (2013) were used who reported 
the average $\mathrm{N}$ and $\mathrm{P}$ content in $\mathrm{GC}, \mathrm{BC}$ and $\mathrm{MC}$. For those countries not included in the study by Amlinger (2004), the median value of all countries was used. Sludge production and application data at country level were taken from Evans (2012). The Cd content as well as the $\mathrm{N}$ and P content in sludge was based on country specific data as listed in the Working Document on Sludge and Biowaste (EC, 2010). For countries with no reported data the median value of data as reported by JRC (2012) was used. Data for manure at country level can vary substantially, even within countries. Here data for slurry (cattle and pig slurry) and solid manure (from cattle, pigs and poultry) were taken from Amlinger (2004) being a representative set of data at EU level. For each of the 5 types of manure distinguished, EU average values were derived and applied to all calculation units.

\subsubsection{Hydrology}

Water fluxes to and from soils were based on the approach from Keuskamp et al. (2012); this allows for the calculation of total runoff, surface runoff, and the excess water flowing recharging shallow groundwater at a $1 \times 1 \mathrm{~km}$ grid level. Differences in climate, rainfall, soil type, lithology, land use and irrigation are taken into account.

\subsubsection{Model inputs and conversions used to calculate cadmium fluxes from inputs considered}

\subsubsection{Animal manure}

Cadmium inputs via manure (in $\mathrm{g} / \mathrm{NCU}$ ) are calculated by multiplication of $\mathrm{N}$ excretion rates at NCU level (in $\mathrm{kg} / \mathrm{NCU}$ ) by the $\mathrm{Me} / \mathrm{N}$ ratio of manure for the 5 types of manure for which data are available:

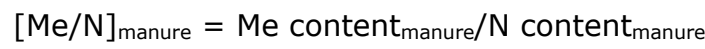

$\mathrm{Me}_{\text {load-NCU }}=\mathrm{N}$-excretion $\times \mathrm{Me} / \mathrm{N}$ ratio manure

The $\mathrm{Me} / \mathrm{N}\left(\mathrm{g}_{\mathrm{Me}} / \mathrm{kg} \mathrm{N}\right.$ ) ratio is derived for all eight types of manure used in Integrator by division of the metal content in manure (in $\mathrm{mg}_{\mathrm{Me}} / \mathrm{kg}$ dry matter) by the $\mathrm{N}$ content in manure (in $\mathrm{g} \mathrm{N} / \mathrm{kg}$ manure dry matter). In total eight types of manure (similar to those used to calculate $\mathrm{N}$ and $\mathrm{P}$ application rates for manure) are considered, including solid or liquid (slurry) manure. However, data for metal concentrations in manure from horses, sheep/goats and fur animals are largely missing. To account for this, data for cattle were used for sheep/goat/horses and data for poultry were used for fur animals. Even though it is likely that levels of metals in manure may differ between regions and/or countries, a single set of values for each type of manure has been used for all NCU's included in the calculations.

\subsubsection{Mineral fertiliser}

Metal inputs by fertiliser ( $\mathrm{kg} / \mathrm{NCU}$ ) are calculated by multiplying $\mathrm{N}, \mathrm{P}$ and $\mathrm{K}$ fertiliser inputs (at NCU level (kton N/NCU) with corresponding $\mathrm{Me} / \mathrm{N}, \mathrm{Me} / \mathrm{P}$ and $\mathrm{Me} / \mathrm{K}$ ratios $\left(\mathrm{kg}_{\mathrm{Me}} / \mathrm{kton} \mathrm{N}\right.$, equivalent to $\mathrm{mg}_{\mathrm{Me}} / \mathrm{kg} \mathrm{N}$ ) in the various fertilisers:

$M e_{\text {fertiliser }}=N_{\text {fertiliser }} \times M e / N+P_{\text {fertiliser }} \times M e / P+K_{\text {fertiliser }} \times M e / K$

The Nutrient to metal ratios have been used for 17 main types of fertilisers as used within Integrator including single nutrient as well as complex $(\mathrm{N}, \mathrm{P}, \mathrm{K})$ fertilisers. In case of complex fertilisers, double counting was avoided by using the dominant nutrient for such complex fertilisers only to calculate the corresponding metal load.

\subsubsection{Biosolids}

Cadmium inputs by biosolids (here we consider only sludge and compost in $\mathrm{kg} / \mathrm{NCU}$ ) are calculated by multiplying application rates of biosolids at NCU level (kton/NCU) with metal contents in biosolids (mg $\mathrm{Me} / \mathrm{kg}$ biosolid equivalent to $\mathrm{kg} \mathrm{Me/kton} \mathrm{biosolid):}$

$\mathrm{Me}_{\text {biosolid-NCU }}=\mathrm{N}-$ load $_{\mathrm{NCU}} \times[\mathrm{Me} / \mathrm{N}]_{\text {biosolids }}$

This was done separately for compost and sludge. 
For both compost and sludge the total reported $\mathrm{N}$ or $\mathrm{P}$ load via either compost or sludge in combination with the total metal load was used to derive a country average $\mathrm{Cd}$ to $\mathrm{N}$ or $\mathrm{P}$ ratio. This ratio was subsequently used in the scenario calculations at NCU level.

\subsubsection{Model Outputs and conversions used to calculate cadmium fluxes}

\subsubsection{Leaching}

Leaching of $\mathrm{Cd}$ from the upper soil layer to the deeper horizons is calculated according to:

$\mathrm{Cd}_{\mathrm{Le}}=\mathrm{Q}_{\mathrm{le}, \mathrm{dc}} \cdot[\mathrm{Cd}]_{\mathrm{ss}} / 1000$

where $\mathrm{Cd}_{\mathrm{le}}$ is $\mathrm{Cd}$ leaching rate from the topsoil $\left(\mathrm{g} \mathrm{ha}^{-1} \mathrm{yr}^{-1}\right), \mathrm{Q}_{\mathrm{le}, \mathrm{dc}}$ is water flux leaving the topsoil (depth of cultivation, $\mathrm{dc}_{\mathrm{n}} \mathrm{m}^{3} \mathrm{ha}^{-1} \mathrm{yr}^{-1}$ ) and $[\mathrm{Cd}]_{\mathrm{ss}}$ is the annual average total Cd concentration in soil solution ( $\mathrm{mg} \mathrm{m}^{-3}$ or $\mathrm{g} \mathrm{L} \mathrm{L}^{-1}$ ). To calculate the dissolved $\mathrm{Cd}$ concentration in solution a non-linear model was used similar to that developed by a.o. Tiktak et al. (1998), Elzinga et al. (1999), and Keller et al. (2001). Solution concentrations in a wide range of soils were obtained by a 1:10 (w:v) extraction using 0.002 and $0.01 \mathrm{M} \mathrm{CaCl}_{2}$ solutions (Römkens et al., 2004) which appear to mimic in situ soil solution concentrations of $\mathrm{Cd}$ (de Greyse et al., 2003). In these models $\mathrm{Cd}_{\mathrm{ss}}$, is predicted from the reactive soil metal content, $\mathrm{Cd}_{\mathrm{re}}$, that represents the total reversibly adsorbed $\mathrm{Cd}$ pool in soils (Groenenberg et al., 2017), when accounting for differences in organic matter (OM, in \%), clay (\%), $\mathrm{pH}_{\mathrm{CaCl} 2}$ (measured in $0.01 \mathrm{M} \mathrm{CaCl}_{2}$ ) and DOC (Dissolved Organic Carbon in $\mathrm{mg} \mathrm{C/L}$ ) according to (Römkens et al., 2004):

${ }^{10} \log \mathrm{Cd}_{\mathrm{ss}}=4.91+1.27 \cdot{ }^{10} \log \left[\mathrm{Cd}_{\mathrm{re}}\right]-0.73 \cdot{ }^{10} \log [\mathrm{OM}]-0.48 \cdot{ }^{10} \log [\mathrm{clay}]-0.39 \cdot \mathrm{pH}_{\mathrm{CaCl} 2}+0.08 \cdot{ }^{10} \log [\mathrm{DOC}]$

With $\mathrm{Cd}_{\mathrm{ss} \text { soil }}$ solution $\mathrm{Cd}\left(\mathrm{mmol} \mathrm{I}^{-1}\right), \mathrm{Cd}_{\mathrm{re}}$ the reactive $\mathrm{Cd}$ pool $\left(\mathrm{mol} \mathrm{kg}^{-1}\right)$,

Estimates of DOC can be obtained using an empirical regression model based on organic matter and $\mathrm{pH}$, according to (Römkens et al., 2004):

$\log [\mathrm{DOC}]=2.04+0.73 \cdot \log [\mathrm{SOM}]-0.17 \cdot \mathrm{pH}_{\mathrm{CaCl}}$

The reactive $\mathrm{Cd}$ pool is related to the total soil metal content, $\mathrm{Cd}_{\text {tot,soil, }}$ correcting for the soil organic matter content (SOM) and clay content according to (Römkens et al., 2004):

$\log \mathrm{Cd}_{\mathrm{re}}=-0.089+1.075 \cdot{ }^{10} \log \left[\mathrm{Cd}_{\mathrm{tot}, \text { soil }}\right]+0.022 \cdot{ }^{10} \log [\mathrm{SOM}]-0.062 \cdot{ }^{10} \log [\mathrm{clay}]$

\subsubsection{Crop uptake}

Removal of $\mathrm{Cd}$ in crops is calculated as the product of harvested biomass times the predicted $\mathrm{Cd}$ content in crops according to:

$\mathrm{Cd}_{\text {off }}=\mathrm{Y} * \mathrm{DM}$ crop $\cdot \mathrm{Cd}_{\text {crop }}$

where $Y$ is the harvested yield (ton ha ${ }^{-1}$ fresh weight), $D M_{\text {crop }}$ is dry matter content of the crops (-) and $\mathrm{Cd}_{\text {crop }}$ is the calculated concentration of $\mathrm{Cd}$ in the harvested crop ( $\mathrm{mg} \mathrm{kg}^{-1} \mathrm{dry}$ weight). Crop yields as well as the list of crops considered are taken from the CAPRI model (Britz and Witzke, 2008). The concentration of $\mathrm{Cd}$ in crops ( $\mathrm{Cd}_{\text {crop }}$ in $\mathrm{mg} \mathrm{kg}^{-1}$ dry matter) is calculated using a linear soil to plant transfer coefficient according to:

$\mathrm{Cd}_{\text {crop }}=\mathrm{BCF}_{\text {crop }} \cdot \mathrm{Cd}_{\text {tot, soil }}$

Where $\mathrm{Cd}_{\text {tot,soil }}$ is total $\mathrm{Cd}$ concentration in soil $\left(\mathrm{mg} \mathrm{kg}^{-1}\right.$ dry matter of soil) and $\mathrm{BCF}_{\text {crop }}$ are cropspecific bioconcentration factors (BCFs), relating the Cd content in crops to those in the soil.

Crop-specific bioconcentration factors (BCFs) for all distinguished crops including potatoes, sugar beets, other root crops; vegetables, barley, soft wheat, durum wheat, rye, oats, grain maize, rice, other cereals including triticale; sunflower, olives, oil crops (including rapeseed), citrus, grapes and other crops, were based on Lübben and Sauerbeck (1991); Versluijs and Otte (2001); Smolders et al., 
(2007) and Römkens et al. (2008, 2009). In reality, the relationship between Cd concentrations in crop and soil depends on soil properties such as $\mathrm{pH}$, clay content and organic matter contents (see e.g. Brus et al., 2002; De Vries et al., 2007b; Römkens et al., 2009, McLaughlin et al., 2011), but such relationships could not be derived for all crops and consequently, simple linear relationships were assumed in agreement with other studies (Six and Smolders, 2014, Smolders. 2017).

Outputs and Scenarios included in the study

The aim of this study is to provide a spatially explicit overview of the Cd balance in current agroecosystems. This includes the balance based on the current inputs and outputs, here called Business as Usual (BaU). Aside from the current balance this paper aims to provide insight in the impact of the proposed revision of EU2003/2003 regarding the quality of mineral fertiliser and other soil amendments, Revision of the Fertiliser Regulation (EU2003/2003) among others includes a proposal for a step-wise reduction of the maximum $\mathrm{Cd}$ content in mineral $\mathrm{P}$ fertilisers (Pcontent $>5 \%$ ) from $60 \mathrm{mg} \mathrm{Cd} \mathrm{kg}{ }^{-1} \mathrm{P}_{2} \mathrm{O}_{5}$ after approval of the proposal to $40 \mathrm{mg} \mathrm{Cd} \mathrm{kg}{ }^{-1} \mathrm{P}_{2} \mathrm{O}_{5} 3$ years after implementation of the proposal and $20 \mathrm{mg} \mathrm{Cd} \mathrm{kg}{ }^{-1} \mathrm{P}_{2} \mathrm{O}_{5} 12$ years after implementation. Here we will include these 3 levels as separate scenarios ( $\mathrm{Cd} 20, \mathrm{Cd} 40$ and $\mathrm{Cd} 60)$ as well as two additional scenarios; one being a maximum allowed content of $80 \mathrm{mg} \mathrm{Cd} \mathrm{kg}^{-1} \mathrm{P}_{2} \mathrm{O}_{5}$, a value being discussed by several stakeholders, the second one being a scenario without additional inputs of $\mathrm{Cd}$ via $\mathrm{P}$ fertilisers which serves as a reference to establish the contribution of $\mathrm{P}$-fertilisers relative to the other scenarios.

Cadmium balances for all scenarios will be calculated at NCU level and up-scaled to country and EU level to provide insight in the degree of accumulation, or depletion. As such the degree of accumulation or depletion which is the result of the $\mathrm{Cd}$ balance does not provide insight in the changes in the $\mathrm{Cd}$ content in soil with time. One of the key issues regarding $\mathrm{Cd}$ is however the question to what extent the proposed policy changes will affect $\mathrm{Cd}$ levels in soil. Aside from the current balance at time 0 (2017) and those related to proposed policy changes, long term (after 100 years) changes in the Cd content in soil will be calculated at NCU level.

Table 5.2 Summary of scenarios included in the model study

\begin{tabular}{ll} 
Scenario & Description \\
$\mathrm{BaU}$ & Business as Usual, current inputs as defined by Integrator \\
\hline $\mathrm{Cd0}{ }^{1}$ & Inputs from mineral $P$ fertiliser reduced to zero \\
\hline $\mathrm{Cd} 20^{1}$ & Level of $\mathrm{Cd}$ in mineral $P$ fertiliser set at $20 \mathrm{mg} \mathrm{Cd} \mathrm{kg}-1 \mathrm{P}_{2} \mathrm{O}_{5}$ \\
\hline $\mathrm{Cd} 40^{1}$ & Level of $\mathrm{Cd}$ in mineral $P$ fertiliser set at $40 \mathrm{mg} \mathrm{Cd} \mathrm{kg}^{-1} \mathrm{P}_{2} \mathrm{O}_{5}$ \\
\hline $\mathrm{Cd} 60^{1}$ & Level of $\mathrm{Cd}$ in mineral $P$ fertiliser set at $60 \mathrm{mg} \mathrm{Cd} \mathrm{kg}^{-1} \mathrm{P}_{2} \mathrm{O}_{5}$ \\
\hline $\mathrm{Cd} 80^{1}$ & Level of $\mathrm{Cd}$ in mineral $P$ fertiliser set at $80 \mathrm{mg} \mathrm{Cd} \mathrm{kg}^{-1} \mathrm{P}_{2} \mathrm{O}_{5}$ \\
\hline
\end{tabular}

${ }^{1}$ all inputs except those from mineral $\mathrm{P}$ fertiliser are similar to BaU scenario

\subsection{Soil properties and Cd levels in soil}

In Figure 5.2 the resulting maps containing input data for the calculations are shown for cadmium, $\mathrm{pH}-\mathrm{CaCl}_{2}$, Organic Carbon content and clay content as calculated at the $1 \times 1 \mathrm{~km}$ level. Here only those areas are shown that are in use for arable crop production or managed grassland. Natural grassland not used for crop or fodder production or natural areas not receiving manure or fertiliser as well as mountainous areas are not included. 

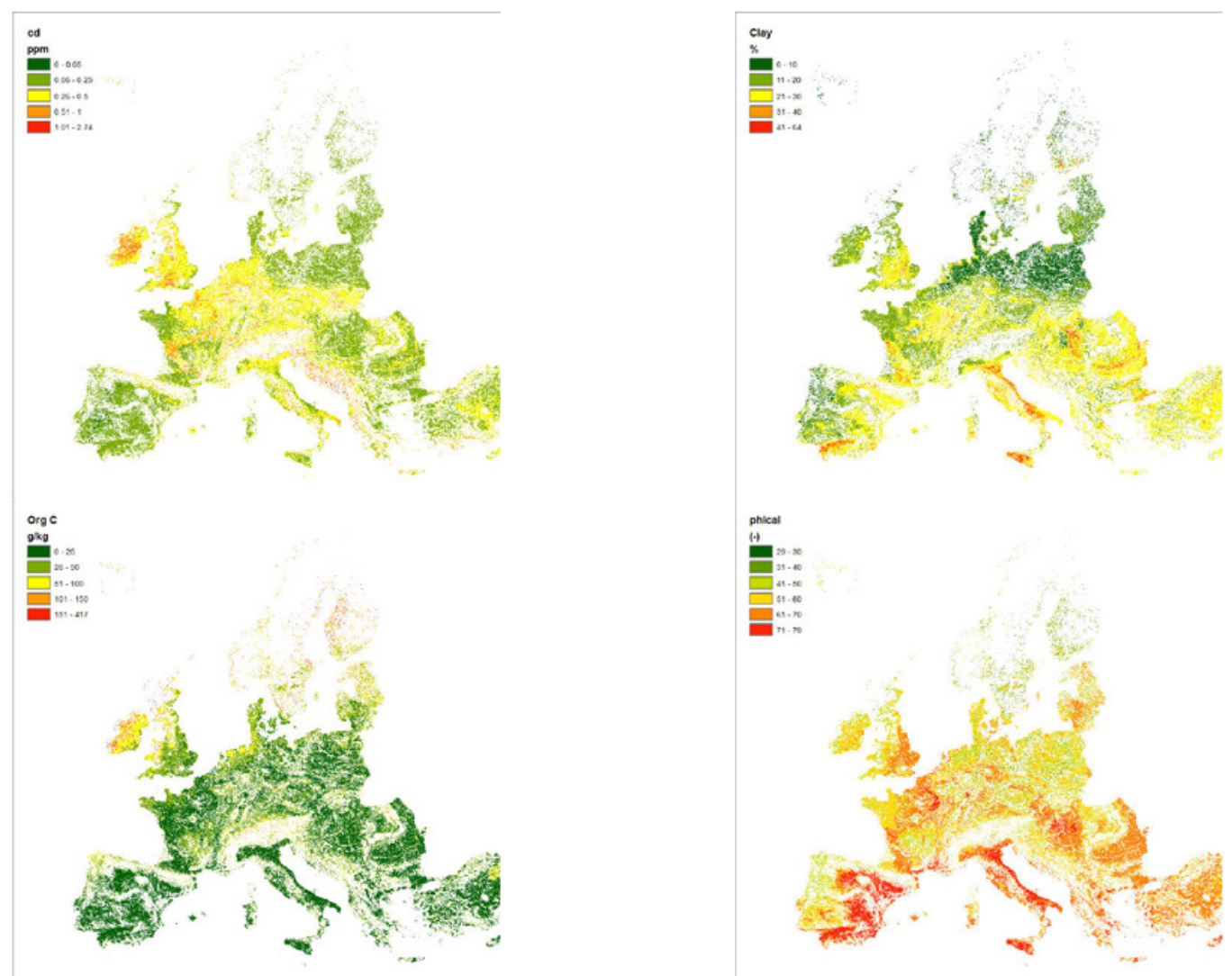

Figure 5.2 Overview of spatial distribution of Cadmium in the topsoil, clay content, soil organic Carbon content and $\mathrm{pH} \mathrm{CaCl}_{2}$ used in the Integrator model

In Table 5.3 a summary of the soil properties is given based on the aggregated distribution at NCU level for arable and grassland separately.

Table 5.3 Overview of regionally explicit soil data used at NCU level

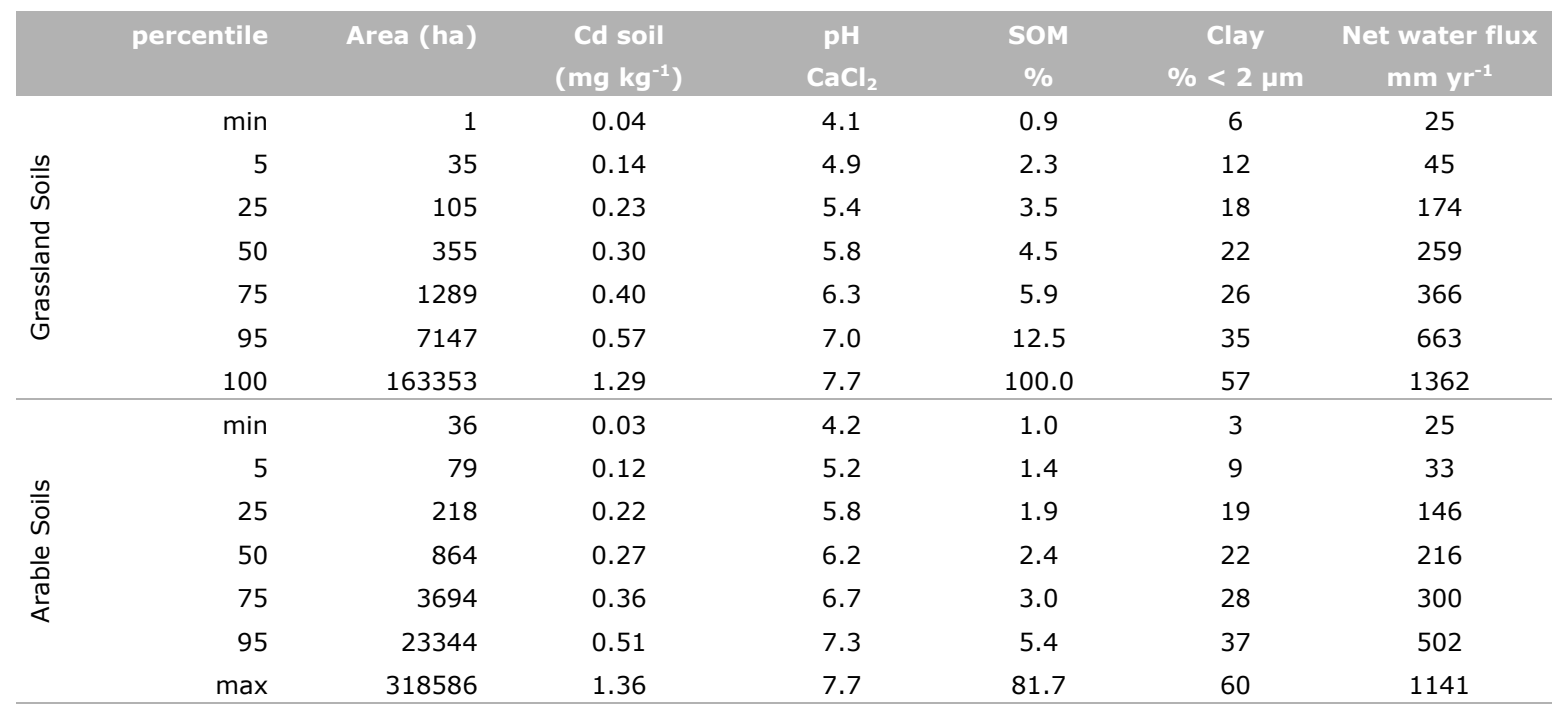

Data in Table 5.3 show that the range in Cd levels in soils range from $<0.1 \mathrm{mg} \mathrm{kg}^{-1}$ to approx. $1.3 \mathrm{mg}$ $\mathrm{kg}^{-1}$ in both arable and pasture soils. The median value of 0.3 (arable) -0.36 (grassland) soils reflects the impact of higher organic matter levels in grassland soils which leads to slightly higher estimates of $\mathrm{Cd}$ in pasture soils. Soils rich in organic matter ( $>10 \%)$ are largely found in north-western parts of the EU including the peat soils commonly found in among others Ireland, Scandinavia and parts of 
Denmark, the Netherlands and Germany. Median pH levels range from 5.8 in pasture soils to 6.2 in arable soils and represent normal values for such forms of landuse. In general pH levels in soils tend to be higher in the calcareous soils in the Mediterranean soils compared to the more acidic soils in the north-western parts of the EU. On average EU soils are characterized by a medium high clay content even though there is a clear distinction between the more sandy soils in the north-western parts of Europe versus the clayey soils that dominate the Mediterranean area. The resulting map of Cd levels in soil reflects a mixture of both history of pollution, elevated background levels, soil type and land use. Relatively high Cd levels are observed in among others the Netherlands, Belgium and the UK which is largely related to diffuse and point source pollution. Elevated levels in a.o. Croatia are largely related to elevated background levels in the rocks from which the soils are formed. Low levels of Cd are found in the Scandinavian countries due to a combination of low emission, low soil pH and high rainfall which favours the leaching of Cd from the topsoil. Soil Cd levels are also low in Portugal and Spain which reflect both low background levels and low historic emission from industry or traffic. Data in Table 5.3 also reveal that there is a large range in surface area covered by the NCU areas, ranging from 1 ha to more than 300000 ha. In order to calculate country or even EU wide representative average values we therefore present such data after correction for surface area.

\subsubsection{Current cadmium balances in agroecosystems at country and EU level}

Current surface weighted EU average balances for Cd are slightly positive in arable soil $(+0.59 \mathrm{~g} \mathrm{Cd}$ $\left.\mathrm{ha}^{-1} \mathrm{yr}^{-1}\right)$ and slightly negative for pasture soils $\left(-0.49 \mathrm{~g} \mathrm{Cd} \mathrm{ha}^{-1} \mathrm{yr}^{-1}\right)$. Due to the larger are used for arable soils compared to pasture, the overall net Ca balance is positive which indicates that at present, $\mathrm{Cd}$ is still accumulating in soils. Positive balances for $\mathrm{Cd}$ in arable cropping systems and/or associated increases in Cd levels in soils with time have been reported by many authors both for European cropping systems (Moolenaar and Lexmond, 1998; Keller et al. 2001, Keller and Schulin, 2003) as well as those in Canada (Sheppard et al., 2009), Australia (de Vries and McLaughlin, 2013) and China (Wang et al., 2014). The majority of published balances are limited to specific farms or farming systems and a spatially explicit analysis at the European level is still lacking. For the Netherlands a spatially explicit model was developed by Tiktak et al. (1998) which was able to explain regional trends in the Cd levels in soil; results indicated that in most cropping systems Cd levels in soil increased from 0.09 in 1930 to $0.27 \mathrm{mg} \mathrm{kg}^{-1}$ in 1990 . Trends of increasing Cd levels in soils were observed in Australia as well (De Vries and McLaughlin, 2013) which basically suggests that in a large number of cropping systems positive Cd balances have dominated. Recent studies by Six and Smolders (2014) and Smolders (2017) for the EU, however seem to suggest that the Cd balance is, on average negative (average: $-1.0 \mathrm{~g} \mathrm{Cd} \mathrm{ha}^{-1} \mathrm{yr}^{-1}$ ) which would lead to a decrease in the soil Cd content with time. The main reason for the deviation in the results by Six and Smolders (2014) and Smolders (2017) compared to other balance studies is the markedly higher calculated leaching loss which results in a net removal of $\mathrm{Cd}$ from soil in current cropping systems included in the assessment (potato and wheat). A second reason that has affected the Cd balance is the marked decrease in atmospheric deposition with time. For the Netherlands it was estimated that average deposition levels increased up to $2 \mathrm{~g} \mathrm{Cd} \mathrm{ha}^{-1} \mathrm{yr}^{-1}$ until the mid-1980's but decreased sharply afterwards to values below $1 \mathrm{~g} \mathrm{Cd} \mathrm{ha}^{-1} \mathrm{yr}^{-1}$, present values being close to $0.58 \mathrm{~g} \mathrm{Cd} \mathrm{ha}^{-1} \mathrm{yr}^{-1}$ as used in this study.

Data in Table 5.4 indicate that the contribution from mineral fertilisers in arable land is the dominant source of $\mathrm{Cd}$ and contributes to $45 \%$ of the total load to soils for arable land and pasture combined. Atmospheric deposition however is still an important source of $\mathrm{Cd}$ inputs to agricultural soils despite the reduction that was achieved during the last decades. In grassland soils, inputs via atmospheric deposition is still larger than that of fertilisers. The contribution of biosolids at EU level is limited and amounts to only $4 \%$ of the total load to agricultural soils. Since it was assumed in the model that biosolids are applied only to arable soils, inputs to grassland are equal to zero. One of the current issues in the Integrator model is related to the fact that plot specific application rates of biosolids are lacking and an equal distribution among all arable land was assumed. Clearly biosolids are not applied equally across all land and the impact on the local Cd balance can be expected to be larger in those fields actually receiving bioslids compared to those not receiving biosolids. An overview by Nicholson et al. (2006) indicates that Cd loads from biosolid treated fields can be as high as $19 \mathrm{~g} \mathrm{Cd} \mathrm{ha}^{-1} \mathrm{yr}^{-1}$ assuming that biosolids are used as prima source for $\mathrm{N}$ fertilisation. Clearly such application rates are not common but such data indicate that the local application of biosolids can significantly alter the 
(local) Cd balance. The contribution of animal manure to the total load of Cd is also limited (18\%) which is due to the low levels of $\mathrm{Cd}$ in animal feed and additives commonly used in agriculture. At EU level, the major output of Cd from the soil occurs via leaching. Both in pasture soils and arable soils the net outflow via leaching exceeds inputs via fertiliser or atmospheric deposition. Crop uptake also leads to a net removal of Cd from soil but the average removal rate of $0.26 \mathrm{~g} \mathrm{Cd} \mathrm{ha}^{-1} \mathrm{yr}^{-1}$ is 2 to 5 times lower than net leaching losses. Due to the lower soil $\mathrm{pH}$ and, on average, higher net water flows in pasture soils, the leaching from pasture is markedly higher $\left(-1.21 \mathrm{~g} \mathrm{Cd} \mathrm{ha}^{-1} \mathrm{yr}^{-1}\right)$ than that in arable soils $\left(-0.55 \mathrm{~g} \mathrm{Cd} \mathrm{ha}^{-1} \mathrm{yr}^{-1}\right)$ which is also the main reason why current $\mathrm{Cd}$ balances in pasture soils are negative compared to the slightly positive results in arable soils.

Table 5.4 Overview of Cd Inputs, Outputs and resulting balance at EU level in $\mathrm{g} \mathrm{Cd} \mathrm{ha-1} \mathrm{yr}^{-1}$ (left) and total load (in ton $\mathrm{yr}^{-1}$ ) and the relative contribution of all fluxes (between brackets in) in 2017 for the Business as Usual scenario

\begin{tabular}{|c|c|c|c|c|c|c|}
\hline & \multicolumn{3}{|c|}{ Cd Load (g Cd ha ${ }^{-1} \mathrm{yr}^{-1}$ ) } & \multicolumn{3}{|c|}{ Total load (ton Cd $\mathrm{yr}^{-1}$ ) } \\
\hline & Grassland & Arable & Total & Grassland & Arable & Total \\
\hline Surface Area (ha) & $3.82 \mathrm{E}+07^{1}$ & $1.13 E+08$ & $1.52 \mathrm{E}+08$ & $3.82 \mathrm{E}+07^{1}$ & $1.13 \mathrm{E}+08$ & $1.52 \mathrm{E}+08$ \\
\hline Manure & 0.16 & 0.26 & 0.23 & 6.1 & 29.5 & $34.9(18 \%)$ \\
\hline Min. Fert. ${ }^{2}$ & 0.39 & 0.64 & 0.58 & 14.9 & 72.6 & $87.9(45 \%)$ \\
\hline Sludge & 0 & 0.06 & 0.04 & 0.0 & 6.8 & $6.1(3 \%)$ \\
\hline Atm. Dep. & 0.43 & 0.42 & 0.42 & 16.4 & 47.6 & $63.7(33 \%)$ \\
\hline Plant Uptake & -0.26 & -0.26 & -0.26 & -9.9 & -29.5 & $-39.4(27 \%)$ \\
\hline Leaching & -1.21 & -0.55 & -0.71 & -46.3 & -62.4 & $-107.7(73 \%)$ \\
\hline
\end{tabular}

${ }^{1}$ excluding rough grazing (non-managed grassland)

2 including liming materials

One of the clear advantages of a spatially explicit approach is the capacity to perform an upscaling of the results from the $1 \times 1 \mathrm{~km}$ grid level to NCU, country or even EU level (as presented in Table 5.4). To illustrate the difference in inputs at country level the relative contribution of atmospheric deposition, manure, mineral fertiliser and manure for pasture soils and arable soils is given in Figure 5.3. Striking differences can be observed for the contribution of atmospheric deposition which is still the dominant source of Cd in a.o. Bulgaria, Hungary, Romania and Slovakia for both pasture soils and arable soils. Relatively large contributions from animal manure are observed in countries with intensive livestock breeding systems like the Netherlands and Belgium. Inputs from mineral fertilisers are especially high in Spain and Portugal. 


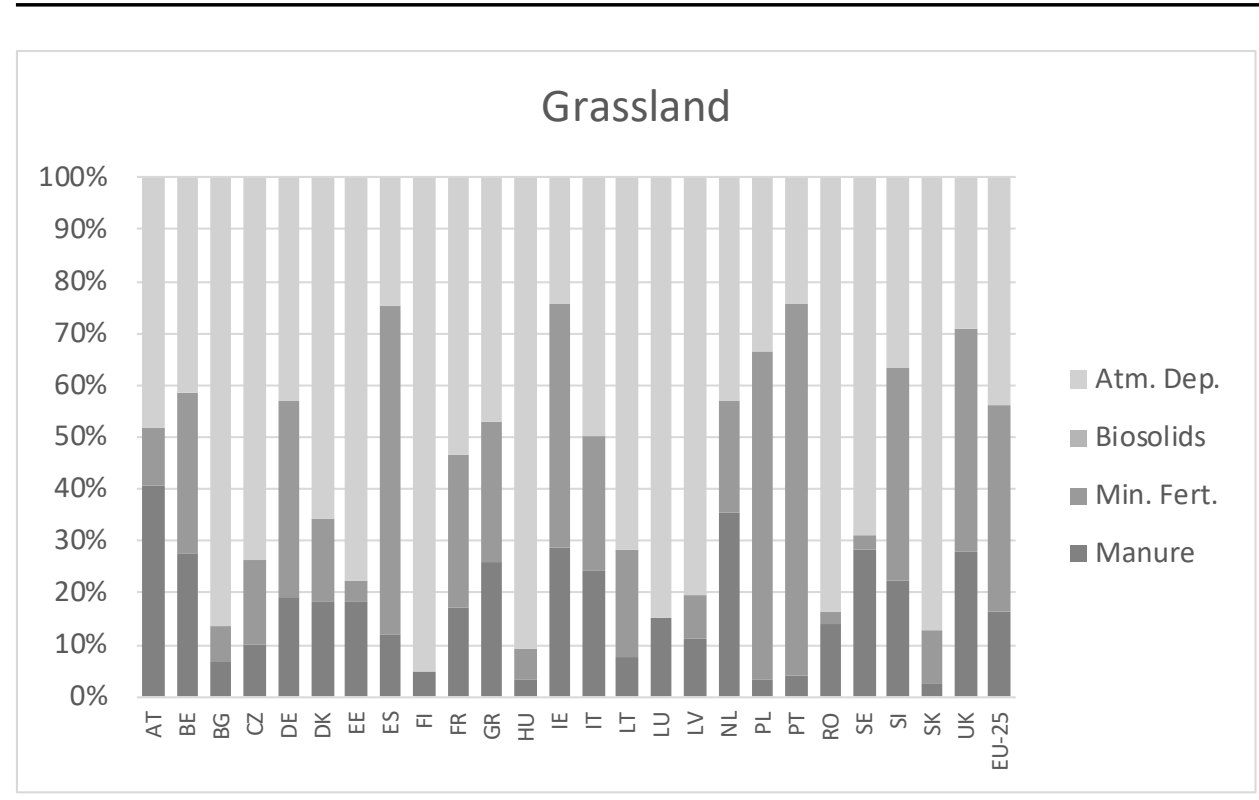

Figure 5.3a Variation in contribution of inputs at country level for grassland soils

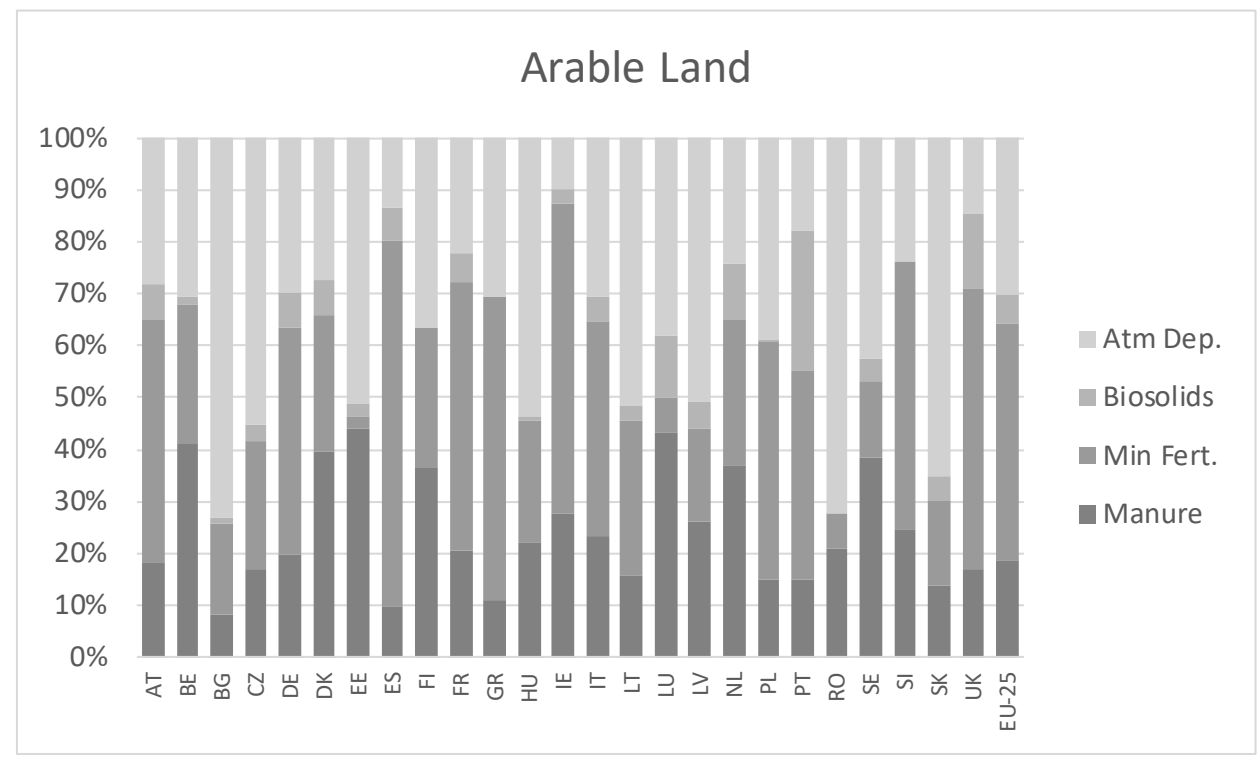

Figure 5.3b Variation in contribution of inputs at country level for arable soils

In Figure 5.4 the total balance (inputs - outputs) at country level is shown for pasture (top) and arable soils (bottom). For pasture soils, net depletion is commonly observed with quite explicit negative balances for a.o. Ireland, Slovakia, Belgium and Austria. In most cases this is related to a combination of a net high water leaching rate (high rainfall, limited evaporation) in combination with predominantly low $\mathrm{pH}$ soils which result in high predicted dissolved $\mathrm{Cd}$ concentrations in these countries. The positive balance for Poland, Portugal and Spain on the other hand is due to a high application rate of fertiliser ( 0.7 to $1.7 \mathrm{~g} \mathrm{Cd} \mathrm{ha}^{-1} \mathrm{yr}^{-1}$ ), or atmospheric deposition (Bulgaria). For arable soils the distribution is similar to pasture soils albeit that most balances are shifted to a positive value. Exceptions for this trend are Belgium and the Netherlands which have a markedly more negative balance. This is largely due to the fact that in both countries the use of mineral $P$ fertiliser is lower compared to other countries since many farmers use animal manure as the main source for $P$ fertilisation and little mineral $P$ fertiliser is required to match the crop demand. Since $\mathrm{Cd}$ levels in animal manure are lower than those in mineral fertiliser the $\mathrm{Cd}$ load to arable soils related to $\mathrm{P}$ fertilisation is low. Additional factors are a rather crop production rate (see Figure 5.5) and high leaching losses due to both lower $\mathrm{pH}$ values (compared to calcareous soils) and higher water fluxes (compared to those in southern EU countries). 

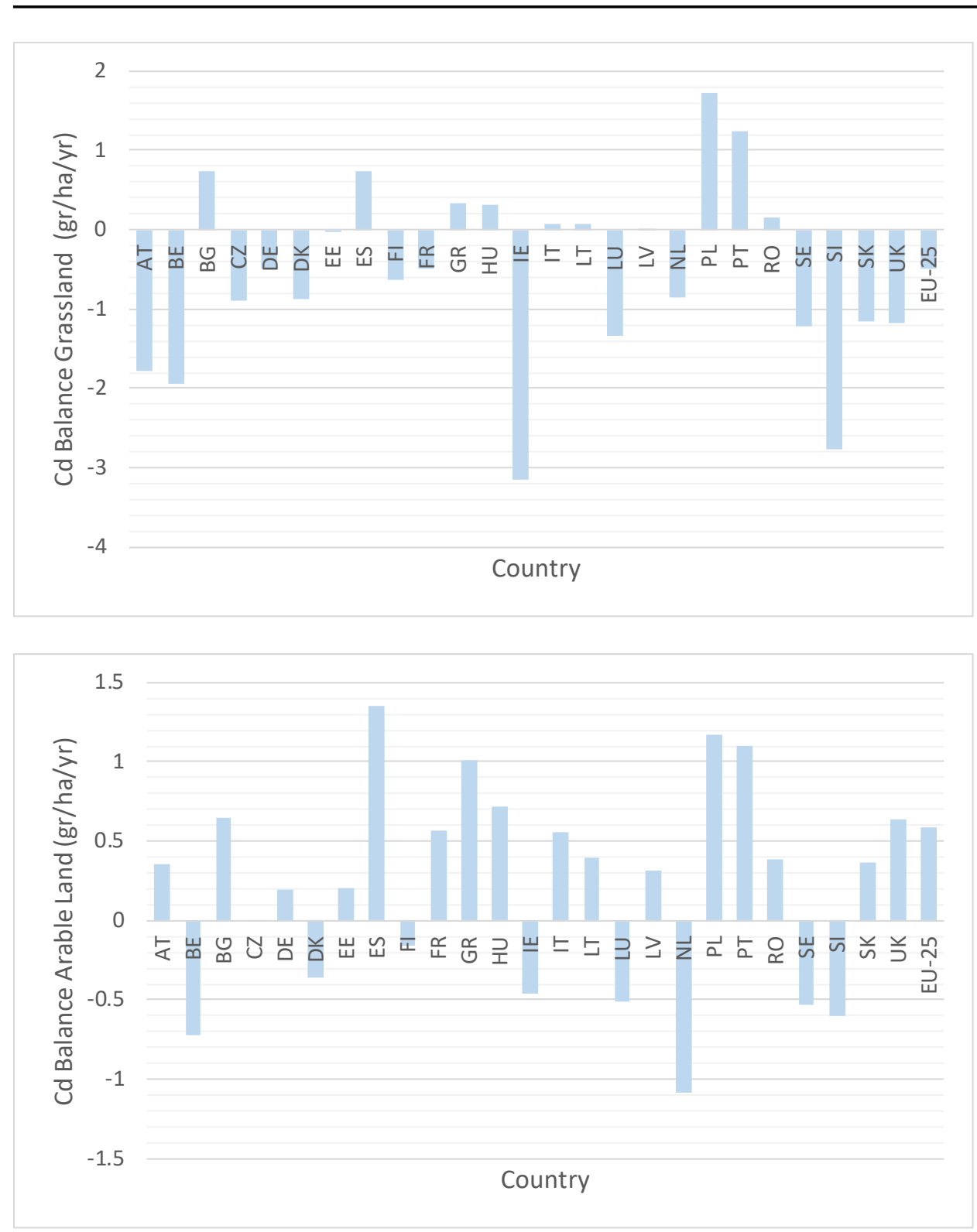

Figure 5.4 Overview of current Cd balance at country and EU-27 level in Grassland (top) and Arable soils (bottom), note the differences in the scale of the $Y$-axes 

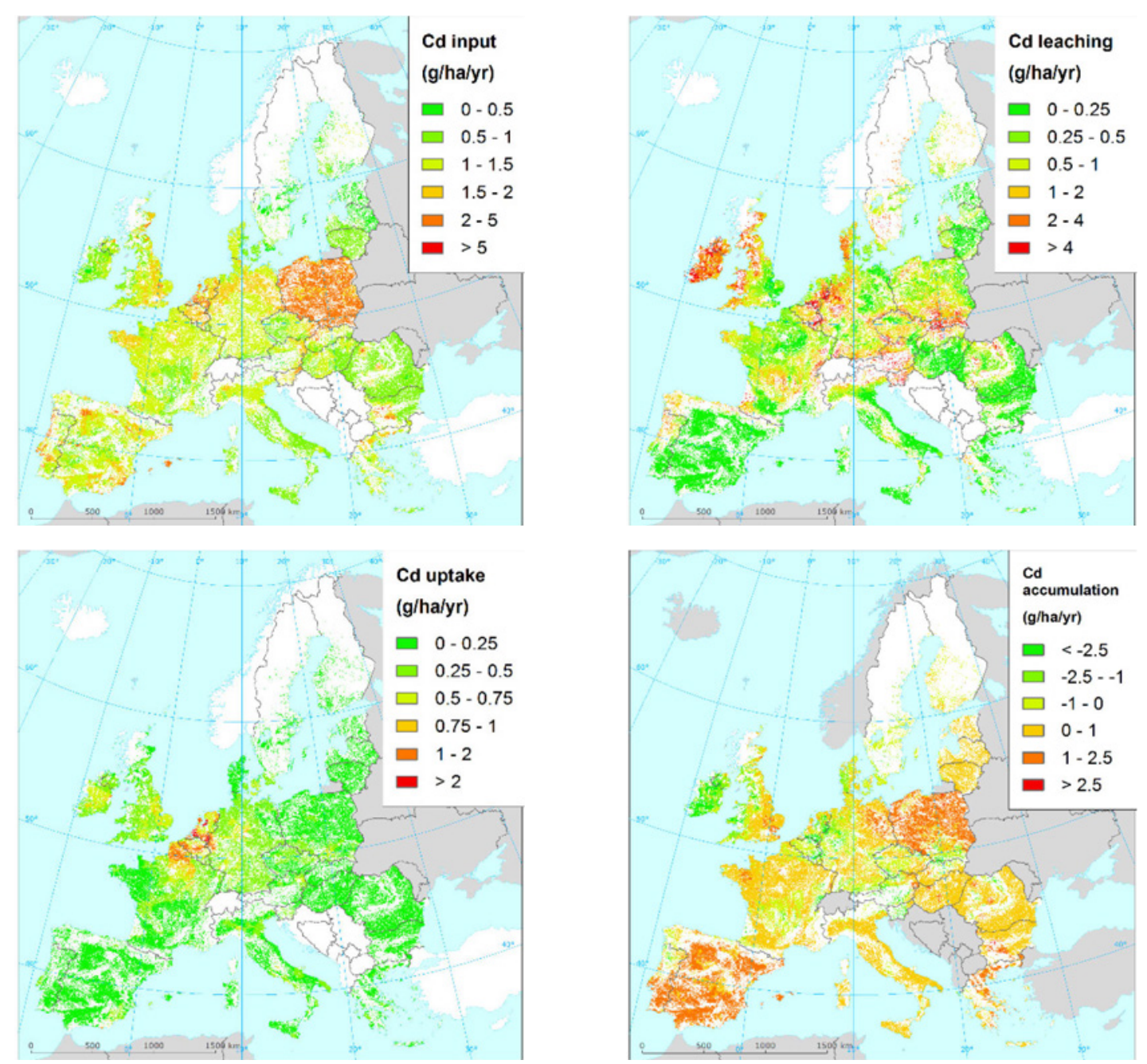

Figure 5.5 Spatial distribution of inputs, outputs and net Cd balance at EU level (data NCU)

Figure 5.5 presents the spatial distribution of the main Cd fluxes with a distinction between the two major outputs leaching and crop uptake. In general outputs from leaching exceed those via crop uptake and the graph with leaching losses clearly defines those areas with either high rainfall (NW Europe), low pH soils (central EU, UK, NW part of Portugal) and/or elevated Cd levels in soil (areas in Central Europe). The resulting map of $\mathrm{Cd}$ balances therefore shows a marked distribution across Europe which reflects a combination of both impact of soil properties or land use. The combination of high rainfall, low pH soils leads to negative balances in a.o. Ireland, Belgium and the Netherlands whereas accumulation is dominant in most of the Mediterranean countries as well as Central and Eastern Europe due to either the presence of high $\mathrm{pH}$, fine textured soils in combination (for Spain and Poland especially) with high consumption rates of mineral P fertilisers and/or low leaching rates. At country level such differences lead to $\mathrm{Cd}$ balances (pasture and arable combined) that range from $-2.5 \mathrm{~g} \mathrm{Cd} \mathrm{ha}^{-1} \mathrm{yr}^{-1}$ for Ireland to $+1.28 \mathrm{~g} \mathrm{Cd} \mathrm{ha}^{-1} \mathrm{yr}^{-1}$ for Poland. 


\subsection{Impact of policy changes on Cd balance and Cd levels in soil}

One of the aims of this paper was to assess to what extent changes in the allowed Cd content in fertiliser will affect the balance at regional (NCU/NUTS), national and EU level. To this purpose changes in the current balance (Table 5.5, Figure 5.6) at country level as well as long term changes in the soil Cd content (Figure 5.6) have been calculated using the same model settings except for the allowed $\mathrm{Cd}$ content in mineral $\mathrm{P}$ fertilisers which varies between 0 and $80 \mathrm{mg} \mathrm{Cd} \mathrm{kg}{ }^{-1} \mathrm{P}_{2} \mathrm{O}_{5}$ which represents the current proposed ranges (corresponding to a proposed maximum level of $60 \mathrm{mg} \mathrm{Cd} \mathrm{kg-}$ ${ }^{1} \mathrm{P}_{2} \mathrm{O}_{5}$ which is to be reduced to 40 and $20 \mathrm{mg} \mathrm{Cd} \mathrm{kg}^{-1} \mathrm{P}_{2} \mathrm{O}_{5}$ within a yet to be specified amount of years) as well as the zero input of $\mathrm{Cd}$ from mineral $\mathrm{P}$ fertilisers. Data in Table 5.5 reveal that for pasture the balance for $\mathrm{Cd}$ will remain negative and only at the level of $80 \mathrm{mg} \mathrm{Cd} \mathrm{kg-1} \mathrm{P}_{2} \mathrm{O}_{5}$ a net zero balance is observed. For arable land however, the reverse is true and stand-still, i.e. no accumulation is obtained only if no $\mathrm{Cd}$ is added to soil via mineral fertiliser (Cd-0 scenario). As was observed for the current balances and the variation therein, the impact of the proposed range in Cd levels in $P$ fertilisers has difference consequences depending on the country. For arable land, which in view of food safety is perhaps of more relevance compared to pasture, balances in the Netherlands, Belgium, Sweden and Denmark remain largely negative and even at $60 \mathrm{mg} \mathrm{Cd} \mathrm{kg}{ }^{-1} \mathrm{P}_{2} \mathrm{O}_{5}$ there is equilibrium between inputs and outputs. On the other hand, the majority of countries will not achieve a balance between inputs and outputs even when reducing Cd inputs from mineral fertiliser to zero. Apparently inputs from other sources than fertilisers are such that accumulation will continue even without inputs from fertilisers. In Figure 5.6 a spatial distribution of current balances (upper left) and changes in the balances relative to the current situation for the remaining scenarios ( $C d-0$ to $\mathrm{Cd}-80$ ) is given. Clearly a reduction to zero inputs will lead to a reduction in the supply and hence a decrease of the accumulation as is reflected by the Cd-0 scenario map. The Cd-40 map clearly reveals the difference between countries which, at present, use below and above average Cd-P fertilisers. Where most countries at present use fertilisers with an average Cd content below or close to $40 \mathrm{mg} \mathrm{Cd} \mathrm{kg}{ }^{-1} \mathrm{P}_{2} \mathrm{O}_{5}$, Poland, Spain and Portugal use fertiliser with, on average higher levels of $\mathrm{Cd}$ in $\mathrm{P}$ fertiliser which results in a reduced load compared to current loads if the limit were to be set at $40 \mathrm{mg} \mathrm{Cd} \mathrm{kg}^{-1} \mathrm{P}_{2} \mathrm{O}_{5}$. The $\mathrm{Cd}-60$ and $\mathrm{Cd}-80$ maps illustrate that at present the average $\mathrm{Cd}$ content used is below 60 (or 80) $\mathrm{mg} \mathrm{Cd} \mathrm{kg}^{-1} \mathrm{P}_{2} \mathrm{O}_{5}$ which implies that these scenarios will lead to an increase in the accumulation as was shown at country level as well (Table 5.5). 
Table 5.5 Present surface weighted mean Cd balances at EU-27 (excl Malta and Cyprus) and country level (in $\mathrm{g} \mathrm{Cd} \mathrm{ha-1} y r^{-1}$ )

\begin{tabular}{|c|c|c|c|c|c|c|c|c|c|c|c|c|}
\hline \multirow[b]{3}{*}{ Country } & \multicolumn{12}{|c|}{ Land Use } \\
\hline & \multicolumn{6}{|c|}{ Grassland } & \multicolumn{6}{|c|}{ Arable Land } \\
\hline & $\mathrm{BaU}$ & $\mathrm{CdO}$ & $\mathrm{Cd} 20$ & $\mathrm{Cd} 40$ & Cd60 & $\mathrm{Cd} 80$ & $\mathrm{BaU}$ & $\mathrm{CdO}$ & $\mathrm{Cd} 20$ & $\mathrm{Cd} 40$ & $\mathrm{Cd} 60$ & $\mathrm{Cd} 80$ \\
\hline AT & -1.78 & -1.87 & -1.82 & -1.77 & -1.72 & -1.67 & 0.36 & -0.33 & 0.05 & 0.44 & 0.82 & 1.20 \\
\hline $\mathrm{BE}$ & -1.93 & -2.35 & -1.97 & -1.58 & -1.20 & -0.82 & -0.72 & -1.20 & -0.76 & -0.31 & 0.13 & 0.57 \\
\hline $\mathrm{CZ}$ & -0.89 & -1.04 & -0.88 & -0.72 & -0.56 & -0.40 & -0.01 & -0.26 & 0.00 & 0.27 & 0.54 & 0.80 \\
\hline $\mathrm{DE}$ & -0.49 & -0.86 & -0.57 & -0.28 & 0.00 & 0.29 & 0.19 & -0.28 & 0.09 & 0.46 & 0.83 & 1.20 \\
\hline DK & -0.87 & -0.92 & -0.87 & -0.81 & -0.75 & -0.70 & -0.36 & -0.54 & -0.36 & -0.17 & 0.01 & 0.19 \\
\hline $\mathrm{EE}$ & -0.02 & -0.03 & 0.11 & 0.25 & 0.38 & 0.52 & 0.20 & 0.20 & 0.37 & 0.55 & 0.72 & 0.89 \\
\hline GR & 0.33 & 0.10 & 0.24 & 0.38 & 0.51 & 0.65 & 1.01 & 0.22 & 0.69 & 1.17 & 1.64 & 2.12 \\
\hline $\mathrm{HU}$ & 0.31 & 0.27 & 0.31 & 0.35 & 0.39 & 0.42 & 0.72 & 0.48 & 0.70 & 0.92 & 1.14 & 1.36 \\
\hline IE & -3.14 & -3.33 & -3.21 & -3.09 & -2.97 & -2.85 & -0.46 & -1.39 & -0.81 & -0.23 & 0.35 & 0.93 \\
\hline IT & 0.07 & -0.10 & 0.05 & 0.20 & 0.35 & 0.50 & 0.56 & 0.12 & 0.51 & 0.90 & 1.28 & 1.67 \\
\hline $\mathrm{LT}$ & 0.07 & -0.04 & 0.11 & 0.25 & 0.39 & 0.53 & 0.40 & 0.19 & 0.48 & 0.77 & 1.05 & 1.34 \\
\hline LU & -1.34 & -1.34 & -1.12 & -0.91 & -0.69 & -0.48 & -0.51 & -0.51 & -0.29 & -0.08 & 0.14 & 0.36 \\
\hline LV & 0.01 & -0.02 & 0.03 & 0.08 & 0.13 & 0.18 & 0.32 & 0.21 & 0.41 & 0.61 & 0.80 & 1.00 \\
\hline $\mathrm{NL}$ & -0.86 & -1.12 & -0.97 & -0.82 & -0.67 & -0.52 & -1.08 & -1.64 & -1.32 & -0.99 & -0.67 & -0.35 \\
\hline PL & 1.72 & -0.01 & 0.84 & 1.69 & 2.54 & 3.38 & 1.17 & 0.14 & 0.65 & 1.15 & 1.66 & 2.16 \\
\hline UK & -1.18 & -1.47 & -1.31 & -1.16 & -1.01 & -0.85 & 0.64 & -0.27 & 0.22 & 0.71 & 1.20 & 1.70 \\
\hline
\end{tabular}



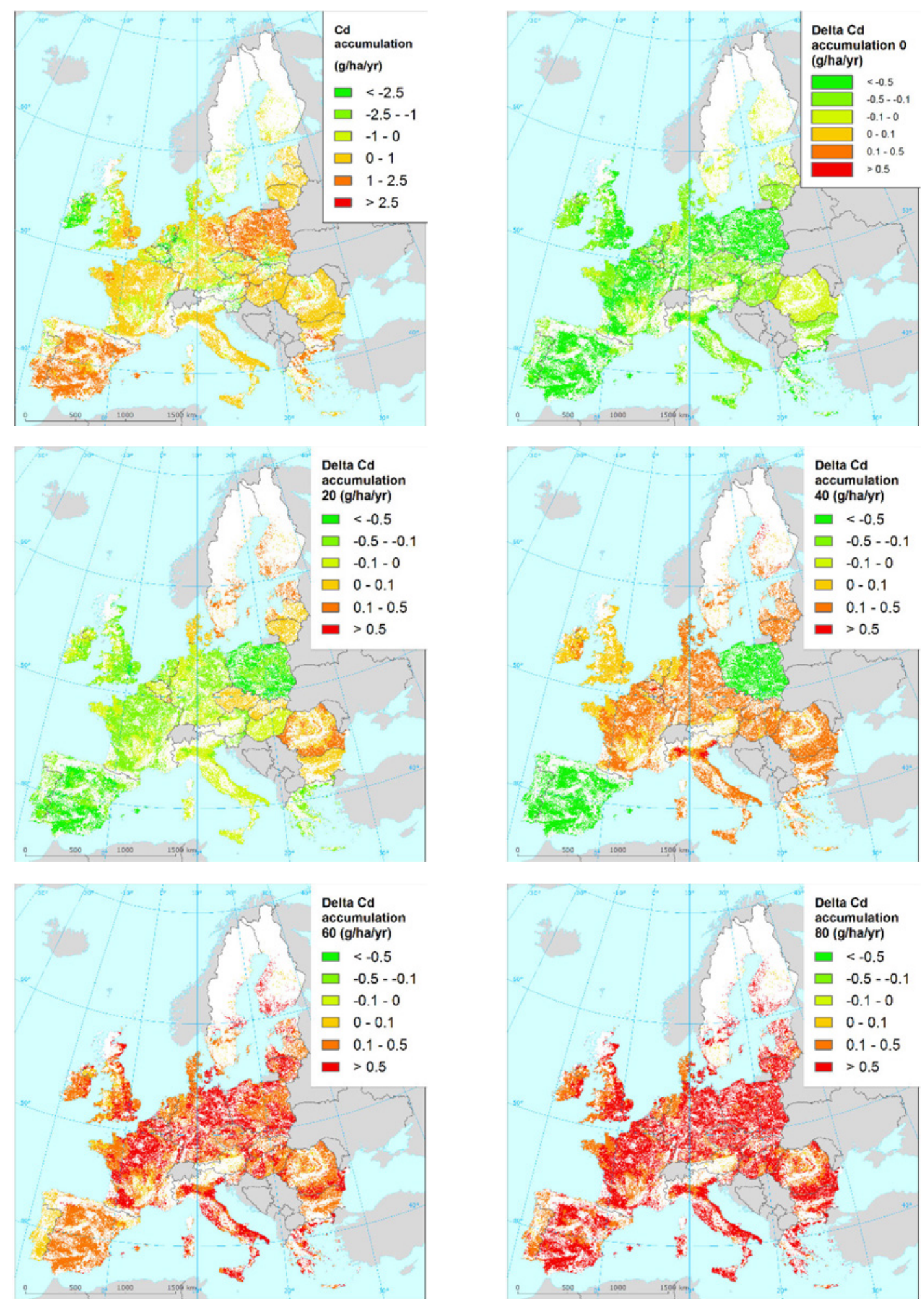

Figure 5.6 Current accumulation at EU level (top left) and changes in Cd balance (inputs - outputs) at $\mathrm{EU}$ level or the $\mathrm{Cd}-\mathrm{O}$ to $\mathrm{Cd}-80$ scenario relative to the current situation

Even though accumulation as such can be an indicator of the impact of proposed revision in the allowed cd content in $\mathrm{P}$ fertilisers, changes in the soil Cd ultimately are more important to address the consequences for the environment and transfer of $\mathrm{Cd}$ from soil to crops. In Figure 5.7 and 5.8 changes in the Cd content at country level (Figure 5.7) and across the EU (Figure 5.8) are shown as predicted at $t=100$ years after the start of the simulation. At EU level changes in Cd levels in pasture soil are very limited and only in case of the Cd-80 scenario, average levels are predicted to increase with $+3.8 \%$ compared to current Cd levels in soils (Table 5.7). And even though the changes in pasture soils in most countries are modest ( -20 to $+20 \%$ compared to current Cd levels in pasture soils), 
changes in the soil Cd content in Poland, Portugal and to a lesser extent Spain are substantial with Cd levels expected to double in both Portugal (increase from 0.09 to $0.2 \mathrm{mg} \mathrm{kg}^{-1}$ ) and Poland (increase from 0.22 to $0.48 \mathrm{mg} \mathrm{kg}^{-1}$ ).

For arable soils the shift from Cd-0 to $\mathrm{Cd}-80$ largely results in an increase in the Cd content of the soil ranging from, at EU level, $0.2 \%$ in case of the Cd-0 scenario to $+16 \%$ in case of the Cd- 80 scenario (Table 5.6). Table 5.6 also reveals that $\mathrm{Cd}$ levels in pasture soils are less prone to accumulation and an EU-wide increase in the soil Cd content is predicted to occur only in case of the Cd-80 scenario. When considering all agricultural land (with the exception of rough grazing areas including natural land), a zero net change in the Cd levels in soils is achieved at a level of approx. $20 \mathrm{mg} \mathrm{Cd} \mathrm{kg}{ }^{-1} \mathrm{P}_{2} \mathrm{O}_{5}$ (Table 5.6). At EU level current levels of $\mathrm{Cd}$ in mineral $\mathrm{P}$ fertilisers are such that soil Cd balances are close to equilibrium with a minor predicted increase $(+2.4 \%)$ when considering the total area. For arable soils only however, balances are, as discussed positive and will lead to an, on average increase of $+6.4 \%$ compared to current Cd levels in soils.

Table 5.6 Predicted relative change in the soil Cd content at EU-25 (excluding Malta and Cyprus) compared to current levels for grassland, arable and combined

\begin{tabular}{|c|c|c|c|}
\hline \multirow[b]{2}{*}{ Scenario } & \multicolumn{3}{|c|}{$\begin{array}{l}\text { Relative change in soil Cd levels } \\
\text { at } t=100 \text { years from now }\end{array}$} \\
\hline & All Agricultural land & Arable & Grassland \\
\hline $\mathrm{Cd}-0$ & $-4.4 \%$ & $0.2 \%$ & $-15.6 \%$ \\
\hline $\mathrm{Cd}-20$ & $-0.1 \%$ & $4.2 \%$ & $-10.7 \%$ \\
\hline$C d-60$ & $8.3 \%$ & $12.1 \%$ & $-1.0 \%$ \\
\hline $\mathrm{Cd}-80$ & $12.5 \%$ & $16.0 \%$ & $3.8 \%$ \\
\hline
\end{tabular}


EU-25 Grassland

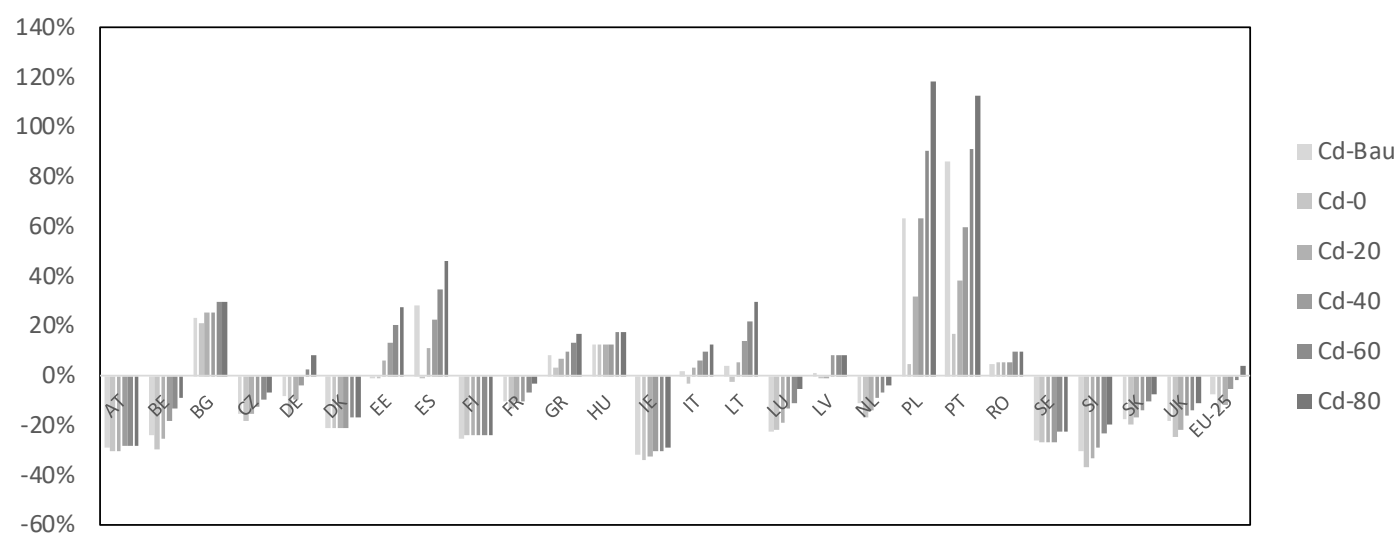

EU-25 Arable Land

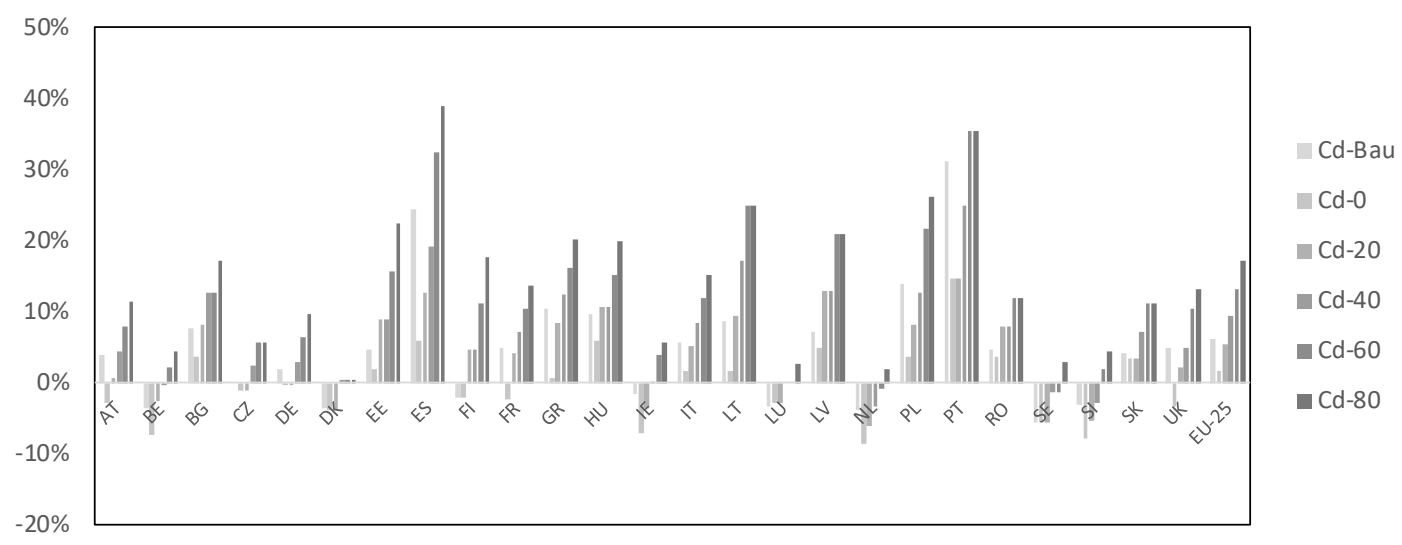

EU-25 Arable + Grassland

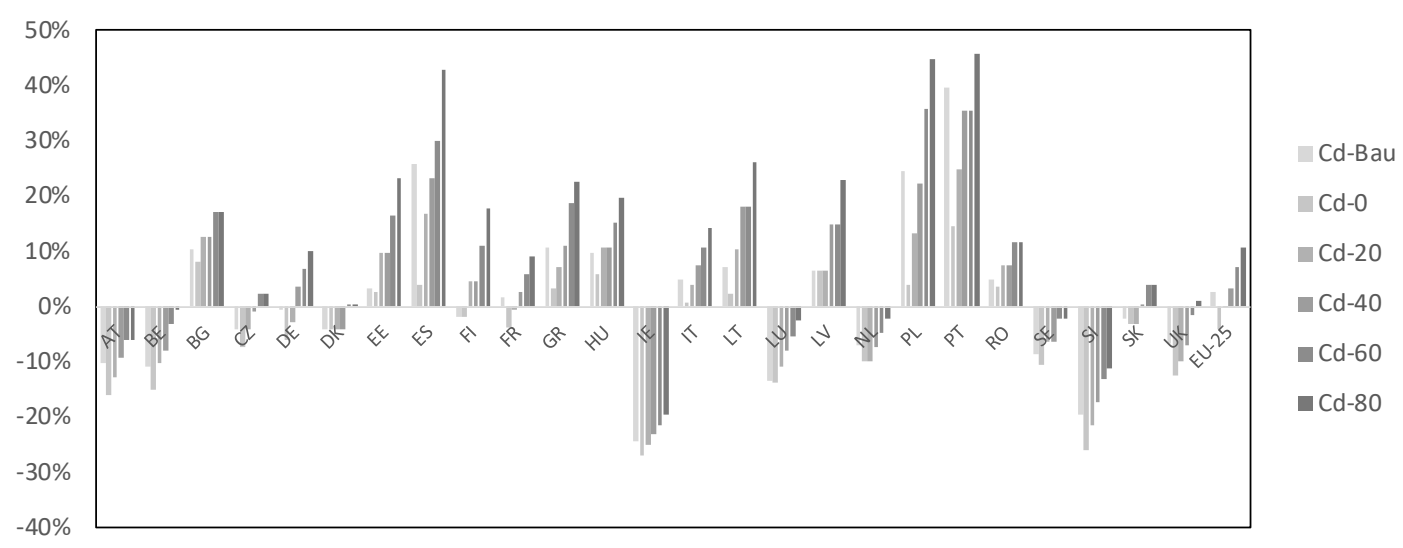

Figure 5.7 Average changes in soil Cd levels at country and EU level at $t=100$ years relative to current levels in soil for grassland (top), Arable land (middle) and all agricultural soils (bottom) 

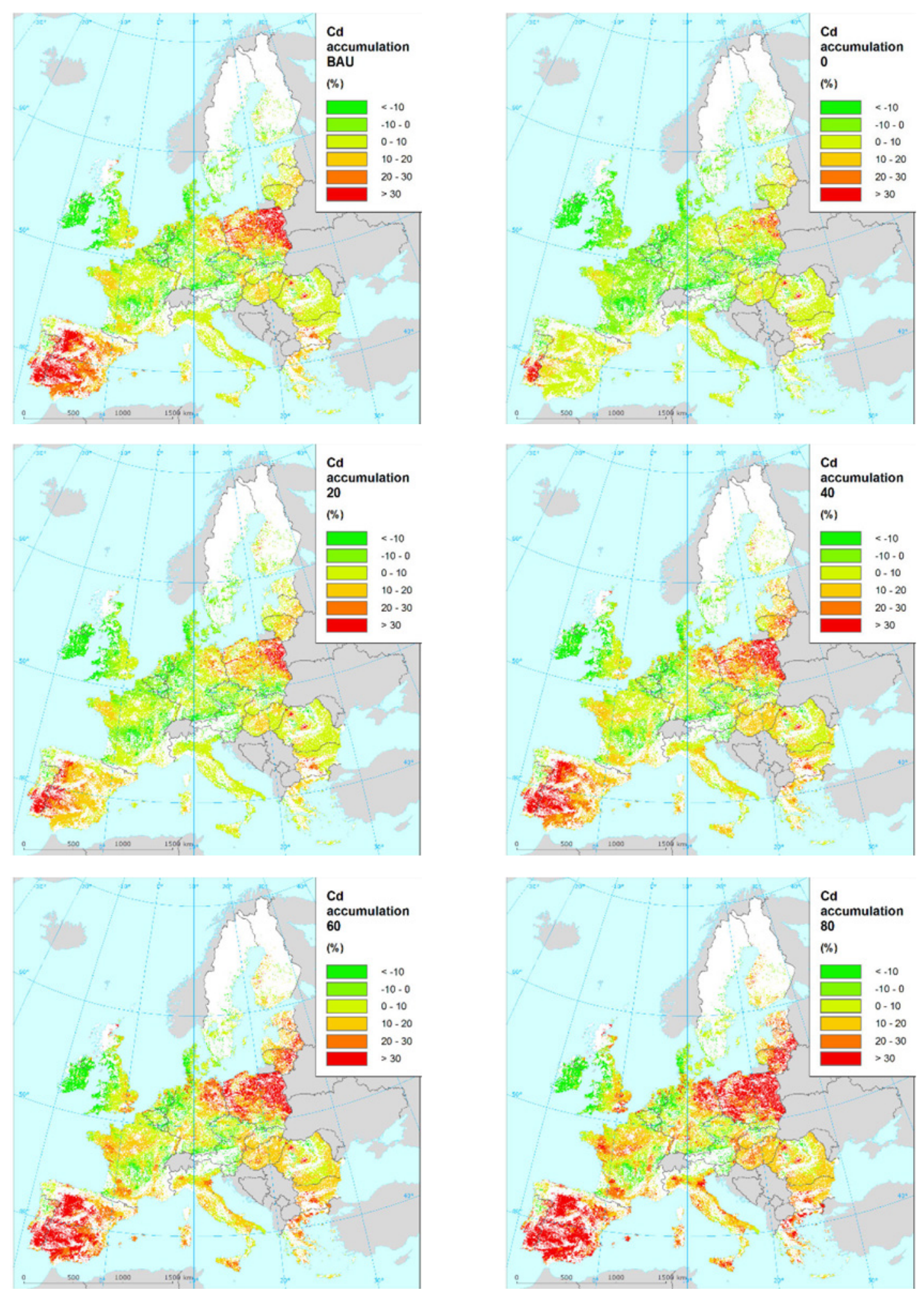

Figure 5.8 Relative changes (\%) in the soil Cd content after 100 years compared to 2010 (all soils, data at NCU level)

As illustrated in Figure 5.8, changes in soil Cd levels vary significantly between countries. At country levels the increase in the $\mathrm{Cd}$ levels in arable soils in a.o. Be, $\mathrm{IE}, \mathrm{NI}$, Se and $\mathrm{SL}$ remains below $5 \%$ compared to current levels even in case of the $\mathrm{Cd}-80$ scenario. This reflects a combination of a relatively low application of mineral $\mathrm{P}$ fertilisers $(\mathrm{NI})$, in combination with high predicted leaching losses from soil ( $\mathrm{Se}, \mathrm{IE}, \mathrm{Be}, \mathrm{NL}$ ). On the other hand, $\mathrm{Cd}$ levels in soil but will increase substantially in countries like ES, PL and Pt regardless of the chosen level of $\mathrm{Cd}$ in mineral P fertilisers with predicted increases ranging from 14 to $30 \%$ in case of the Cd-0 scenario and between 35 to $38 \%$ in case of the 
Cd-80 scenario. These difference are related to both relatively high inputs via mineral $\mathrm{P}$ fertiliser on one hand $(\mathrm{PI})$ in combination with lower crop offtake rates and leaching (Es, Pt).

To illustrate how changes in the soil Cd content become more pronounced at a regional level, data in Table 5.7 present the frequency distribution of the calculated changes in the soil Cd content at NUTS3 level; here both arable land and pasture is combined. The data in Table 5.7 reveal that even in case of the Cd-0 scenario, the soil Cd content in more than $25 \%$ of the NUTS3 regions is expected to increase, where, on the other hand $25 \%$ of the regions also are close to equilibrium even in case of the Cd-80 scenario.

Table 5.7 Distribution of predicted changes in soil Cd at $t=100$ compared to $t=0$ at NUTS3 level

\begin{tabular}{|c|c|c|c|c|c|c|}
\hline percentile & BaU & $\mathrm{Cd}-\mathrm{O}$ & Cd-20 & $C d-40$ & Cd-60 & Cd-8C \\
\hline 1 & $-35 \%$ & $-38 \%$ & $-36 \%$ & $-35 \%$ & $-33 \%$ & $-32 \%$ \\
\hline 5 & $-24 \%$ & $-28 \%$ & $-25 \%$ & $-23 \%$ & $-21 \%$ & $-19 \%$ \\
\hline 50 & $2 \%$ & $-3 \%$ & $1 \%$ & $4 \%$ & $8 \%$ & $11 \%$ \\
\hline 75 & $8 \%$ & $2 \%$ & $7 \%$ & $11 \%$ & $15 \%$ & $20 \%$ \\
\hline 99 & $61 \%$ & $24 \%$ & $41 \%$ & $58 \%$ & $75 \%$ & $91 \%$ \\
\hline avg & $+2 \%$ & $-5 \%$ & $-0 \%$ & $+4 \%$ & $+8 \%$ & $+12 \%$ \\
\hline
\end{tabular}

\subsection{Level of $\mathrm{Cd}$ in P fertilisers to achieve net zero balances in soil}

An assessment was made of the $\mathrm{Cd}$ content in $\mathrm{P}$ fertilisers at which the $\mathrm{Cd}$ content in soil remains unchanged at $\mathrm{t}=100$. This was done using data NUTS3 level for which changes in soil Cd were derived including both grassland and arable land. The underlying assumption was that changes in soil Cd were induced largely by a decrease in the Cd load from fertilisers; other inputs to soil remain constant (manure, biosolids, atmospheric deposition, other mineral fertilisers). Clearly changes in Cd content in soil are also affected by the changes in uptake and leaching but since changes in absolute levels of Cd in soil were relatively small, the impact of the changes in both outputs which are derived from the soil $\mathrm{Cd}$ content were also small. As a results, a highly significant positive linear relation was found between the imposed maximum levels of $\mathrm{Cd}$ in $\mathrm{P}$ fertiliser and the resulting relative changes of $\mathrm{Cd}$ in soil as is illustrated for a number of countries in Figure 5.9 which presents the 5, 50 and 95 percentile values of the predicted changes in the soil Cd content at $t=100$ for each of the scenarios ( $C d-0$ to $C d-80$ ). 


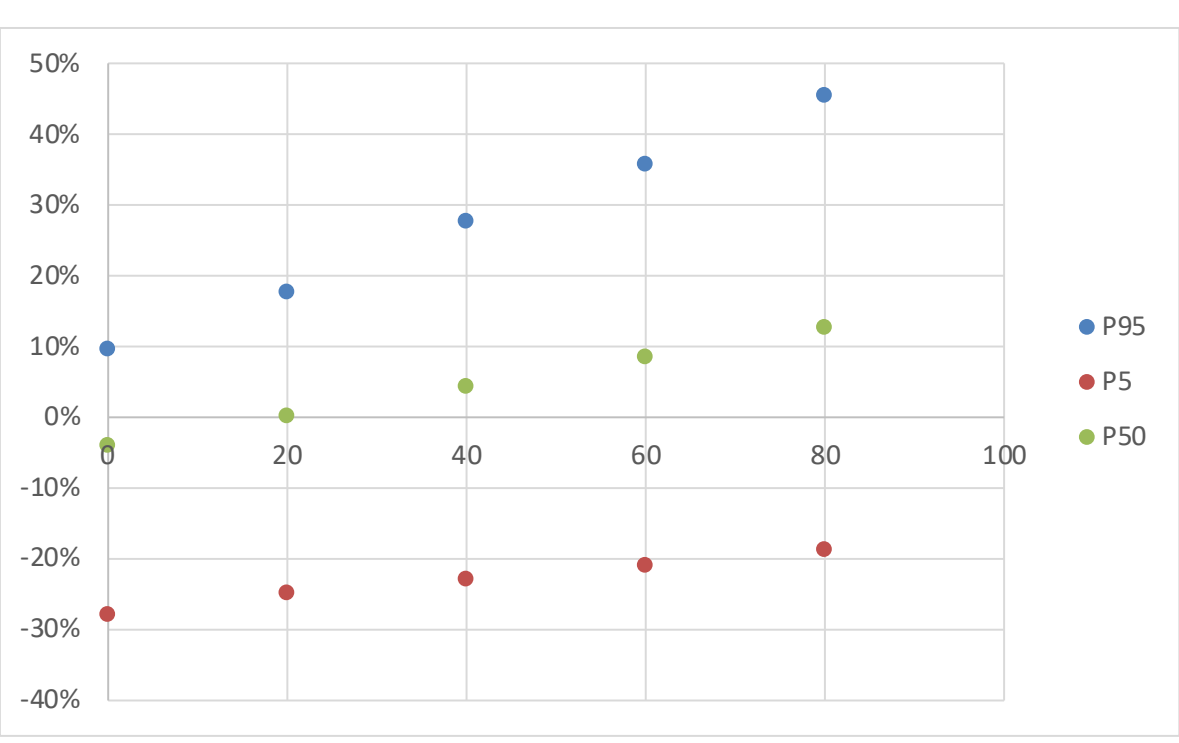

Figure 5.9 Five, fifty and ninety-five percentile of the predicted relative change of Cd in soil at the Cd0, Cd-20, Cd-40, Cd-60 and Cd-80 scenarios at NUTS3 level for the combined arable and grassland soils

Consequently the relationship between the predicted changes in soil $\mathrm{Cd}$ and the input concentration of $\mathrm{Cd}$ in fertiliser were used to back-calculate the critical $\mathrm{Cd}$ content in P fertilisers at which no change in soil cd would have been predicted. Based on the country averaged data (Table 5.6), the EU-wide critical level ranges from (a theoretical) $-1.2 \mathrm{mg} \mathrm{Cd} \mathrm{kg}{ }^{-1} \mathrm{P}_{2} \mathrm{O}_{5}$ for arable land to $64.2 \mathrm{mg} \mathrm{Cd} \mathrm{kg}{ }^{-1} \mathrm{P}_{2} \mathrm{O}_{5}$ for grassland soils. For the total surface area covering both arable and grassland the mean critical level equal $20.7 \mathrm{mg} \mathrm{Cd} \mathrm{kg}^{-1} \mathrm{P}_{2} \mathrm{O}_{5}$ as shown in Figure 5.9 as well. The negative value obtained for arable soils suggests that even if inputs via mineral $P$ fertilisers were reduced to zero, inputs would still exceed outputs even though the balance is very close to zero.

\subsection{Plausibility of results and impact of model choice on predicted changes in Cd levels in soil}

One of the main findings as revealed by the Integrator model is that in order to obtain equilibrium between inputs and outputs, an EU-wide average level of $20 \mathrm{mg} \mathrm{Cd} \mathrm{kg}{ }^{-1} \mathrm{P}_{2} \mathrm{O}_{5}$ would be required, whereas in fact a zero input from mineral $P$ fertilisers would be required to reach stand still in arable soils. This result deviates substantially from those as obtained by Smolders (2017) who obtained a value of $73 \mathrm{mg} \mathrm{Cd} \mathrm{kg}^{-1} \mathrm{P}_{2} \mathrm{O}_{5}$ as the critical value for arable soils (limited to wheat cropping and potato cropping systems only). From a conceptual model point of view the Smolders (2017) study is comparable to the one described here in that similar inputs and outputs are considered. In both approaches manure, mineral fertiliser, biosolids, atmospheric deposition and lime are considered as main inputs and also outputs, i.e. crop uptake and leaching from the topsoil are similar. In both the study by Smolders (2017) and this paper, inputs are largely based on existing data on quality of fertilisers, manure etc. and current application rates of such products. Consequently, calculated average levels of inputs to soil at EU level are in close agreement as shown in Table 5.8. Since the model predictions from Smolders (2017) are derived for arable crops (potato and wheat) only, we use data from arable crops as calculated by Integrator for comparison purposes. Outputs from the soil in both cases are calculated using existing models. To calculate $\mathrm{Cd}$ removal via crop uptake, both models use a Bioconcentration factor assuming a linear transfer from soil to crop. Even though in the Integrator model more crops are considered compared to the ones in the study by Smolders (2017), the calculated average Cd removal rates by crops are also quite similar (Table 5.8). Hence, the partial balance as calculated by the two models, which is also sometimes used in cases where leaching is not considered, is very comparable which confirms that despite differences in some of the assumptions used, predicted $\mathrm{Cd}$ balances are in the same order or magnitude. 
Three major differences however can be identified between the approach presented in this paper (Integrator) and the one presented by Smolders (2017):

1. The model by Smolders is not based on spatial units but rather as a distribution of predictions from specific soil samples with known levels of $\mathrm{Cd}$ in soil and soil properties (GEMAS database, Reimann et a., 2014). Such an approach only would yield similar results if the database used by Smolders would be spatially representative for the entire surface covered by the database, which in its present form and data coverage is not necessarily the case.

2. Another difference is that Smolders (2017) only considered potato and wheat as relevant crops whereas the Integrator model is based on the true land use including 30 crops clustered in 11 specific crop groups, each with its own BCF. As discussed, this difference will not lead to major differences between the EU-wide average crop removal rate albeit that the data calculated for specific points are not necessarily representative for the actual removal rate due to differences in crops grown.

3. A large discrepancy between both approaches was observed for the leaching of Cd from the soil. EU-wide average leaching rates by Smolders (2017) are $2.0 \mathrm{~g} \mathrm{Cd} \mathrm{ha}^{-1} \mathrm{yr}^{-1}$ (Table 5.8) whereas this was $0.55 \mathrm{~g} \mathrm{Cd} \mathrm{ha}^{-1} \mathrm{yr}^{-1}$ for arable soils using the Integrator model. The full balances, therefore, which include leaching and is used to calculate changes of $\mathrm{Cd}$ levels in soils with time differ substantially with a net negative balance of $-1.0 \mathrm{~g} \mathrm{Cd} \mathrm{ha}^{-1} \mathrm{yr}^{-1}$ as calculated by Smolders (2017) compared to a net positive balance of $+0.6 \mathrm{~g} \mathrm{Cd} \mathrm{ha}^{-1} \mathrm{yr}^{-1}$ as calculated by Integrator. Even though such differences in the annual Cd load to soil are very small compared to the total Cd pool in soils which, on average, equals approximately $750 \mathrm{~g} \mathrm{Cd} \mathrm{ha}^{-1} \mathrm{yr}^{-1}$ (Smolders, 2017), such differences in the balance lead to markedly different predictions of the average relative change of Cd levels in soils for the scenarios evaluated in this paper as shown in Table 5.9.

Table 5.8 Comparison of average inputs and outputs considered in the balance and resulting EU

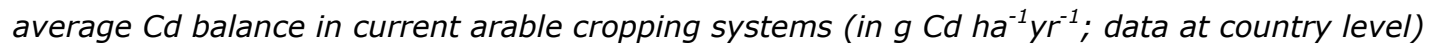

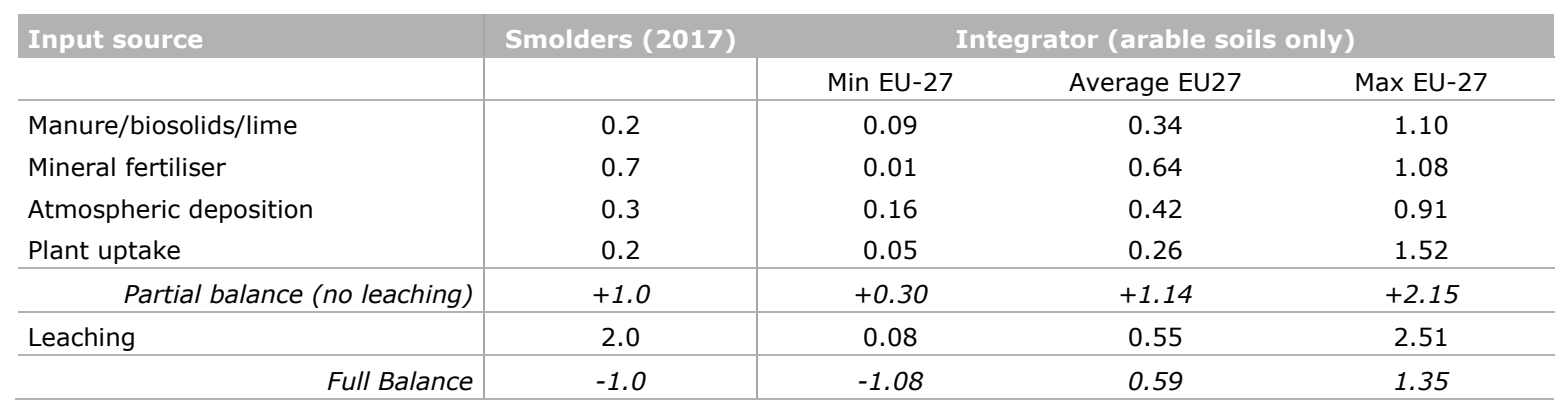

Table 5.9 Predicted relative changes in soil Cd levels for the BaU and Cd-O to Cd-80 scenario

\begin{tabular}{|c|c|c|c|c|}
\hline \multirow[b]{2}{*}{ Scenario } & \multicolumn{4}{|c|}{$\begin{array}{c}\text { Relative change in soil Cd } \\
\text { (in \% compared to current Cd levels in soil) }\end{array}$} \\
\hline & $\begin{array}{l}\text { Smolders (2017) } \\
\text { EU-average }\end{array}$ & All soils & $\begin{array}{l}\text { Integrator } \\
\text { Arable }\end{array}$ & Grassland \\
\hline Business as Usual & -16 & $2.4 \%$ & $6.4 \%$ & $-7.2 \%$ \\
\hline $\mathrm{Cd}-0$ & Not included & $-4.4 \%$ & $0.2 \%$ & $-15.6 \%$ \\
\hline $\mathrm{Cd}-40$ & -13 & $4.1 \%$ & $8.1 \%$ & $-5.8 \%$ \\
\hline Cd-60 & -5 & $8.3 \%$ & $12.1 \%$ & $-1.0 \%$ \\
\hline $\mathrm{Cd}-80$ & +3 & $12.5 \%$ & $16.0 \%$ & $3.8 \%$ \\
\hline
\end{tabular}

In both cases the water flux (in $\mathrm{mm}$ water percolating through the soil) used to derive the flux was comparable and the main difference in the outcome was, therefore, related solely to the model used to predict the $\mathrm{Cd}$ concentration in solution. Aside from the fact that the model used by Smolders (2017) to calculate $\mathrm{Cd}$ concentrations in the soil solution was based on different source data $(n=151)$ and did not include a correction for the reactivity of $\mathrm{Cd}$ in soil as was done in case of the Integrator model, the 
main difference between the two models was the use of a linear model ( $n=1$ in [eq]. 12) used by Smolders (2017) to calculate the $\mathrm{Cd}$ concentration in solution using $\mathrm{pH}$ and the soil organic matter content:

$\mathrm{K}_{\mathrm{f}}=\left[\mathrm{Cd}_{\text {soil }}\right] /\left[\mathrm{Cd}_{\text {solution }}\right]^{\mathrm{n}}$

With:

${ }^{10} \log K f=$ constant $+a_{1} \cdot p H+\beta_{1} \cdot \log ($ Soil Organic Carbon $)$

With $\mathrm{pH}$ being $\mathrm{pH} \mathrm{CaCl}_{2}(0.01 \mathrm{M})$ as measured in soil extracts obtained by the GEMAS database. A crucial difference appears to be the assumed 1:1 linear relationship between $\mathrm{Cd}$ in soil and in solution as represented by [eq.] 12 using a value of 1 for $n$. In the current version of Integrator used in this study, the value of $n$ was not a priori assumed to be 1 but instead a non-linear version of the Freundlich model $(n \neq 1$ ) was used as described by Römkens et al. (2004) and later on used by a.o. Groenenberg et al. (2012) for a number of metals. In this version the variation in the Cd concentration in solution is related directly to that of the soil $\mathrm{Cd}$ content and soil properties:

${ }^{10} \log C d_{\text {solution }}=$ Constant $+\mathrm{a}_{2} \cdot \mathrm{pH}+\beta_{2} \cdot \log ($ Soil Organic Carbon $)+\mathrm{v} \cdot{ }^{10} \log ($ clay $)+\delta \cdot{ }^{10} \log \left(\mathrm{Cd}_{\text {soil }}\right)$

The critical difference between both approaches is the consideration of non-linearity in the model used in integrator as represented by the coefficient $\delta$ in equation [14] whereas the model used by Smolders implicitly assumes that the value of $\delta$ equals 1 which then would render the same model in both cases, that is, if the same soil properties are being used to explain the variation in Cd in solution. To assess the consequence of the impact of the choice of model, both models (eq. 13 and eq. 14) were derived from a similar set of source data (Römkens and Salomons, 1998) that contains measured data in field derived soil solution samples from arable soils and soils under pasture and forest. Here we only used solution $\mathrm{pH}$ and soil organic matter as variables to keep the model structure comparable as the one by Smolders (2017). In Table 5.10 the ratio of the predicted Cd concentration in soil solution as calculated by both models is given for a selected number of combinations of $\mathrm{pH}$ and soil organic matter and relevant $\mathrm{Cd}$ ranges in soil $(0.2$ to $1.0 \mathrm{mg} / \mathrm{kg})$.

Table 5.10 Ratio of calculated Cd concentrations in solution using the linear and non-linear models (eq. 13 and 14) based on the same source data (Römkens and Salomons, 1998).

\begin{tabular}{|c|c|c|c|c|}
\hline \multicolumn{2}{|c|}{ Soll Properties used } & \multicolumn{3}{|c|}{$\begin{array}{l}\text { Ratio of predicted Cd solution concentrations } \\
\text { (Linear Kf/non-linear model) }\end{array}$} \\
\hline$\%$ SOM & $\mathrm{pH}$ & $\mathrm{Cd}_{\text {soil }}=0.2$ & $\mathrm{Cd}_{\text {soil }}=0.5$ & $\mathrm{Cd}_{\text {soil }}=1.0$ \\
\hline 5 & 5 & 1.1 & 2.2 & 3.8 \\
\hline 10 & 5 & 0.7 & 1.4 & 2.4 \\
\hline 2 & 6 & 1.5 & 3.1 & 5.3 \\
\hline 5 & 6 & 0.9 & 1.7 & 3.0 \\
\hline 10 & 6 & 0.6 & 1.1 & 1.9 \\
\hline 30 & 6 & 0.3 & 0.6 & 1.0 \\
\hline 30 & 7 & 0.2 & 0.4 & 0.7 \\
\hline
\end{tabular}

The data in Table 5.10 clearly illustrate that in a substantial number of combinations of soil properties representative for a large area used for arable crop production, predicted Cd concentration in solution by the linear model is 1.2 to 6.8 times of those as obtained by the non-linear model. Only in soils with high (> 10\%) organic matter predicted concentrations by the non-linear model are higher those 
obtained by the linear model. However, most of the organic soils are usually not used for arable crop production but are in use for grassland which was not considered in this comparison.

This significant difference in calculated values of $\mathrm{Cd}$ in solution was observed as well when using the source data underlying the models used by Smolders (2016), (de Greyse, pers. comm.) which suggests that the use of either a linear or non-linear relation between $\mathrm{Cd}$ in soil and $\mathrm{Cd}$ in solution results in significantly different estimates in the Cd concentration in solution, at least in the range of $\mathrm{Cd}$ in soils and the combinations of soil properties that prevail in arable soils. To further assess to what extent the choice of model would affect the model outcome, the linear Kf model used by Smolders was incorporated in the Integrator model to be used in the dynamic scenario analyses instead of the default model. This allowed us to calculate, at the most detailed level (NCU) the magnitude of the leaching fluxes. In Table 5.11 a comparison is made between leaching fluxes at NCU level for both grassland and arable land using both models in Integrator both at time 0 and at $\mathrm{t}=100$ years from now. Both models reveal the large range that exists in the calculated leaching fluxes related to different combinations of soil properties and climatic conditions. Extreme leaching rates with annual Cd removal rates of more than $5 \mathrm{~g} \mathrm{Cd} \mathrm{ha}^{-1} \mathrm{yr}^{-1}$ occur in both cases but are far more common (the predicted 75 percentile by the linear model equals $5.5 \mathrm{~g} \mathrm{Cd} \mathrm{ha}^{-1} \mathrm{yr}^{-1}$ for arable soils and $7.4 \mathrm{~g} \mathrm{Cd}$ $\mathrm{ha}^{-1} \mathrm{yr}^{-1}$ in pasture soils). Also at NCU level, the median predicted leaching fluxes at $\mathrm{t}=0$ calculated by the linear model are 5 to 6 times higher compared to those calculated by the non-linear model used in Integrator.

Table 5.11 Comparison of frequency distribution of predicted leaching losses at NCU level in Arable and Grassland soils (BaU scenario at $t=0$ and $t=100$ ) using the standard non-linear leaching model (INT) and the linear model (INT_S)

\begin{tabular}{|c|c|c|c|c|c|c|c|c|}
\hline & \multicolumn{4}{|c|}{$\begin{array}{l}\text { Leaching flux Arable soils } \\
\left(\mathrm{g} \mathrm{ha}^{-1} \mathrm{yr}^{-1}\right)\end{array}$} & \multicolumn{4}{|c|}{$\begin{array}{l}\text { Leaching flux Grassland soils } \\
\left(\mathrm{g} \mathrm{ha}^{-1} \mathrm{yr}^{-1}\right)\end{array}$} \\
\hline & INT & INT_S & INT & INT_S & INT & INT_S & INT & INT_S \\
\hline 1 & 0.01 & 0.06 & 0.01 & 0.08 & 0.01 & 0.06 & 0.02 & 0.08 \\
\hline 5 & 0.03 & 0.15 & 0.03 & 0.18 & 0.03 & 0.21 & 0.05 & 0.25 \\
\hline 50 & 0.43 & 2.5 & 0.48 & 2.2 & 0.58 & 3.3 & 0.60 & 1.5 \\
\hline 75 & 1.0 & 5.5 & 1.0 & 3.7 & 1.3 & 7.4 & 1.2 & 2.1 \\
\hline 95 & 2.8 & 14.8 & 2.5 & 6.2 & 3.8 & 19.3 & 2.2 & 3.1 \\
\hline 99 & 5.4 & 27.6 & 4.2 & 8.1 & 6.6 & 31.9 & 3.0 & 4.1 \\
\hline
\end{tabular}

Even though measurements of leaching fluxes are difficult to obtain and often prone to methodically induced bias, existing data seem to suggest that the predicted range in leaching fluxes by the INTEGRATOR model are reasonable. Data from Gray et al. (2003) for example indicate that leaching of $\mathrm{Cd}$ ranged from 0.27 to $0.86 \mathrm{~g} \mathrm{Cd} \mathrm{ha}^{-1} \mathrm{yr}^{-1}$ in agricultural soils from New Zealand. A large Cd balancing study for German arable soils by Schütze et al. (2003) reports Cd leaching losses between 0.1 and $1.2 \mathrm{~g} \mathrm{Cd} \mathrm{ha}^{-1} \mathrm{yr}^{-1}$ with a median value of $0.28 \mathrm{~g} \mathrm{Cd} \mathrm{ha}^{-1} \mathrm{yr}^{-1}$ based on measured concentrations of Cd in leachates (Bielert, 1999). In the Canadian study by Sheppard et al. (2009) a Kd value of 1300 was used which corresponds to an annual leaching loss ranging from 0.1 to $1.2 \mathrm{~g} \mathrm{Cd} \mathrm{ha}^{-1} \mathrm{yr}^{-1}$ (average $0.7 \mathrm{~g} \mathrm{Cd} \mathrm{ha}^{-1} \mathrm{yr}^{-1}$ ) in soils with a Cd content between 0.1 and $0.5 \mathrm{mg} \mathrm{kg}^{-1}$ and a net leaching rate of $300 \mathrm{~mm}_{\text {year }}{ }^{-1}$. For Austria, Spiegel et al. (2003) used a non-linear model similar to the one applied in Integrator to calculate leaching losses based on work by McBride et al. (1997). Leaching losses for typical Austrian farming systems thus calculated range from 0.26 to $0.45 \mathrm{~g} \mathrm{Cd} \mathrm{ha}^{-1} \mathrm{yr}^{-1}$ for arable cropping systems. An inventory of monitoring data in acid forest soils from Scandinavia (Sevel et al., 2009) on the other hand reveals that Cd leaching fluxes in forest soils range can be as high as 1 to $5 \mathrm{~g}$ $\mathrm{Cd} \mathrm{ha}^{-1} \mathrm{yr}^{-1}$, values which are in line with the predicted leaching rates by Smolders et al (2017). However, in contrast to the other reported values the high fluxes reported by Sevel et al. (2009) are related to the low $\mathrm{pH}(3.5-4.5)$ of the forest soils included in the study which is approx. two units lower than $\mathrm{pH}$ values in arable cropping systems as used in this study and by Smolders (2017). The impact of $\mathrm{pH}$ on the leaching flux is illustrated in Table 5.12 where average leaching fluxes (arable 
soils only) calculated at NCU level are clustered as a function of $\mathrm{pH}$. Results from the acid soils ( $\mathrm{pH}$ $<4.5$ ) as calculated by the non-linear model agree well with the reported values by Sevel et al. (2009) whereas those calculated by the linear model appear extremely high. Due to the high leaching losses as calculated by both models, leaching rates at $t=100$ decreased substantially due to the reduction of $\mathrm{Cd}$ levels in soils with $\mathrm{pH}$ levels $<5.5$. this effect is even more pronounced when using the linear $\mathrm{Kd}$ model compared to the non-linear model resulting in a $90 \%$ decrease of $\mathrm{Cd}$ in soil in those units with levels below 4.5.

Table 5.12 Predicted changes in leaching rates ( $\mathrm{g} \mathrm{Cd} \mathrm{ha-1} \mathrm{yr}^{-1}$ ) and relative changes in Cd in soil (in $\%)$ at $t=100$ compared to $t=0$

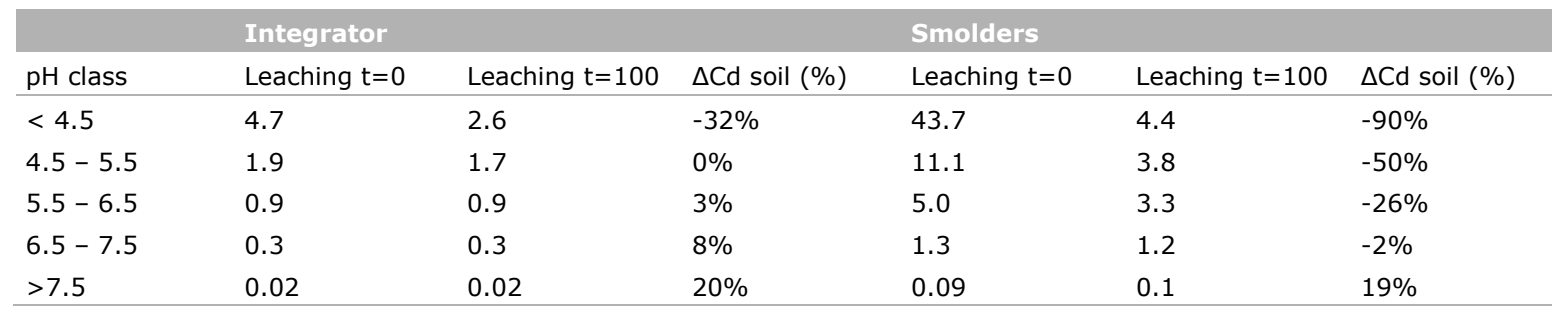

\subsection{Conclusions from the model study}

- At EU level, $45 \%$ ( 88 ton $\mathrm{yr}^{-1}$ ) of all inputs of $\mathrm{Cd}$ to agricultural soils is from mineral fertilisers followed by atmospheric deposition (33\%, 64 ton $\mathrm{yr}^{-1}$ ) and manure (18\%, 35 ton $\mathrm{yr}^{-1}$ ). At present, biosolids (compost and sludge) only contribute $4 \%\left(8\right.$ ton $\left.\mathrm{yr}^{-1}\right)$ of the total inputs.

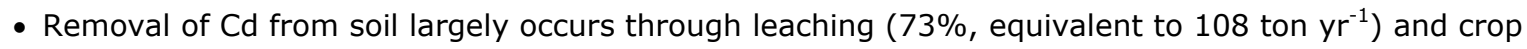
removal only contributes to $27 \%$ (39 ton $\mathrm{yr}^{-1}$ ).

- Present $\mathrm{Cd}$ balances in arable land are positive for arable land but negative for pasture soils, which is largely due elevated leaching losses that prevail in pasture soils due to the lower soil pH compare to arable soils.

- For arable soils, accumulation occurs at all proposed levels of $\mathrm{Cd}$ (Cd-20 to Cd-60), albeit that the predicted increase in $\mathrm{Cd}$ soil levels decreases from $12.1 \%$ (at EU level) in case of the Cd60 scenario to $4.2 \%$ in the $\mathrm{Cd} 20$ scenario (relative to current levels of $\mathrm{Cd}$ in soil).

- A stand-still level for $\mathrm{Cd}$ in arable soils at $\mathrm{t}=100$ years from now is achieved only if the supply of $\mathrm{Cd}$ via mineral $\mathrm{P}$ fertiliser is reduced to zero. When considering the total surface area used for agriculture (i.e. arable land and pasture) a standstill is achieved at approx. $20 \mathrm{mg} \mathrm{Cd} \mathrm{kg}{ }^{-1} \mathrm{P}_{2} \mathrm{O}_{5}$.

- Regional variation in Cd balances is large with accumulation prevailing in the Mediterranean areas and Poland. This is due to either high (average) levels of $\mathrm{Cd}$ in mineral $\mathrm{P}$ fertilisers used (PI, Pt) or a very low Cd removal rate from soil due to low water fluxes in most Mediterranean countries.

- The difference in the magnitude of the dissolved $\mathrm{Cd}$ concentration used to calculate the leaching flux is the main reason for the pronounced difference between model results presented by Smolders (2017) and those generated in the present study.

- The main reason for this is choice of model, it was shown here that a linear Kd model by definition leads to higher predicted leaching concentrations under the conditions that dominate EU soils (SOM, $\mathrm{pH}, \mathrm{Cd}$ soil). Predicted leaching rates by the linear model as used by Smolders (2017) appear to be substantially higher than those previously reported.

- Differences between models operating at point level as used by Smolders (2017) and those based on predictions for the complete surface area (this study) are substantial which is largely due to the non-linear response of the leaching flux to the combination of soil properties. To obtain representative area-wide EU average values for $\mathrm{Cd}$ balances or changes in of Cd levels in soil, point based models therefore require a surface weighted representative distribution of all combinations of soil properties and Cd levels in soil which, at present is not the case. 


\section{$6 \quad$ General Conclusions}

\section{Experimental results}

- Results from the greenhouse experiments indicate that within one year after application, there is no significant difference in absorption of $\mathrm{Cd}$ or other metals included here $(\mathrm{Cu}, \mathrm{Cr}, \mathrm{As}, \mathrm{Zn}$ and $\mathrm{Pb})$ by crops when mineral $P$ fertiliser is used with levels of $C d$ varying between 0 and $60 \mathrm{mg} \mathrm{Cd} \mathrm{kg}^{-1} \mathrm{P}_{2} \mathrm{O}_{5}$.

- Soil chemical tests reveal that the added amount of contaminants via fertilisers or manure during one cropping cycle do not affect the plant available metal pool nor the total available pool adsorbed to the soil even in soils with a low to very low Cd status.

- Differences in soil properties (e.g. acidity and organic matter content) in combination with the initial content of $\mathrm{Cd}$ in the soil are the main factors that control the short term ( 1 harvest cycle) variation of Cd concentrations in crops.

Plot scale simulation studies based on soils used in the experiments

- Long term model simulations at plot level (field) using the soils and fertilisers used in the greenhouse study reveal that a 'low' Cd fertiliser ( $0 \mathrm{mg} \mathrm{Cd} \mathrm{kg}{ }^{-1} \mathrm{P}_{2} \mathrm{O}_{5}$ ) would, on average lead to $34 \%$ lower levels of $\mathrm{Cd}$ in crops included in the experiments (potato, wheat, lettuce) whereas a 'high' $\mathrm{Cd}$ fertiliser (approx. $60 \mathrm{mg} \mathrm{Cd} \mathrm{kg}^{-1} \mathrm{P}_{2} \mathrm{O}_{5}$ ) results in an average increase of $22 \%$ of crop Cd levels.

- The magnitude of changes in both soil and crop $\mathrm{Cd}$ is related to both the initial $\mathrm{Cd}$ content in soil as well as the acidity and organic matter content. Increases in the soil and crop Cd content are more pronounced in low $\mathrm{Cd}$ soils at near neutral $\mathrm{pH}$. In soils with higher levels of $\mathrm{Cd}$ (here: $\mathrm{Cd}>2 \mathrm{mg} \mathrm{kg}^{-1}$ soil) the Cd content of fertilisers has limited impact on the development of soil and crop Cd levels with time.

- Differences in the content of $\mathrm{As}, \mathrm{Pb}, \mathrm{Cr}$ and $\mathrm{Ni}$ in the mineral $\mathrm{P}$ fertilisers or animal manure used in this study are too small to cause differences in the soil metal concentration after 100 years even without considering uptake and leaching which would further reduce the potential difference as calculated with a simplified mass balance.

Regional scale model studies using lettuce, wheat and potato as indicator crops

- When applied to 23000 spatial units representing the range in arable soil in the EU, relative changes in crop Cd after 100 years range from $+0.9 \%$ if no $\mathrm{Cd}$ is present in mineral $\mathrm{P}$ fertilisers to $+7.9 \%$ if the quality of fertilisers remains unchanged. When applying the 'high' $\mathrm{Cd}$ fertiliser used in this study (60 $\mathrm{mg} \mathrm{Cd} \mathrm{kg}^{-1} \mathrm{~kg} \mathrm{P}_{2} \mathrm{O}_{5}$ ) the increase in crop $\mathrm{Cd}$ is $+13.4 \%$.

- Absolute changes in crop Cd are most pronounced for lettuce with an average (EU-25 level) increase from $0.74 \mathrm{mg} \mathrm{Cd} \mathrm{kg}{ }^{-1} \mathrm{~d} . \mathrm{m}$. (present average) to $0.81 \mathrm{mg} \mathrm{Cd} \mathrm{kg}^{-1} \mathrm{~d} . \mathrm{m}$. in case of the Cd-60 scenario. For potato average $\mathrm{Cd}$ levels increase from 0.12 to $0.13 \mathrm{mg} \mathrm{Cd} \mathrm{kg}{ }^{-1} \mathrm{~d} . \mathrm{m}$. in the same scenarios; and for wheat Cd levels increase from 0.05 to $0.06 \mathrm{mg} \mathrm{Cd} \mathrm{kg}^{-1} \mathrm{~d} . \mathrm{m}$.

- Relative changes in both soil and crop Cd levels vary strongly between countries. In case of the Cd-0 scenario ( $\mathrm{Cd}$ in mineral $\mathrm{P}$ fertilisers set at 0 ), relative changes in crop Cd after 100 years at country level vary between $-10 \%$ in Ireland to $+7.9 \%$ for Bulgaria. In case of the Cd-60 scenario, $\mathrm{Cd}$ crop levels still decrease by $4.8 \%$ in Sweden but increase by almost $30 \%$ in Spain.

- In general the magnitude of the change is highly correlated to $i$. leaching rates (water flow), with lower leaching rates in Mediterranean areas compared to northern areas in the EU, ii. soil acidity which low $\mathrm{pH}$ values in north-western parts of the EU enhancing leaching of $\mathrm{Cd}$ versus near neutral or alkaline soils in southern Europe which favours accumulation of $\mathrm{Cd}$. 


\section{Regional scale models at EU-25 based on actual land use}

- Long-term (100 years) calculations on a regional scale for EU-25 show that the content of Cd in P fertilisers does affect both levels in soil and that in crops. Dynamic model simulations at EU level indicate that accumulation of $\mathrm{Cd}$ in soil (arable and grassland) continues if the Cd content in $\mathrm{P}$ fertilisers exceeds $20 \mathrm{mg} \mathrm{Cd} \mathrm{kg}^{-1} \mathrm{P}_{2} \mathrm{O}_{5}$.

- For arable land, zero inputs of Cd via fertiliser would result in an approximate -EU average- stand still (no change in the soil Cd content) at $\mathrm{t}=100$ years.

- The calculated average long-term changes in both soil and arable crops relative to current levels are in the order of magnitude of $+0.2 \%$ if no more $\mathrm{Cd}$ is applied via $\mathrm{P}$ fertiliser to $+12.1 \%$ or $+16 \%$ if, at the European level the concentration of $\mathrm{Cd}$ in mineral P-fertilisers averages 60 or $80 \mathrm{Cd} \mathrm{mg} \mathrm{kg-1}$ $\mathrm{P}_{2} \mathrm{O}_{5}$ respectively.

- Cd balances at EU-25 level agree well with those presented earlier (Smolders, 2017) except for leaching losses which are, in the model used here, significantly lower resulting in higher accumulation of $\mathrm{Cd}$ at lower loading rates.

- Differences between predicted leaching rates appear to be due to differences in model structure where the use of a $\mathrm{Kd}$ model implicitly leads to higher predicted $\mathrm{Cd}$ solution concentrations compared to those predicted by a non-linear model.

- A second reason for differences between the two leaching models is the differences in concentrations ranges present in the source data. A shift towards higher concentrations in the source data leads to an increase of the predicted levels of $\mathrm{Cd}$ in solution when applied to the spatial units at NCU level. 


\section{References}

Amlinger, F., 2004. Heavy metals and organic compounds from wastes used as organic fertilisers. Working Group Compost. ENV. A.2./ETU/2001/0024.

Barth, J., F. Amlinger, E. Favoino, S. Siebert, B. Kehres, R. Gottschall, M. Bieker, A. Löbig and W. Bidlingmaier, 2008. Compost Production and use in the EU; Final Report. Tender No. J02/35/2006 Contract Notice 2007/S 013-014117.

Bielert, U., H. Heinrichs and K.-W. Becker, 1999. Validierung von Boden-Eluatgehalten zur Prognose von Inhaltsstoffen des Boden-Sickerwassers für das untergesetzliche Regelwerk/BBodSchV. Forschungsbericht des Geochemischen Instituts der Universität Göttingen und des Inst. f. Bodenwissenschaften der Christian-Albrechts-Universität zu Kiel, im Auftrag des Umweltbundesamtes, UBA-Texte 86/99.

Bigalke, M., Ulrich, A., Rehmus, A., Keller, A., 2017. Accumulation of cadmium and uranium in arable soils in Switzerland. Environmental Pollution, 221, pp. 85-93.

Bonten, L.T.C., Kroes, J.G., Groenendijk, P., Van Der Grift, B., 2012. Modeling diffusive Cd and Zn contaminant emissions from soils to surface waters. Journal of Contaminant Hydrology, 138-139, pp. 113-122.

Boysen, P., 1992. Schwermetalle und andere Schadstoffe in Düngemitteln. Literaturauswertung und Analysen. UBA. Forschungsbericht 107 01-016/01 UBA-FB 92-104.

Britz, W. and Witzke, P., 2008. CAPRI model documentation 2008: Version 2. Institute for Food and Resource Economics, University of Bonn, Bonn, Germany.

Brus, D.J., J.J. de Gruijter, D.J.J. Walvoort, F. de Vries, J.J.B. Bronswijk, P.F.A.M. Römkens and W. de Vries, 2002. Mapping the probability of exceeding critical thresholds for cadmium concentrations in soils in the Netherlands. J. Environ. Qual., 31 (6): 1875-1884.

Com, 1991. Council Directive of 12 December 1991 concerning the protection of waters against pollution caused by nitrates from agricultural sources. (Ed, C.o.t.E. Communities) Official Journal of the European Communities No L 375/1.

COM, 2005. A Thematic Strategy on the prevention and recycling of waste. COMMISSION OF THE EUROPEAN COMMUNITIES Brussels, 21.12.2005.

COM, 2016. Circular economy package. Annexes to the Proposal for a regulation of the European Parliament and of the Council laying down rules on the making available on the market of CE marked fertilising products and amending Regulations (EC) No 1069/2009 and (EC) No 1107/2009. Brussels, 17.3.2016 COM(2016) 157 final. ANNEXES 1 to 5.

Degryse, F., K. Broos, E. Smolders, R. Merckx, 2003. Soil solution concentration of Cd and Zn can be predicted with a $\mathrm{CaCl} 2$ soil extract. European Journal of Soil Science, 54, 149-157.

De Vries, W., G. Schütze, S. Lofts, M. Meili, P.F.A.M. Römkens, R. Farret, L. de Temmerman and M. Jakubowski, 2002. Critical Limits for Cadmium, Lead and Mercury related to ecotoxicological effects on soil organisms, aquatic organisms, plants, animals and humans. Proceedings Expert Meeting on Critical Limits for Heavy Metals and Methods for their application Berlin, 2.-4. Dezember 2002. UBA Texte 47/03. 
De Vries, W., P.F.A.M. Römkens \& J.C.H. Voogd, 2004. Prediction of the long term accumulation and leaching of zinc in Dutch agricultural soils: a risk assessment study. Alterra rapport 1030, Alterra, Wageningen UR.

De Vries, W., P.F.A.M. Römkens and G. Schütze, 2007. Impact of soil properties on critical concentrations of cadmium, lead and mercury in soil in view of health effects on animals and humans. Reviews of Environmental Contamination and Toxicology, vol. 191:91-130.

De Vries, W., A. Leip, G.J. Reinds, J. Kros, J.P. Lesschen and A.F. Bouwman, 2011a. Comparison of land nitrogen budgets for European agriculture by various modeling approaches. Environ. Pollut. 159 (11), 3254-3268.

De Vries, W., A. Leip, G.J. Reinds, J. Kros, J.P. Lesschen, A.F. Bouwman, B. Grizzetti, F. Bouraoui, K. Butterbach Bahl, P. Bergamaschi and W. Winiwarter, 2011b. Geographic variation in terrestrial nitrogen budgets across Europe. In: M.A. Sutton, C.M. Howard, J.W. Erisman, G. Billen, A. Bleeker, P. Grennfelt, H. van Grinsven en B. Grizzetti (Eds). The European Nitrogen Assessment. Cambridge University Press, Chapter 15, Cambridge, UK, pp. 317-344.

De Vries, W. and M.J. McLaughlin, 2013. Modeling the cadmium balance in Australian agricultural systems in view of potential impacts on food and water quality. Science of the Total Environment 461-462 (2013) 240-257.

De Vries, W., J. Kros, J.C.H. Voogd and G. Louwagie, 2018. Assessment of spatially explicit current and critical inputs of nitrogen in agriculture within EU-27. In Preparation.

Dittrich, B. and R. Klose, 2008. Bestimmung und Bewertung von Schwermetallen in Düngemitteln, Bodenhilfsstoffen und Kultursubstraten. Schriftenreihe der Sächsischen Landesanstalt für Landwirtschaft Heft 3/2008.

EC, 2010. Working Document Sludge and Biowaste. 21 September 2010, Brussels.

Eckel, H., 2005. Assessment and Reduction of Heavy Metal Input Into Agro Ecosystems: Final Report of the EU-concerted Action AROMIS. Volume 432 of KTBL-Schrift, Kuratorium für Technik und Bauwesen in der Landwirtschaft.

EEA, 2009. Corine land cover 2000 (CLC2000) 100 m - version 12/2009. EEA, Copenhagen.

EEA, 2017. European Union emission inventory report 1990-2015 under the UNECE Convention on Long-range Transboundary Air Pollution (LRTAP). EEA Report No 9/2017. Luxembourg: Publications Office of the European Union, 2017.

Elzinga, E.J., J.J.M. van Grinsven and F.A. Swartjes, 1999. General purpose Freundlich isotherms for Cadmium, copper and zinc in soils. Eur. J. Soil Sci., 50:139-149.

European Food Safety Authority, 2012. Cadmium dietary exposure in the European population. EFSA Journal 2012;10(1):2551.

EC, 2003. Regulation (EC) No 2003/2003 of the European Parliament and of the council of 13 October 2003 relating to fertilisers.

Evans, T., 2012. Biosolids in Europe. Proc. 26th WEF Residuals \& Biosolids Conference. 25-28 March 2012, Raleigh, NC, USA.

Fels-Klerx, I., van der, P.F.A.M. Römkens, E. Franz and L. van Raamsdonk, 2011. Modeling cadmium in the feed chain and cattle organs. Biotechnol. Agron. Soc. Environ. 2011, 15(S1), 53-59. 
Franz, E., P.F.A.M. Römkens, L. van Raamsdonk and I. van der Fels-Klerx, 2008. A chain modeling approach to estimate the impact of soil cadmium pollution on human dietary exposure. J. Food Protection, 71(12):2504-2513.

Gray, C.W., R.G. McLaren and A.H.C. Roberts, 2003. Cadmium leaching from some New Zealand pasture soils. Eur. J. Soil Sci. 54 (1), 159-166.

Groenenberg, J.E., P.F.A.M. Römkens and W. de Vries, 2006. Prediction of the long term accumulation and leaching of copper in Dutch agricultural soils: a risk assessment study. Alterra report 1278. Alterra, Wageningen UR, the Netherlands.

Groenenberg, J.E., J.J. Dijkstra, L.T.C. Bonten, W. De Vries and R.N.J. Comans, 2012. Evaluation of the performance and limitations of empirical partition-relations and process based multisurface models to predict trace element solubility in soils. Environmental Pollution, 166, pp. 98-107.

Groenenberg, J.E., P.F.A.M. Römkens, A.V. Zomeren, S.M. Rodrigues and R.N.J. Comans, 2017. Evaluation of the Single Dilute $(0.43 \mathrm{M})$ Nitric Acid Extraction to Determine Geochemically Reactive Elements in Soil. Environmental Science and Technology, 51 (4), pp. 2246-2253.

Hengl, T., J.M. de Jesus, R.A. MacMillan, N.H. Batjes, G.B.M. Heuvelink, E. Ribeiro, A. Samuel-Rosa, B. Kempen, J.G.B. Leenaars, M.G. Walsh en M.R. Gonzalez, 2014. SoilGrids $1 \mathrm{~km}$ - Global Soil Information Based on Automated Mapping. Plos One 9 (8), e105992.

Hiederer, R., 2013. Mapping soil properties for Europe - spatial representation of soil database attributes. Joint Research Centre, European Commission. Technical Report EUR 26082 EN.

Heuvelink, G.B.M., J. Kros, G.J. Reinds en W. De Vries, 2016. Geostatistical prediction and simulation of European soil property maps. Geoderma Regional 7 (2), 201-215.

Hollis, J.M., J. Hannam and P H. Bellamy, 2012. Empirically-derived pedotransfer functions for predicting bulk density in European soils. European Journal of Soil Science, February 2012, 63, 96-109.

Houba, V.J.G., J.J.G van der Lee, I. Novozamsky, 1997. Soil and plant analysis. Part 1: Soil analysis procedures, Wageningen University, Wageningen.

Ilyin, I., Rozovskaya, O., Sokovyh, V., Travnikov, O., Aas, W., 2009. Heavy Metals: Transboundary Pollution of the Environment. EMEP Status Report 2/2009.

JRC, 2012. Occurrence and levels of selected compounds in European Sewage Sludge Samples. Results of a Pan-European Screening Exercise (FATE SEES). Report EUR 25598 EN.

Keller, A., B. von Steiger, S.E.A.T.M. van der Zee and R. Schulin, 2001. A Stochastic Empirical Model for Regional Heavy-Metal Balances in Agroecosystems. J. Environ. Qual. 30:1976-1989.

Keller, A., B. von Steiger, S.E.A.T.M. van der Zee and R. Schulin, 2001. A Stochastic Empirical Model for Regional Heavy-Metal Balances in Agroecosystems. J. Environ. Qual. 30:1976-1989.

Kros, J., G.B.M. Heuvelink, G.J. Reinds, J.P. Lesschen, V. Ioannidi and W. De Vries, 2012. Uncertainties in model predictions of nitrogen fluxes from agro-ecosystems in Europe. Biogeosciences 9 (11), 4573-4588.

Lesschen, J.P., J.W.H. van der Kolk, K.C. van Dijk and J. Willems, 2013. Options for closing the phosphorus cycle in agriculture. Assessment of options for Northwest Europe and the Netherlands. Wageningen, Statutory Research Tasks Unit for Nature and the Environment. WOt-werkdocument 353. 47 p. 
Lübben, S. and D. Sauerbeck, 1991. Transferfaktoren und Transferkoeffizienten für den

Schwermetallübergang Boden-Pflanze. In: Forschungszentrum Jülich GmbH (Hrsg.): Auswirkungen von Siedlungsabfällen auf Böden, Bodenorganismen und Pflanzen, Berichte aus der ökologischen Forschung 6, 180-223.

McBride, M.B., S. Sauvé and W. Hendershot, 1997. Solubility control of $\mathrm{Cu}, \mathrm{Zn}, \mathrm{Cd}$ and $\mathrm{Pb}$ in contaminated soils. European Journal of Soil Science, 48, 337-346.

McLaughlin, M.J., E. Smolders, F. Degryse and R.P.J.J Rietra, 2011. Uptake of Metals from Soil into Vegetables. In: F.A. Swartjes (ed.) Dealing with Contaminated Sites. From Theory towards Practical Application. Springer, pp. 325-367.

Mirzabeygi, M., A. Abbasnia, M. Yunesian, R.N. Nodehi, N. Yousefi, M. Hadi and A.H. Mahvi, 2017. Heavy metal contamination and health risk assessment in drinking water of Sistan and Baluchistan, Southeastern Iran. Human and Ecological Risk Assessment: An International Journal, 23:8, 1893-1905.

Moolenaar, S. and Th.M. Lexmond, 1998. Heavy-metal balances of agro-ecosystems in the Netherlands. Neth. J. Agric. Sci. 46 (1998), 171-192.

Nicholson, F.A., B.J. Chambers, J.R. Williams, R.J. Unwin, 1999. Heavy metal contents of livestock feeds and animal manures in England and Wales. Bioresource Technology 70:23-31.

Nicholson, F.A., Smith, S.R., Alloway, B.J., Carlton-Smith, C., Chambers, B.J., 2006. Quantifying heavy metal inputs to agricultural soils in England and Wales. Water and Environment Journal, 20 (2), pp. 87-95.

Nicholson, F.A., Humphries, S., Anthony, S.G., Smith, S.R., Chadwick, D., Chambers, B.J., 2012. A software tool for estimating the capacity of agricultural land in England and Wales for recycling organic materials (ALOWANCE). Soil Use and Management, 28 (3), pp. 307-317.

Nziguheba, G. and E. Smolders, 2008. Inputs of trace elements in agricultural soils via phosphate fertilisers in European countries. Sci. Tot. Environ., 390:53-57.

Peng, C., Cai, Y., Wang, T., Xiao, R., Chen, W., 2016. Regional probabilistic risk assessment of heavy metals in different environmental media and land uses: An urbanization-affected drinking water supply area. Scientific Reports, 6, art. no. 37084.

Reimann, C., M. Birke, A. Demetriades, P. Filzmoser and Patrick O'Connor (eds.), 2014. Chemistry of Europe's Agricultural Soils, Part A Methodology and Interpretation of the GEMAS Data Set. Geologisches Jahrbuch Reihe B, Band B 102.

Reinds, G.J., 1994. A database for European forest soils. Technisch Document. The Winand Staring Centre for Integrated Soil and Water Research. Wageningen; The Netherlands, 77 pp.

Rietra, R.P.J.J., Mol, G., Rietjens, I.M.C.M., Römkens, P.F.A.M., 2017. Cadmium in soil, crops and resultant dietary exposure. WENR Report 2784, Wageningen University and Research, Wageningen, the Netherlands.

Rodrigues, S.M., Henriques, B., Reis, A.T., Duarte, A.C., Pereira, E., Römkens, P.F.A.M., 2012. Hg transfer from contaminated soils to plants and animals. Environmental Chemistry Letters 10 (1), pp. 61-67.

Römkens, P.F.A.M. and W. Salomons, 1998. Cd, Cu and Zn solubility in arable and forest soils: consequences of land use changes for metal mobility and risk assessment. Soil Sci., 163:859-871. 
Römkens, P.F.A.M., Groenenberg, J.E., Bonten, L.T.C., Vries, W. de, Bril, J., 2004. Derivation of partition relationships to calculate $\mathrm{Cd}, \mathrm{Cu}, \mathrm{Ni}, \mathrm{Pb}, \mathrm{Zn}$ solubility and activity in soil solutions. Alterra, Wageningen. Alterra-report 305.

Römkens, P.F.A.M., J.E. Groenenberg, R.P.J.J. Rietra en W. de Vries, 2007. Soil-Plant relationships to support the revision of Agricultural Advisory Levels (LAC) and implementation in the Risk Tool Box (in Dutch). Alterra rapport 1442. Alterra, Wageningen UR, Wageningen, the Netherlands.

Römkens, P.F.A.M., Guo, H.Y., Chu, C.L., Liu, T.S., Chiang, C.F., Koopmans, G.F., 2009. Prediction of Cadmium uptake by brown rice and derivation of soil-plant transfer models to improve soil protection guidelines. Environmental Pollution, 157 (8-9), pp. 2435-2444.

Römkens, P.F.A.M., Rietra, R.P.J.J. en Ehlert, P.A.I., 2016. Effectbeoordeling van het voorstel voor een nieuwe Europese Meststoffenverordening: Analyse van de aanvoer van zware metalen de landbouwbodem en gevolgen voor vrije verhandeling van nationale meststoffen. WENR Rapport 2766.

Salmanzadeh, M., A. Hartland, C.H. Stirling, M.R. Balks, L.A. Schipper, C. Joshi, and E. George, 2017. Isotope Tracing of Long-Term Cadmium Fluxes in an Agricultural Soil. Environmental Science and Technology, 51 (13), pp. 7369-7377.

Schipper, L.A., G.P. Sparling, L.M. Fisk, M.B. Dodd, I.L. Power, R.A. Littler, 2017. Rates of accumulation of cadmium and uranium in a New Zealand hill farm soil as a result of long-term use of phosphate fertiliser. Agriculture, Ecosystems \& Environment, Volume 144, Issue 1, 2011, Pages 95-101.

Schütze, G., U. Dämmgen, A. Schlutow, R. Becker, H-D. Nagel and H-J. Weigel, 2003. Risikoabschätzung der Cadmium-Belastung für Mensch und Umwelt infolge der Anwendung von cadmiumhaltigen Düngemitteln. Landbauforschung Völkenrode 53(2003)2/3:63-170.

Sheppard, S.C., C.A. Grant, M.I. Sheppard, R. de Jong and J. Long, 2009. Risk Indicator for Agricultural Inputs of Trace Elements to Canadian Soils. J. Environ. Qual. 38:919-932 (2009).

Sevel, L., H.C. Hansen and K. Raulund-Rasmussen, 2009. Mass Balance of Cadmium in Two contrasting Oak Forest Ecosystems. J Environ Qual. 13;38(1):93-102.

Six, L. and E. Smolders, 2014. Future trends in soil cadmium concentration under current cadmium fluxes to European agricultural soils. Science of the Total Environment, 485-486 (1), pp. 319-328.

Smolders, E., G. Jansson, L. Van Laer, A. Ruttens, J. Vangronsveld, P.F.A.M. Römkens, L. De Temmerman, N. Waegeneers and J. Bries, 2007. Teeltadvies voor de landbouw in kader van het Interreg project BeNeKempen (In Dutch). Internal report OVAM. Mechelen, Belgium.

Smolders, E., 2017. Scientific aspects underlying the regulatory framework in the area of fertilisers state of play and future reforms. IP/A/IMCO/2016-19 - PE 595.354. Europena Union, 2017.

Spiegel, H., G. Zethner, R. Goodchild, M. Dachler and I. Kernmayer, 2003. Cadmium in the Environment - An Austrian review. 2nd Report: Soil Balances and Risk Characterisation. Die Bodenkultur 54(2):83-91.

Spijker, J., Mol, G., Posthuma, L., 2011. Regional ecotoxicological hazards associated with anthropogenic enrichment of heavy metals. Environmental Geochemistry and Health, 33 (4), pp. 409-426.

Temminghoff, E.J.M., V.J.G. Houba, W. van Vark, G.A. Gaikhorts, 2000. Soil and plant analysis. Part 3: Plant analysis procedures. Wageningen University, Wageningen. 
Tiktak, A., J.R.M. Alkemade, J.J.M. van Grinsven and G.B. Makaske, 1998. Modelling cadmium accumulation at a regional scale in the Netherlands. Nutrient Cycling in Agroecosystems 50: 209-222.

Tóth, G., A. Jones and L. Montanarella, 2013. The LUCAS topsoil database and derived information on the regional variability of cropland topsoil properties in the European Union. Environ Monit Assess. 185: 7409-7425. doi:10.1007/s10661-013-3109-3.

UNFCCC, 2012. National Inventory Submissions 2012. Status Reports for 2012.

Versluijs, C.W. and P.F. Otte, 2001. Accumulation of metals in crops (in Dutch). RIVM report 711701 024/2001. RIVM - Bilthoven, the Netherlands.

Wang, Q., J. Zhang and B. Zhao, X. Xin \& Congzhi Zhang \& Hailin Zhang, 2014. The influence of longterm fertilization on cadmium (Cd) accumulation in soil and its uptake by crops. Environ Sci Pollut Res 21:10377-10385. 
Wageningen Environmental Research P.O. Box 47

6700 AA Wageningen

The Netherlands

T +31 (0)317480700

www.wur.nl/environmental-research

Wageningen Environmental Research Report 2889

ISSN 1566-7197
The mission of Wageningen University \& Research is "To explore the potential of nature to improve the quality of life". Under the banner Wageningen University \& Research, Wageningen University and the specialised research institutes of the Wageningen Research Foundation have joined forces in contributing to finding solutions to important questions in the domain of healthy food and living environment. With its roughly 30 branches, 5,000 employees and 10,000 students, Wageningen University \& Research is one of the leading organisations in its domain. The unique Wageningen approach lies in its integrated approach to issues and the collaboration between different disciplines.

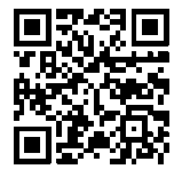





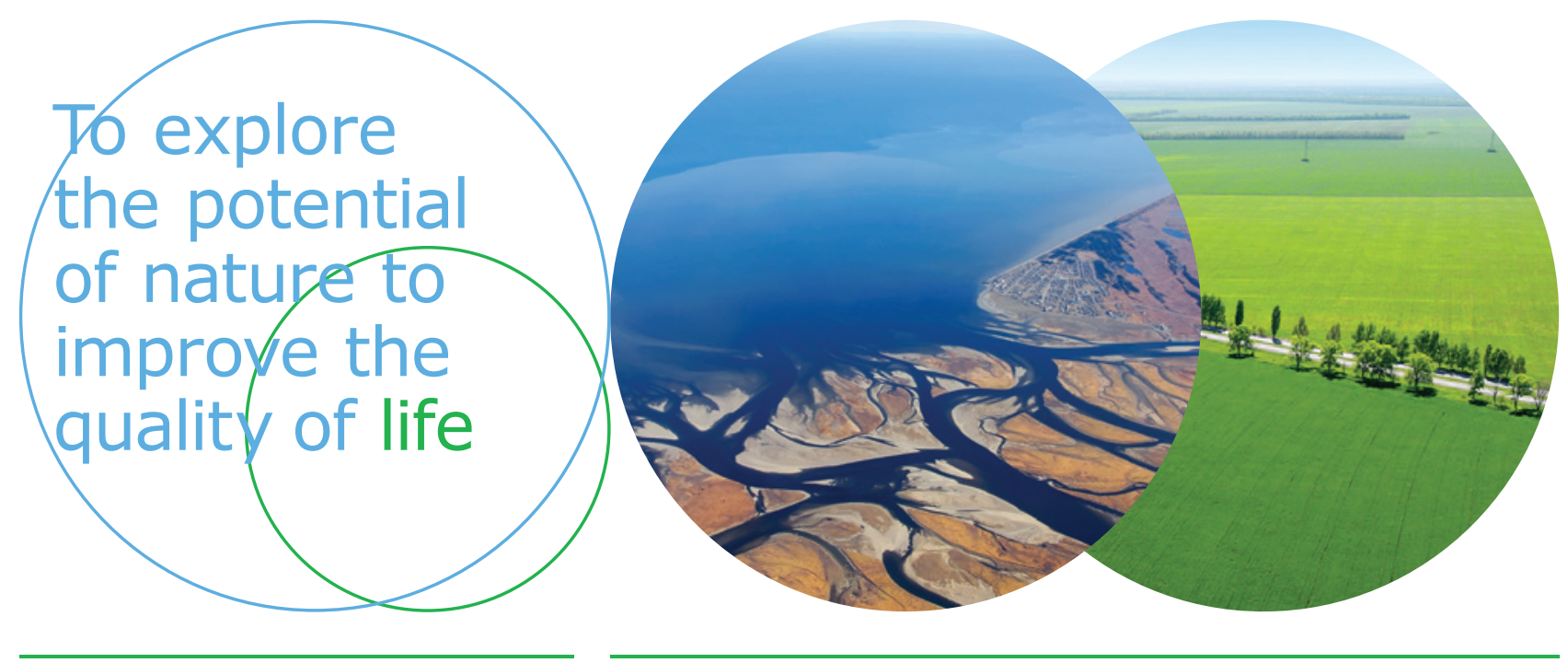

Wageningen Environmental Research P.O. Box 47

$6700 \mathrm{AB}$ Wageningen

The Netherlands

$\mathrm{T}+31(0) 317480700$

www.wur.eu/environmental-research

Report 2889

ISSN 1566-7197
The mission of Wageningen University \& Research is "To explore the potential of nature to improve the quality of life". Under the banner Wageningen University \& Research, Wageningen University and the specialised research institutes of the Wageningen Research Foundation have joined forces in contributing to inding solutions to important questions in the domain of healthy food and living environment. With its roughly 30 branches, 5,000 employees and 10,000 students, Wageningen University \& Research is one of the leading organisations in its domain. The unique Wageningen approach lies in its integrated approach to issues and the collaboration between different disciplines. 